\title{
Red to Near-Infrared Isoindole BODIPY Fluorophores: Synthesis, Crystal Structures, Spectroscopic and Electrochemical Properties
}

Changjiang Yu, Qinghua Wu, Jun Wang, Yun Wei, Erhong Hao* and Lijuan Jiao*

The Key Laboratory of Functional Molecular Solids, Ministry of Education; Anhui Laboratory of Molecule-Based Materials; School of Chemistry and Materials Science, Anhui Normal University, Wuhu, Anhui, China 241000.

*To whom correspondence should be addressed.

E-mail: haoehong@mail.ahnu.edu.cn, jiao421@mail.ahnu.edu.cn.

\section{Contents:}

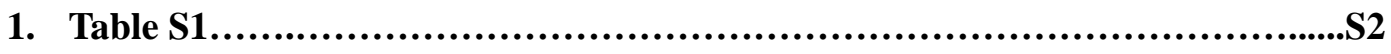

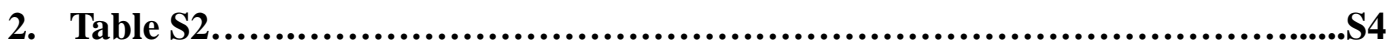

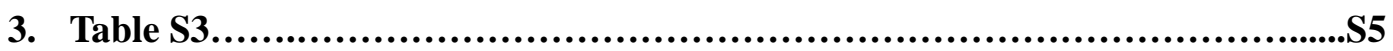

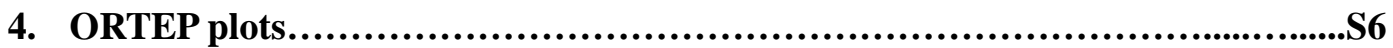

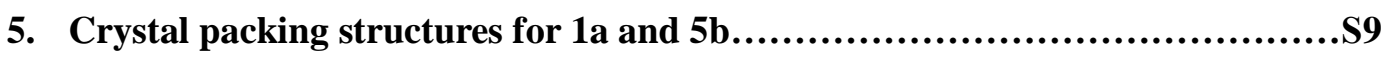

6. Overlaid and Normalized absorption and fluorescence emission spectra in

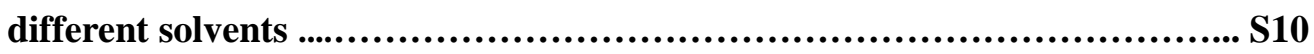

7. Fluorescence decay spectra.............................................S34

8. Normalized titration spectra of $7 \mathrm{f}$ in acetonitrile............................S57

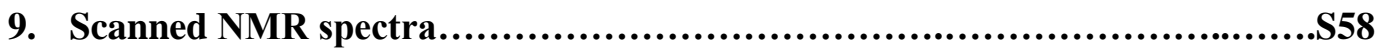

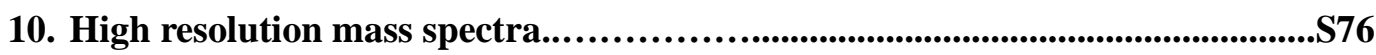

11. DFT calculation optimized coordinates.....................................S82 
1. Table S1. Photophysical properties of $\mathbf{1 , 5}$ and $\mathbf{7}$ in different solvents at room temperature

\begin{tabular}{|c|c|c|c|c|c|c|}
\hline BODIPYs & solvents & $\lambda_{\mathrm{abs}}^{\max }(\mathrm{nm})$ & $\log \varepsilon_{\max }^{b}$ & $\lambda_{\mathrm{em}}^{\max }(\mathrm{nm})$ & $\phi^{\mathrm{c}}$ & $\begin{array}{c}\text { Stokes Shift } \\
\left(\mathrm{cm}^{-1}\right)\end{array}$ \\
\hline \multirow{6}{*}{ 1a } & Hexane & 574 & 4.89 & 588 & 0.83 & 415 \\
\hline & Toluene & 577 & 4.72 & 600 & 0.81 & 664 \\
\hline & Dichloromethane & 570 & 4.65 & 599 & 0.80 & 849 \\
\hline & Tetrahydrofuran & 571 & 4.68 & 596 & 0.82 & 735 \\
\hline & Acetonitrile & 561 & 4.61 & 594 & 0.80 & 990 \\
\hline & Methanol & 565 & 4.67 & 592 & 0.76 & 807 \\
\hline \multirow{6}{*}{$1 b$} & Hexane & 602 & 4.36 & 613 & 0.83 & 298 \\
\hline & Toluene & 606 & 4.55 & 623 & 0.78 & 450 \\
\hline & Dichloromethane & 600 & 4.46 & 624 & 0.79 & 641 \\
\hline & Tetrahydrofuran & 599 & 4.58 & 621 & 0.81 & 591 \\
\hline & Acetonitrile & 592 & 4.43 & 620 & 0.80 & 763 \\
\hline & Methanol & 595 & 4.24 & 616 & 0.83 & 573 \\
\hline \multirow{6}{*}{ 1c } & Hexane & 610 & 5.01 & 626 & 0.85 & 419 \\
\hline & Toluene & 616 & 4.92 & 633 & 0.81 & 436 \\
\hline & Dichloromethane & 609 & 4.87 & 631 & 0.61 & 573 \\
\hline & Tetrahydrofuran & 609 & 4.89 & 627 & 0.06 & 471 \\
\hline & Acetonitrile & 601 & 4.84 & 624 & 0.02 & 613 \\
\hline & Methanol & 603 & 4.88 & 622 & 0.03 & 507 \\
\hline \multirow{6}{*}{ 1d } & Hexane & 629 & 5.03 & 641 & 0.86 & 298 \\
\hline & Toluene & 636 & 4.94 & 651 & 0.75 & 362 \\
\hline & Dichloromethane & 629 & 4.91 & 650 & 0.73 & 514 \\
\hline & Tetrahydrofuran & 629 & 4.91 & 644 & 0.09 & 370 \\
\hline & Acetonitrile & 620 & 4.82 & 643 & 0.03 & 577 \\
\hline & Methanol & 623 & 4.86 & 642 & 0.04 & 475 \\
\hline \multirow{6}{*}{ 1e } & Hexane & 623 & 4.63 & 644 & 0.14 & 523 \\
\hline & Toluene & 625 & 4.87 & 656 & 0.14 & 756 \\
\hline & Dichloromethane & 611 & 4.99 & 648 & 0.08 & 935 \\
\hline & Tetrahydrofuran & 608 & 4.86 & 646 & 0.04 & 967 \\
\hline & Acetonitrile & 591 & 4.67 & 637 & 0.04 & 1222 \\
\hline & Methanol & 598 & 4.73 & 643 & 0.03 & 1170 \\
\hline \multirow{6}{*}{ 1f } & Hexane & 566 & 5.02 & 582 & 0.65 & 486 \\
\hline & Toluene & 570 & 4.81 & 594 & 0.72 & 709 \\
\hline & Dichloromethane & 563 & 4.88 & 592 & 0.91 & 870 \\
\hline & Tetrahydrofuran & 564 & 4.85 & 589 & 0.54 & 753 \\
\hline & Acetonitrile & 555 & 4.71 & 586 & 0.64 & 953 \\
\hline & Methanol & 558 & 4.55 & 585 & 0.69 & 827 \\
\hline \multirow{6}{*}{$1 g$} & Hexane & 601 & 5.27 & 619 & 0.86 & 484 \\
\hline & Toluene & 605 & 5.05 & 635 & 0.82 & 781 \\
\hline & Dichloromethane & 599 & 4.96 & 625 & 0.80 & 694 \\
\hline & Tetrahydrofuran & 599 & 5.27 & 627 & 0.19 & 746 \\
\hline & Acetonitrile & 590 & 4.99 & 623 & 0.05 & 898 \\
\hline & Methanol & 593 & 4.95 & 622 & 0.07 & 786 \\
\hline \multirow{6}{*}{$1 \mathrm{~h}$} & Hexane & 620 & 5.14 & 636 & 0.93 & 406 \\
\hline & Toluene & 625 & 5.05 & 646 & 0.71 & 520 \\
\hline & Dichloromethane & 619 & 5.07 & 645 & 0.72 & 651 \\
\hline & Tetrahydrofuran & 618 & 5.06 & 656 & 0.27 & 937 \\
\hline & Acetonitrile & 610 & 4.97 & 652 & 0.21 & 1056 \\
\hline & Methanol & 613 & 5.01 & 650 & 0.21 & 929 \\
\hline \multirow{6}{*}{$5 \mathbf{a}$} & Hexane & 601 & 5.07 & 617 & 0.87 & 431 \\
\hline & Toluene & 606 & 4.97 & 627 & 0.78 & 553 \\
\hline & Dichloromethane & 602 & 4.93 & 621 & 0.87 & 508 \\
\hline & Tetrahydrofuran & 599 & 4.96 & 620 & 0.80 & 565 \\
\hline & Acetonitrile & 594 & 4.89 & 618 & 0.85 & 654 \\
\hline & Methanol & 595 & 4.96 & 618 & 0.90 & 625 \\
\hline $5 \mathbf{b}$ & Hexane & 586 & 4.90 & 605 & 0.96 & 536 \\
\hline
\end{tabular}




\begin{tabular}{|c|c|c|c|c|c|c|}
\hline & Toluene & 591 & 4.85 & 613 & 0.94 & 607 \\
\hline & Dichloromethane & 585 & 4.83 & 611 & 0.99 & 727 \\
\hline & Tetrahydrofuran & 585 & 4.86 & 608 & 0.96 & 647 \\
\hline & Acetonitrile & 580 & 4.82 & 606 & 0.97 & 740 \\
\hline & Methanol & 581 & 4.84 & 605 & 0.98 & 683 \\
\hline \multirow{6}{*}{$5 c$} & Hexane & 583 & 4.76 & 605 & 0.99 & 624 \\
\hline & Toluene & 590 & 4.71 & 613 & 0.99 & 636 \\
\hline & Dichloromethane & 584 & 4.72 & 611 & 0.99 & 757 \\
\hline & Tetrahydrofuran & 584 & 4.71 & 610 & 0.98 & 730 \\
\hline & Acetonitrile & 577 & 4.70 & 606 & 0.99 & 829 \\
\hline & Methanol & 579 & 4.72 & 607 & 0.96 & 797 \\
\hline \multirow{6}{*}{$5 d$} & Hexane & 607 & 4.96 & 618 & 0.91 & 293 \\
\hline & Toluene & 612 & 4.88 & 629 & 0.83 & 442 \\
\hline & Dichloromethane & 608 & 4.79 & 629 & 0.89 & 549 \\
\hline & Tetrahydrofuran & 607 & 4.84 & 625 & 0.82 & 474 \\
\hline & Acetonitrile & 600 & 4.78 & 623 & 0.84 & 615 \\
\hline & Methanol & 602 & 4.85 & 620 & 0.83 & 482 \\
\hline \multirow{6}{*}{$5 e$} & Hexane & 616 & 5.14 & 630 & 0.99 & 361 \\
\hline & Toluene & 623 & 5.02 & 642 & 0.93 & 475 \\
\hline & Dichloromethane & 616 & 4.95 & 640 & 0.86 & 609 \\
\hline & Tetrahydrofuran & 615 & 5.01 & 635 & 0.07 & 512 \\
\hline & Acetonitrile & 607 & 4.93 & 632 & 0.02 & 652 \\
\hline & Methanol & 610 & 4.98 & 631 & 0.04 & 546 \\
\hline \multirow{6}{*}{$5 f$} & Hexane & 580 & 4.94 & 598 & 0.99 & 519 \\
\hline & Toluene & 587 & 4.93 & 608 & 0.96 & 588 \\
\hline & Dichloromethane & 581 & 4.89 & 606 & 0.98 & 710 \\
\hline & Tetrahydrofuran & 583 & 4.90 & 606 & 0.97 & 651 \\
\hline & Acetonitrile & 575 & 4.85 & 602 & 0.96 & 780 \\
\hline & Methanol & 579 & 4.89 & 603 & 0.96 & 687 \\
\hline \multirow{6}{*}{$5 g$} & Hexane & 610 & 5.00 & 626 & 0.87 & 419 \\
\hline & Toluene & 615 & 4.95 & 636 & 0.79 & 537 \\
\hline & Dichloromethane & 608 & 4.90 & 631 & 0.85 & 600 \\
\hline & Tetrahydrofuran & 604 & 4.88 & 628 & 0.16 & 633 \\
\hline & Acetonitrile & 596 & 4.86 & 623 & 0.03 & 727 \\
\hline & Methanol & 598 & 4.89 & 624 & 0.02 & 697 \\
\hline \multirow{6}{*}{$5 h$} & Hexane & 614 & 4.56 & 626 & 0.82 & 312 \\
\hline & Toluene & 620 & 4.46 & 635 & 0.72 & 381 \\
\hline & Dichloromethane & 616 & 4.45 & 634 & 0.66 & 461 \\
\hline & Tetrahydrofuran & 613 & 4.52 & 631 & 0.71 & 465 \\
\hline & Acetonitrile & 608 & 4.44 & 628 & 0.74 & 524 \\
\hline & Methanol & 609 & 4.46 & 628 & 0.65 & 497 \\
\hline \multirow{6}{*}{$5 i$} & Hexane & 604 & 4.91 & 622 & 0.93 & 479 \\
\hline & Toluene & 609 & 4.57 & 630 & 0.81 & 547 \\
\hline & Dichloromethane & 605 & 4.85 & 629 & 0.92 & 631 \\
\hline & Tetrahydrofuran & 604 & 4.47 & 627 & 0.88 & 607 \\
\hline & Acetonitrile & 597 & 4.53 & 623 & 0.88 & 699 \\
\hline & Methanol & 599 & 4.40 & 622 & 0.97 & 617 \\
\hline \multirow{6}{*}{$7 \mathbf{a}$} & Hexane & 679 & 4.66 & 693 & 0.73 & 298 \\
\hline & Toluene & 687 & 4.77 & 707 & 0.69 & 412 \\
\hline & Dichloromethane & 680 & 4.94 & 705 & 0.75 & 521 \\
\hline & Tetrahydrofuran & 679 & 4.71 & 703 & 0.34 & 503 \\
\hline & Acetonitrile & 670 & 4.63 & 699 & 0.30 & 619 \\
\hline & Methanol & 671 & 4.40 & 697 & 0.08 & 556 \\
\hline \multirow{6}{*}{$7 b$} & Hexane & 677 & 4.33 & 698 & 0.74 & 444 \\
\hline & Toluene & 682 & 4.72 & 709 & 0.71 & 558 \\
\hline & Dichloromethane & 675 & 4.76 & 714 & 0.68 & 809 \\
\hline & Tetrahydrofuran & 675 & 4.69 & 709 & 0.28 & 710 \\
\hline & Acetonitrile & 664 & 4.65 & 707 & 0.09 & 916 \\
\hline & Methanol & 666 & 4.59 & 711 & 0.20 & 950 \\
\hline
\end{tabular}




\begin{tabular}{ccccccc}
\hline \multirow{4}{*}{ 7c } & Hexane & 608 & 4.87 & 679 & 0.013 & 1720 \\
& Toluene & 614 & 4.91 & 690 & 0.012 & 1794 \\
& Dichloromethane & 608 & 3.92 & 687 & 0.014 & 1891 \\
& Tetrahydrofuran & 608 & 4.83 & 684 & 0.012 & 1827 \\
& Acetonitrile & 602 & 4.84 & 681 & 0.005 & 1927 \\
& Methanol & 603 & 4.82 & 680 & 0.002 & 1878 \\
\hline \multirow{7}{*}{ 7d } & Hexane & 674 & 5.04 & 731 & 0.04 & 1157 \\
& Toluene & 683 & 5.01 & 735 & 0.009 & 1036 \\
& Dichloromethane & 676 & 5.16 & 733 & 0.012 & 1150 \\
& Tetrahydrofuran & 676 & 5.16 & 730 & 0.005 & 1094 \\
& Acetonitrile & 667 & 5.02 & 727 & 0.009 & 1237 \\
& Methanol & 668 & 5.06 & 726 & 0.002 & 1196 \\
\hline \multirow{7}{*}{ 7e } & Hexane & 587 & 4.18 & 630 & 0.009 & 1163 \\
& Toluene & 592 & 4.64 & 637 & 0.004 & 1193 \\
& Dichloromethane & 585 & 4.63 & 631 & 0.003 & 1246 \\
& Tetrahydrofuran & 586 & 4.71 & 625 & 0.003 & 1065 \\
& Acetonitrile & 577 & 4.82 & 617 & 0.003 & 1124 \\
& Methanol & 580 & 4.63 & 624 & 0.005 & 1216 \\
\hline 7f & Hexane & 719 & 4.95 & 740 & 0.27 & 395 \\
& Toluene & 730 & 4.86 & 760 & 0.16 & 541 \\
& Dichloromethane & 725 & 4.80 & 770 & 0.13 & 806 \\
& Tetrahydrofuran & 720 & 4.85 & 764 & 0.11 & 800 \\
& Acetonitrile & 713 & 4.77 & 805 & 0.05 & 1603 \\
& Methanol & 712 & 4.80 & 770 & 0.05 & 1058 \\
\hline
\end{tabular}

${ }^{\mathrm{a}}$ All of values are corrected for changes in refractive indexes of different solvents. ${ }^{b}$ Molar absorption coefficients are in the maximum of the highest peak. ${ }^{\mathrm{c}}$ The fluorescence quantum yields $(\phi)$ were calculated using Cresyl violet perchlorate $(\phi=0.54$ in methanol) as the reference for $\mathbf{1 a - h}, \mathbf{5}, \mathbf{7 c}$, and 7e, and using 1,7-diphenyl-3,5-di( $p$-methoxyphenyl)-azadipyrromethene ( $\phi=0.36$ in chloroform) as the reference for $\mathbf{7 a}, \mathbf{7 b}$ and $\mathbf{7 d}$. The standard errors are less than $10 \%$.

2. Table S2. Selected geometrical parameters of isoindole BODIPYs $\mathbf{1 a}, \mathbf{1 b}, \mathbf{1 h}, \mathbf{5 b}, \mathbf{5 d}, \mathbf{5 e}, \mathbf{5 f}, \mathbf{5 g}$ and $\mathbf{5 i}$ obtained from crystallography

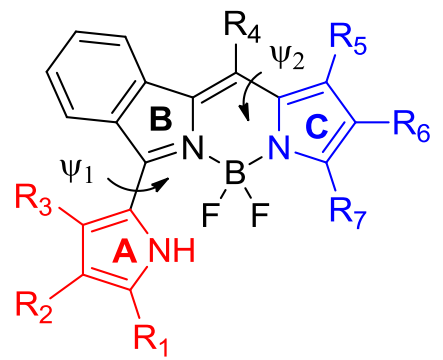

\begin{tabular}{cccccccccc}
\hline & $\mathbf{1 a}$ & $\mathbf{1 b}$ & $\mathbf{1 h}$ & $\mathbf{5 b}$ & $\mathbf{5 d}$ & $\mathbf{5 e}$ & $\mathbf{5 f}$ & $\mathbf{5 g}$ & $\mathbf{5 i}$ \\
\hline B-N bond & 1.517 & 1.532 & 1.529 & 1.537 & 1.534 & 1.525 & 1.515 & 1.576 & 1.515 \\
distances $(\AA)$ & 1.577 & 1.571 & 1.565 & 1.568 & 1.569 & 1.568 & 1.554 & 1.537 & 1.554 \\
\hline \multirow{3}{*}{$\mathrm{H} \cdots \mathrm{F}$} & 1.738 & 2.069 & 2.138 & 2.501 & 2.03 & 2.026 & 2.256 & 2.103 & 2.036 \\
distance $(\AA)$ & 2.578 & 2.629 & 2.547 & 2.573 & 2.679 & 2.584 & 2.593 & 2.374 & 2.383 \\
& & 2.692 & 2.829 & 2.864 & 2.716 & 2.688 & 2.753 & 2.816 & 2.754 \\
\hline$\psi_{1}(\mathrm{deg})$ & $11.6(2)$ & $23.9(2)$ & $41.0(2)$ & $53.1(2)$ & $22.2(2)$ & $36.5(2)$ & $48.3(2)$ & $46.6(2)$ & $31.0(2)$ \\
\hline$\psi_{2}(\operatorname{deg})$ & $3.2(2)$ & $2.9(2)$ & $1.8(2)$ & $2.4(2)$ & $4.0(2)$ & $3.4(2)$ & $6.5(2)$ & $2.1(2)$ & $3.6(2)$ \\
\hline
\end{tabular}


3. Table S3. Selected electronic excitation energies $(\mathrm{eV})$ and oscillator strengths $(f)$, configurations of the low-lying excited states of the isoindole BODIPYs $\mathbf{1 a}, \mathbf{1 c}, \mathbf{5 a}, \mathbf{5 b}, \mathbf{5 d}, \mathbf{5 e}$ and $\mathbf{5 h}$ calculated by TD-B3LYP/6-31+G(d, p) // B3LYP/6-31G(d) based on the optimized ground state geometries. The TDDFT of all the molecules in dichloromethane were using the Self-Consistent Reaction Field (SCRF) method and the Polarizable Continuum Model (PCM).

\begin{tabular}{|c|c|c|c|c|c|c|}
\hline & \multirow{2}{*}{$\begin{array}{l}\text { Electronic } \\
\text { transition }\end{array}$} & \multicolumn{5}{|c|}{ TD-B3LYP/6-31+G(d,p)//B3LYP/6-31G(d) } \\
\hline & & Energy & $/ \mathrm{eV}^{[\mathrm{a}]}$ & $f^{[\mathrm{b}]}$ & Composition $^{[\mathrm{c}]}$ & $\mathrm{CI}^{[\mathrm{d}]}$ \\
\hline \multirow[t]{2}{*}{ 1a } & $\mathrm{S} 0 \rightarrow \mathrm{S} 1$ & $2.3661 \mathrm{eV}$ & $524.00 \mathrm{~nm}$ & 0.7215 & HOMO $\rightarrow$ LUMO & 0.7077 \\
\hline & & & & & HOMO $\leftarrow$ LUMO & 0.1012 \\
\hline \multirow[t]{2}{*}{ 1c } & $\mathrm{S} 0 \rightarrow \mathrm{S} 1$ & $2.2294 \mathrm{eV}$ & $556.14 \mathrm{~nm}$ & 0.7372 & HOMO $\rightarrow$ LUMO & 0.7086 \\
\hline & & & & & $\mathrm{HOMO} \leftarrow$ LUMO & 0.1019 \\
\hline \multirow[t]{2}{*}{ 5a } & $\mathrm{S} 0 \rightarrow \mathrm{S} 1$ & $2.2858 \mathrm{eV}$ & $542.40 \mathrm{~nm}$ & 0.7539 & $\mathrm{HOMO} \rightarrow$ LUMO & 0.7090 \\
\hline & & & & & $\mathrm{HOMO} \leftarrow$ LUMO & 0.1051 \\
\hline $5 \mathbf{b}$ & $\mathrm{S} 0 \rightarrow \mathrm{S} 1$ & $2.3230 \mathrm{eV}$ & $533.73 \mathrm{~nm}$ & 0.7335 & $\mathrm{HOMO} \rightarrow$ LUMO & 0.7061 \\
\hline \multirow[t]{2}{*}{$5 d$} & $\mathrm{~S} 0 \rightarrow \mathrm{S} 1$ & $2.2524 \mathrm{eV}$ & $550.46 \mathrm{~nm}$ & 0.7506 & $\mathrm{HOMO} \rightarrow$ LUMO & 0.7091 \\
\hline & & & & & HOMO $\leftarrow$ LUMO & 0.1048 \\
\hline \multirow[t]{2}{*}{$5 e$} & $\mathrm{~S} 0 \rightarrow \mathrm{S} 1$ & $2.2071 \mathrm{eV}$ & $561.74 \mathrm{~nm}$ & 0.7666 & HOMO $\rightarrow$ LUMO & 0.7084 \\
\hline & & & & & $\mathrm{HOMO} \leftarrow$ LUMO & 0.1009 \\
\hline \multirow[t]{2}{*}{$5 h$} & $\mathrm{~S} 0 \rightarrow \mathrm{S} 1$ & $2.2519 \mathrm{eV}$ & $550.57 \mathrm{~nm}$ & 0.7693 & HOMO $\rightarrow$ LUMO & 0.7079 \\
\hline & & & & & HOMO $\leftarrow$ LUMO & 0.1041 \\
\hline
\end{tabular}

${ }^{[a]}$ Only the selected low-lying excited states are presented. ${ }^{[\mathrm{b}]}$ Oscillator strength. ${ }^{[\mathrm{c}]}$ Only the main configurations are presented. ${ }^{[\mathrm{d}]}$ The CI coefficients are in absolute values. 


\section{ORTEP plots}
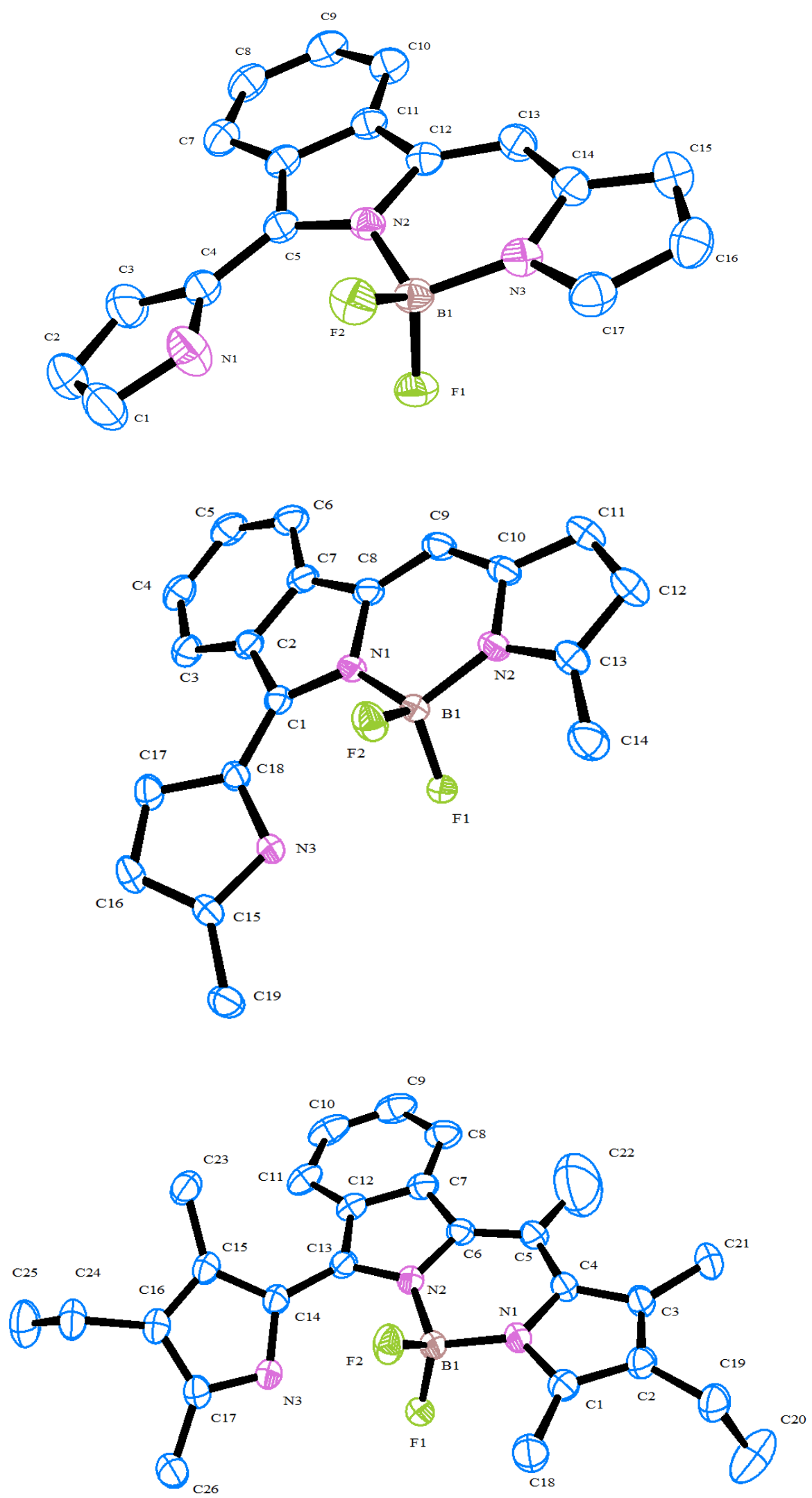

Figure S1. ORTEP plot of 1a (top), 1b (middle) and 1h (bottom) with thermal ellipsoids at $30 \%$ probability level 


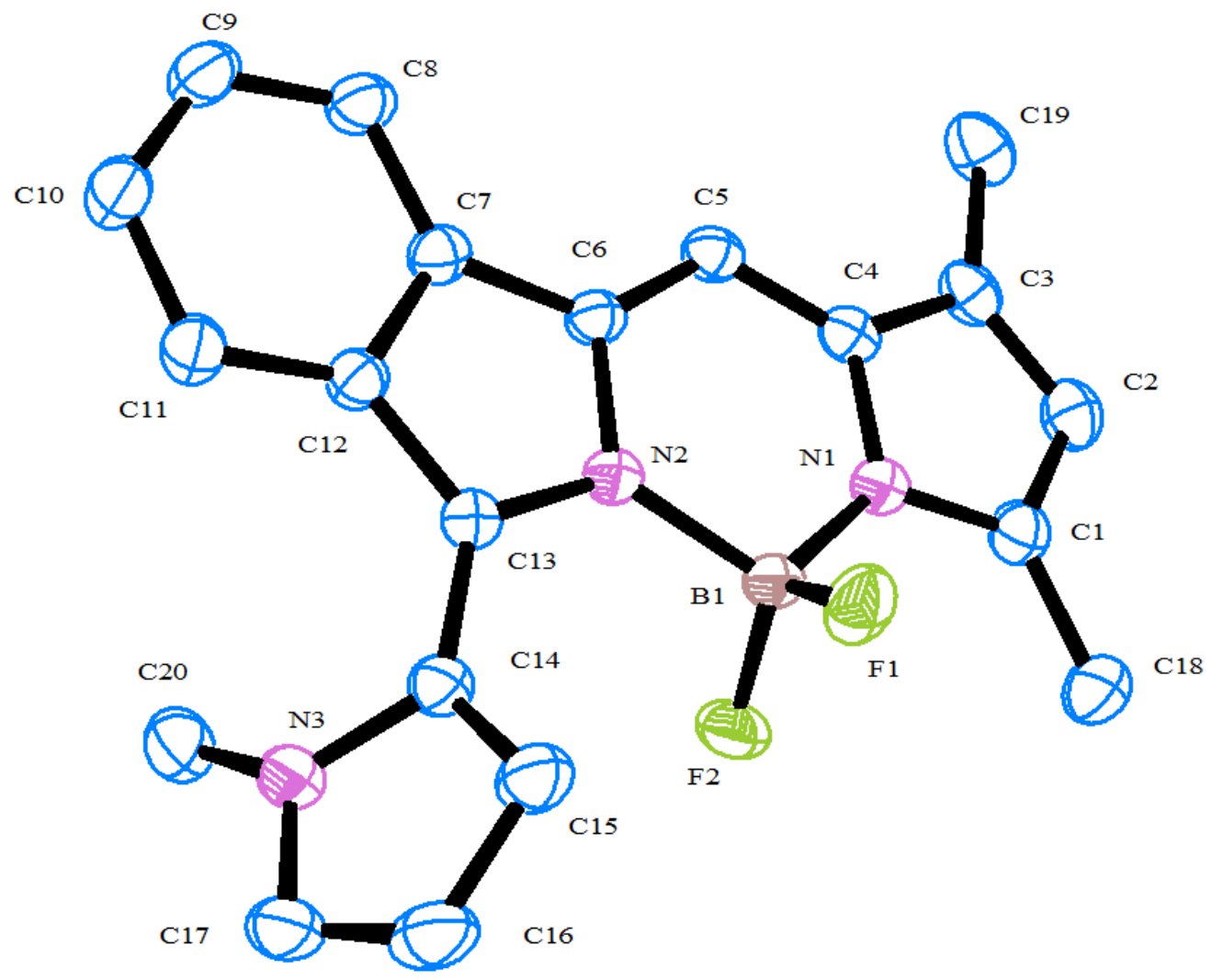

Figure S2. ORTEP plot of $\mathbf{5 b}$ with thermal ellipsoids at 30\% probability level

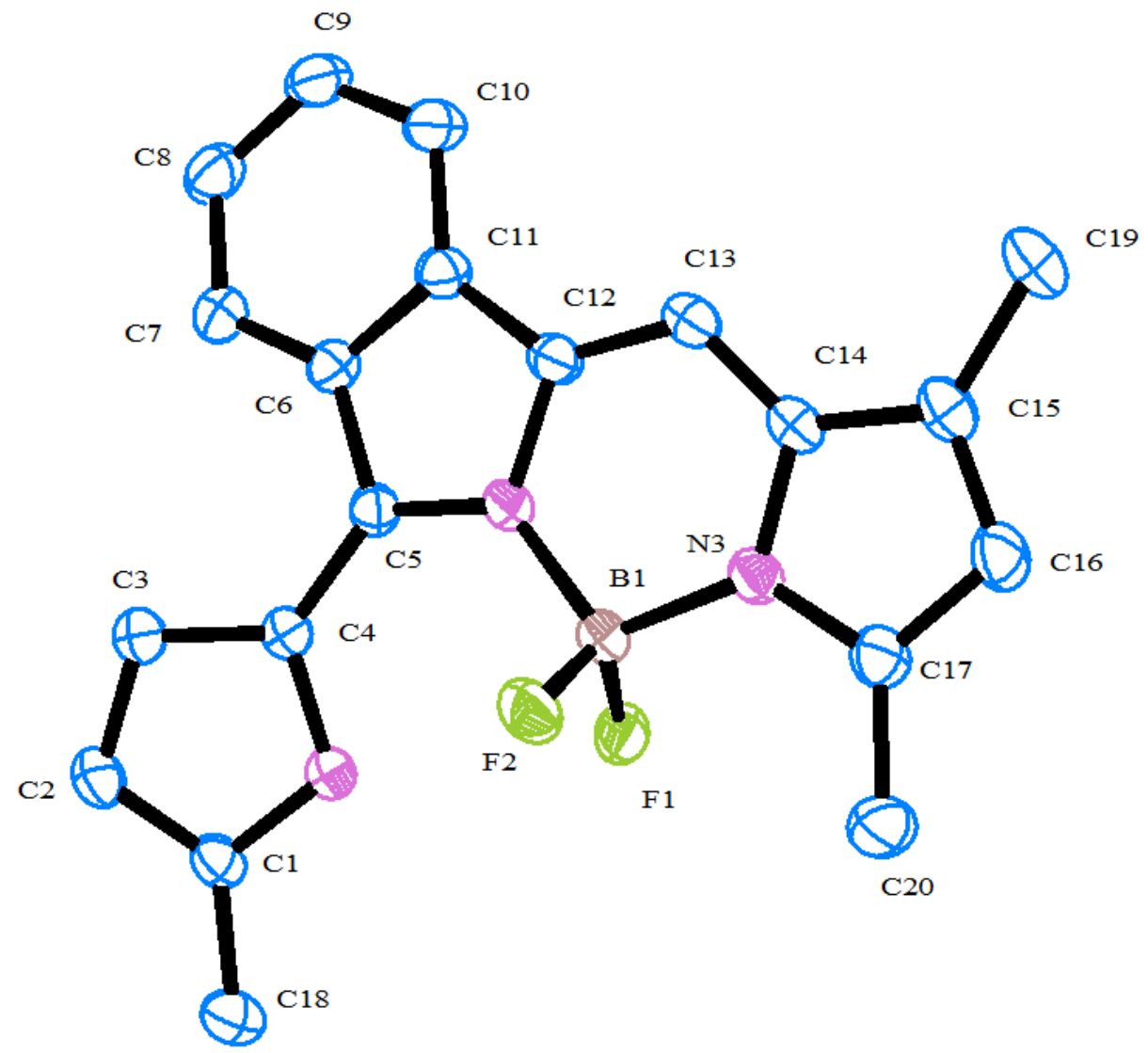

Figure S3. ORTEP plot of 5d with thermal ellipsoids at 30\% probability level 


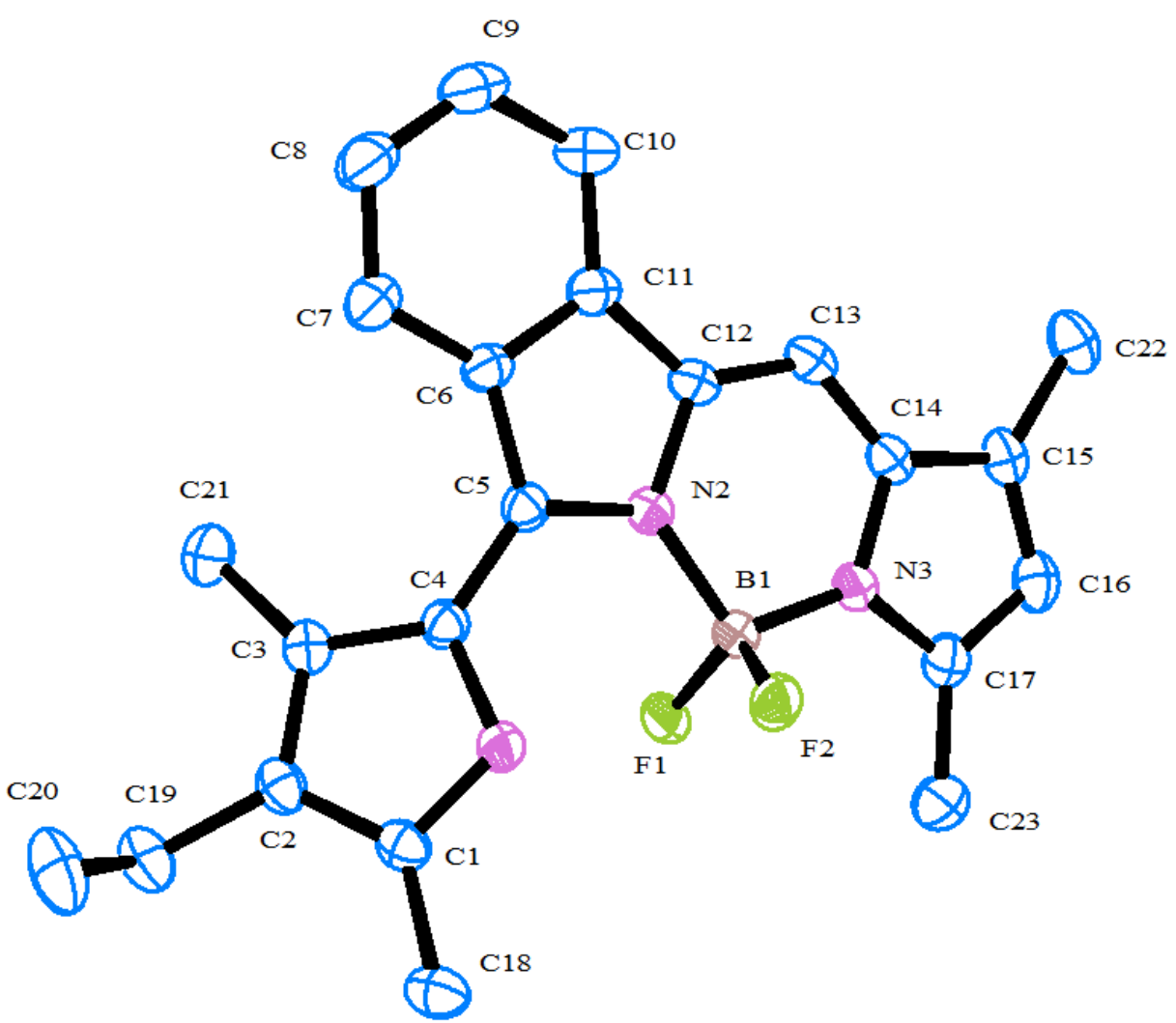

Figure S4. ORTEP plot of 5e with thermal ellipsoids at 30\% probability level

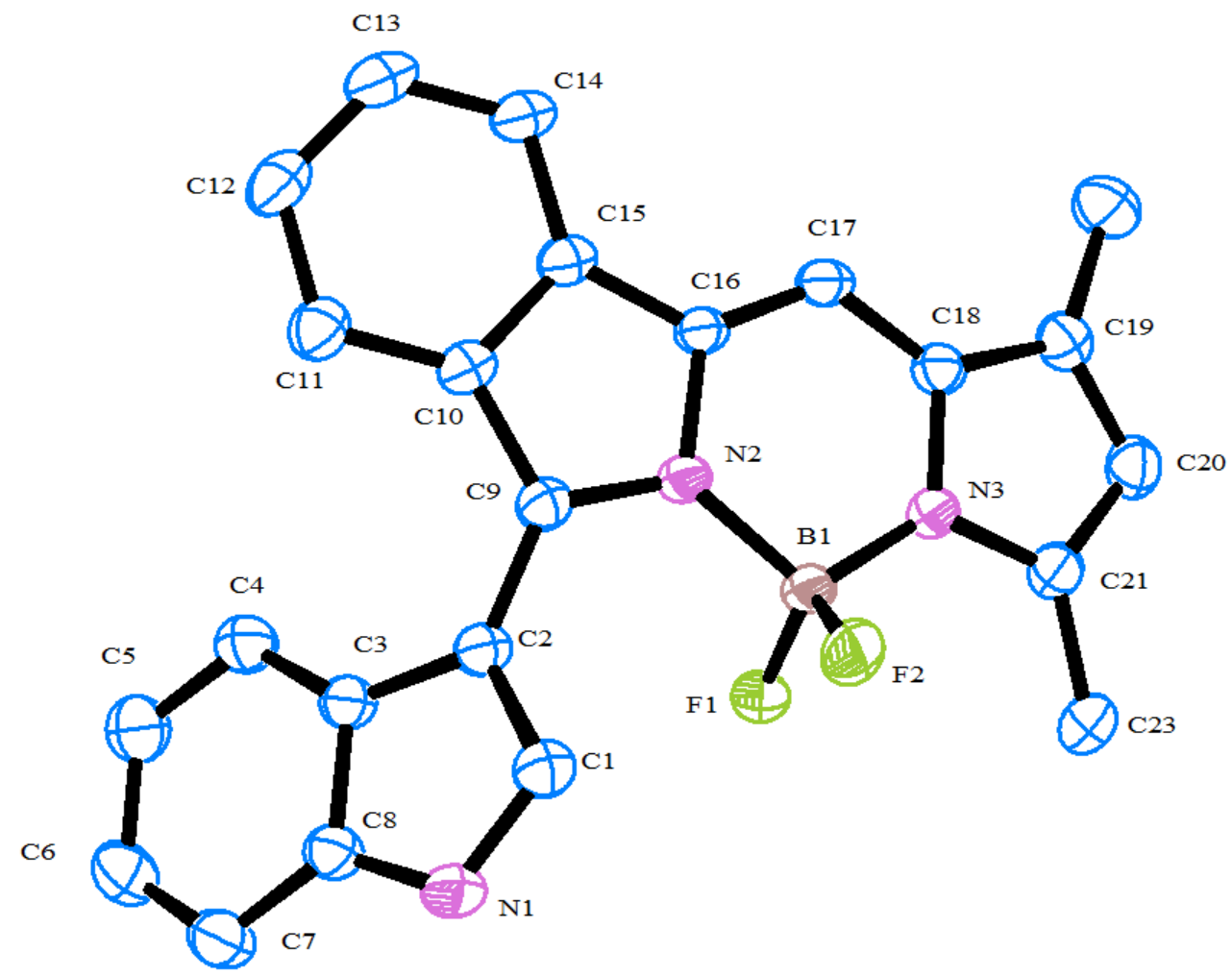

Figure S5. ORTEP plot of $\mathbf{5 f}$ with thermal ellipsoids at 30\% probability level 


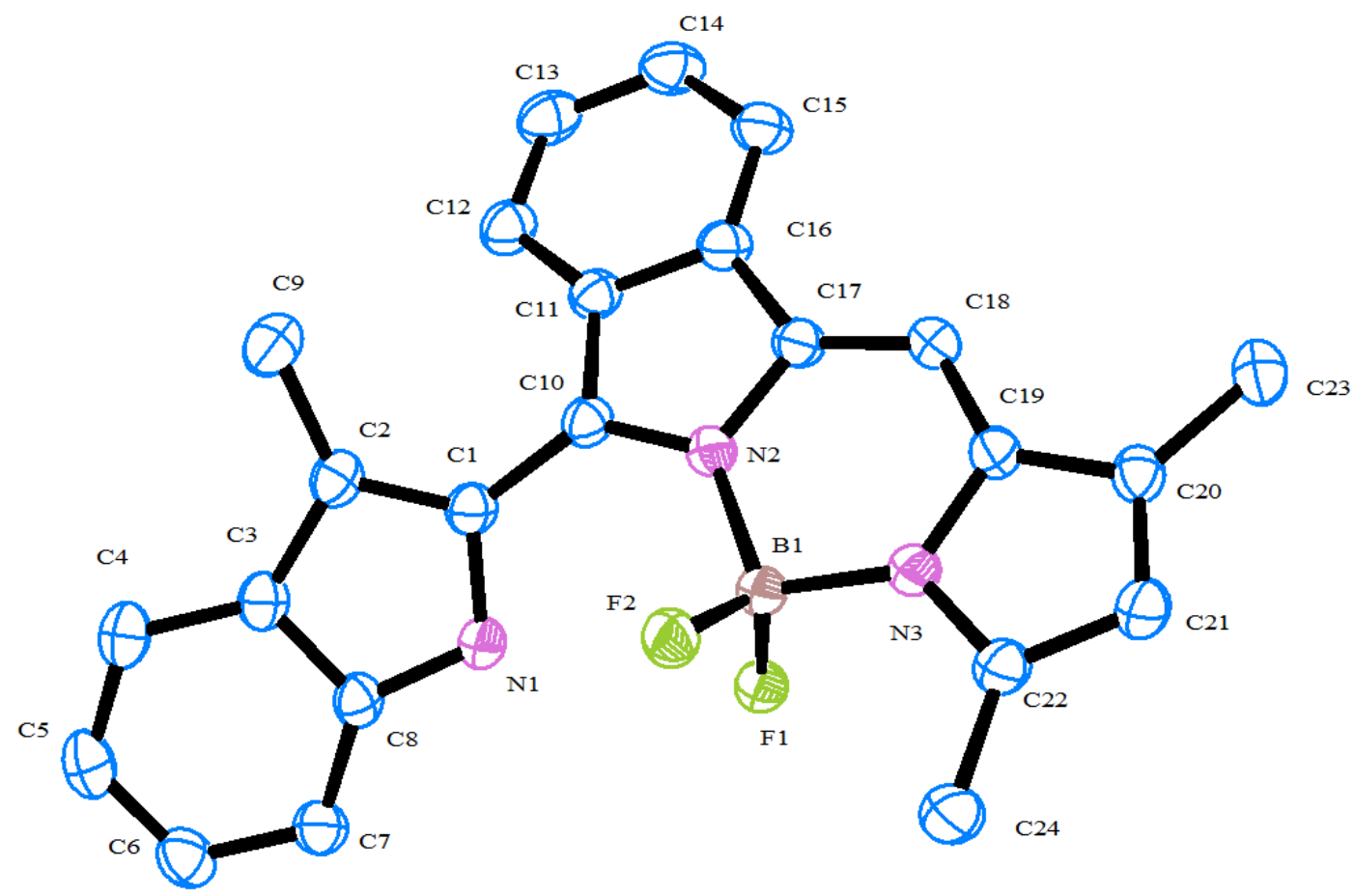

Figure S6. ORTEP plot of $\mathbf{5 g}$ with thermal ellipsoids at 30\% probability level

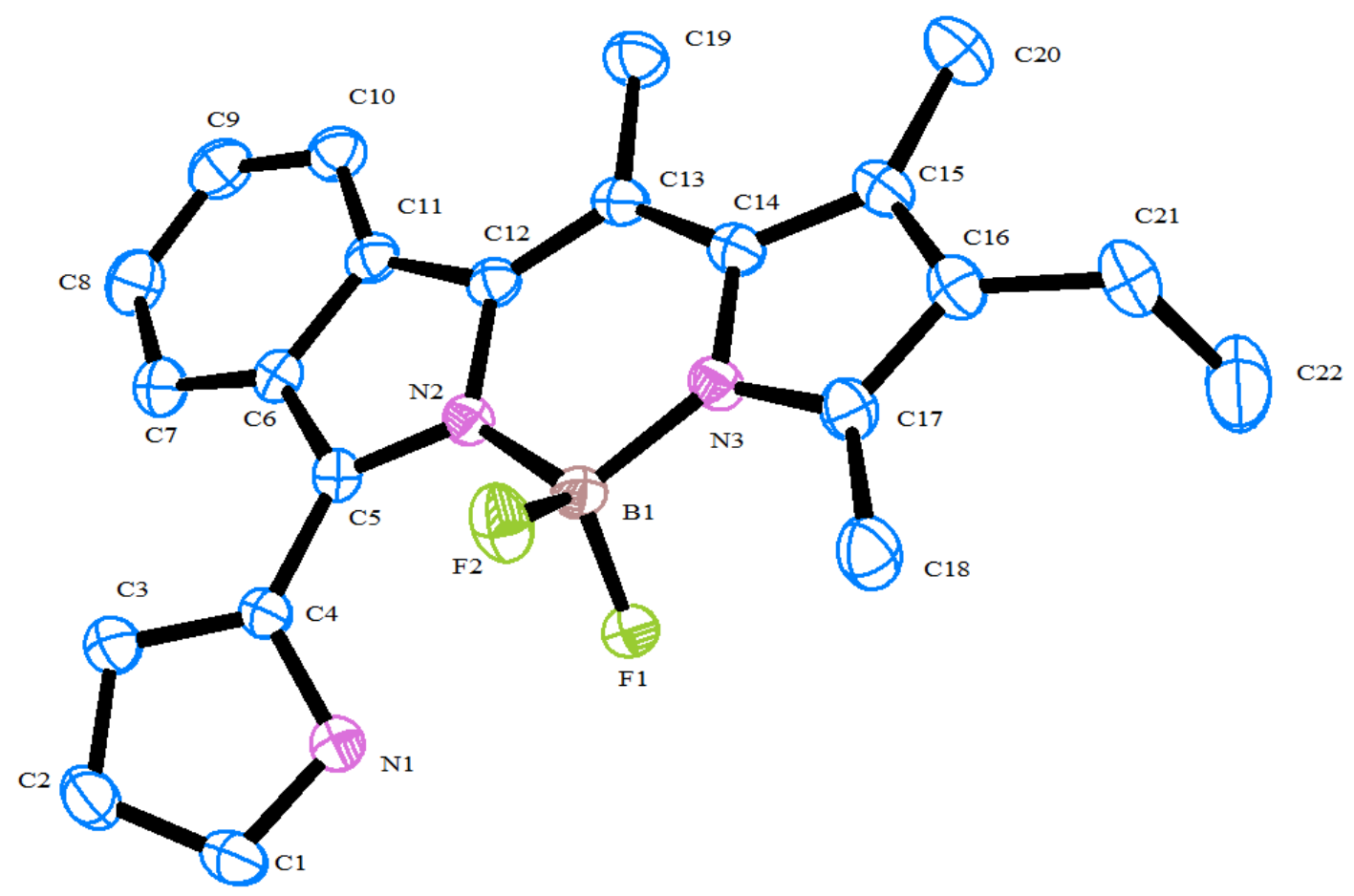

Figure S7. ORTEP plot of $\mathbf{5 i}$ with thermal ellipsoids at $30 \%$ probability level 


\section{Crystal packing structures for $1 \mathrm{a}$ and $5 \mathrm{~b}$}

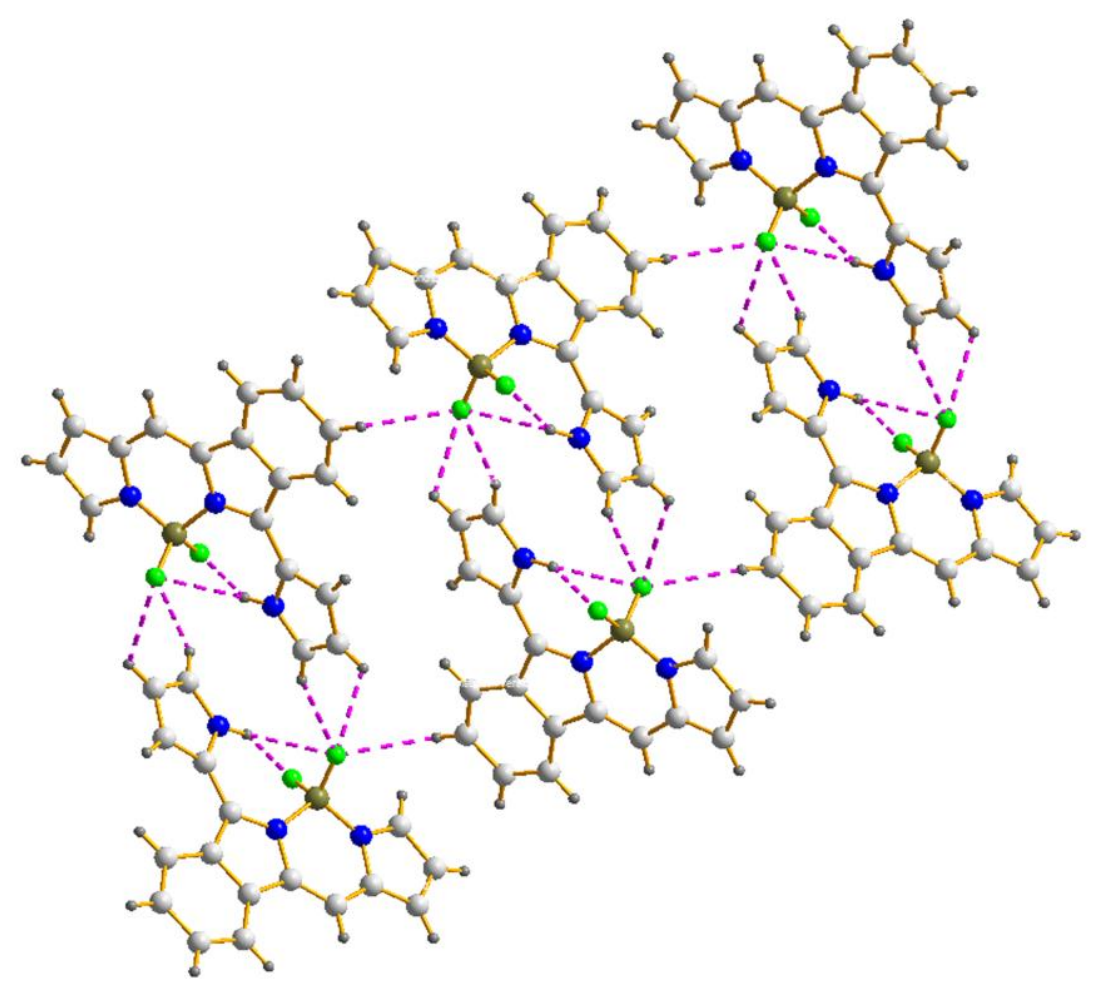

Figure S8. Crystal-packing pattern of 1a between the adjacent interlayered crystals through various intramolecular and intermolecular hydrogen bondings; $\mathrm{C}$, light gray; $\mathrm{H}$, medium gray; $\mathrm{N}$, blue; $\mathrm{B}$, dark yellow; F, green.

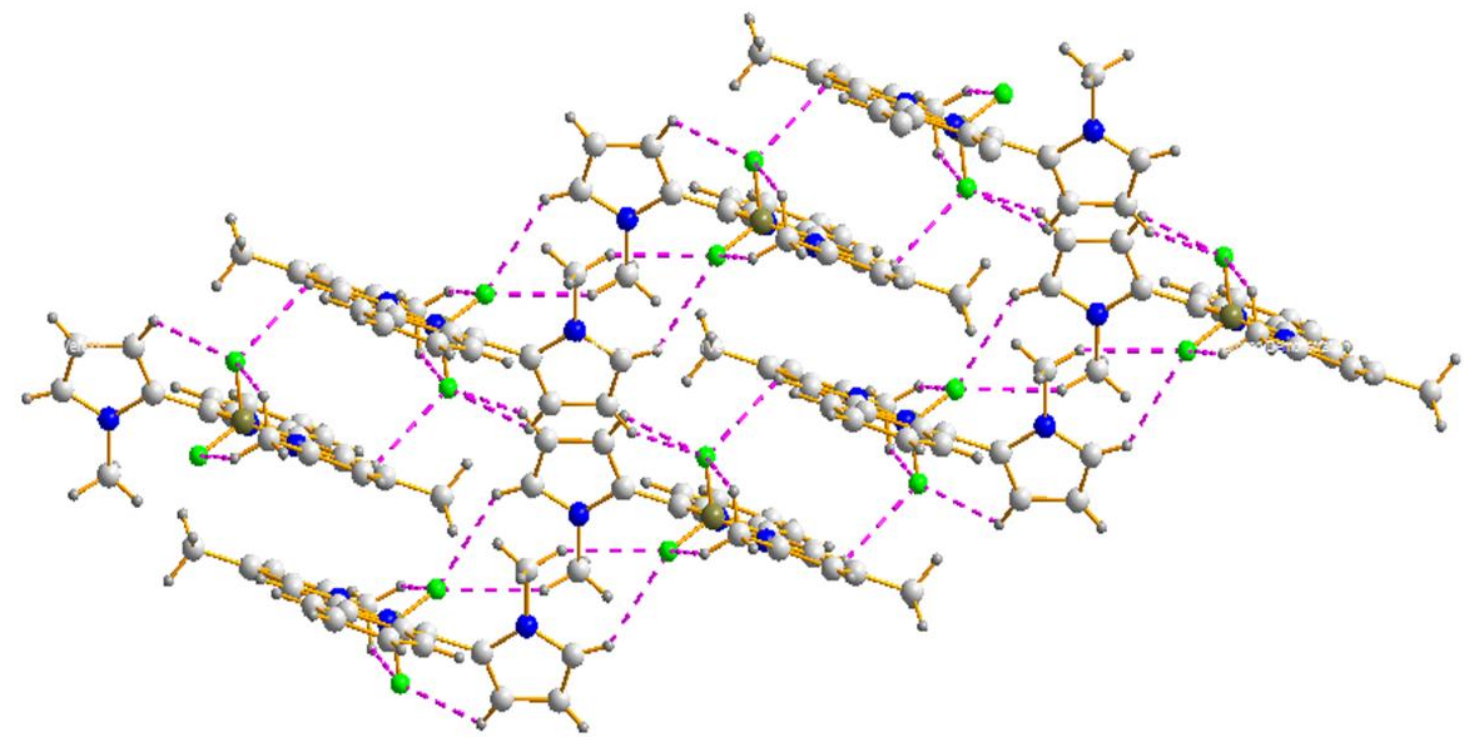

Figure S9. Crystal-packing pattern of $\mathbf{5 b}$ between the adjacent interlayered crystals through various intramolecular and intermolecular hydrogen bondings; $\mathrm{C}$, light gray; $\mathrm{H}$, medium gray; N, blue; B, dark yellow; F, green. 
6. Overlaid and Normalized absorption and fluorescence emission spectra in different solvents
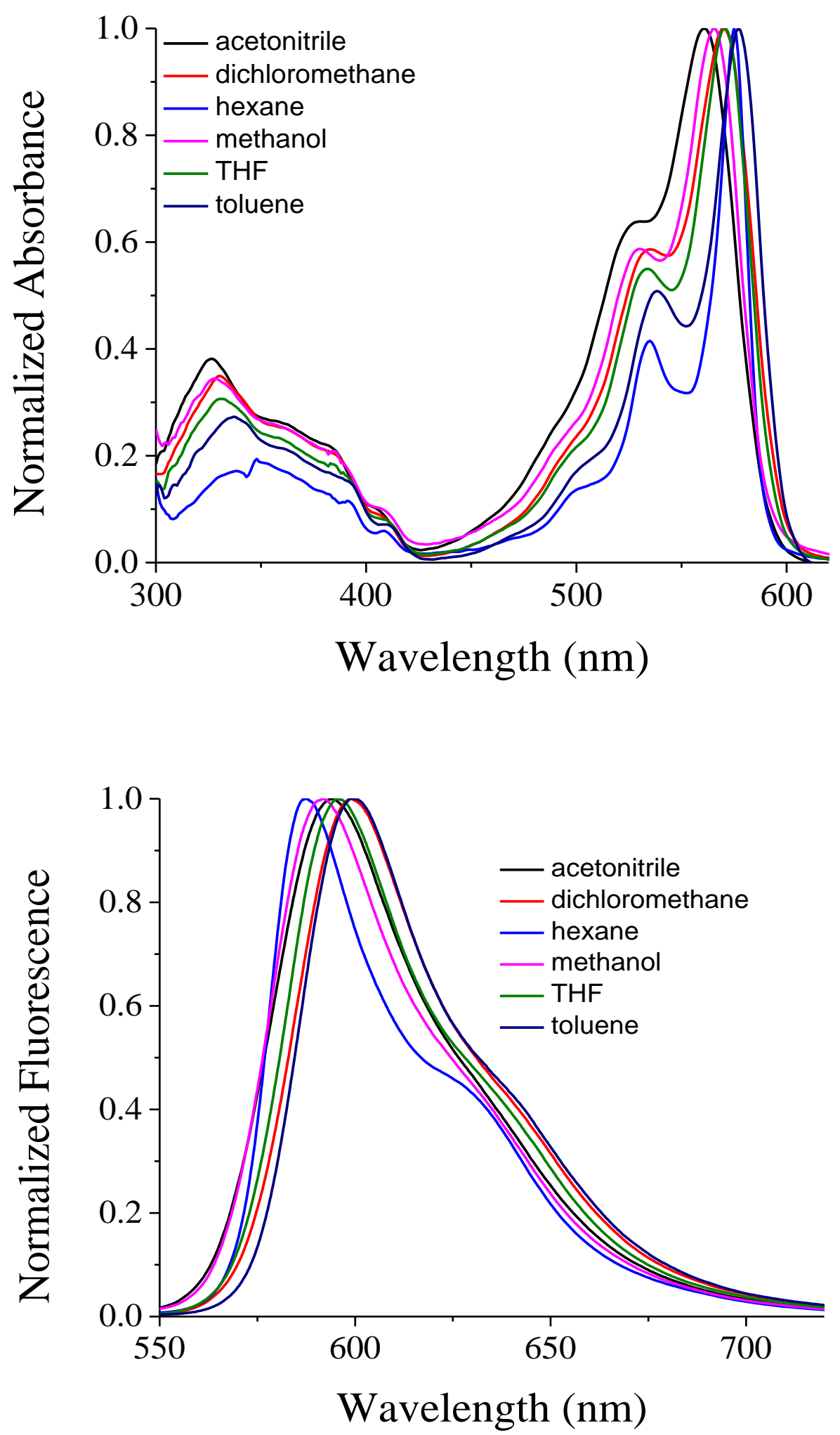

Figure S10. Overlaid and normalized absorption (top) and emission spectra (bottom) of 1a in different solvents, excited at $535 \mathrm{~nm}$. 

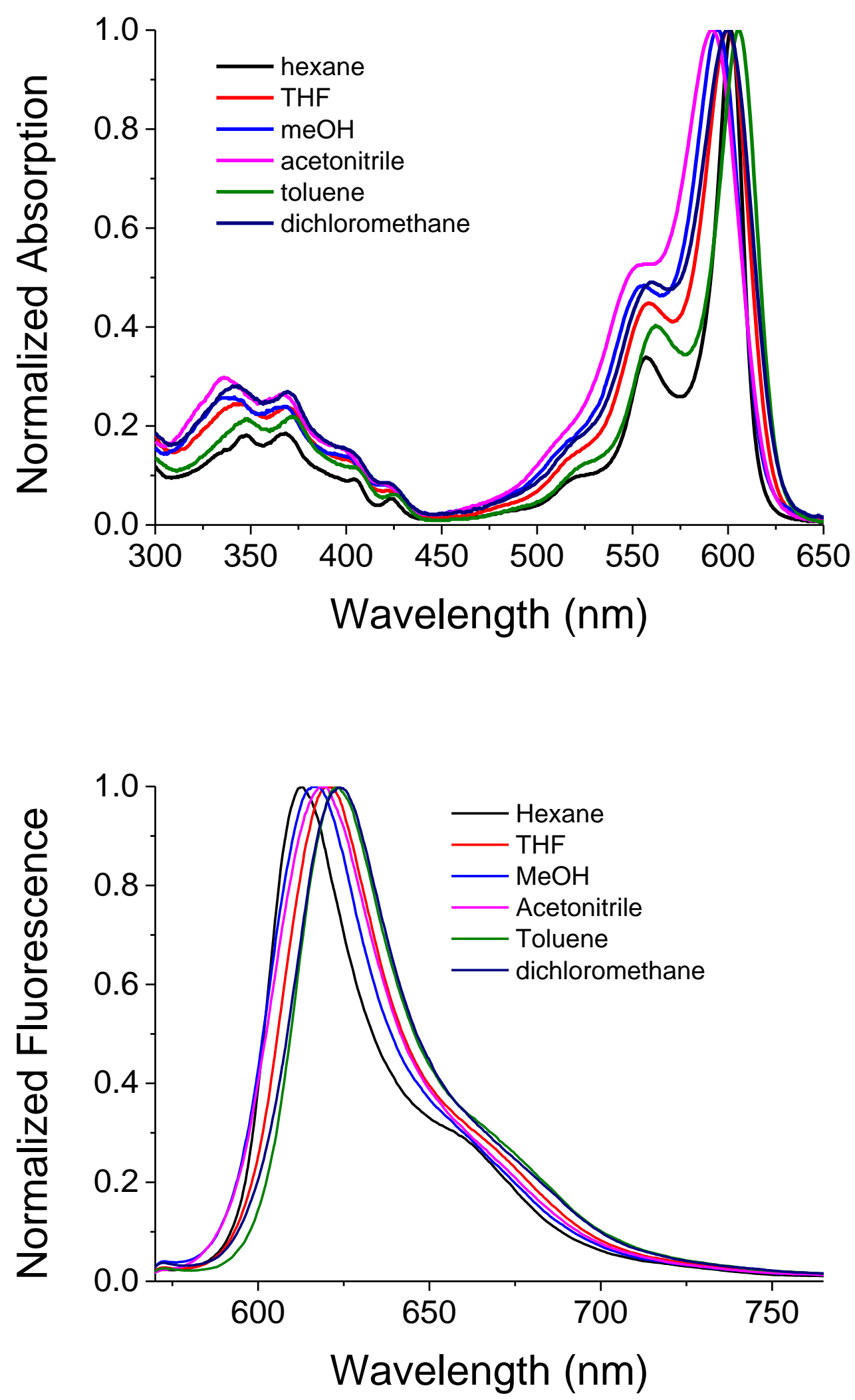

Figure S11. Overlaid and normalized absorption (top) and emission spectra (bottom) of $\mathbf{1 b}$ in different solvents, excited at $550 \mathrm{~nm}$. 

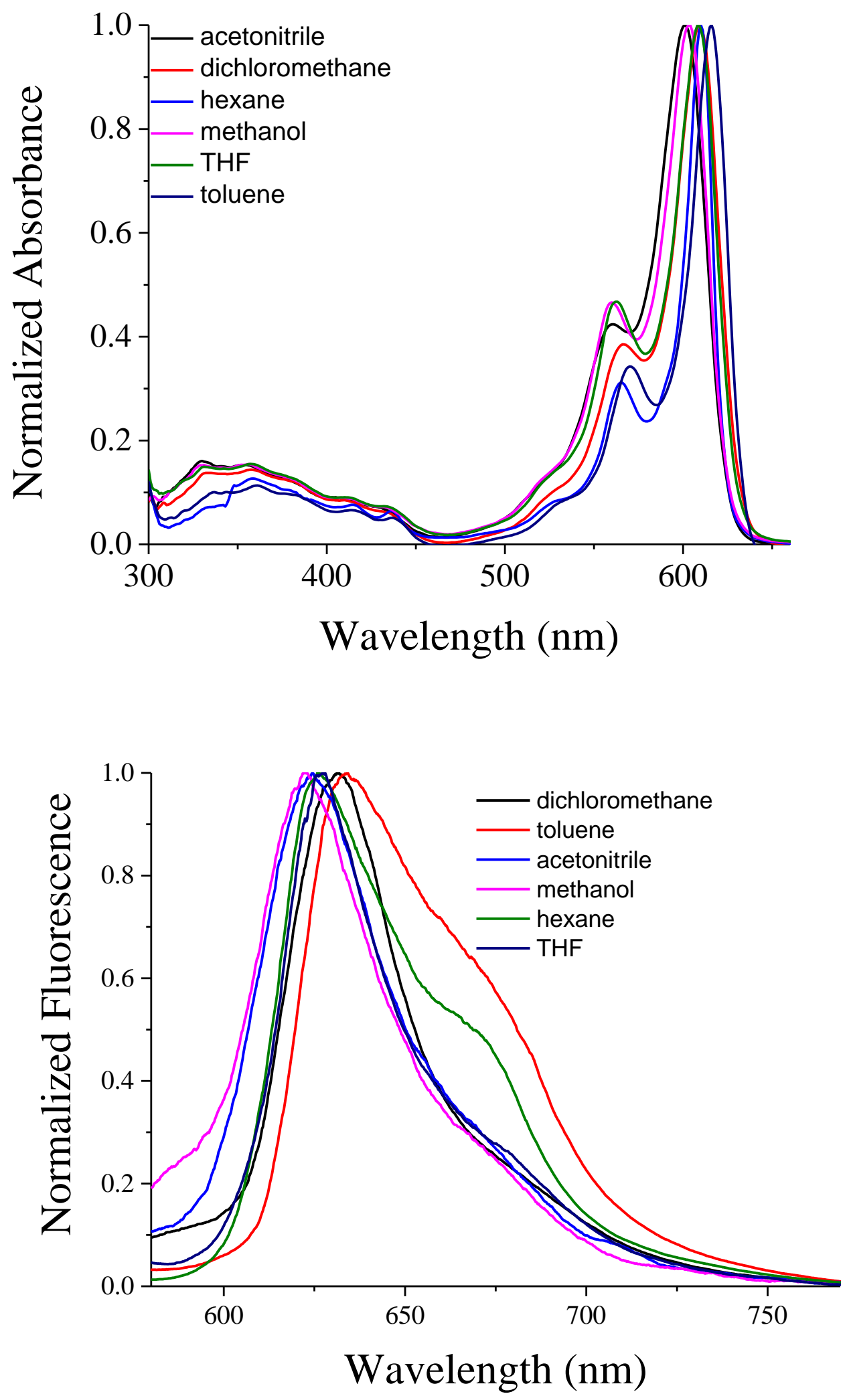

Figure S12. Overlaid and normalized absorption (top) and emission spectra (bottom) of 1c in different solvents, excited at $570 \mathrm{~nm}$. 

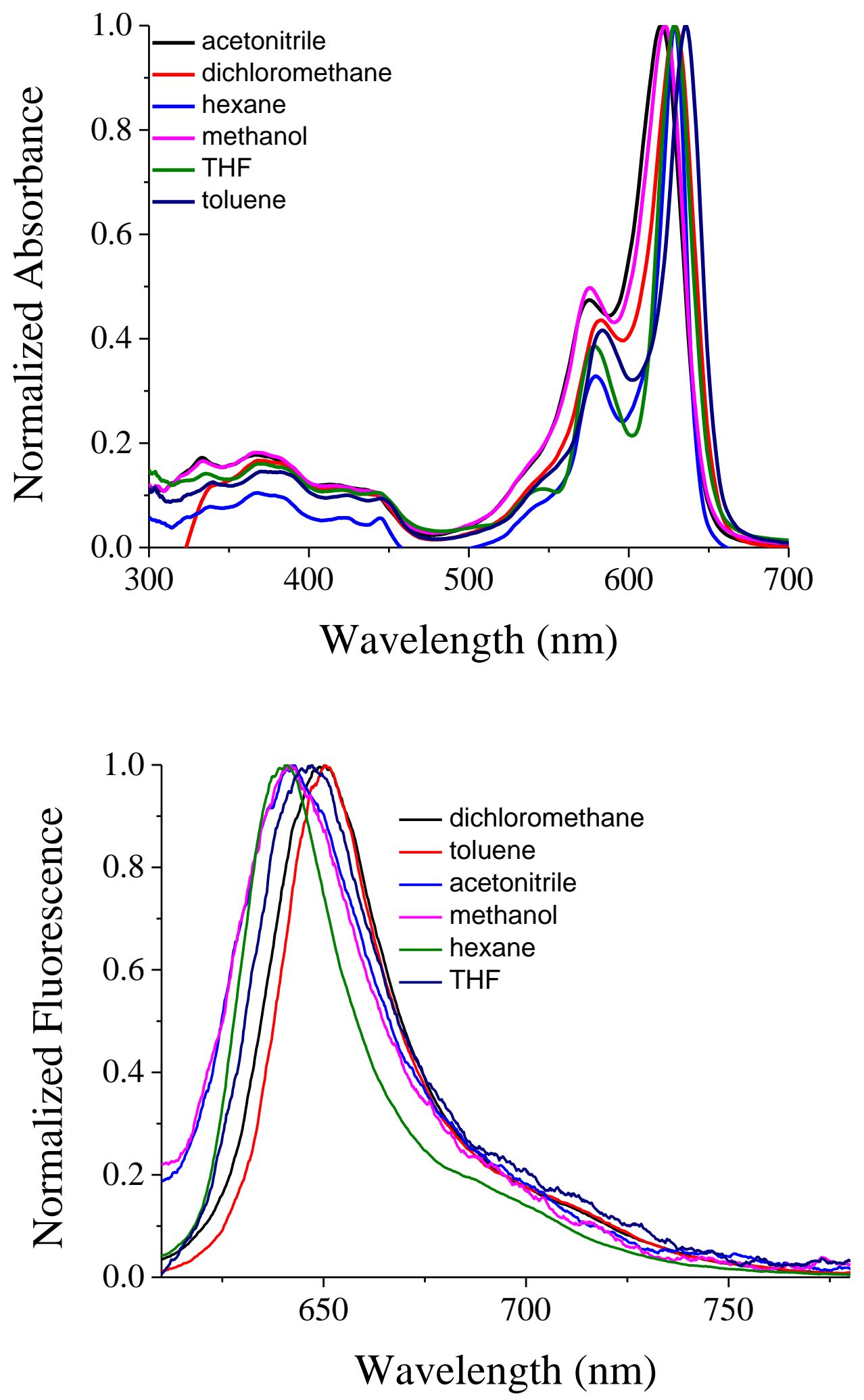

Figure S13. Overlaid and normalized absorption (top) and emission spectra (bottom) of 1d in different solvents, excited at $600 \mathrm{~nm}$. 

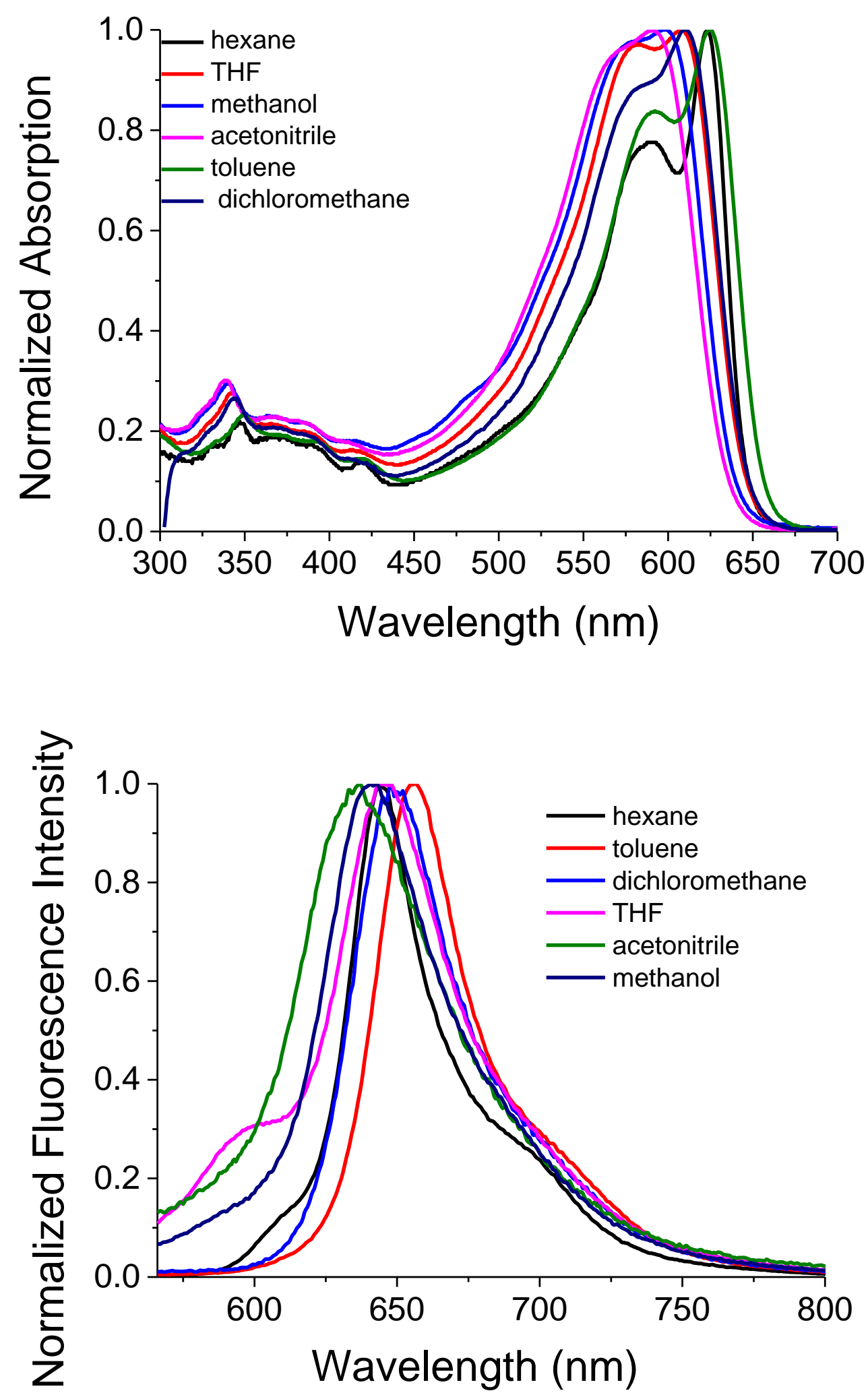

Figure S14. Overlaid and normalized absorption (top) and emission spectra (bottom) of 1e in different solvents, excited at $570 \mathrm{~nm}$. 

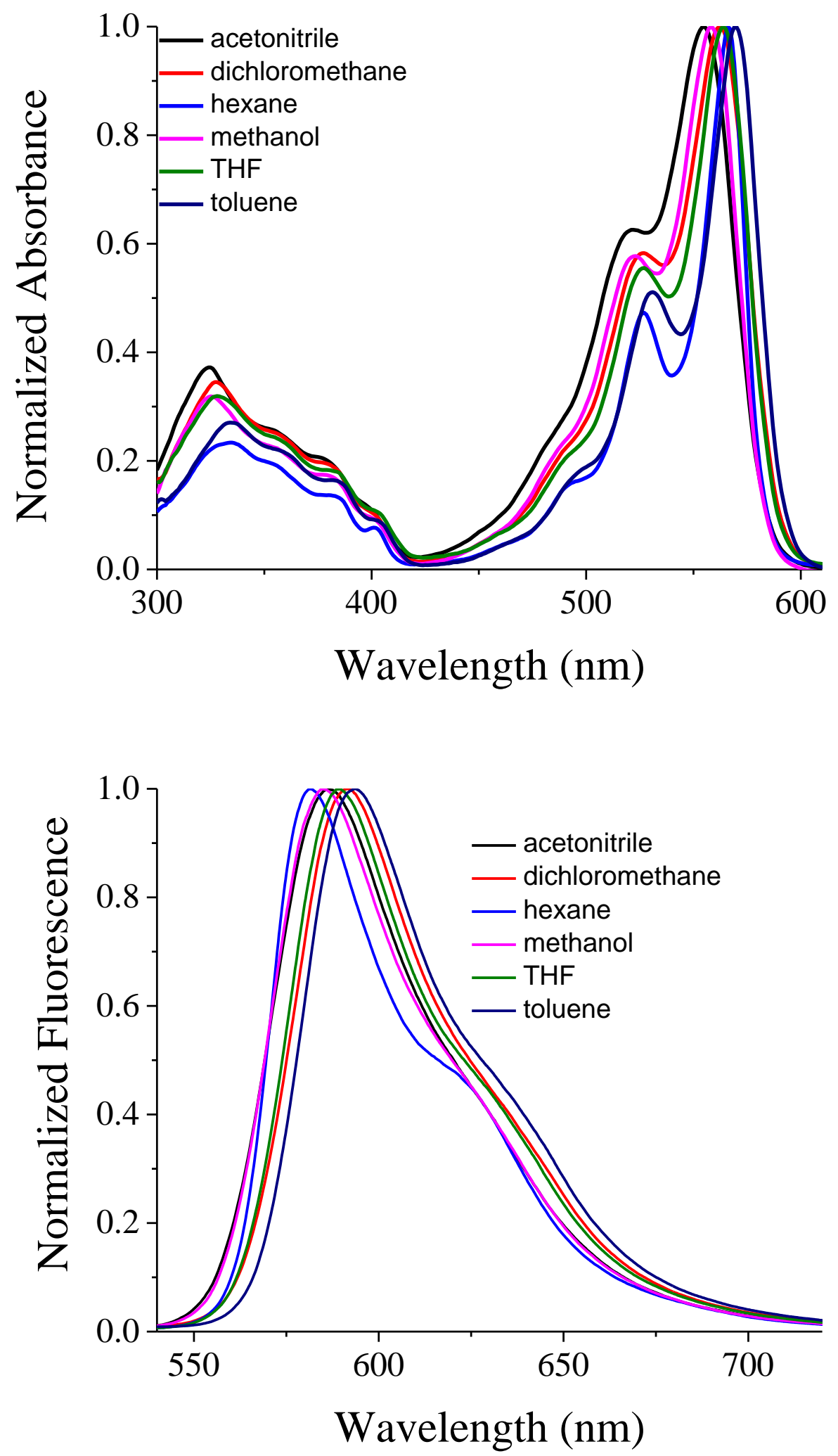

Figure S15. Overlaid and normalized absorption (top) and emission spectra (bottom) of $\mathbf{1 f}$ in different solvents, excited at $520 \mathrm{~nm}$. 

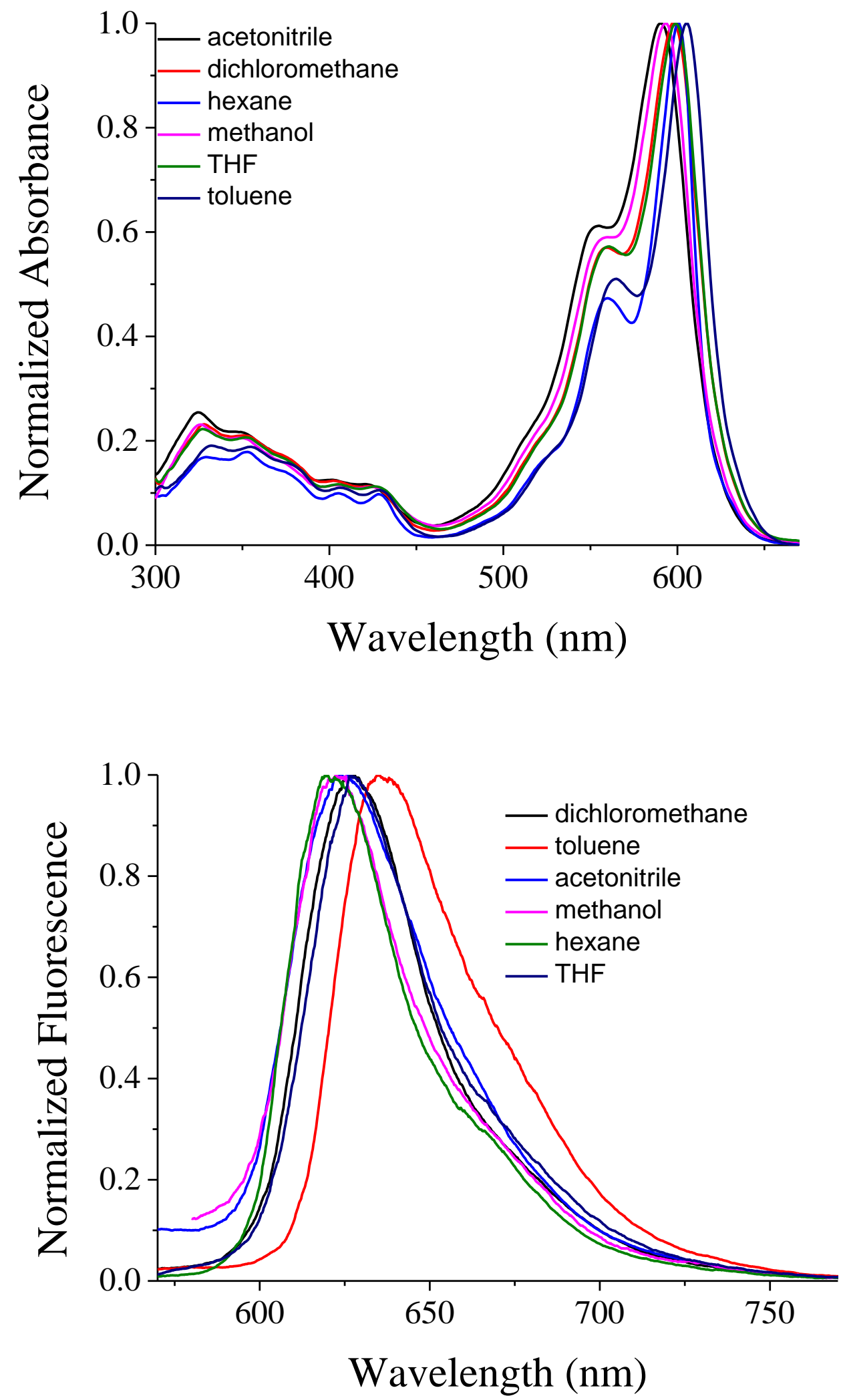

Figure S16. Overlaid and normalized absorption (top) and emission spectra (bottom) of $\mathbf{1 g}$ in different solvents, excited at $560 \mathrm{~nm}$. 

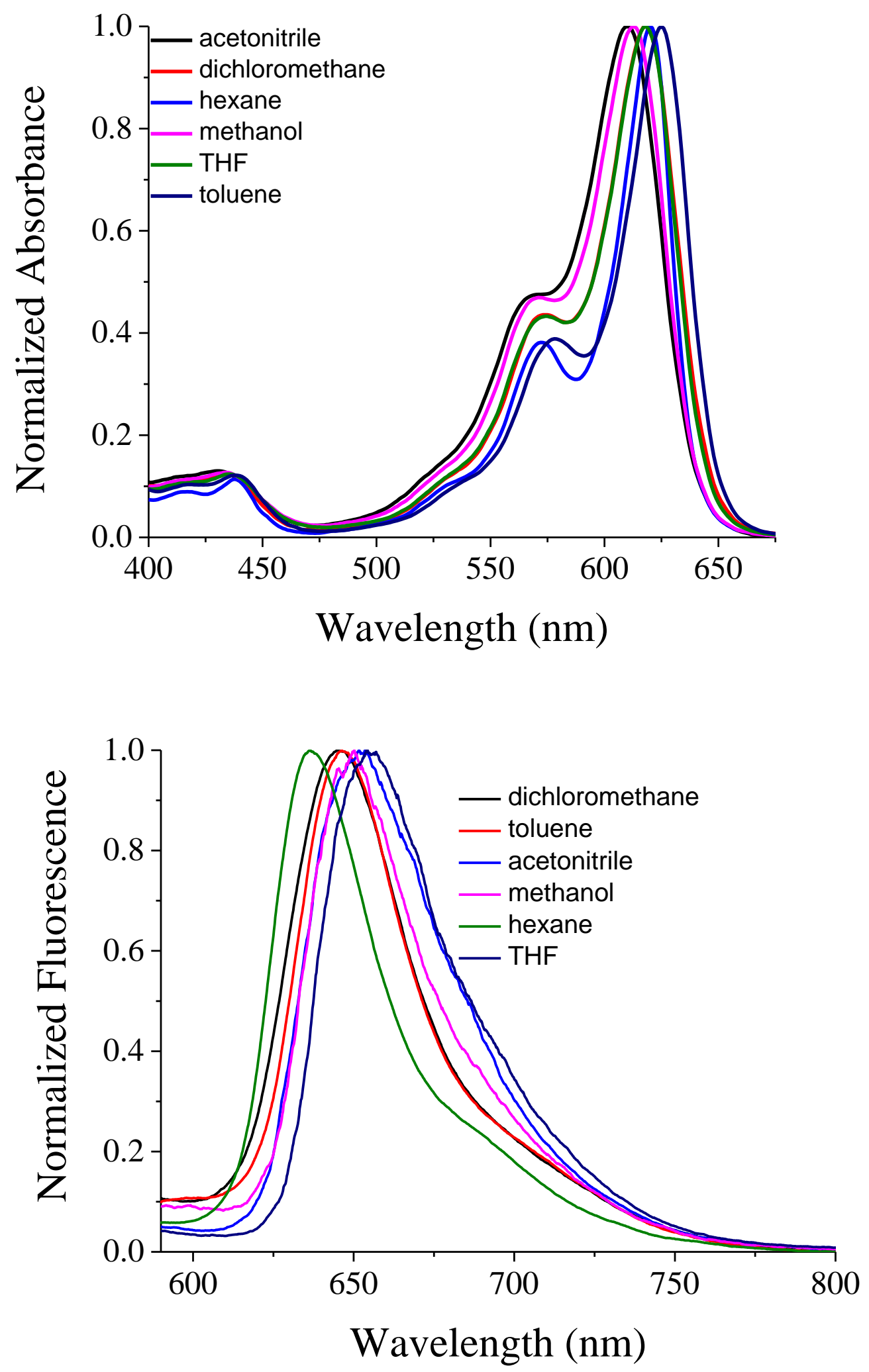

Figure S17. Overlaid and normalized absorption (top) and emission spectra (bottom) of $\mathbf{1 h}$ in different solvents, excited at $575 \mathrm{~nm}$. 

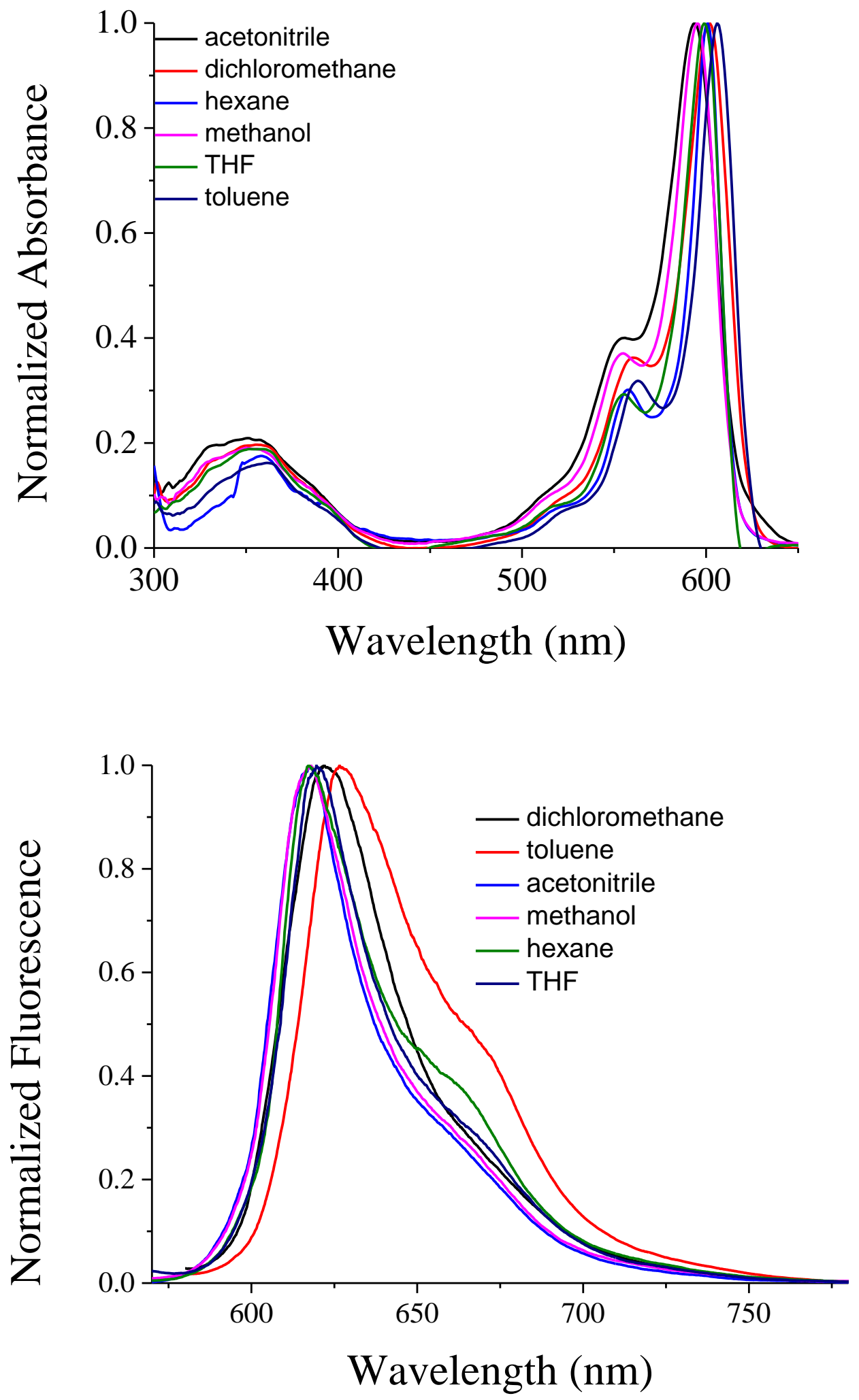

Figure S18. Overlaid and normalized absorption (top) and emission spectra (bottom) of 5a in different solvents, excited at $560 \mathrm{~nm}$. 

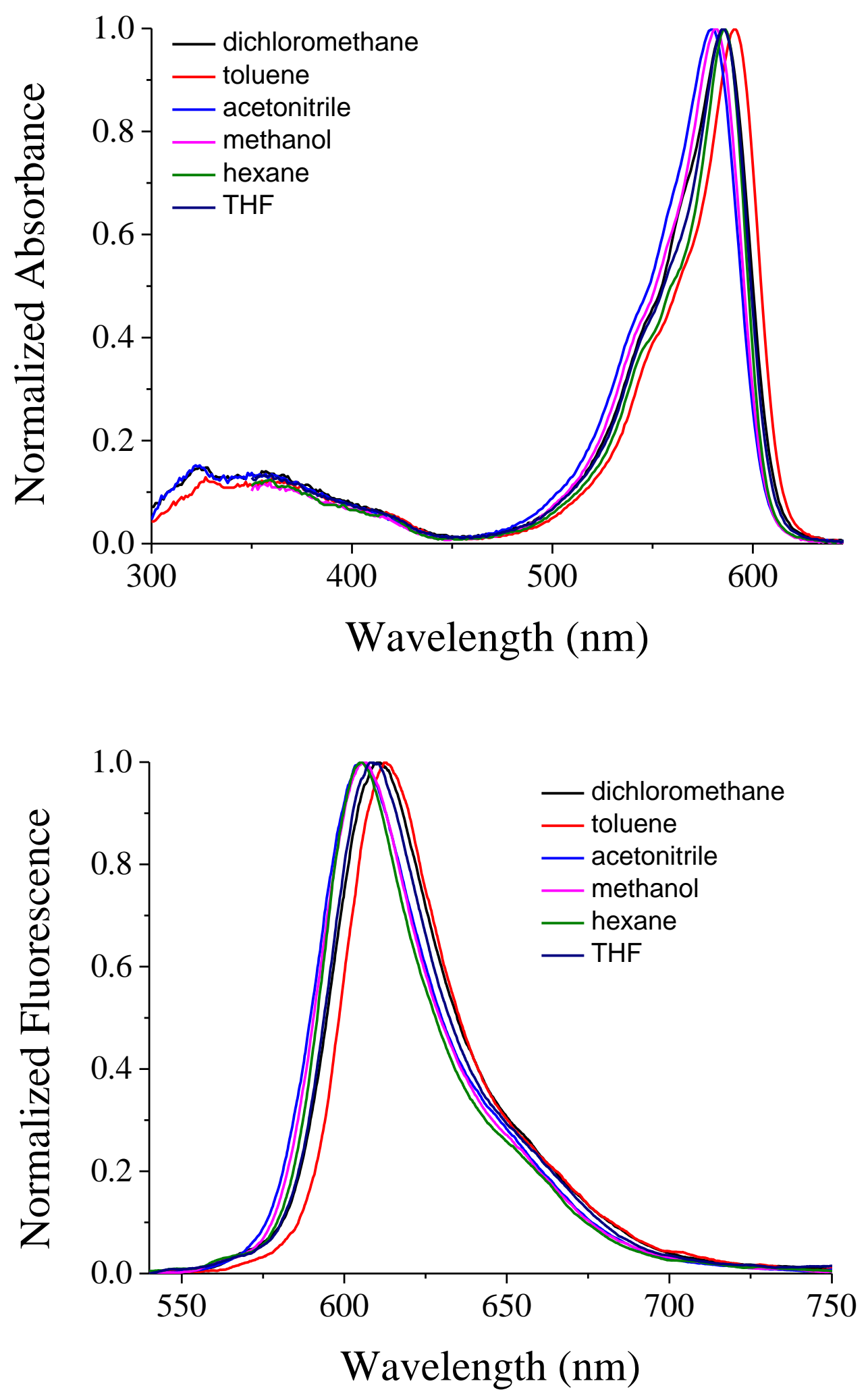

Figure S19. Overlaid and normalized absorption (top) and emission spectra (bottom) of $\mathbf{5 b}$ in different solvents, excited at $530 \mathrm{~nm}$. 

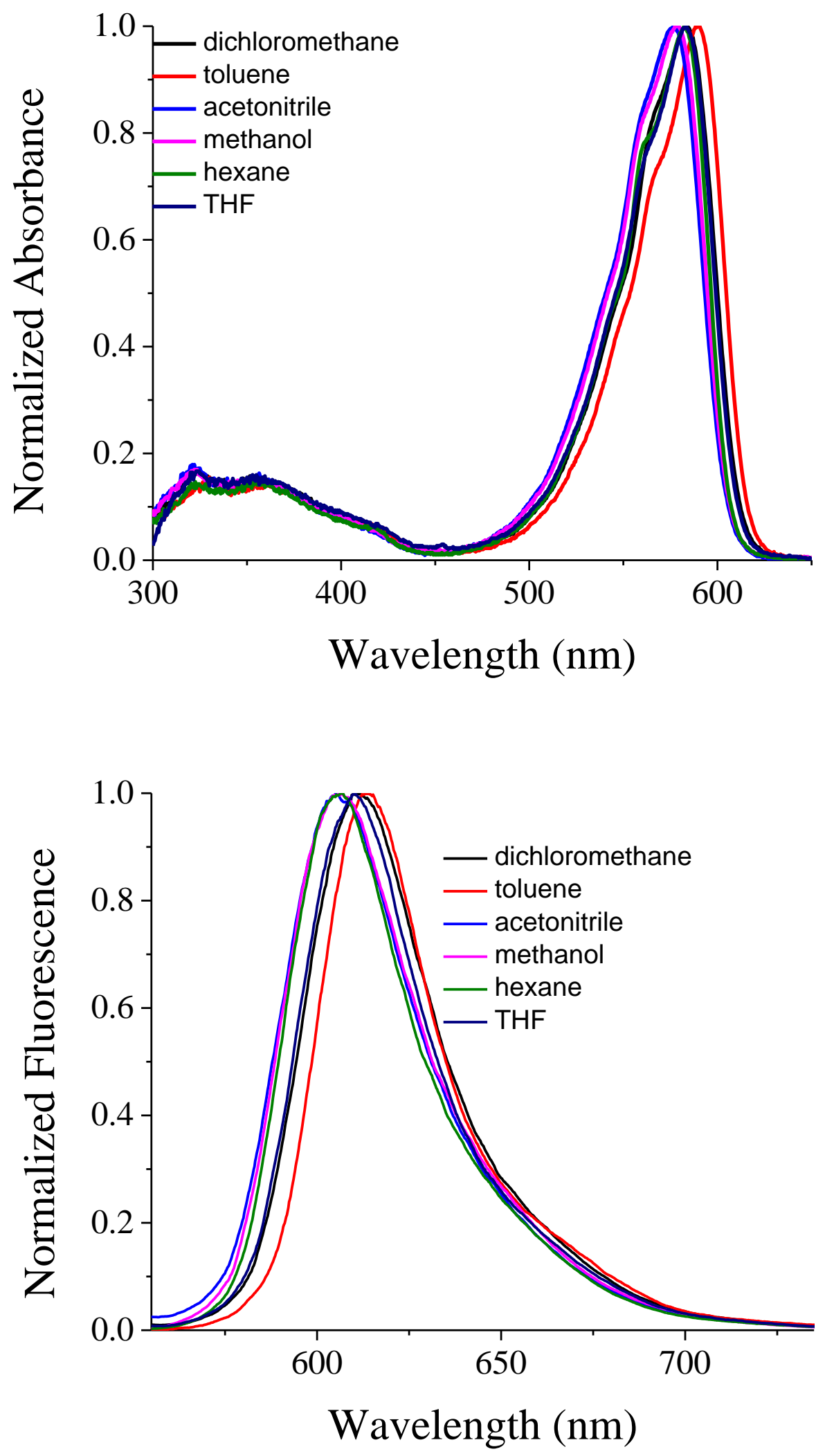

Figure S20. Overlaid and normalized absorption (top) and emission spectra (bottom) of $\mathbf{5 c}$ in different solvents, excited at $540 \mathrm{~nm}$. 

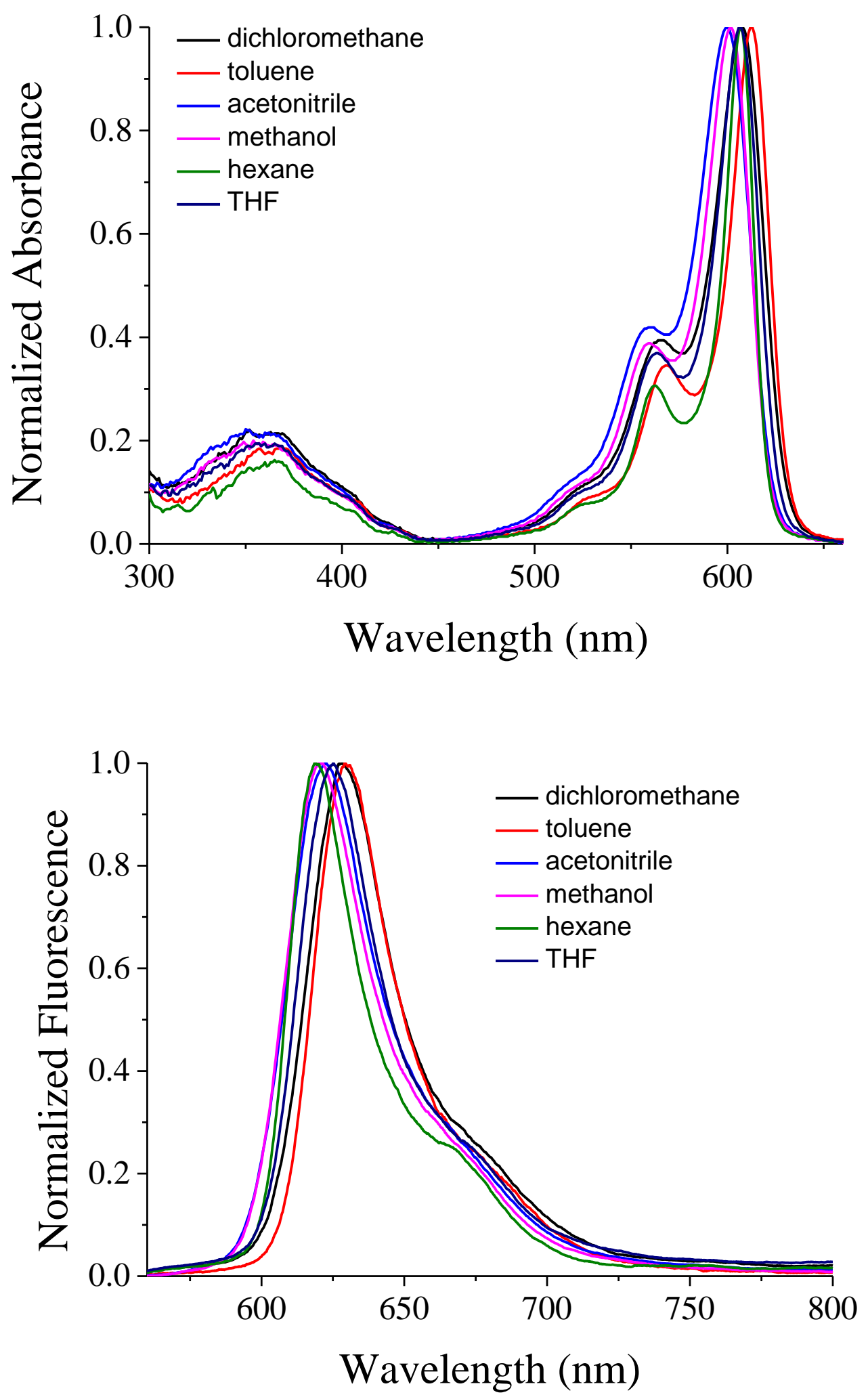

Figure S21. Overlaid and normalized absorption (top) and emission spectra (bottom) of $\mathbf{5 d}$ in different solvents, excited at $550 \mathrm{~nm}$. 

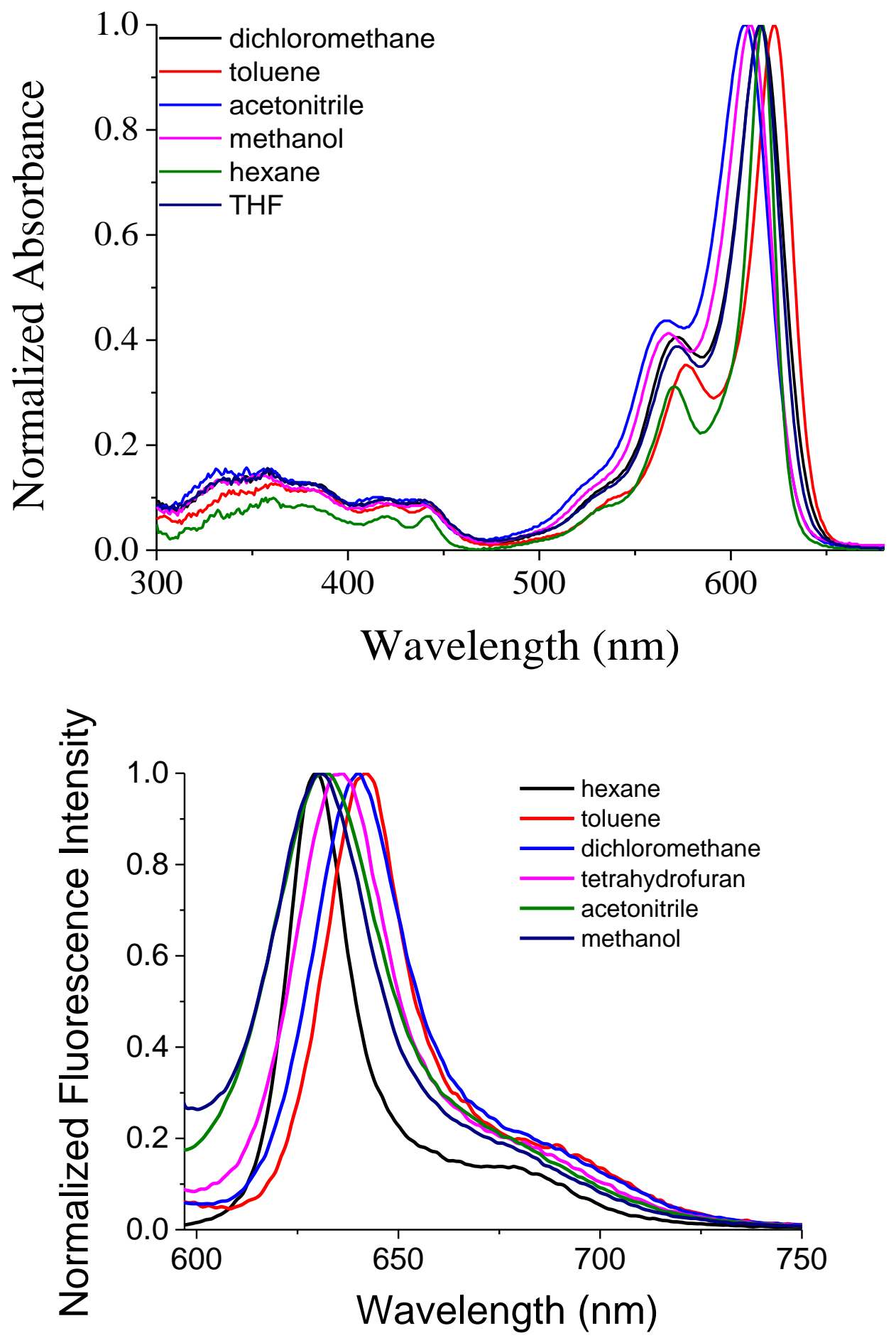

Figure S22. Overlaid and normalized absorption (top) and emission spectra (bottom) of $\mathbf{5 e}$ in different solvents, excited at $570 \mathrm{~nm}$. 

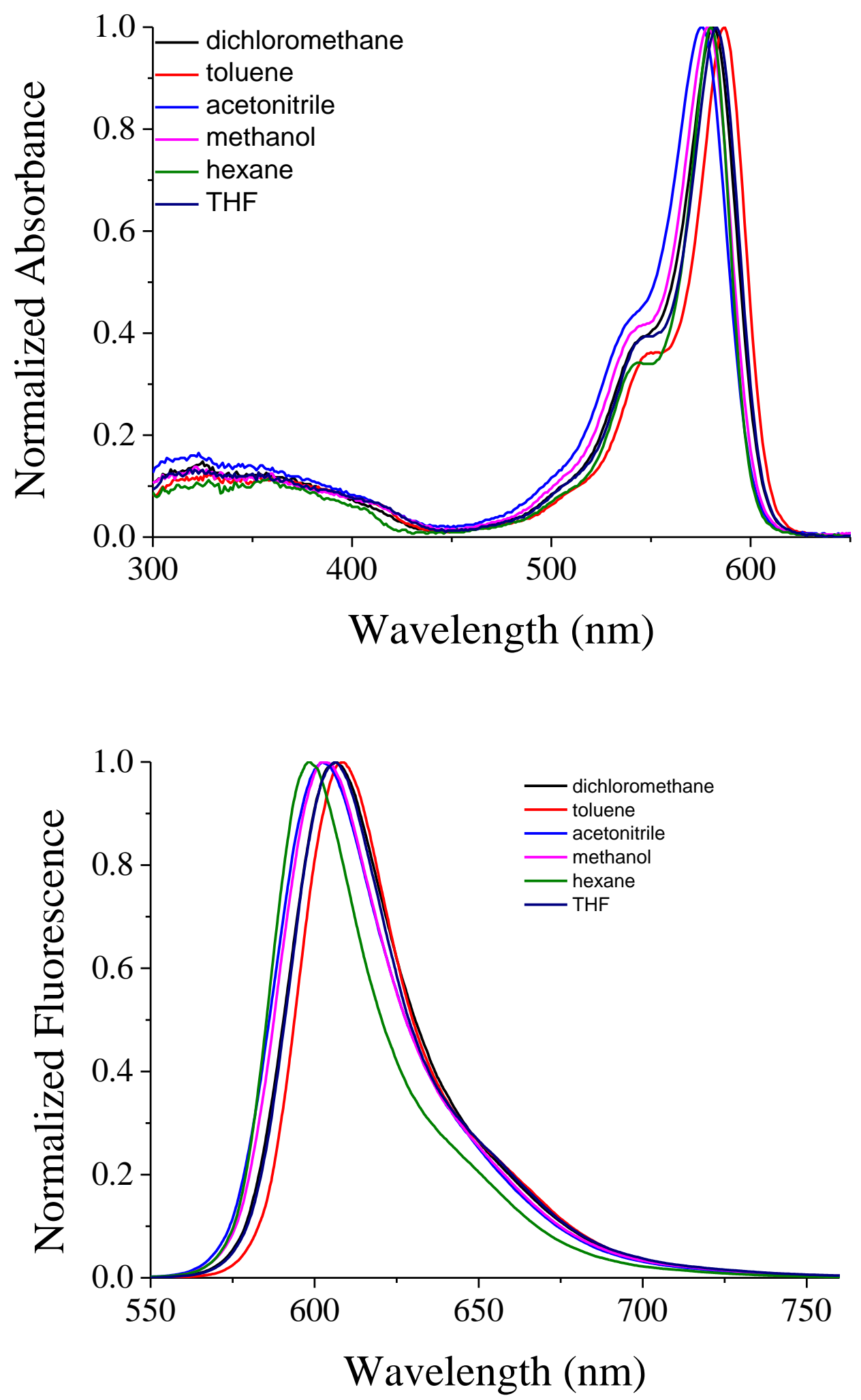

Figure S23. Overlaid and normalized absorption (top) and emission spectra (bottom) of $\mathbf{5 f}$ in different solvents, excited at $540 \mathrm{~nm}$. 

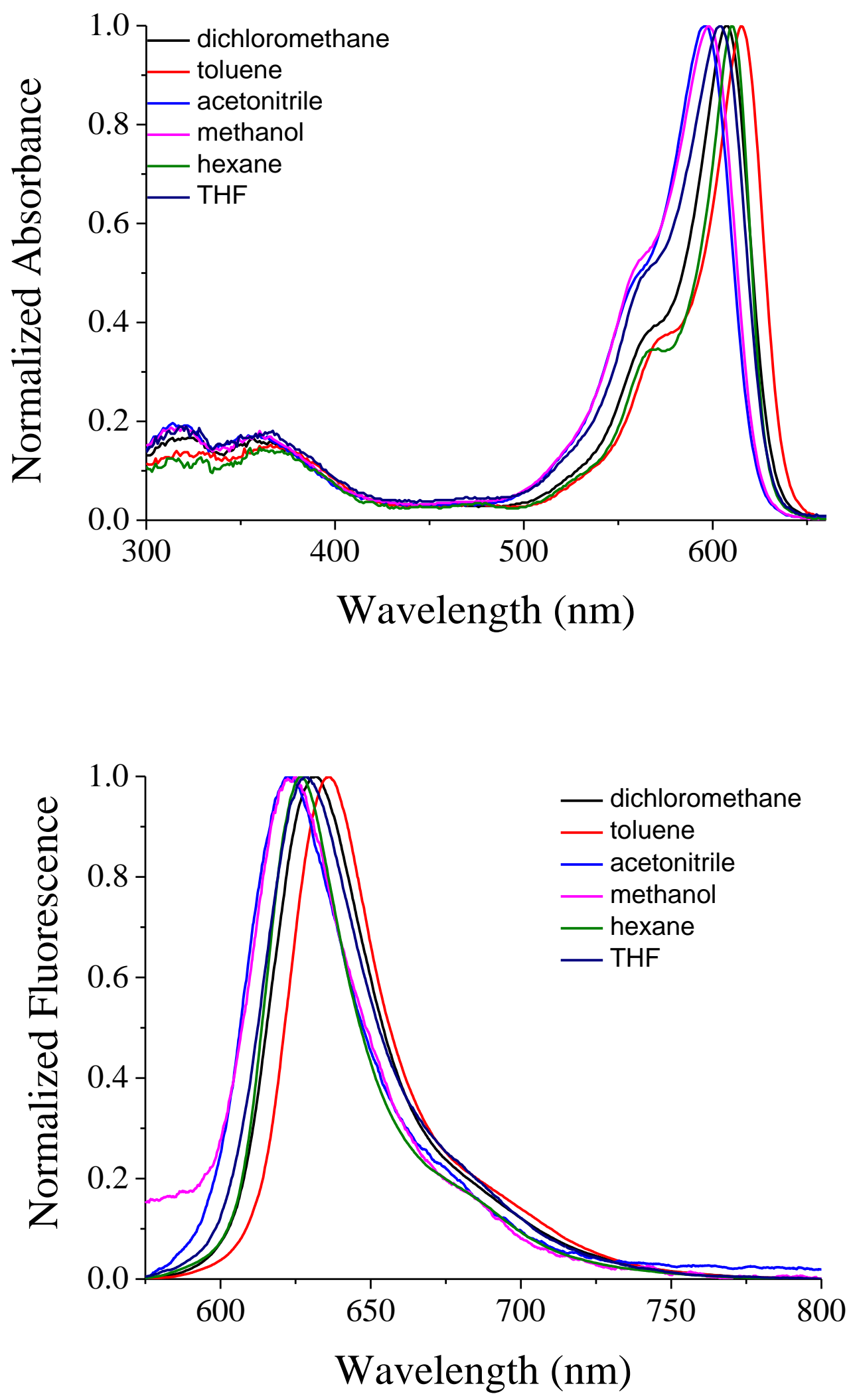

Figure S24. Overlaid and normalized absorption (top) and emission spectra (bottom) of $\mathbf{5 g}$ in different solvents, excited at $565 \mathrm{~nm}$. 

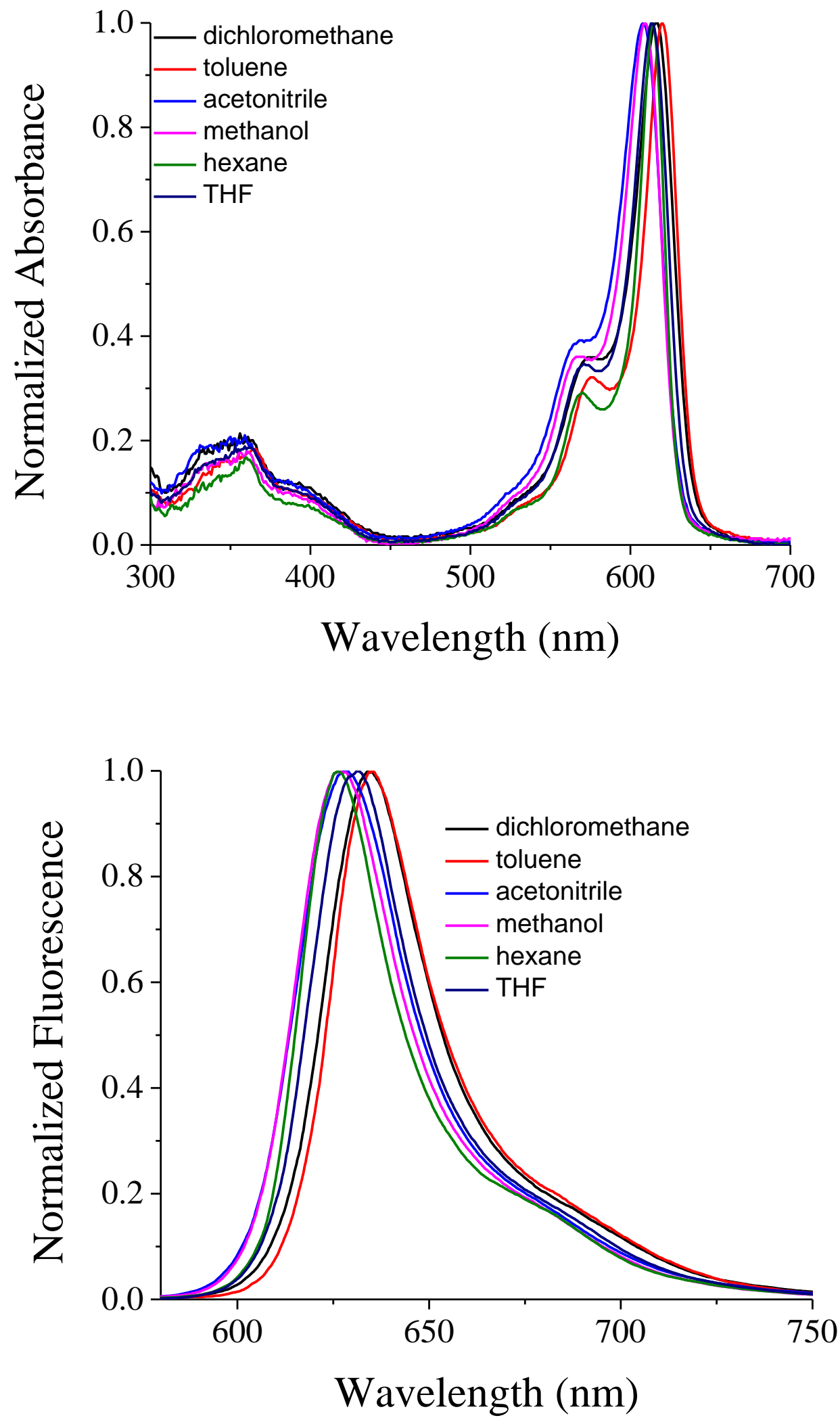

Figure S25. Overlaid and normalized absorption (top) and emission spectra (bottom) of $\mathbf{5 h}$ in different solvents, excited at $560 \mathrm{~nm}$. 

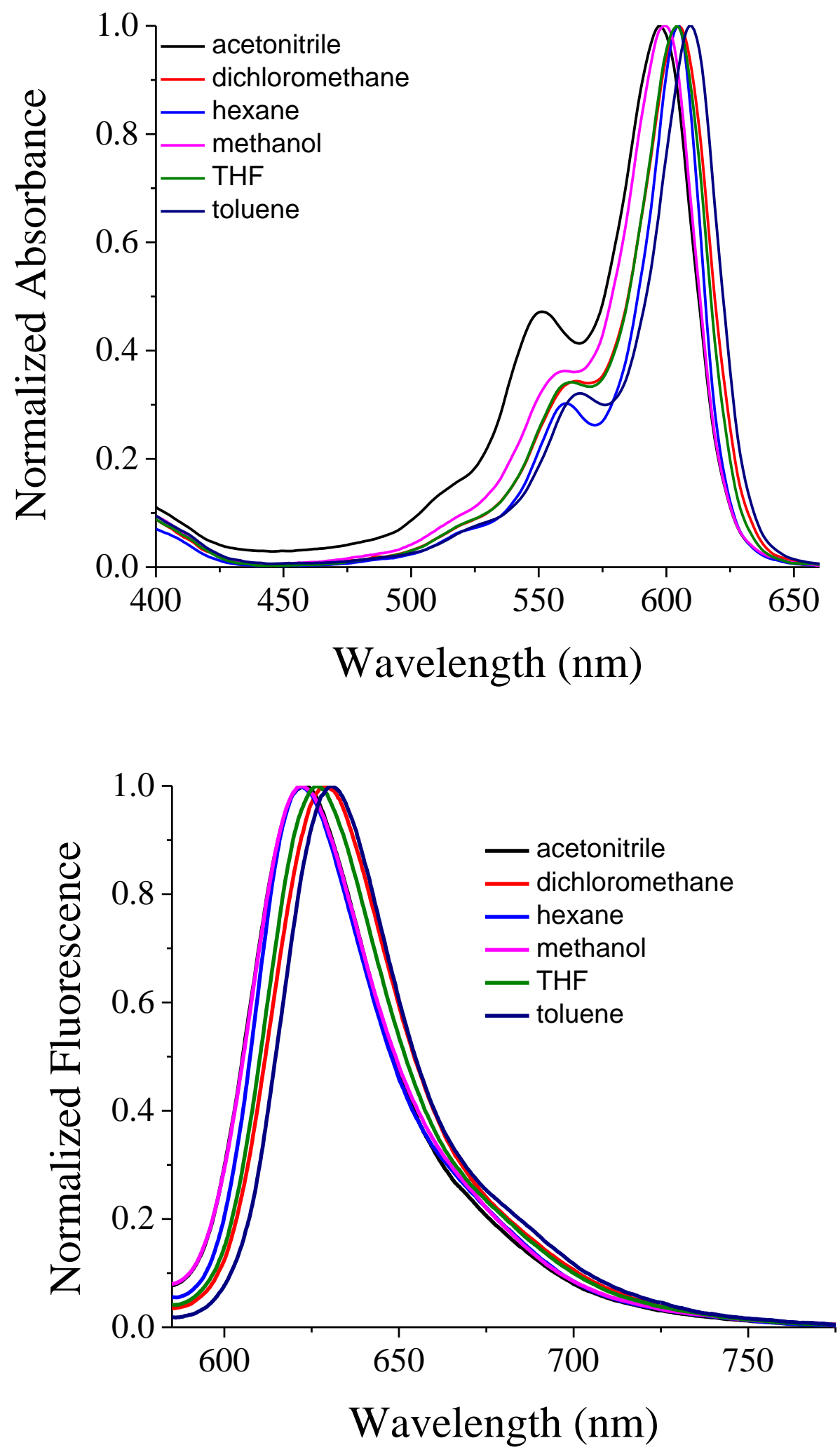

Figure S26. Overlaid and normalized absorption (top) and emission spectra (bottom) of 5i in different solvents, excited at $575 \mathrm{~nm}$. 

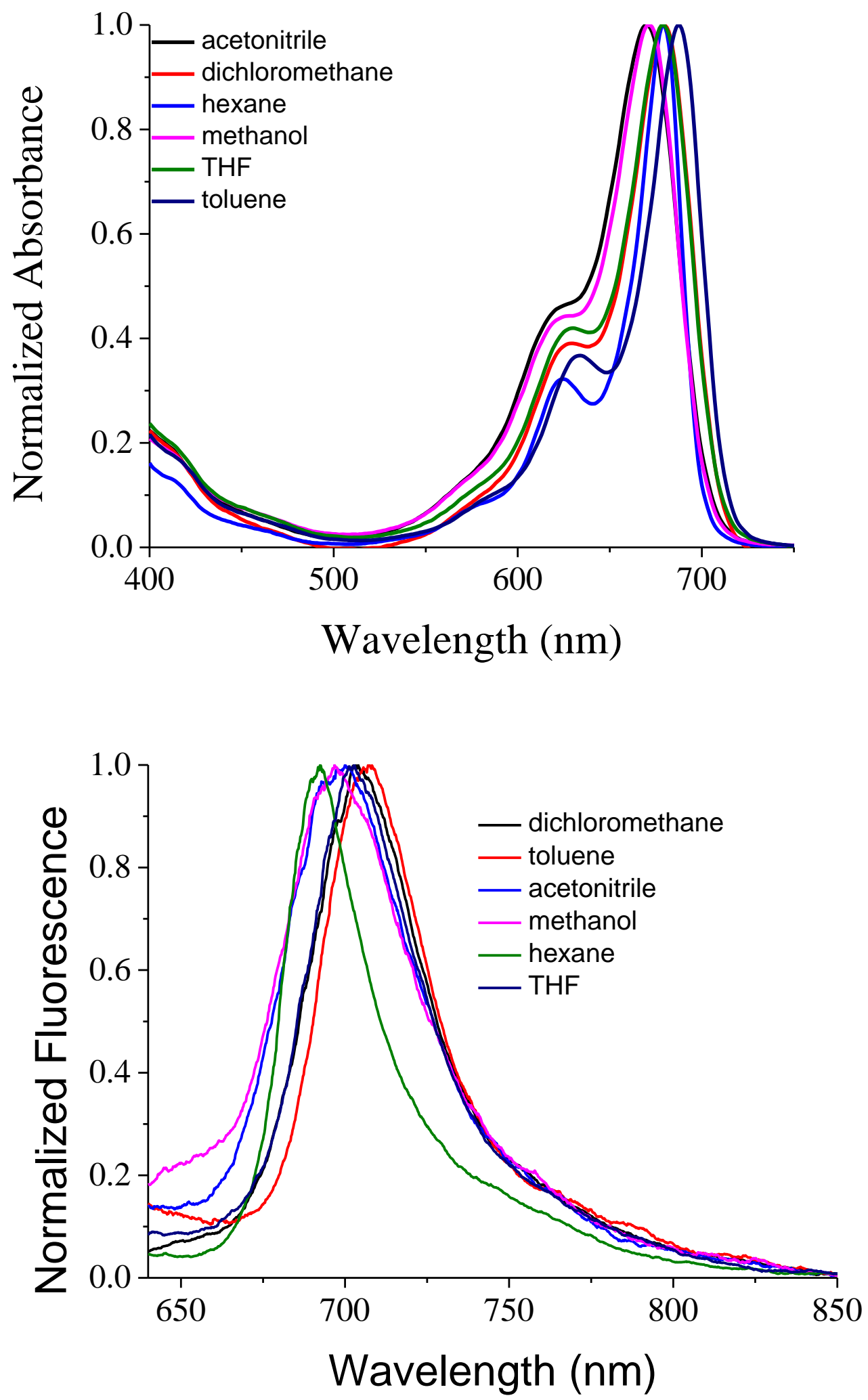

Figure S27. Overlaid and normalized absorption (top) and emission spectra (bottom) of 7a in different solvents, excited at $630 \mathrm{~nm}$. 

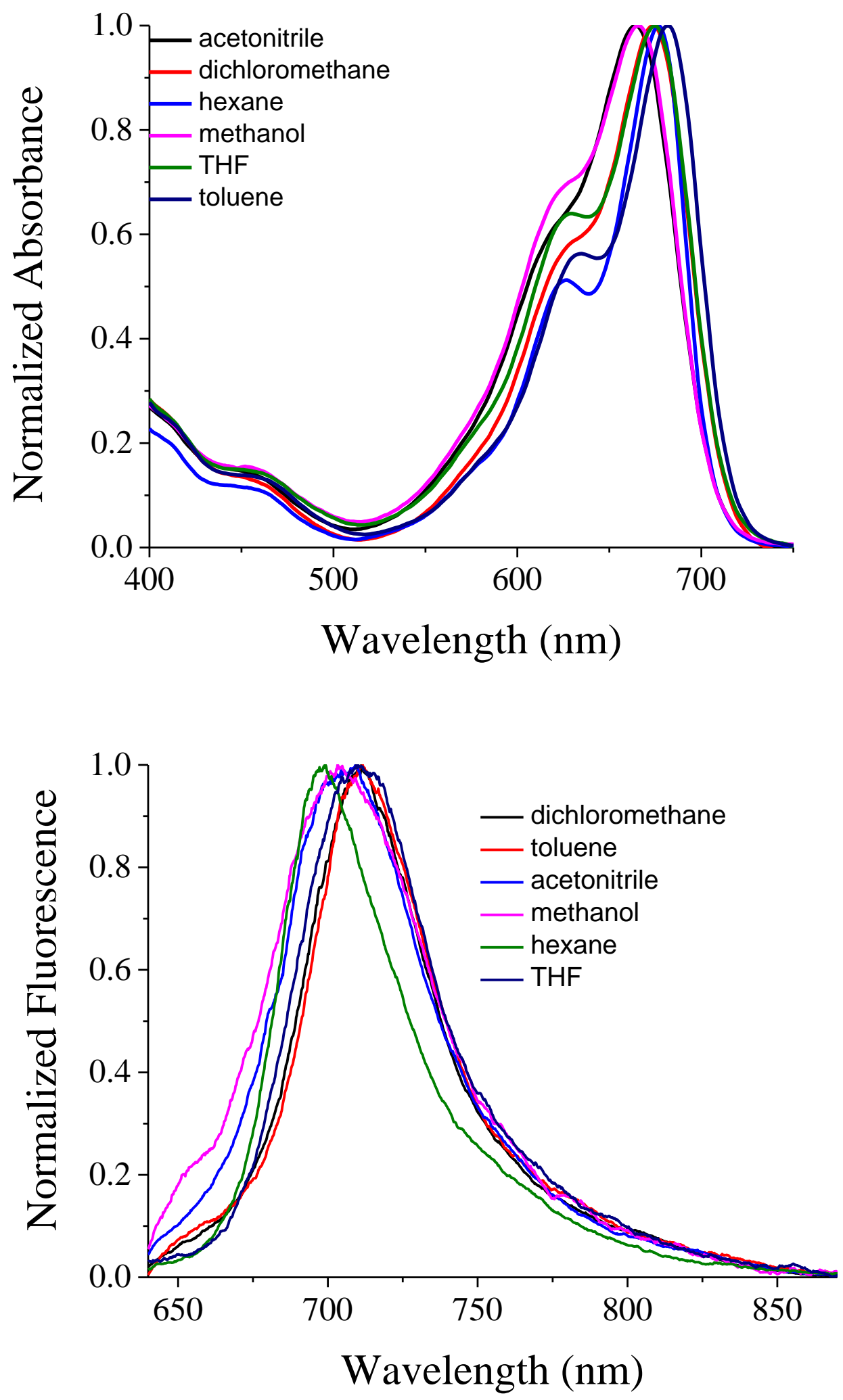

Figure S28. Overlaid and normalized absorption (top) and emission spectra (bottom) of $\mathbf{7 b}$ in different solvents, excited at $630 \mathrm{~nm}$. 

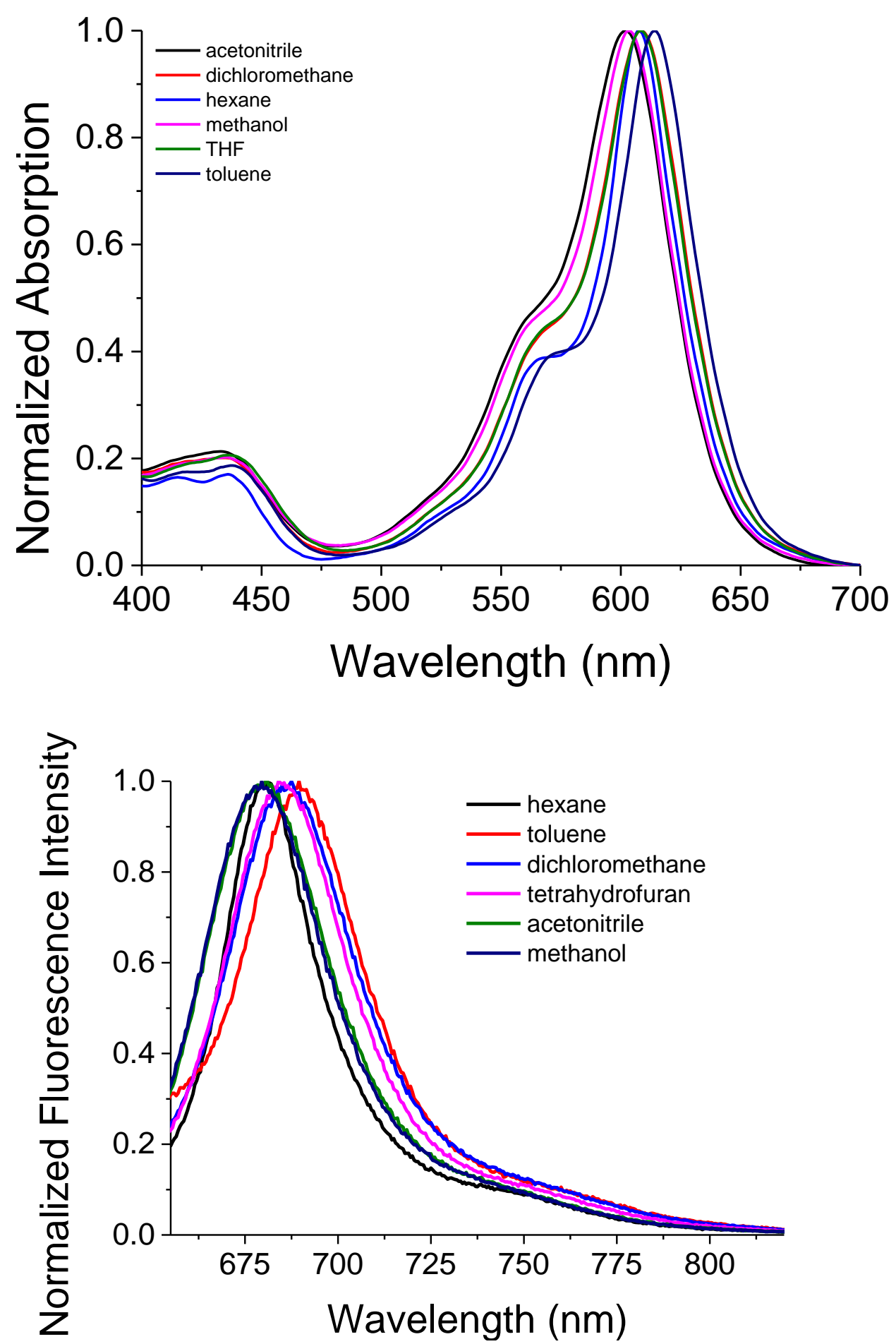

Figure S29. Overlaid and normalized absorption (top) and emission spectra (bottom) of 7c in different solvents, excited at $560 \mathrm{~nm}$. 

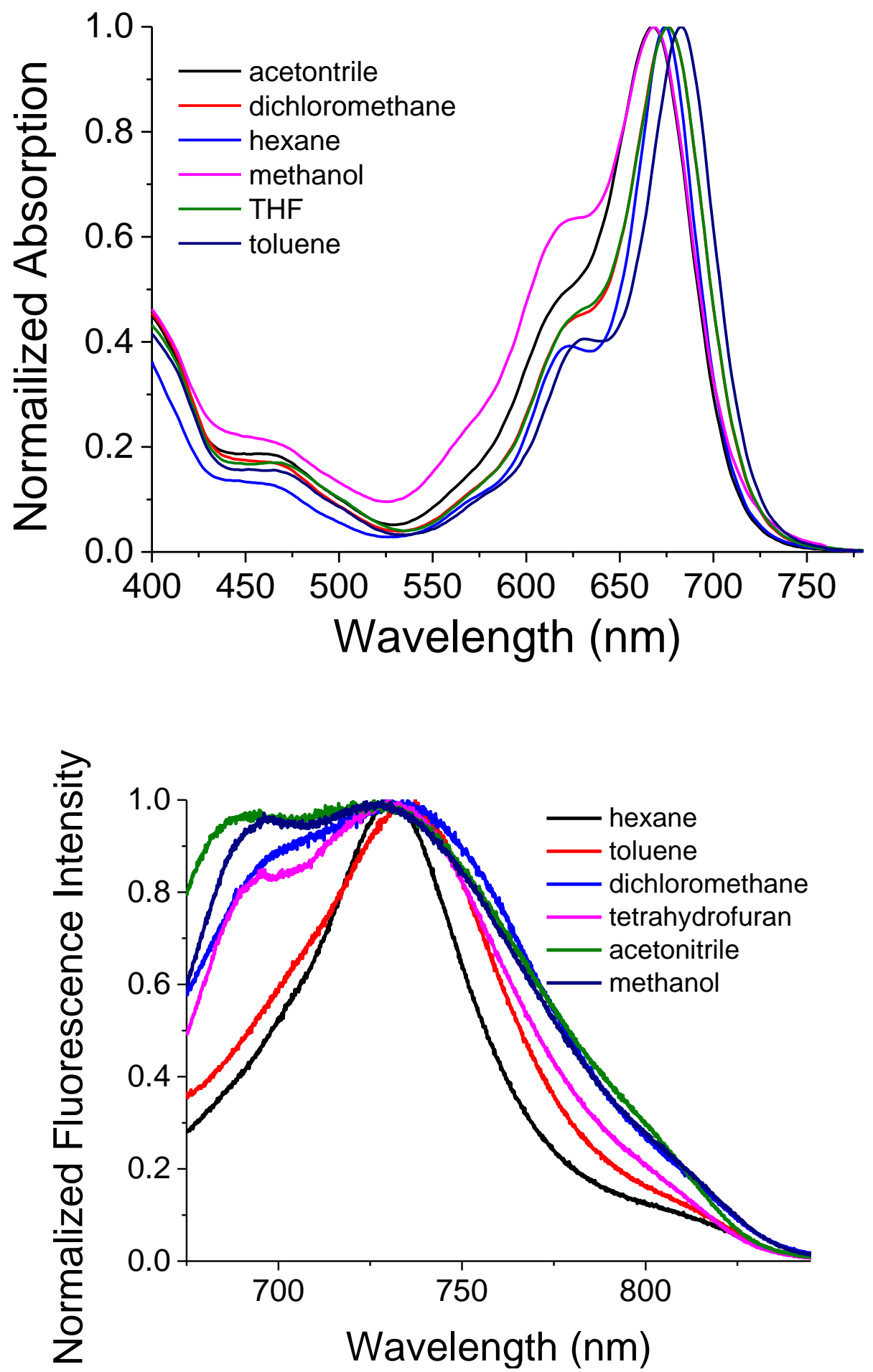

Figure S30. Overlaid and normalized absorption (top) and emission spectra (bottom) of 7d in different solvents, excited at $630 \mathrm{~nm}$. 

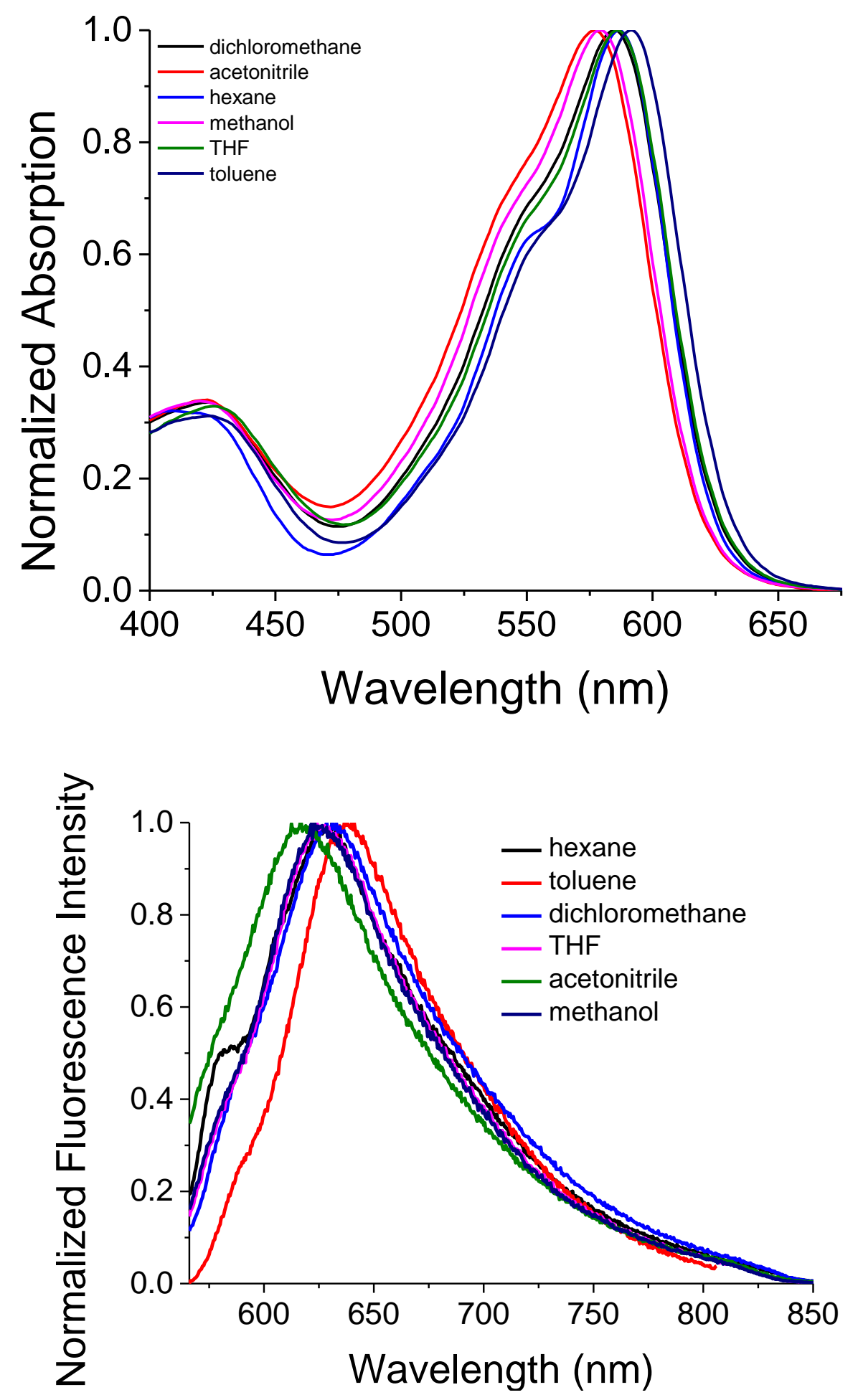

Figure S31. Overlaid and normalized absorption (top) and emission spectra (bottom) of 7e in different solvents, excited at $530 \mathrm{~nm}$. 

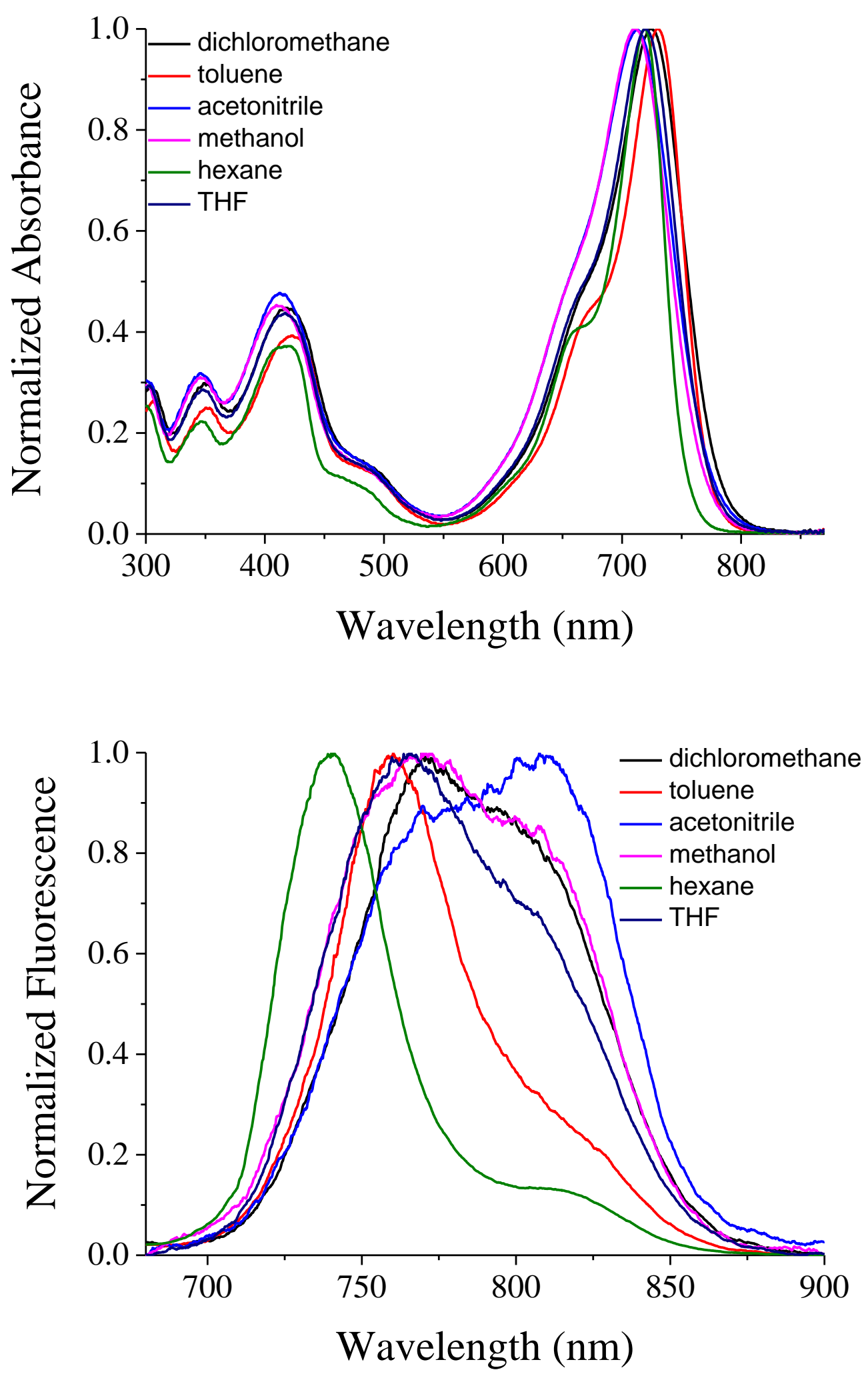

Figure S32. Overlaid and normalized absorption (top) and emission spectra (bottom) of $7 \mathbf{f}$ in different solvents, excited at $670 \mathrm{~nm}$. 


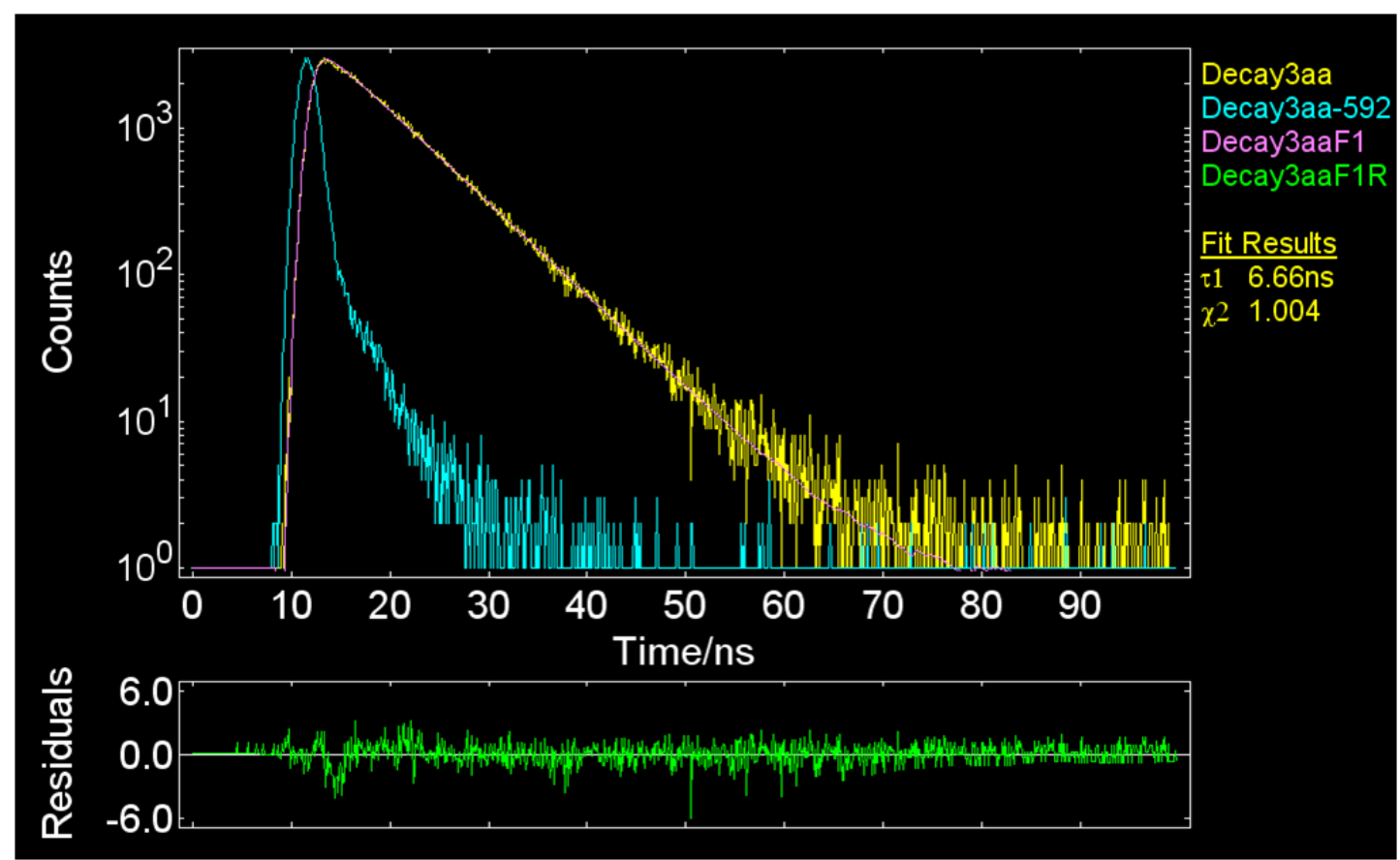

Figure S33. Fluorescence decay of isoindole BODIPY $1 \mathrm{a}$ in distilled $\mathrm{CH}_{2} \mathrm{Cl}_{2}$ measured by single photon counting method with emission was monitored at $599 \mathrm{~nm}$, excited at $535 \mathrm{~nm}$.

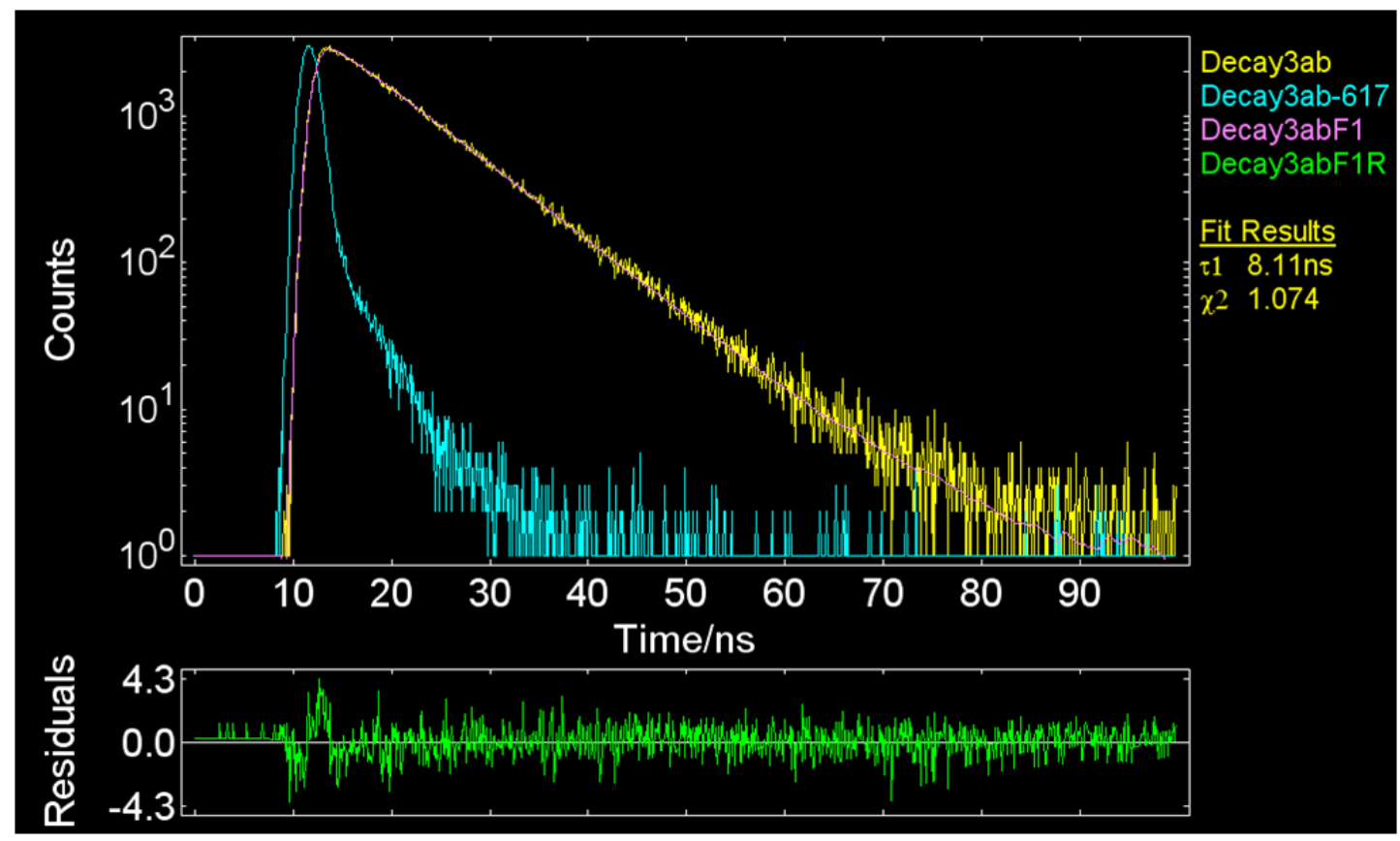

Figure S34. The fluorescence decay of isoindole BODIPY $\mathbf{1 b}$ in distilled $\mathrm{CH}_{2} \mathrm{Cl}_{2}$ measured by single photon counting method with emission was monitored at $624 \mathrm{~nm}$, excited at $550 \mathrm{~nm}$. 


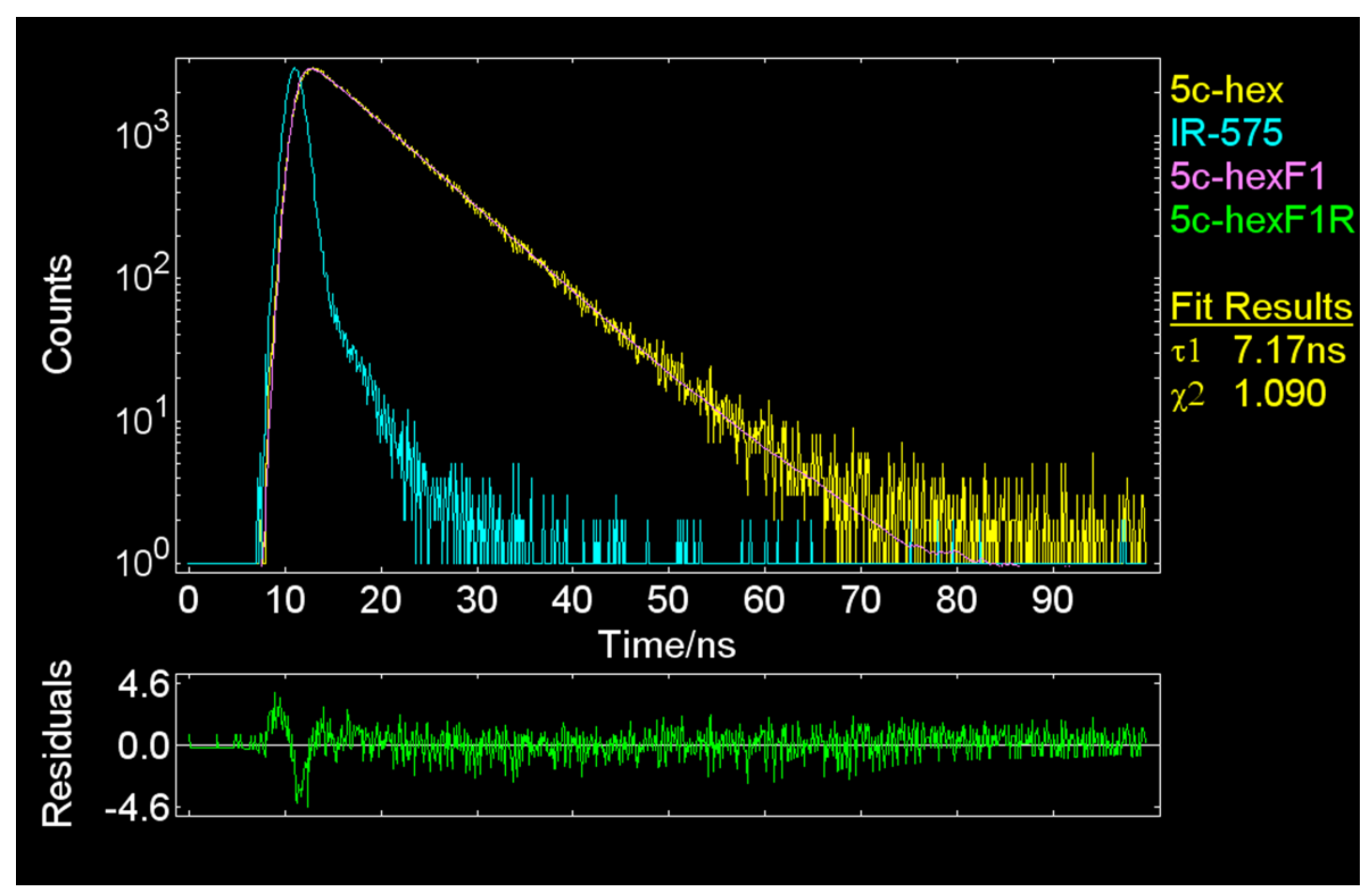

Figure S35. The fluorescence decay of isoindole BODIPY 1c in distilled hexane measured by single photon counting method with emission was monitored at $626 \mathrm{~nm}$, excited at $575 \mathrm{~nm}$.

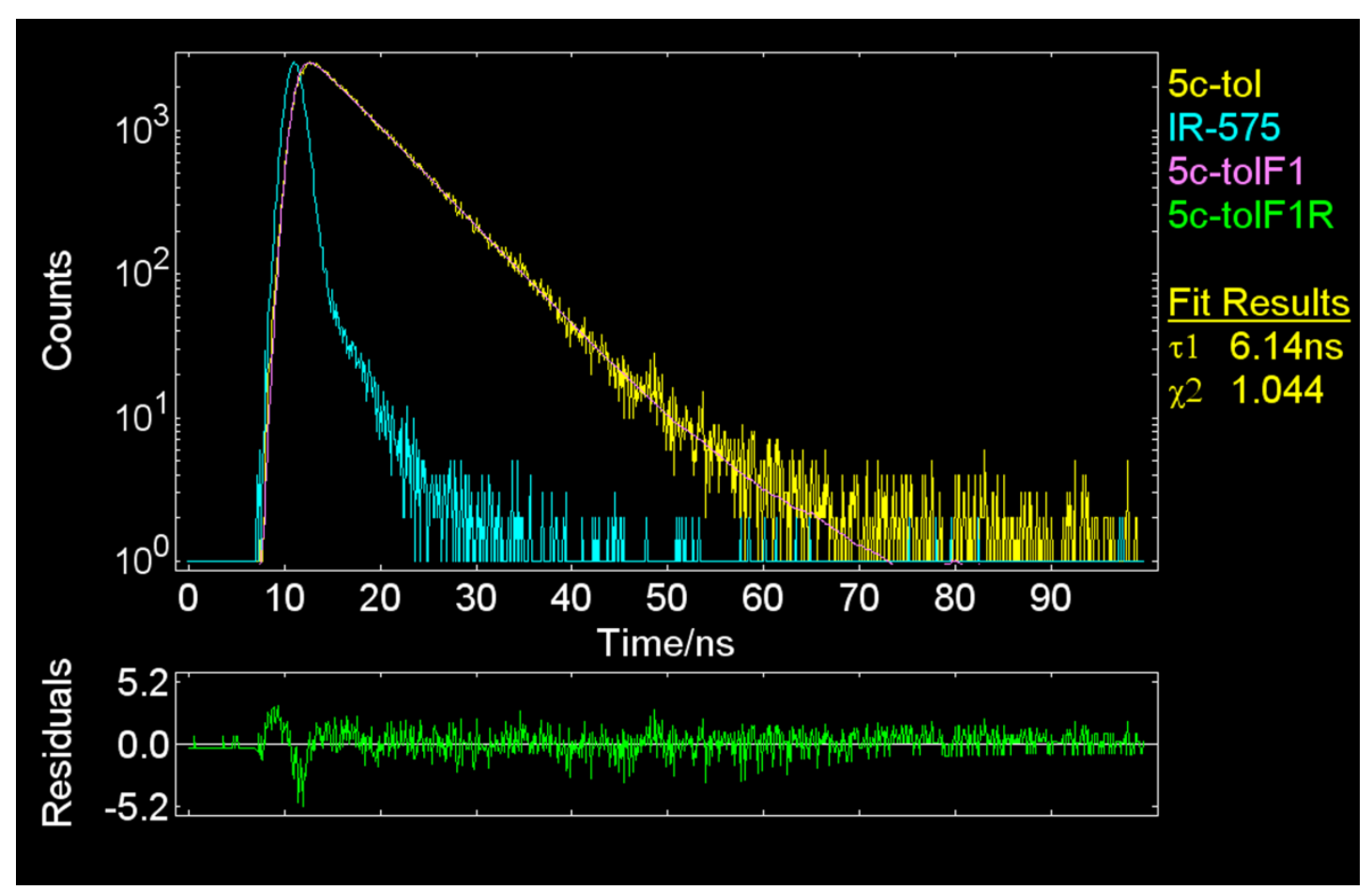

Figure S36. The fluorescence decay of isoindole BODIPY 1c in distilled toluene measured by single photon counting method with emission was monitored at $633 \mathrm{~nm}$, excited at $575 \mathrm{~nm}$. 


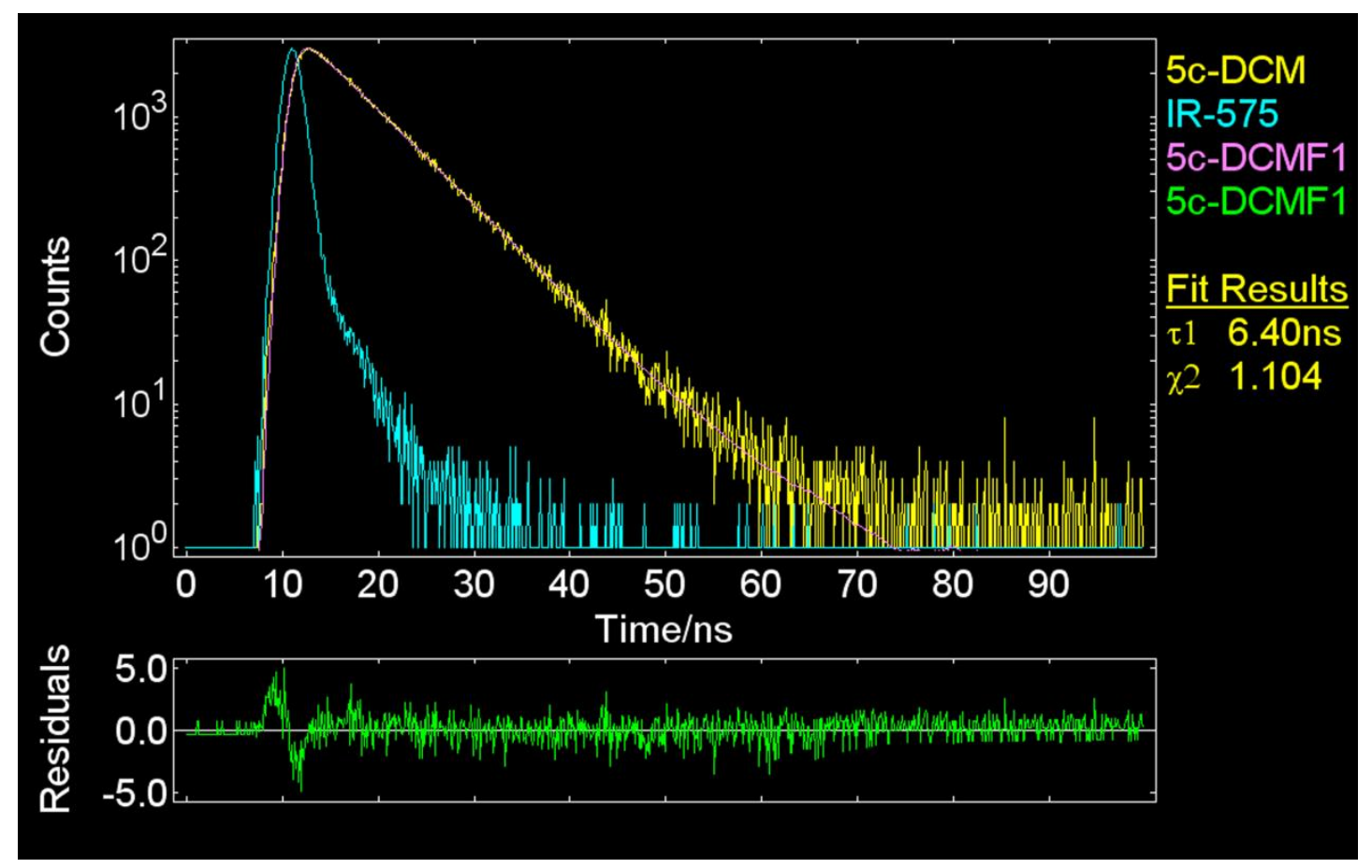

Figure S37. The fluorescence decay of isoindole BODIPY $1 \mathrm{c}$ in distilled $\mathrm{CH}_{2} \mathrm{Cl}_{2}$ measured by single photon counting method with emission was monitored at $631 \mathrm{~nm}$, excited at $575 \mathrm{~nm}$.

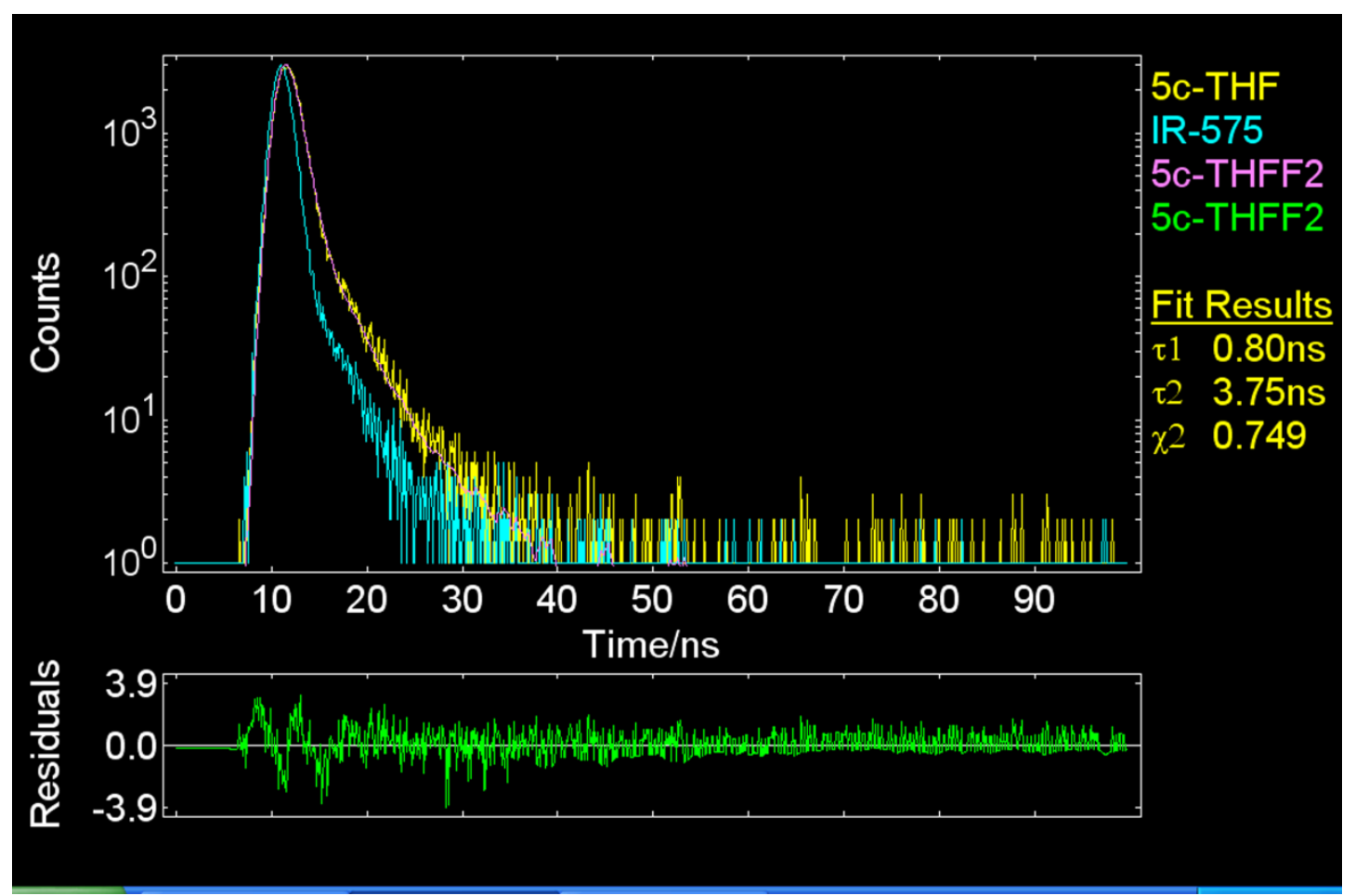

Figure S38. The fluorescence decay of isoindole BODIPY 1c in distilled THF measured by single photon counting method with emission was monitored at $627 \mathrm{~nm}$, excited at $575 \mathrm{~nm}$. 


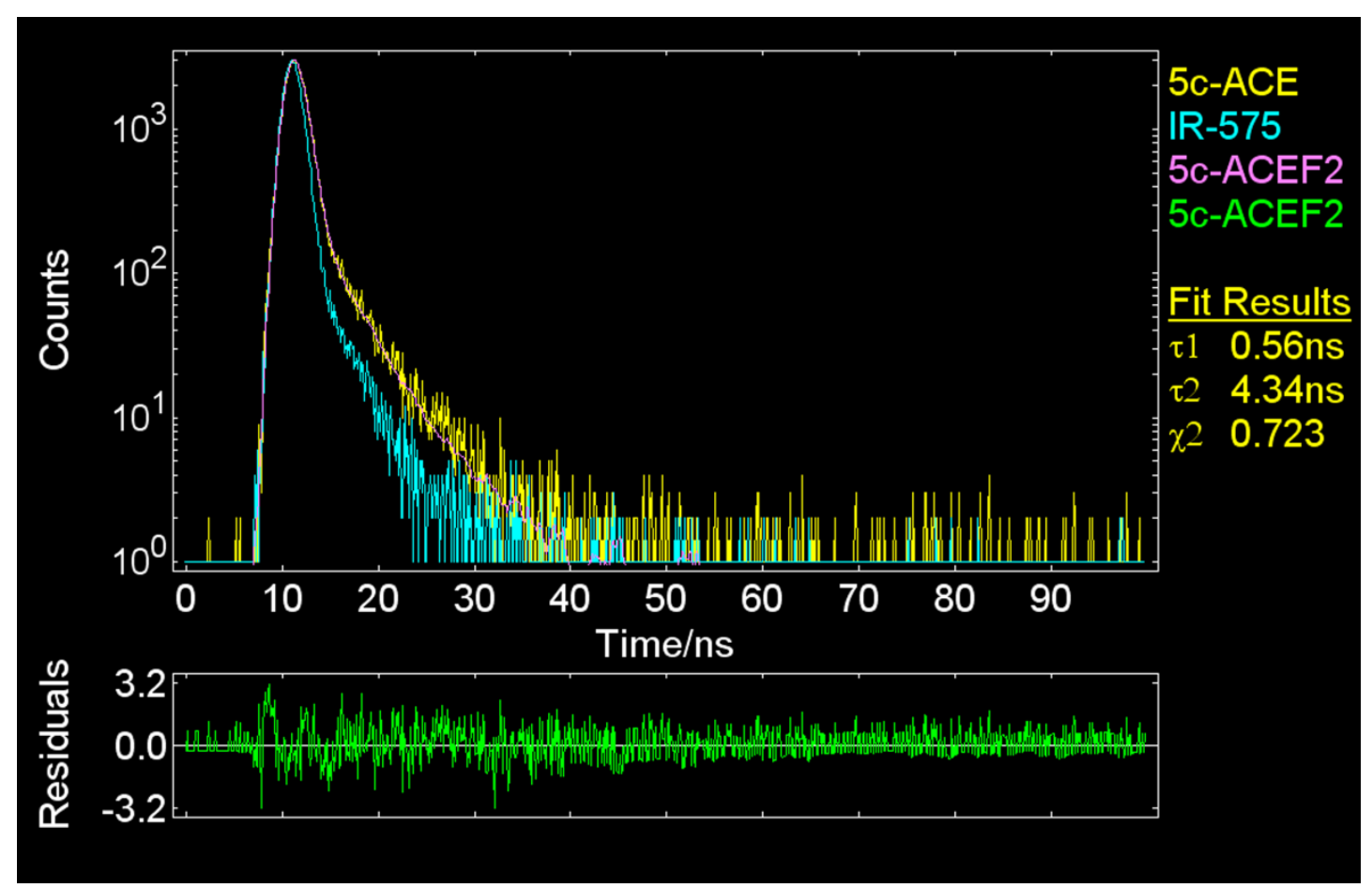

Figure S39. The fluorescence decay of isoindole BODIPY 1c in distilled acetonitrile measured by single photon counting method with emission was monitored at $624 \mathrm{~nm}$, excited at $575 \mathrm{~nm}$.

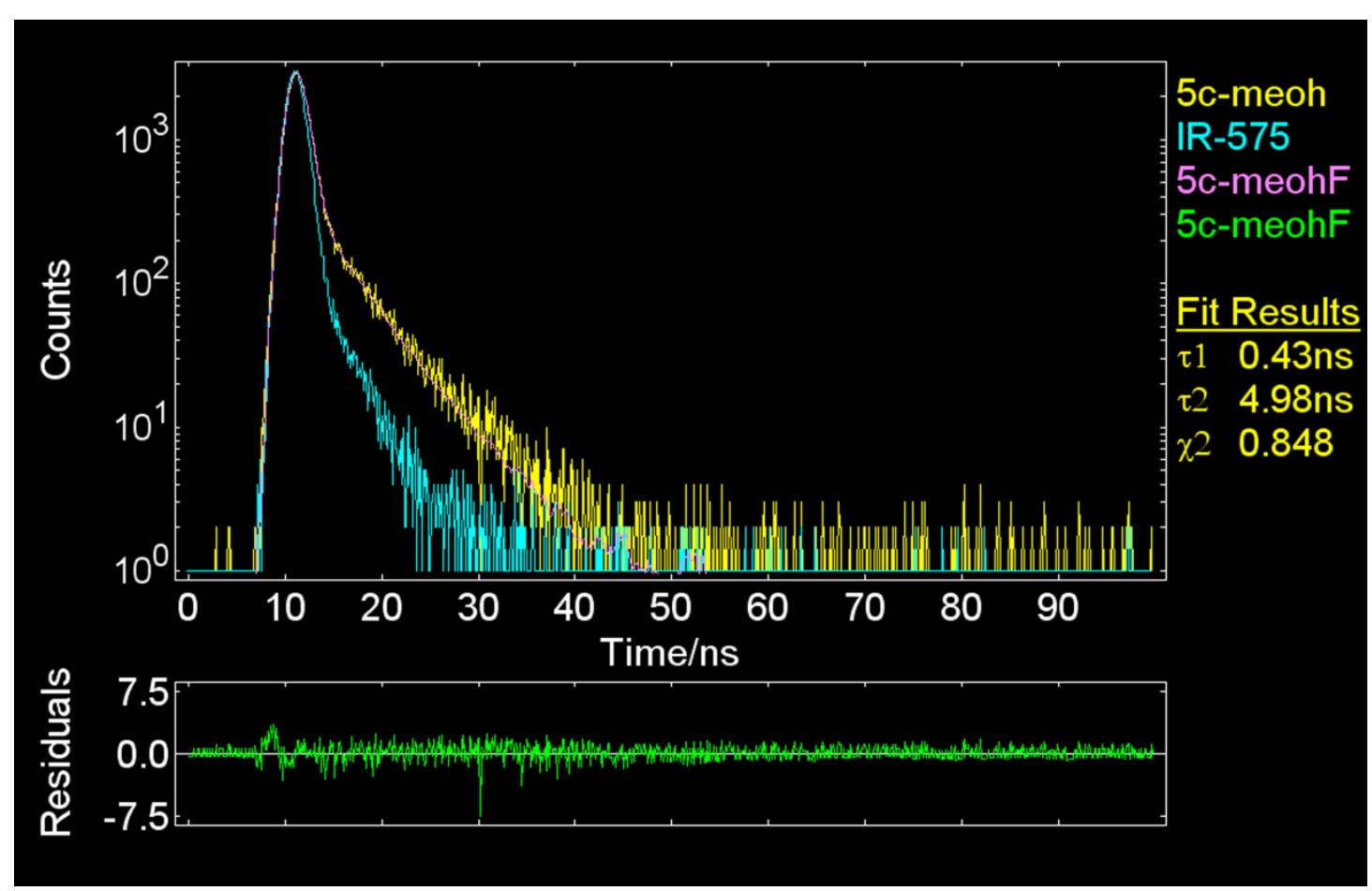

Figure S40. The fluorescence decay of isoindole BODIPY 1c in distilled $\mathrm{MeOH}$ measured by single photon counting method with emission was monitored at $622 \mathrm{~nm}$, excited at $575 \mathrm{~nm}$. 


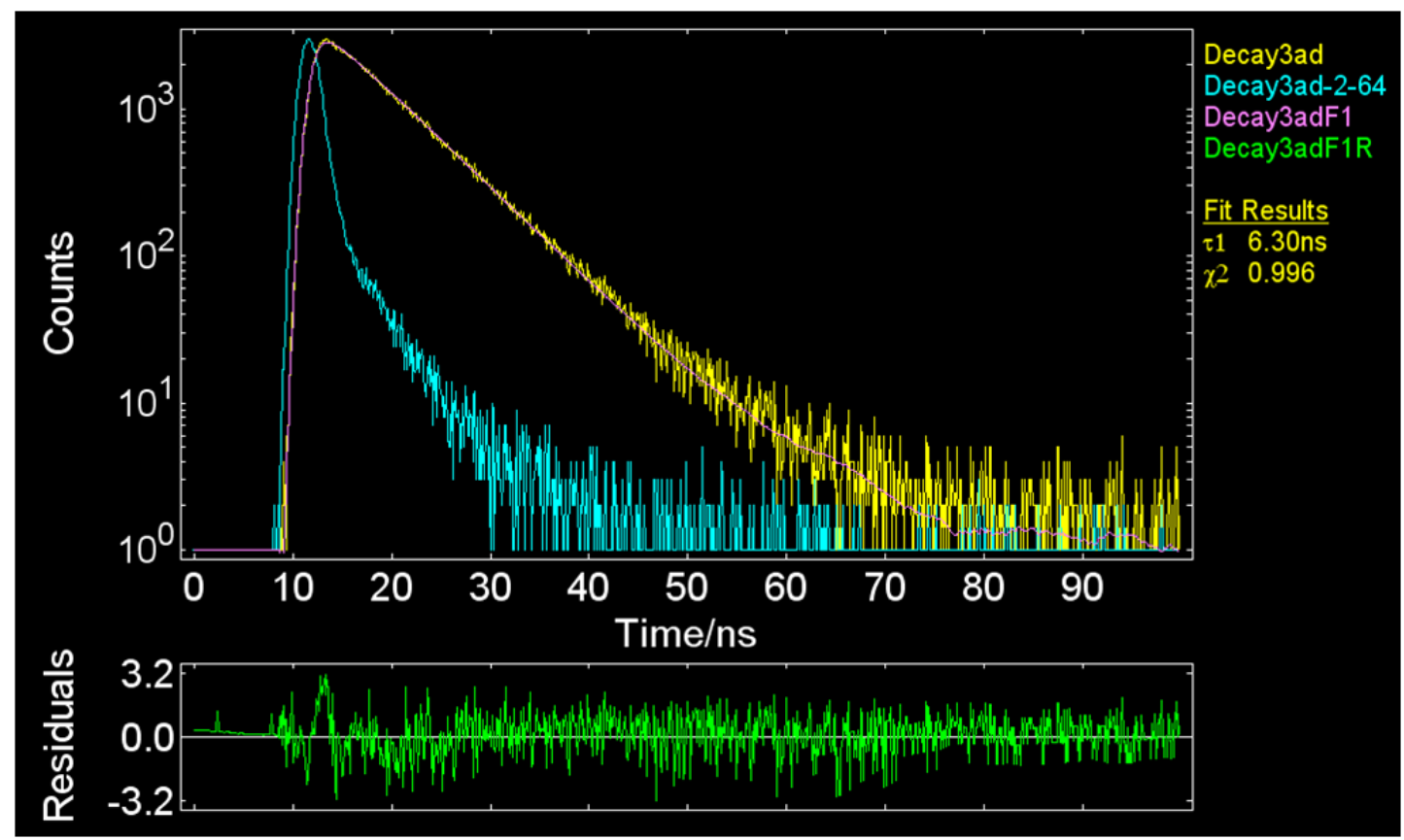

Figure S41. The fluorescence decay of isoindole BODIPY $1 \mathbf{d}$ in distilled $\mathrm{CH}_{2} \mathrm{Cl}_{2}$ measured by single photon counting method with emission was monitored at $650 \mathrm{~nm}$, excited at $600 \mathrm{~nm}$.

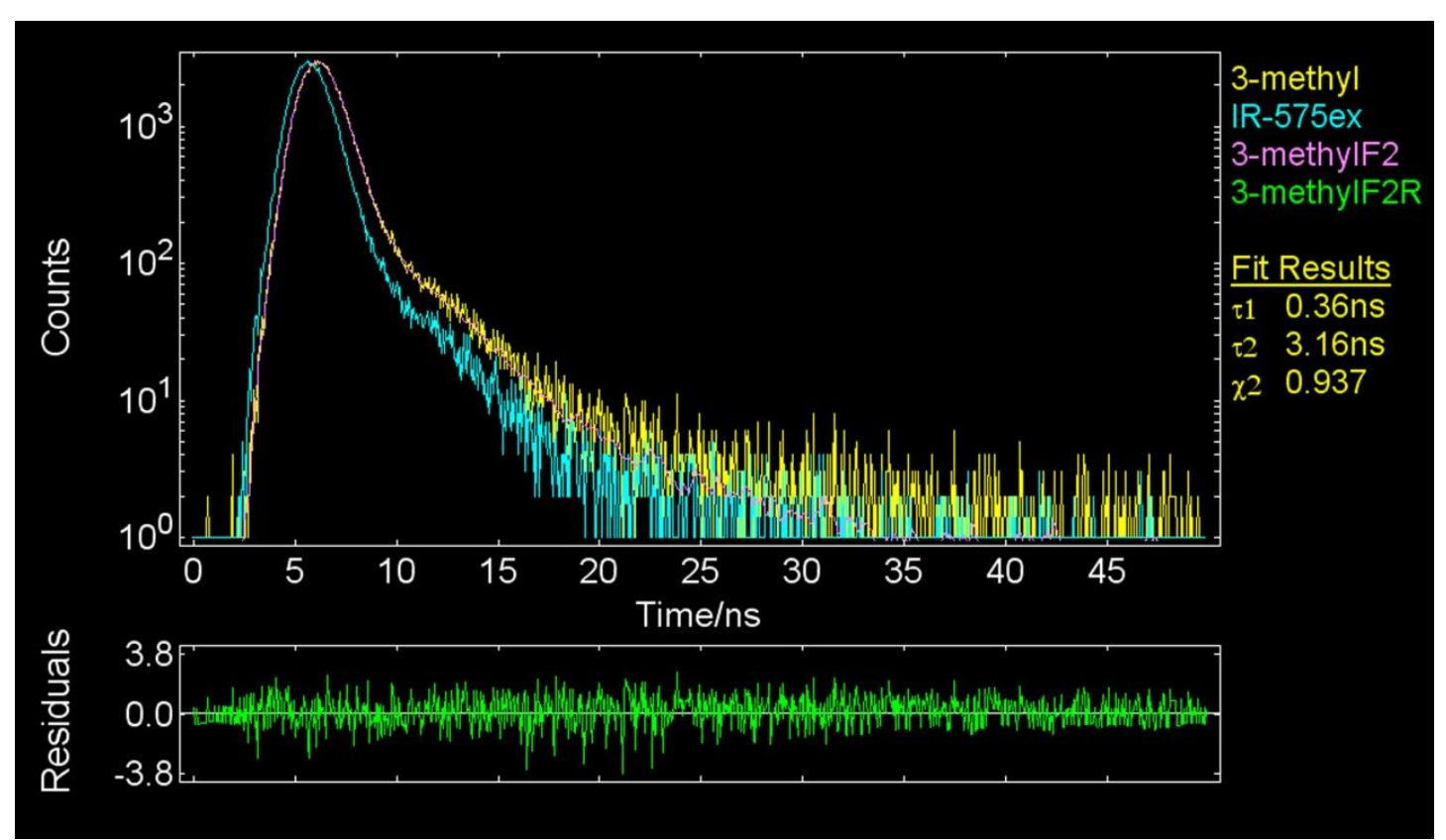

Figure S42. The fluorescence decay of isoindole BODIPY 1e in distilled $\mathrm{CH}_{2} \mathrm{Cl}_{2}$ measured by single photon counting method with emission was monitored at $648 \mathrm{~nm}$, excited at $575 \mathrm{~nm}$. 


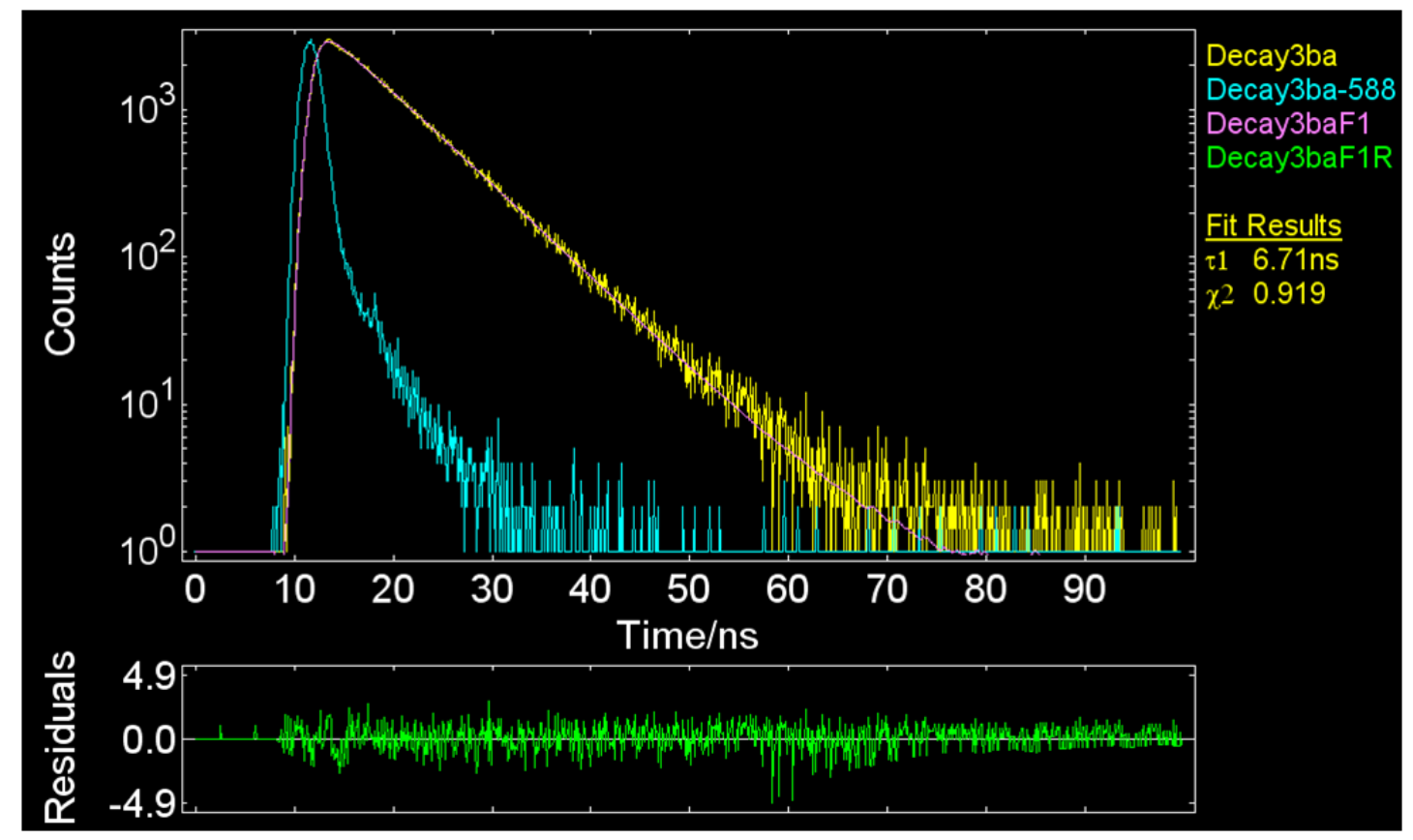

Figure S43. The fluorescence decay of isoindole BODIPY 1 if in distilled $\mathrm{CH}_{2} \mathrm{Cl}_{2}$ measured by single photon counting method with emission was monitored at $592 \mathrm{~nm}$, excited at $520 \mathrm{~nm}$.

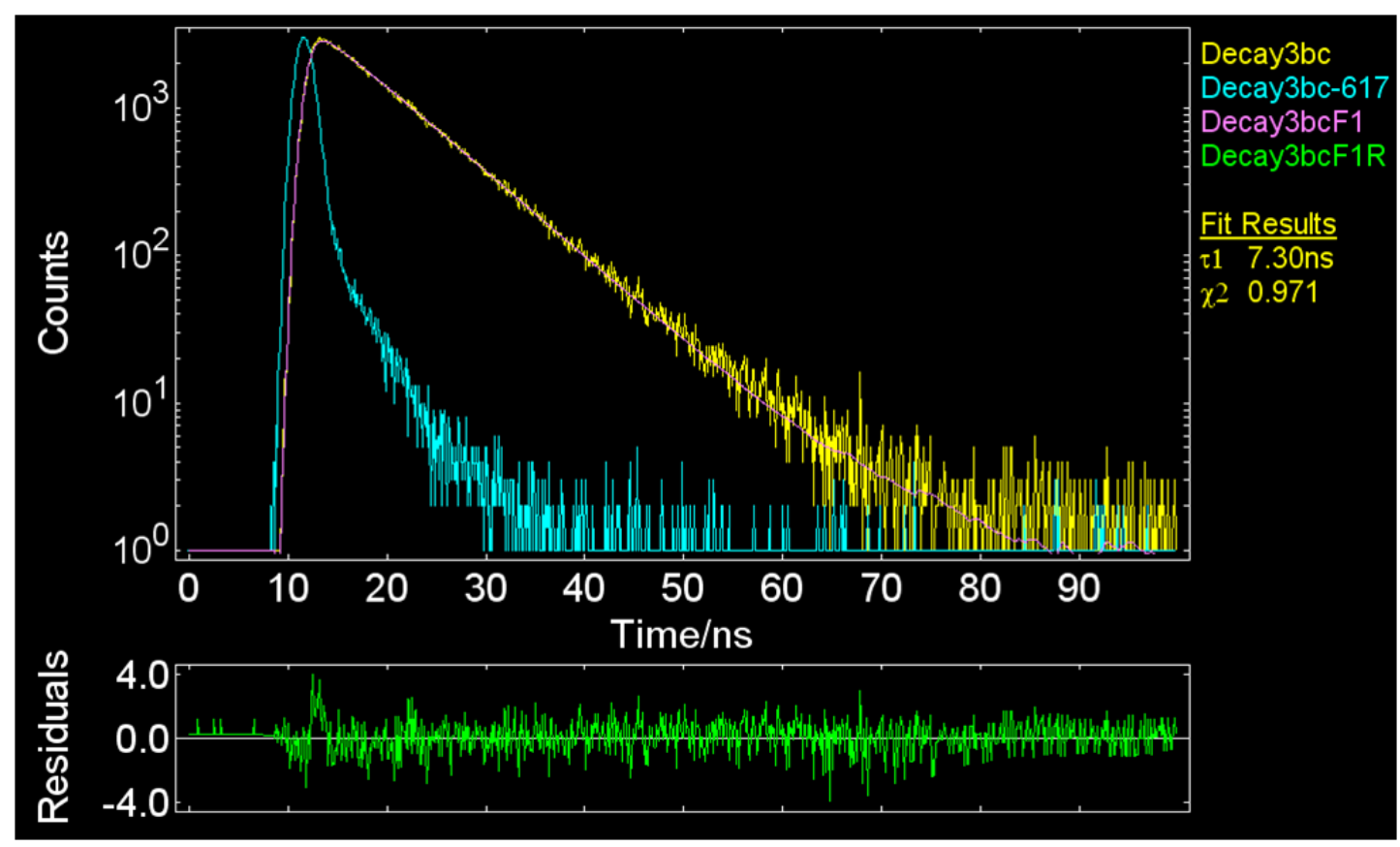

Figure S44. The fluorescence decay of isoindole BODIPY $1 \mathrm{~g}$ in distilled $\mathrm{CH}_{2} \mathrm{Cl}_{2}$ measured by single photon counting method with emission was monitored at $625 \mathrm{~nm}$, excited at $560 \mathrm{~nm}$. 


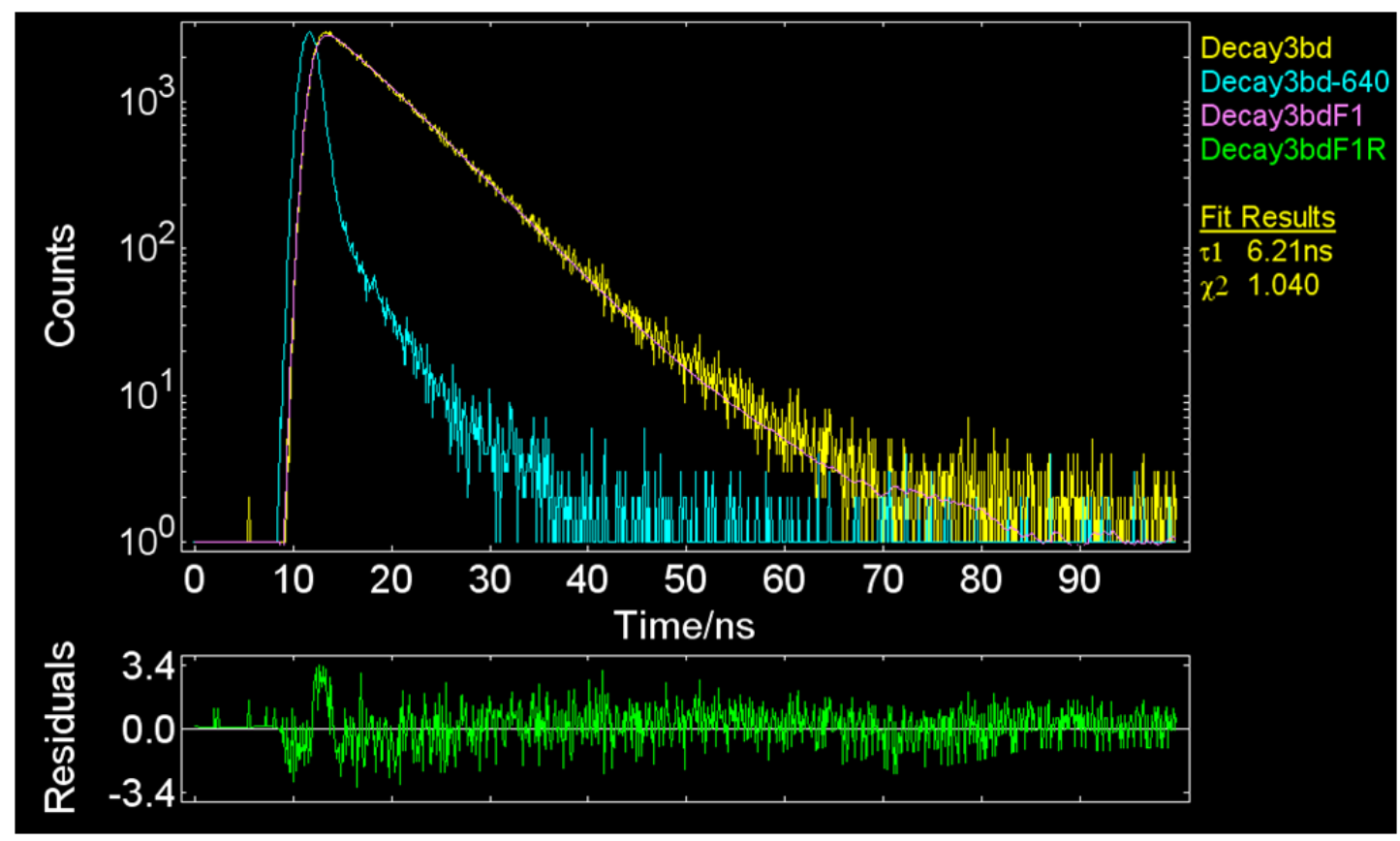

Figure S45. The fluorescence decay of isoindole BODIPY $\mathbf{1 h}$ in distilled $\mathrm{CH}_{2} \mathrm{Cl}_{2}$ measured by single photon counting method with emission was monitored at $645 \mathrm{~nm}$, excited at $575 \mathrm{~nm}$.

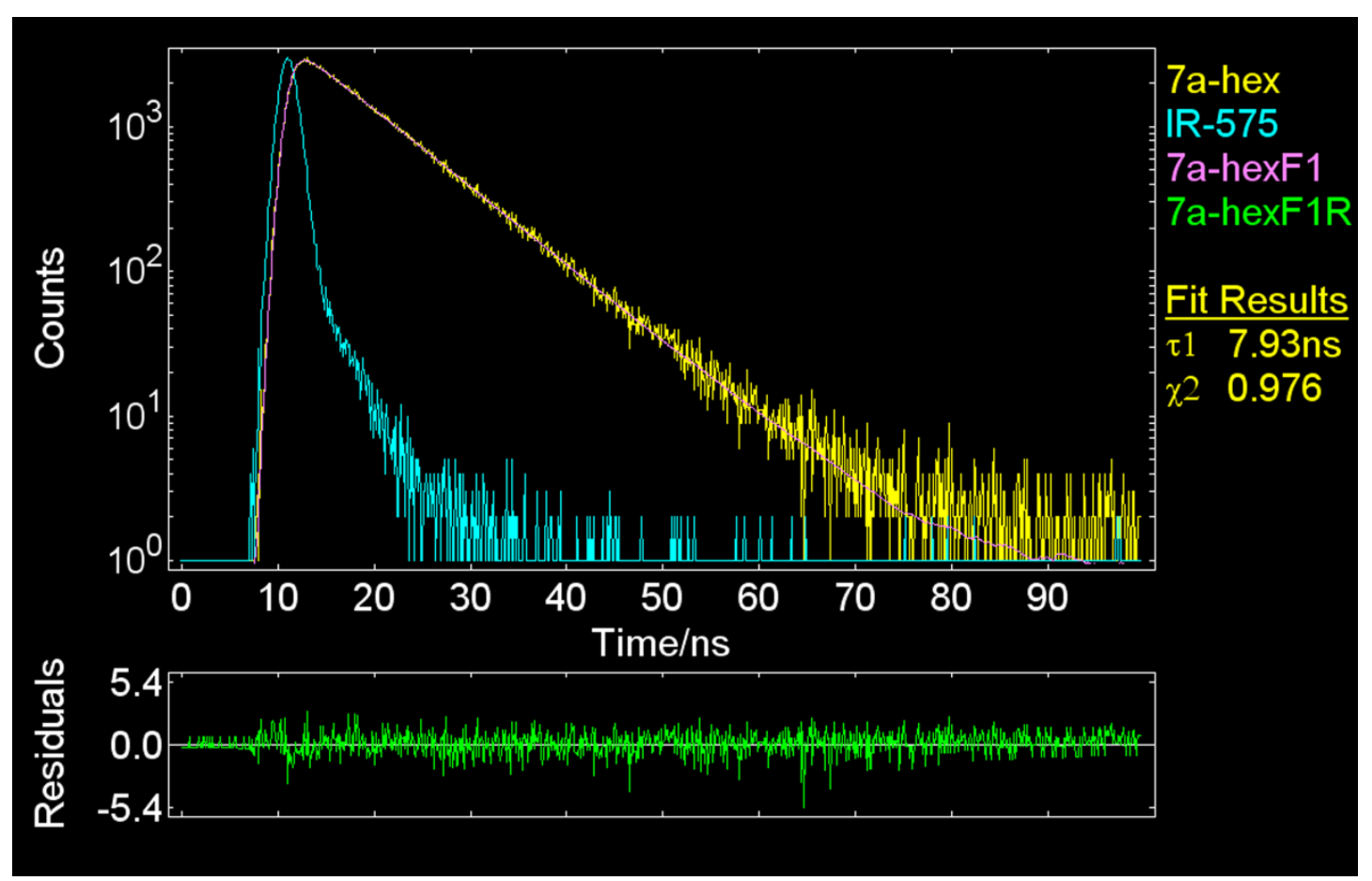

Figure S46. The fluorescence decay of isoindole BODIPY 5a in distilled hexane measured by single photon counting method with emission was monitored at $617 \mathrm{~nm}$, excited at $575 \mathrm{~nm}$. 


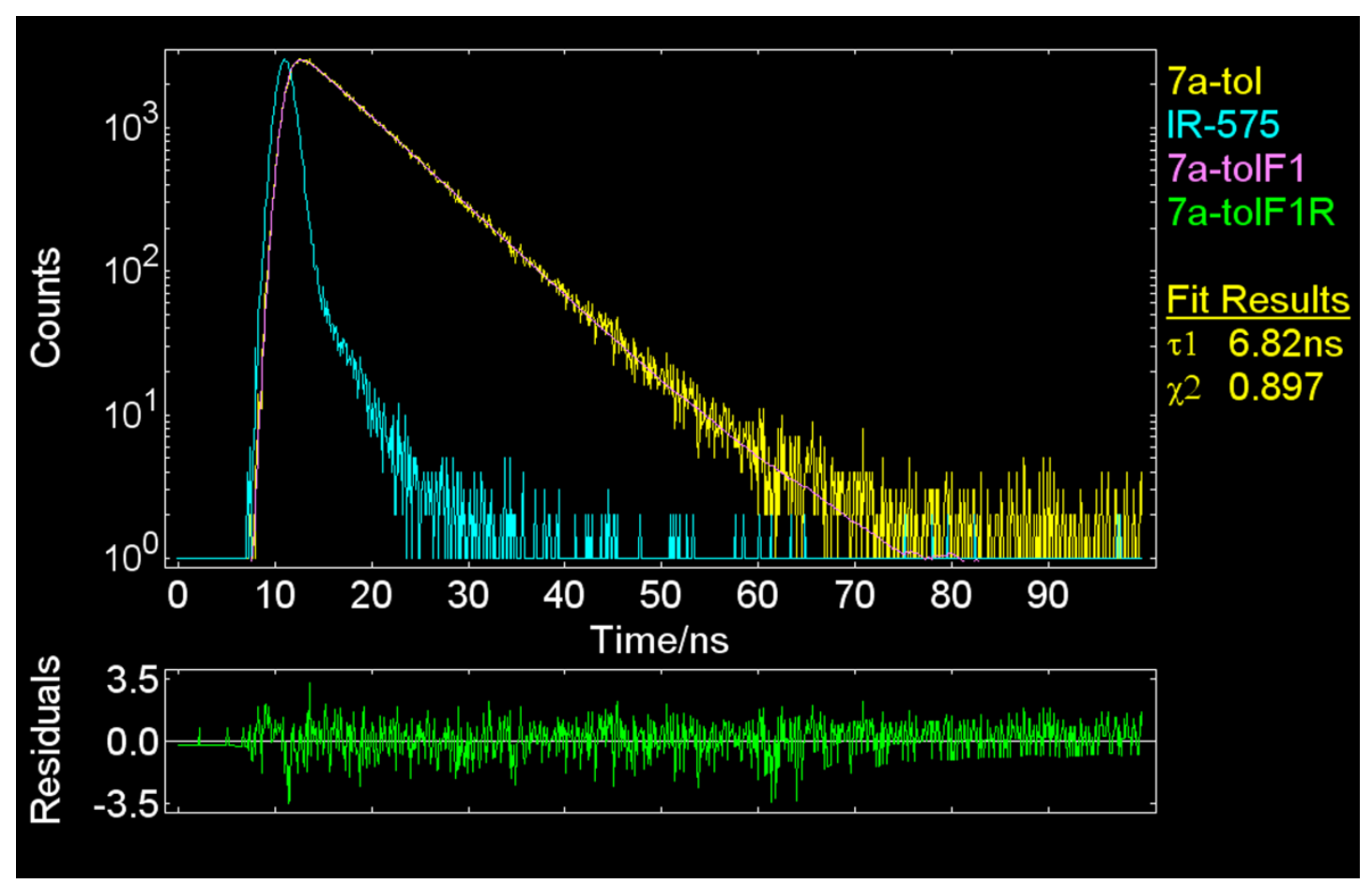

Figure S47. The fluorescence decay of isoindole BODIPY 5a in distilled toluene measured by single photon counting method with emission was monitored at $627 \mathrm{~nm}$, excited at $575 \mathrm{~nm}$.

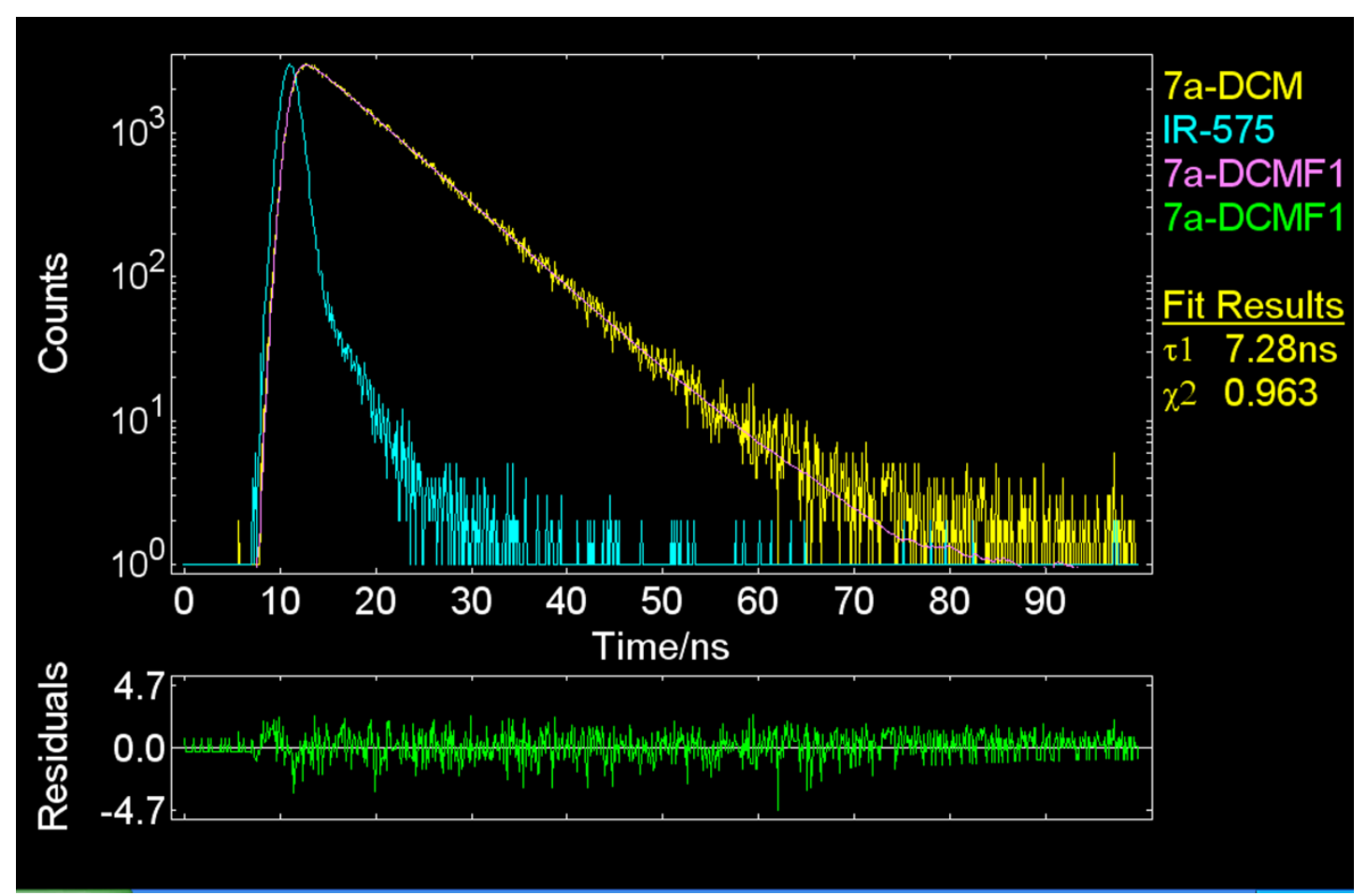

Figure S48. The fluorescence decay of isoindole BODIPY 5a in distilled $\mathrm{CH}_{2} \mathrm{Cl}_{2}$ measured by single photon counting method with emission was monitored at $621 \mathrm{~nm}$, excited at $575 \mathrm{~nm}$. 


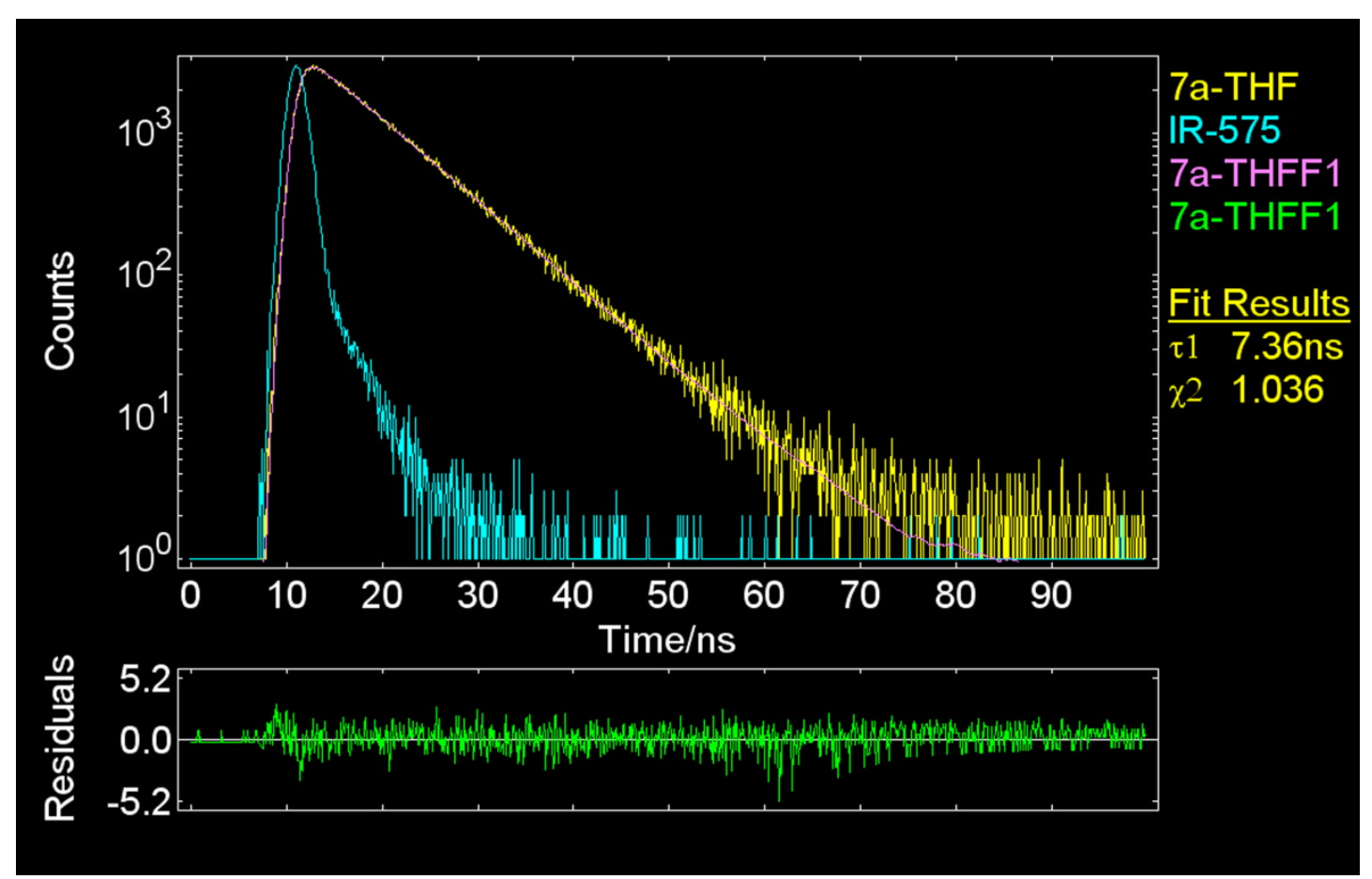

Figure S49. The fluorescence decay of isoindole BODIPY 5a in distilled THF measured by single photon counting method with emission was monitored at $620 \mathrm{~nm}$, excited at $575 \mathrm{~nm}$.

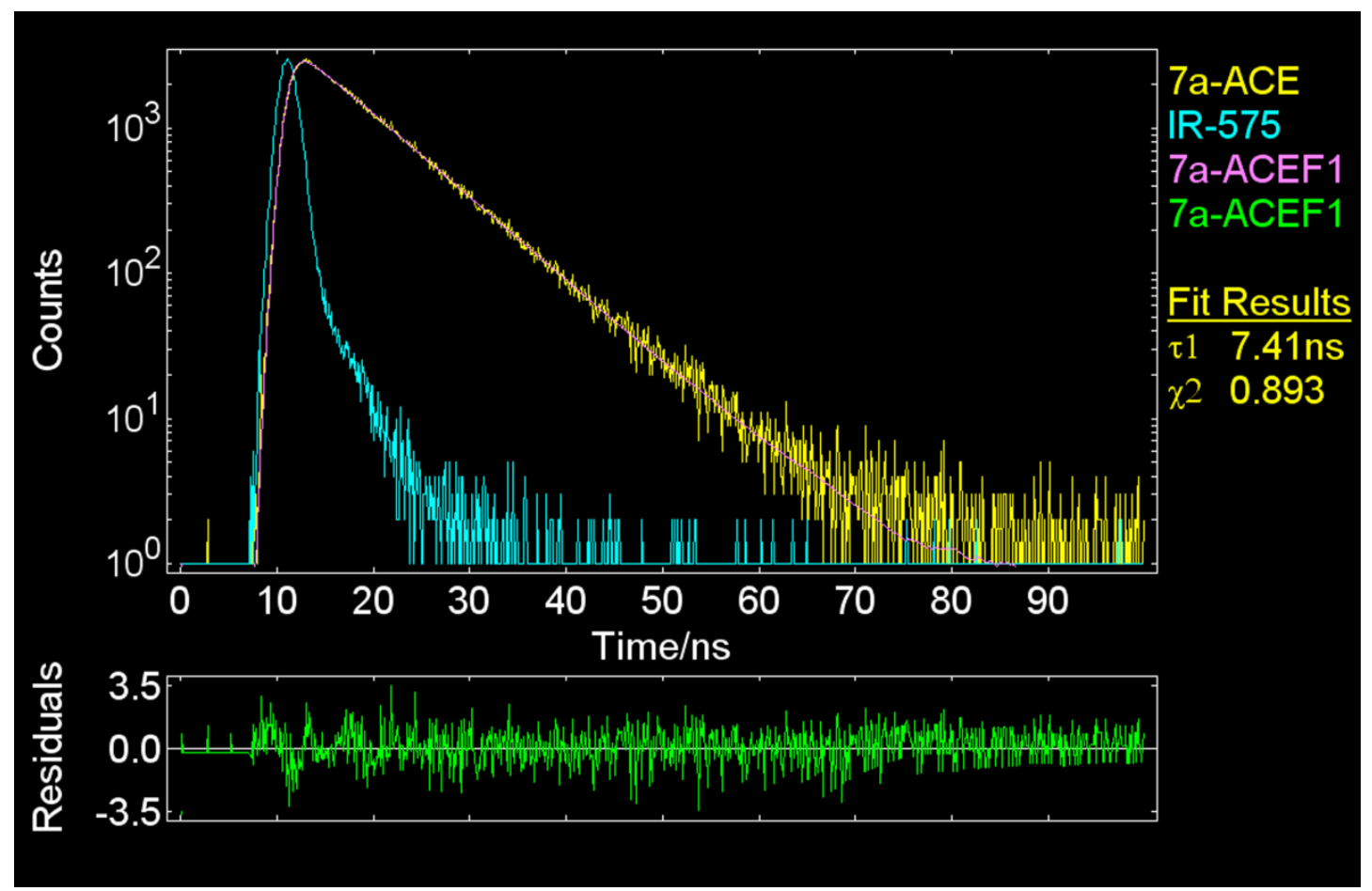

Figure S50. The fluorescence decay of isoindole BODIPY 5a in distilled acetonitrile measured by single photon counting method with emission was monitored at $618 \mathrm{~nm}$, excited at $575 \mathrm{~nm}$. 


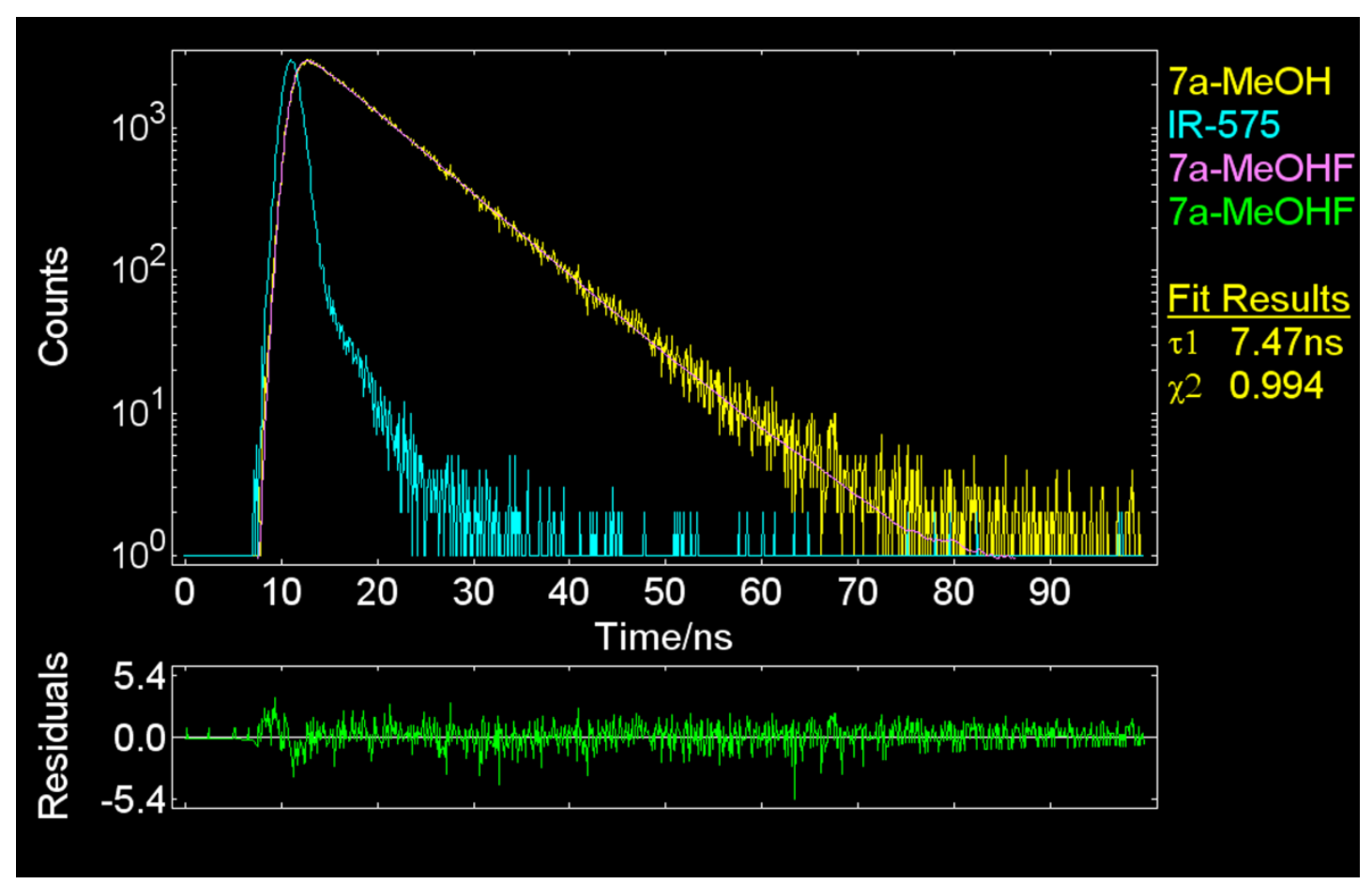

Figure S51. The fluorescence decay of isoindole BODIPY 5a in distilled MeOH measured by single photon counting method with emission was monitored at $618 \mathrm{~nm}$, excited at $575 \mathrm{~nm}$.

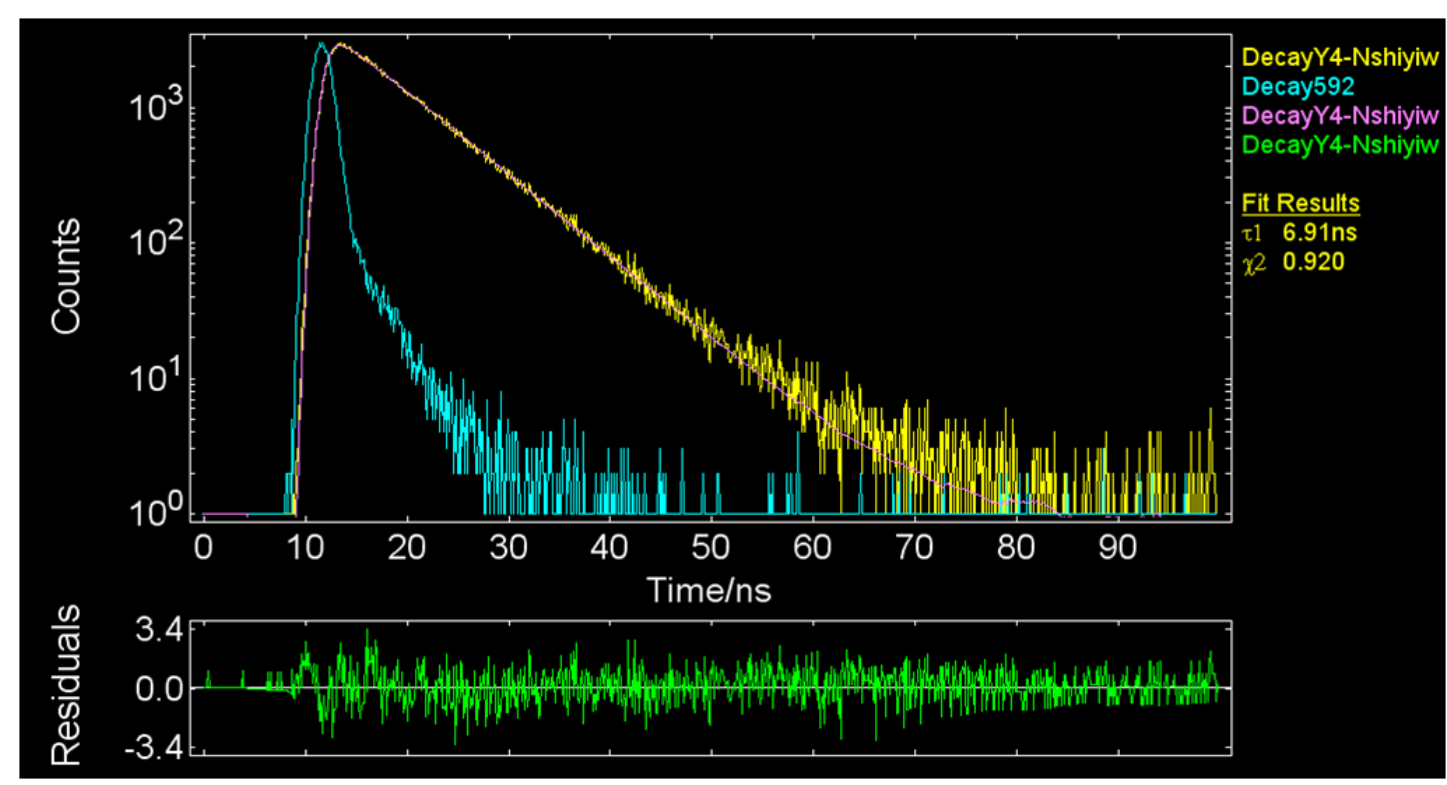

Figure S52. The fluorescence decay of isoindole BODIPY $\mathbf{5 b}$ in distilled $\mathrm{CH}_{2} \mathrm{Cl}_{2}$ measured by single photon counting method with emission was monitored at $611 \mathrm{~nm}$, excited at $530 \mathrm{~nm}$. 


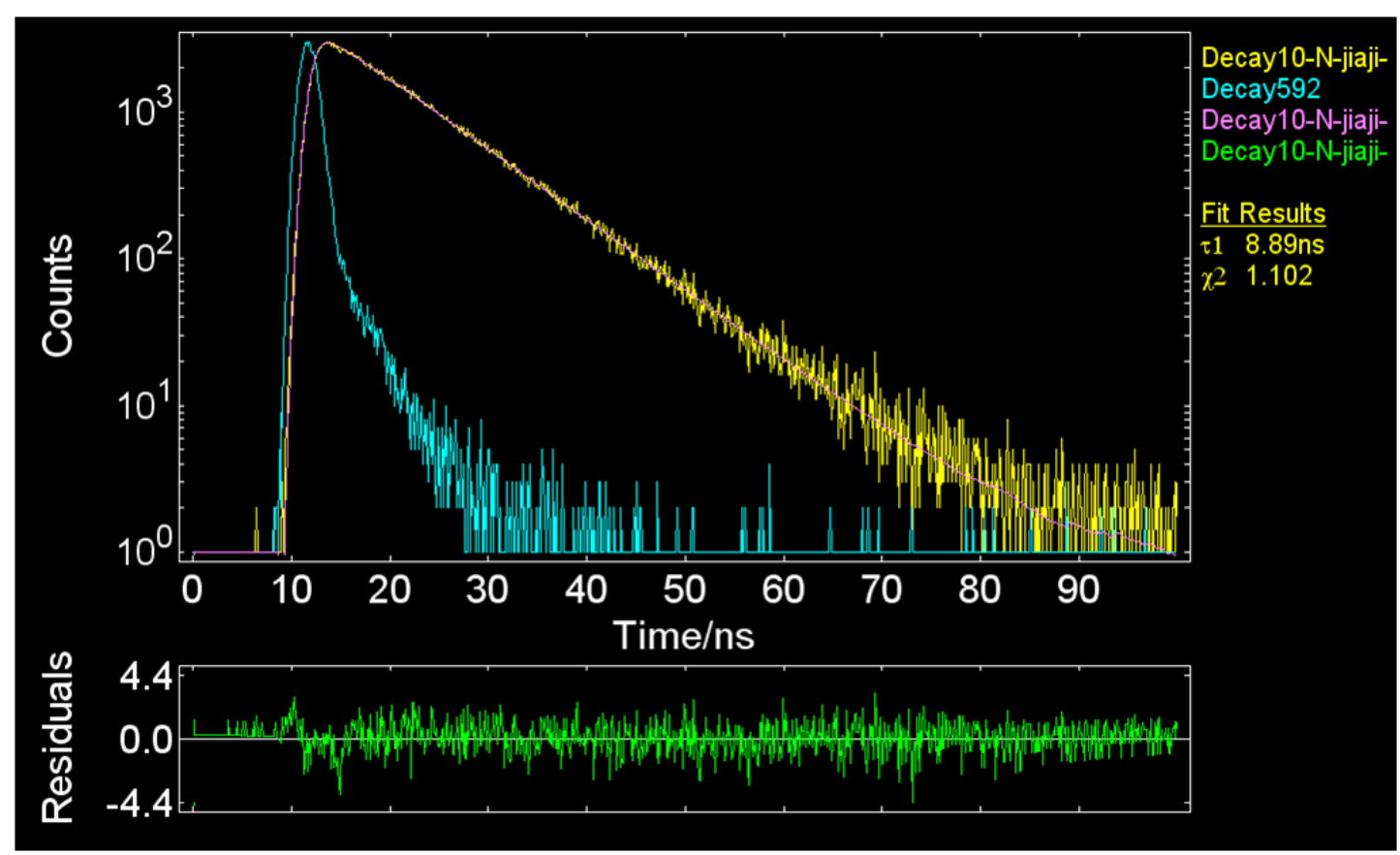

Figure S53. The fluorescence decay of isoindole BODIPY $5 \mathbf{c}$ in distilled $\mathrm{CH}_{2} \mathrm{Cl}_{2}$ measured by single photon counting method with emission was monitored at $611 \mathrm{~nm}$, excited at $545 \mathrm{~nm}$.

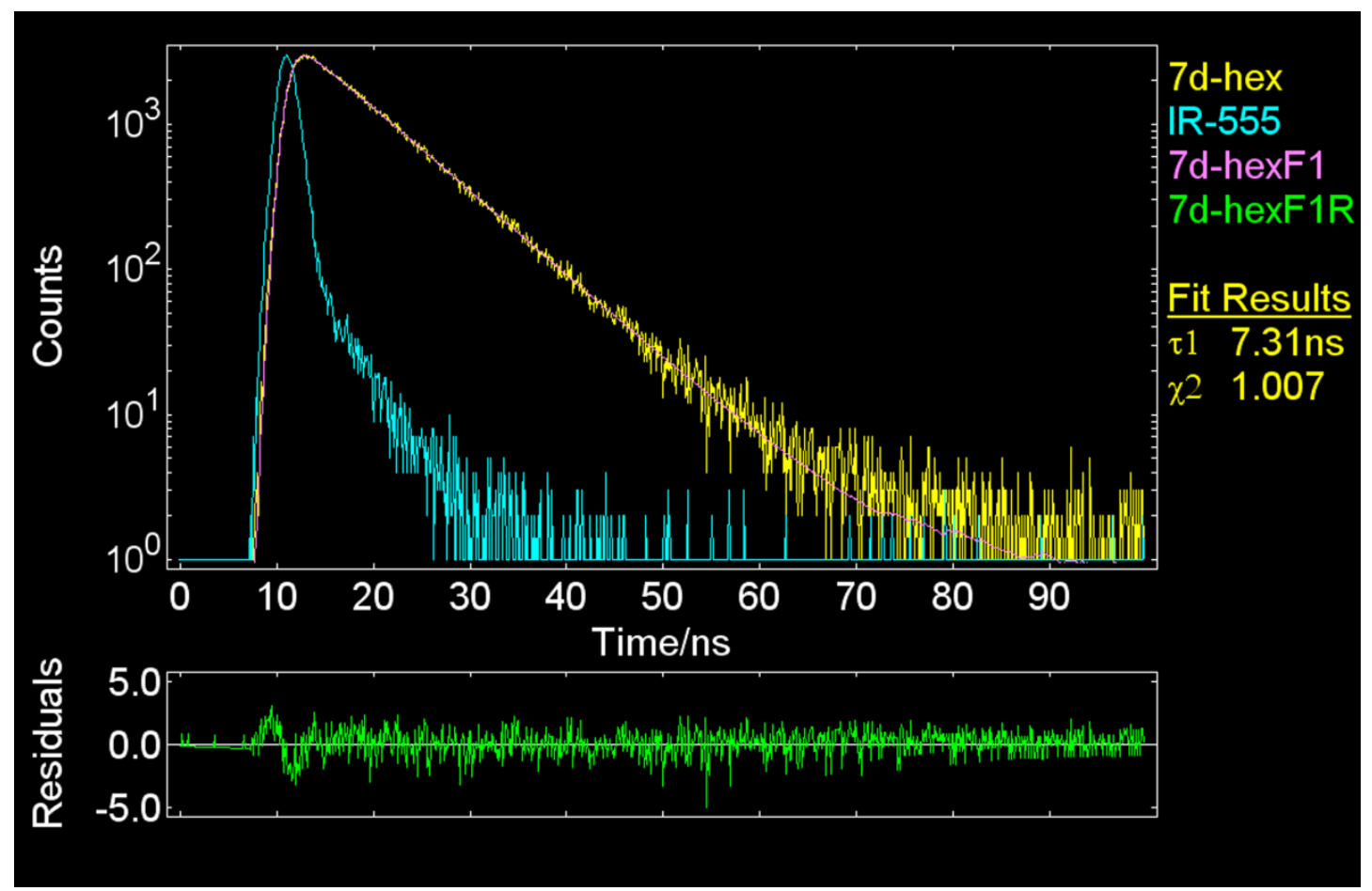

Figure S54. The fluorescence decay of isoindole BODIPY 5d in distilled hexane measured by single photon counting method with emission was monitored at $618 \mathrm{~nm}$, excited at $555 \mathrm{~nm}$. 


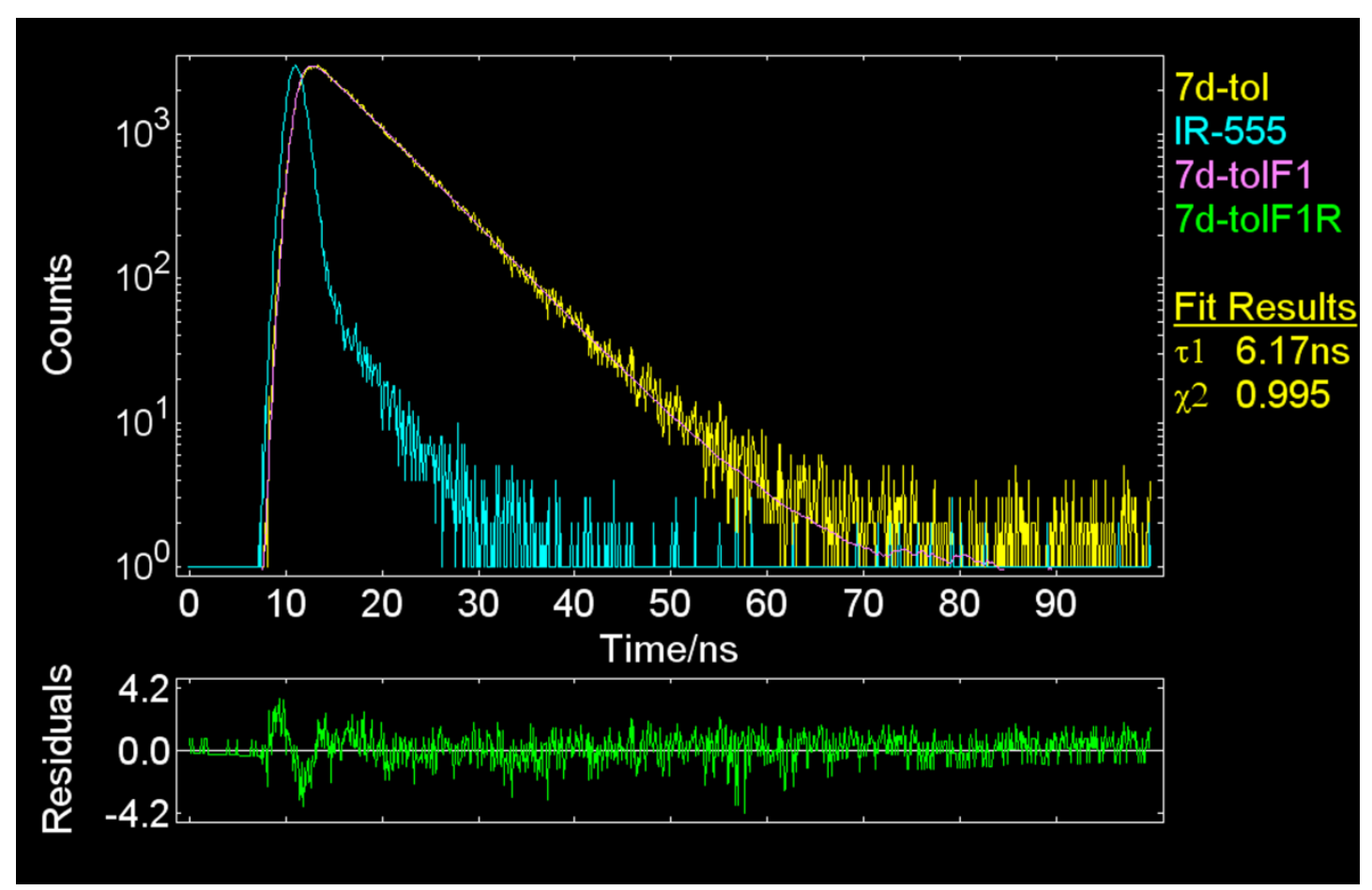

Figure S55. The fluorescence decay of isoindole BODIPY $\mathbf{5 d}$ in distilled toluene measured by single photon counting method with emission was monitored at $629 \mathrm{~nm}$, excited at $555 \mathrm{~nm}$.

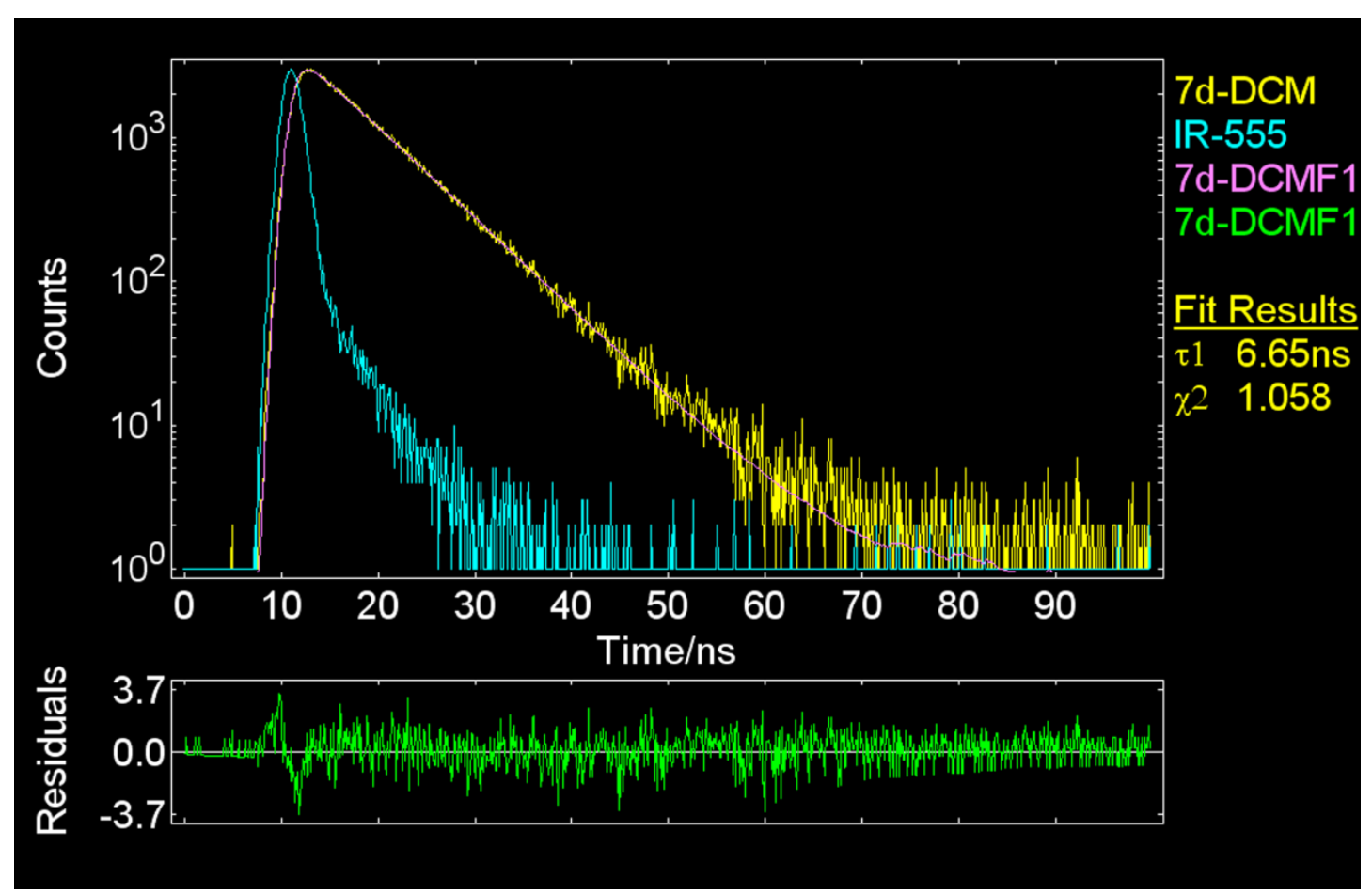

Figure S56. The fluorescence decay of isoindole BODIPY $5 \mathbf{d}$ in distilled $\mathrm{CH}_{2} \mathrm{Cl}_{2}$ measured by single photon counting method with emission was monitored at $629 \mathrm{~nm}$, excited at $555 \mathrm{~nm}$. 


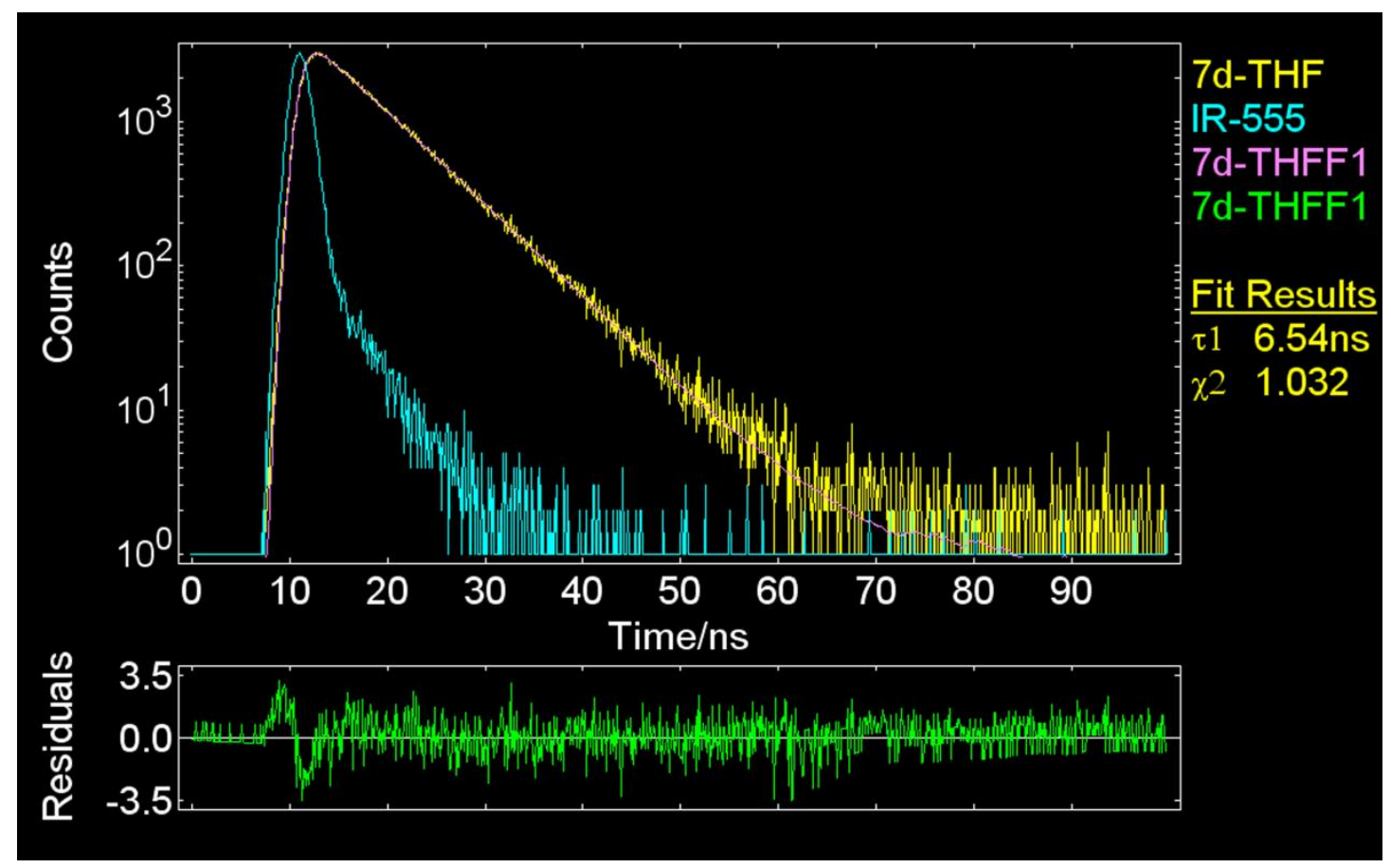

Figure S57. The fluorescence decay of isoindole BODIPY 5d in distilled THF measured by single photon counting method with emission was monitored at $625 \mathrm{~nm}$, excited at $555 \mathrm{~nm}$.

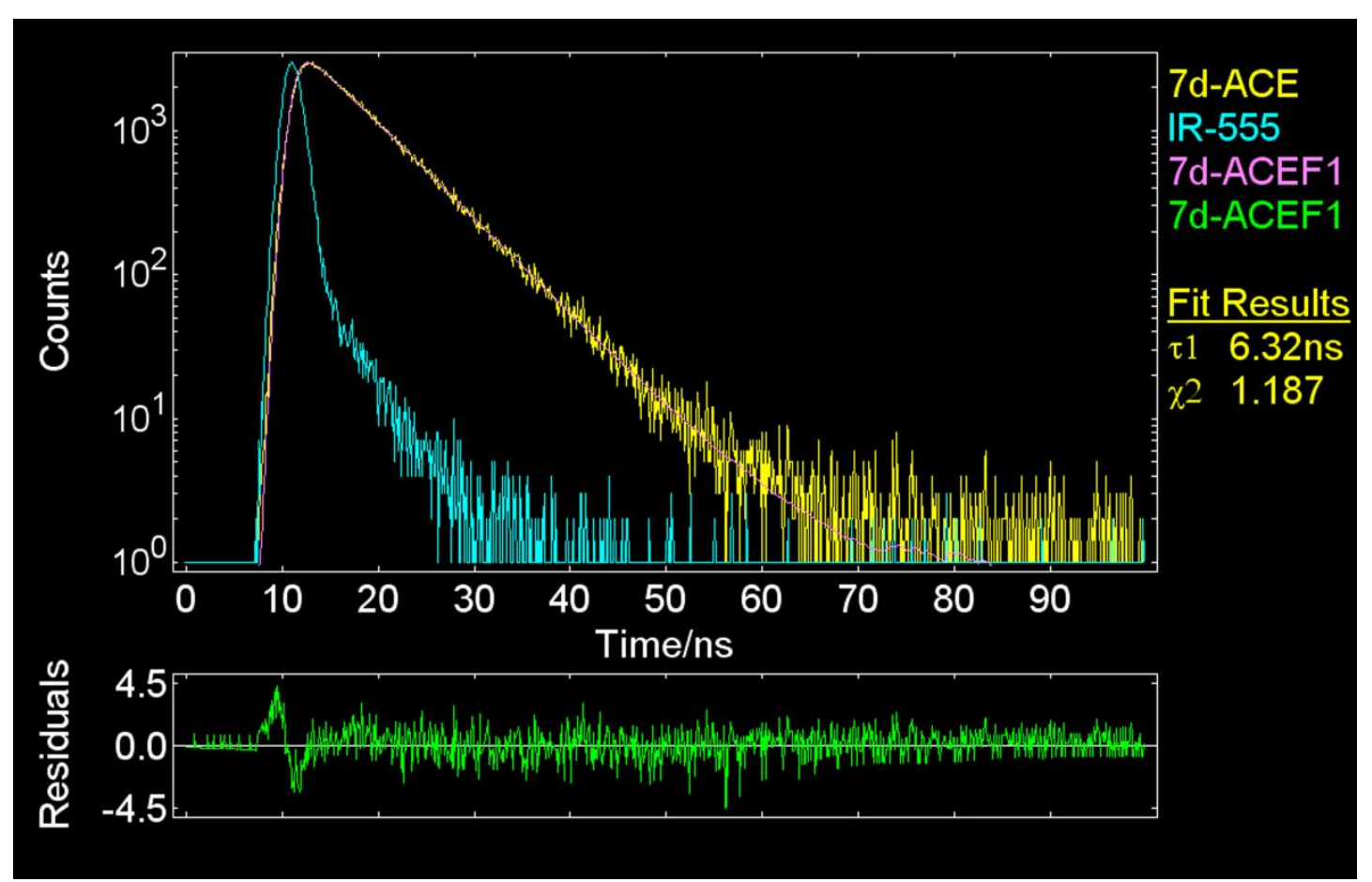

Figure S58. The fluorescence decay of isoindole BODIPY $\mathbf{5 d}$ in distilled acetonitrile measured by single photon counting method with emission was monitored at $623 \mathrm{~nm}$, excited at $555 \mathrm{~nm}$. 


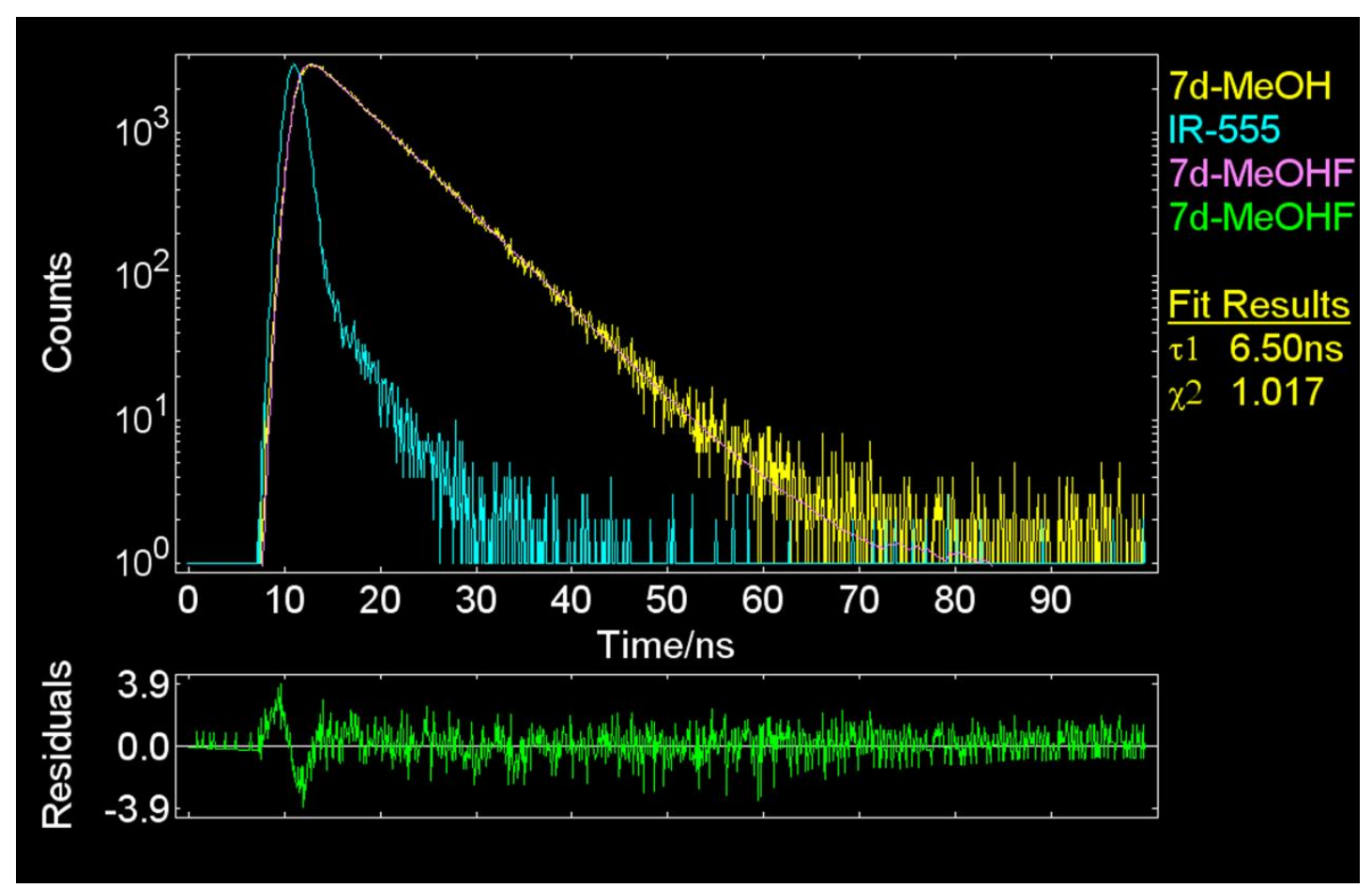

Figure S59. The fluorescence decay of isoindole BODIPY 5d in distilled MeOH measured by single photon counting method with emission was monitored at $620 \mathrm{~nm}$, excited at $555 \mathrm{~nm}$.

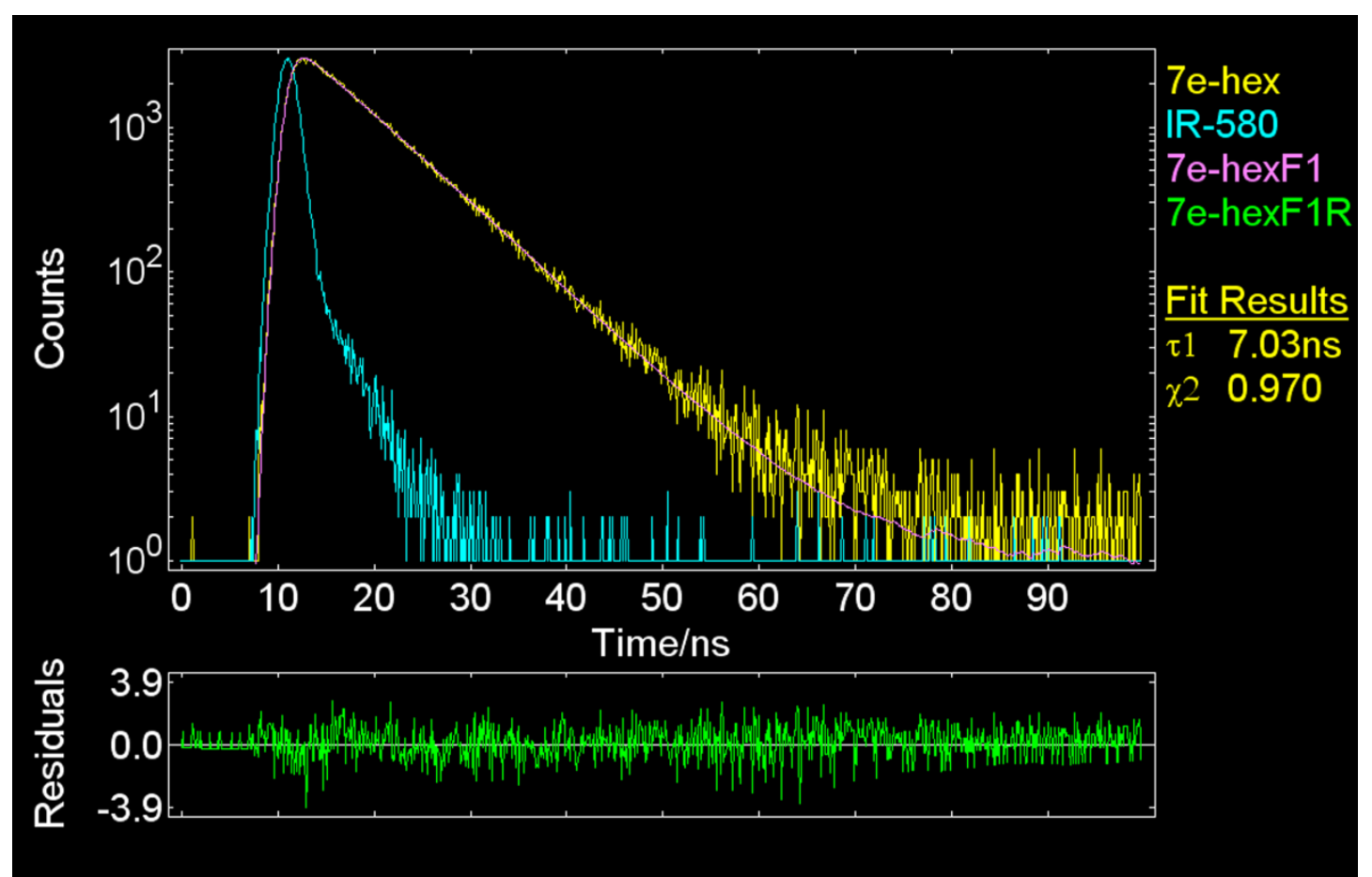

Figure S60. The fluorescence decay of isoindole BODIPY 5e in distilled hexane measured by single photon counting method with emission was monitored at $630 \mathrm{~nm}$, excited at $570 \mathrm{~nm}$. 


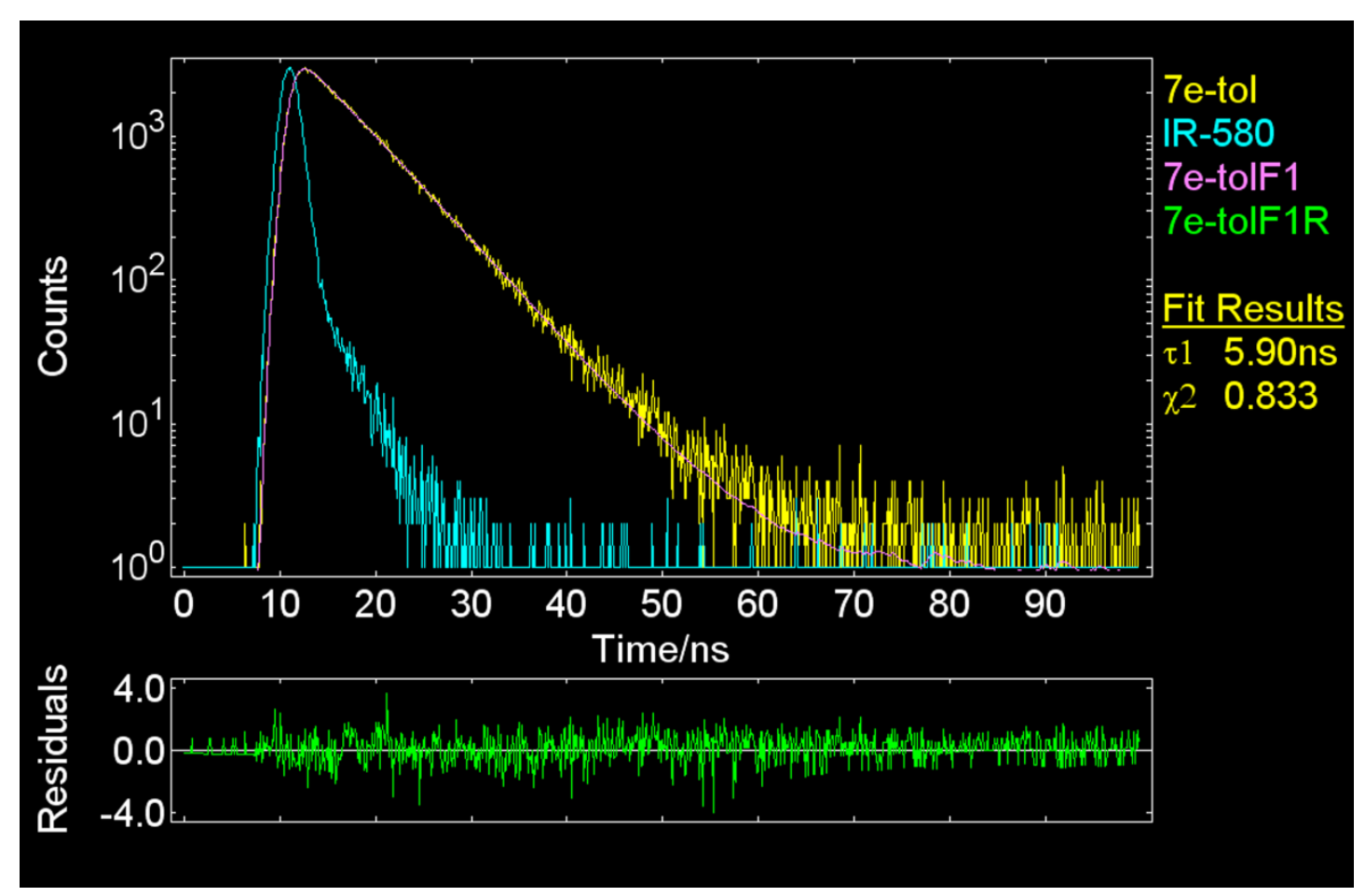

Figure S61. The fluorescence decay of isoindole BODIPY 5e in distilled toluene measured by single photon counting method with emission was monitored at $642 \mathrm{~nm}$, excited at $570 \mathrm{~nm}$.

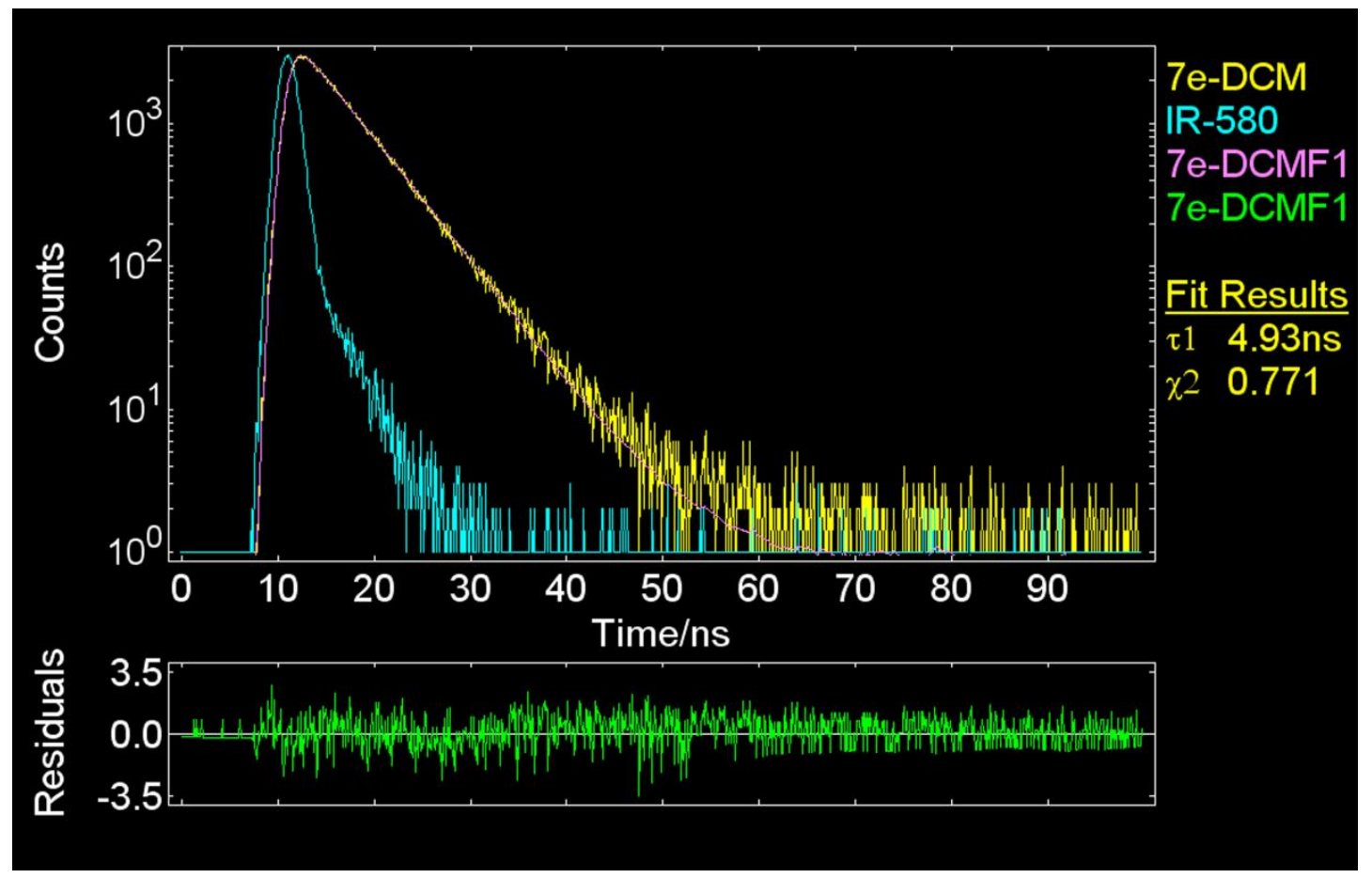

Figure S62. The fluorescence decay of isoindole BODIPY $5 e$ in distilled $\mathrm{CH}_{2} \mathrm{Cl}_{2}$ measured by single photon counting method with emission was monitored at $640 \mathrm{~nm}$, excited at $570 \mathrm{~nm}$. 


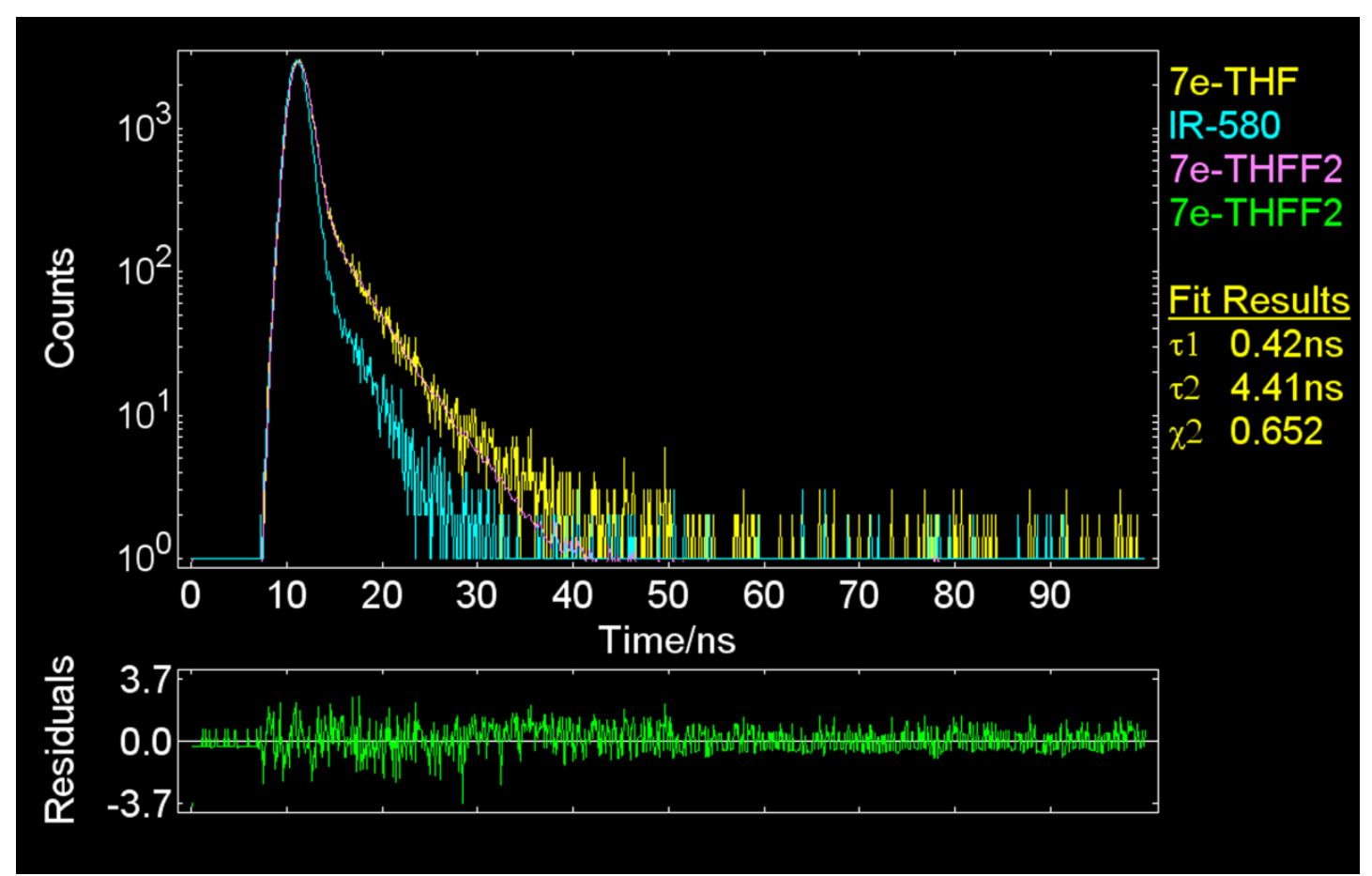

Figure S63. The fluorescence decay of isoindole BODIPY 5e in distilled THF measured by single photon counting method with emission was monitored at $635 \mathrm{~nm}$, excited at $570 \mathrm{~nm}$.

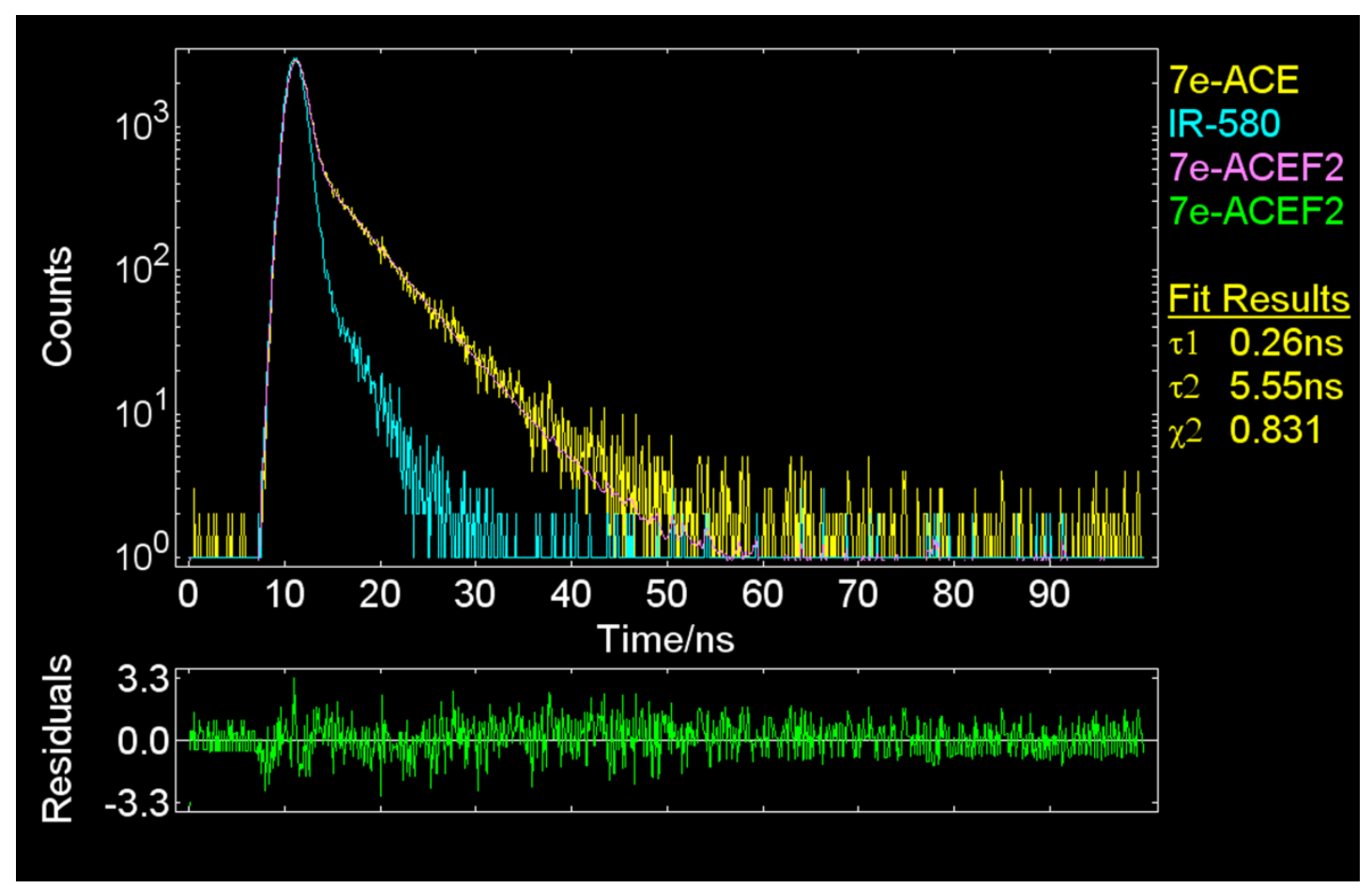

Figure S64. The fluorescence decay of isoindole BODIPY $5 \mathbf{e}$ in distilled acetonitrile measured by single photon counting method with emission was monitored at $632 \mathrm{~nm}$, excited at $570 \mathrm{~nm}$. 


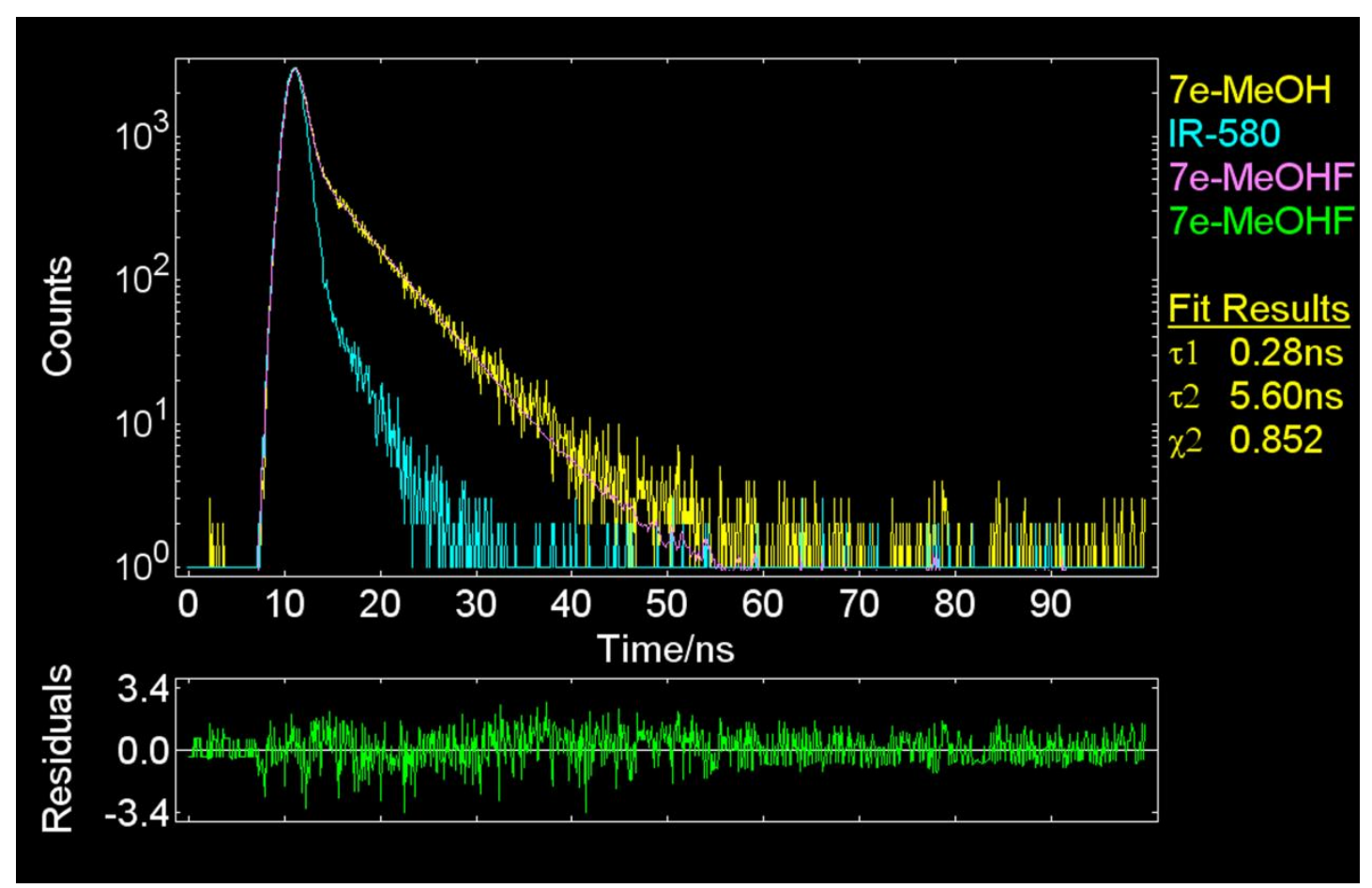

Figure S65. The fluorescence decay of isoindole BODIPY 5e in distilled MeOH measured by single photon counting method with emission was monitored at $631 \mathrm{~nm}$, excited at $570 \mathrm{~nm}$.

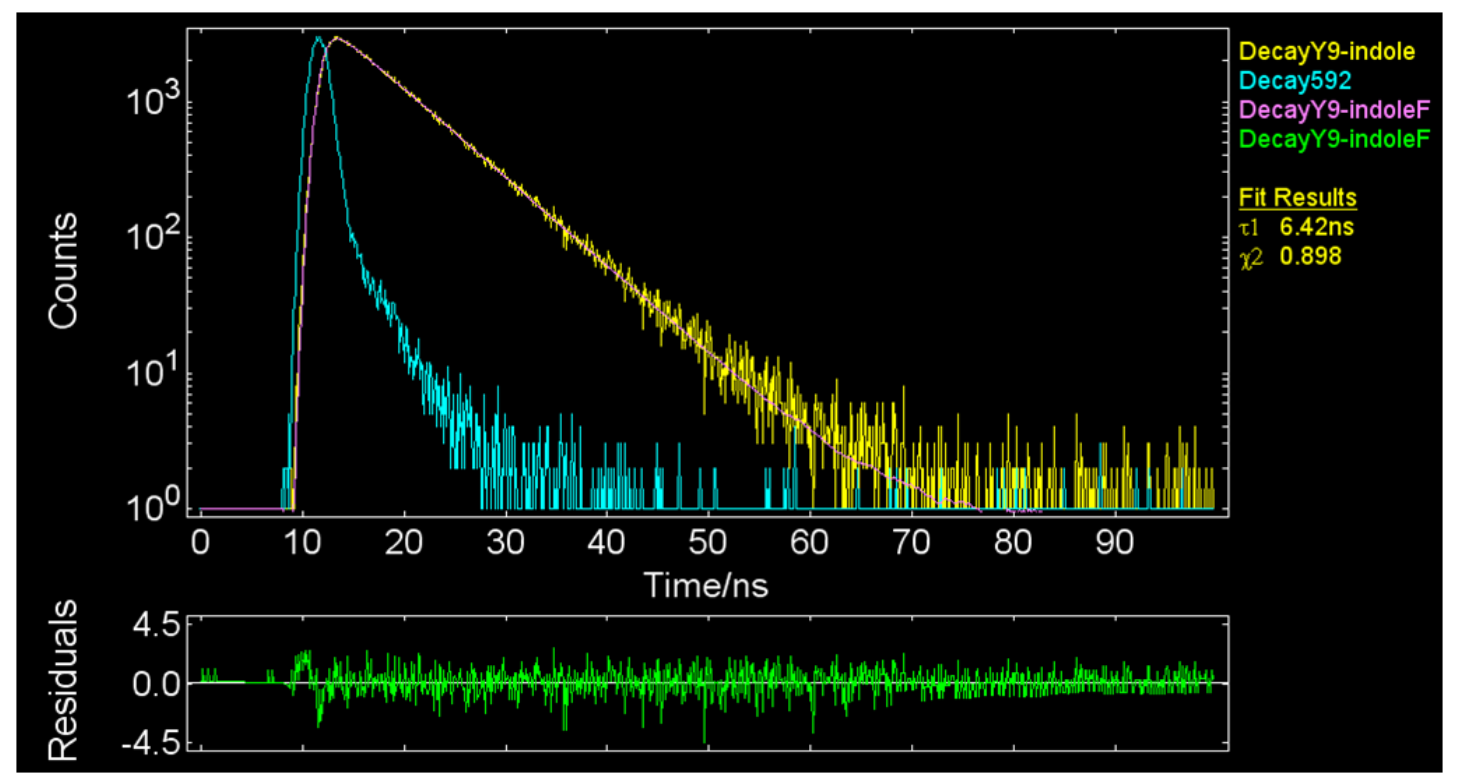

Figure S66. The fluorescence decay of isoindole BODIPY $5 \mathbf{f}$ in distilled $\mathrm{CH}_{2} \mathrm{Cl}_{2}$ measured by single photon counting method with emission was monitored at $606 \mathrm{~nm}$, excited at $540 \mathrm{~nm}$. 


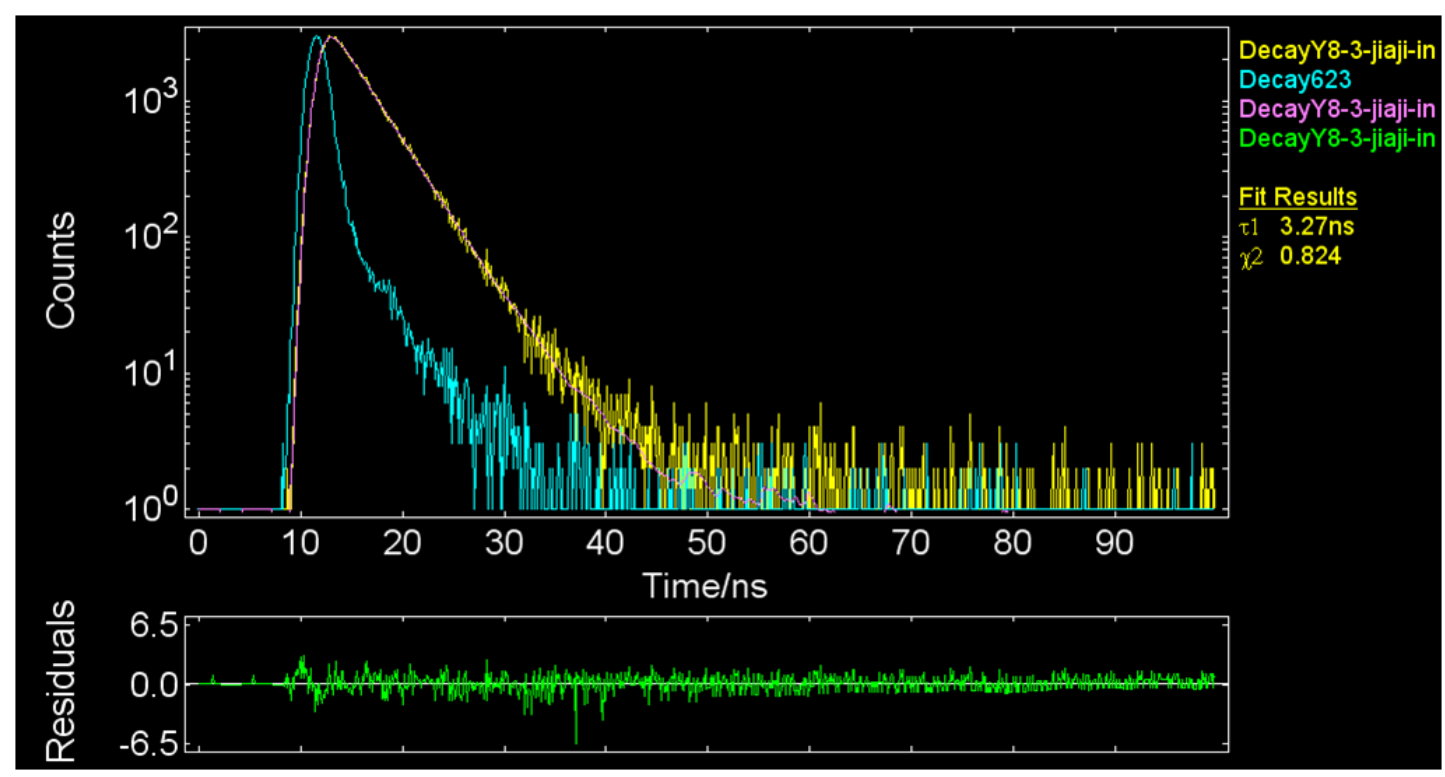

Figure S67. The fluorescence decay of isoindole BODIPY $5 \mathrm{~g}$ in distilled $\mathrm{CH}_{2} \mathrm{Cl}_{2}$ measured by single photon counting method with emission was monitored at $631 \mathrm{~nm}$, excited at $565 \mathrm{~nm}$.

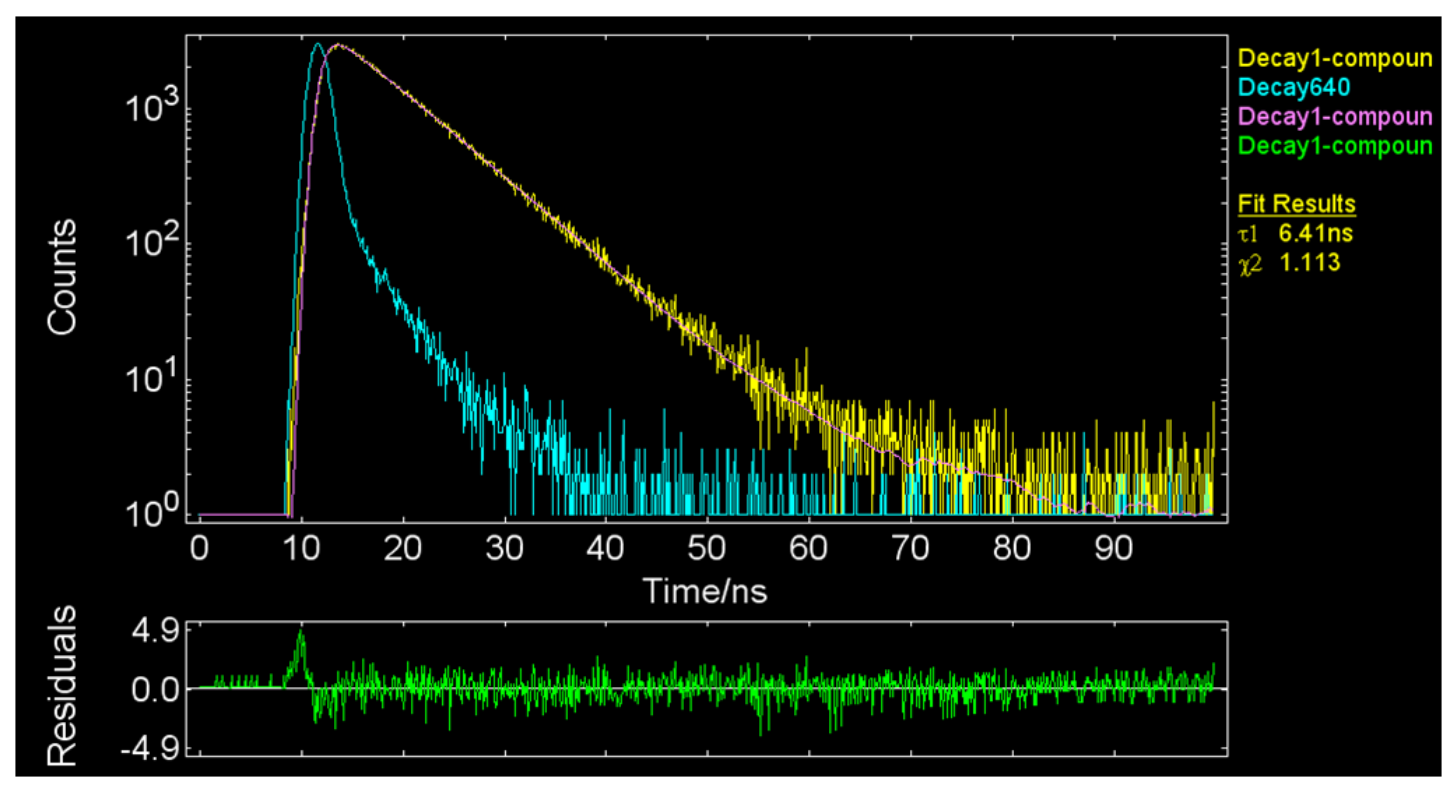

Figure S68. The fluorescence decay of isoindole BODIPY $\mathbf{5 h}$ in distilled $\mathrm{CH}_{2} \mathrm{Cl}_{2}$ measured by single photon counting method with emission was monitored at $634 \mathrm{~nm}$, excited at $560 \mathrm{~nm}$. 


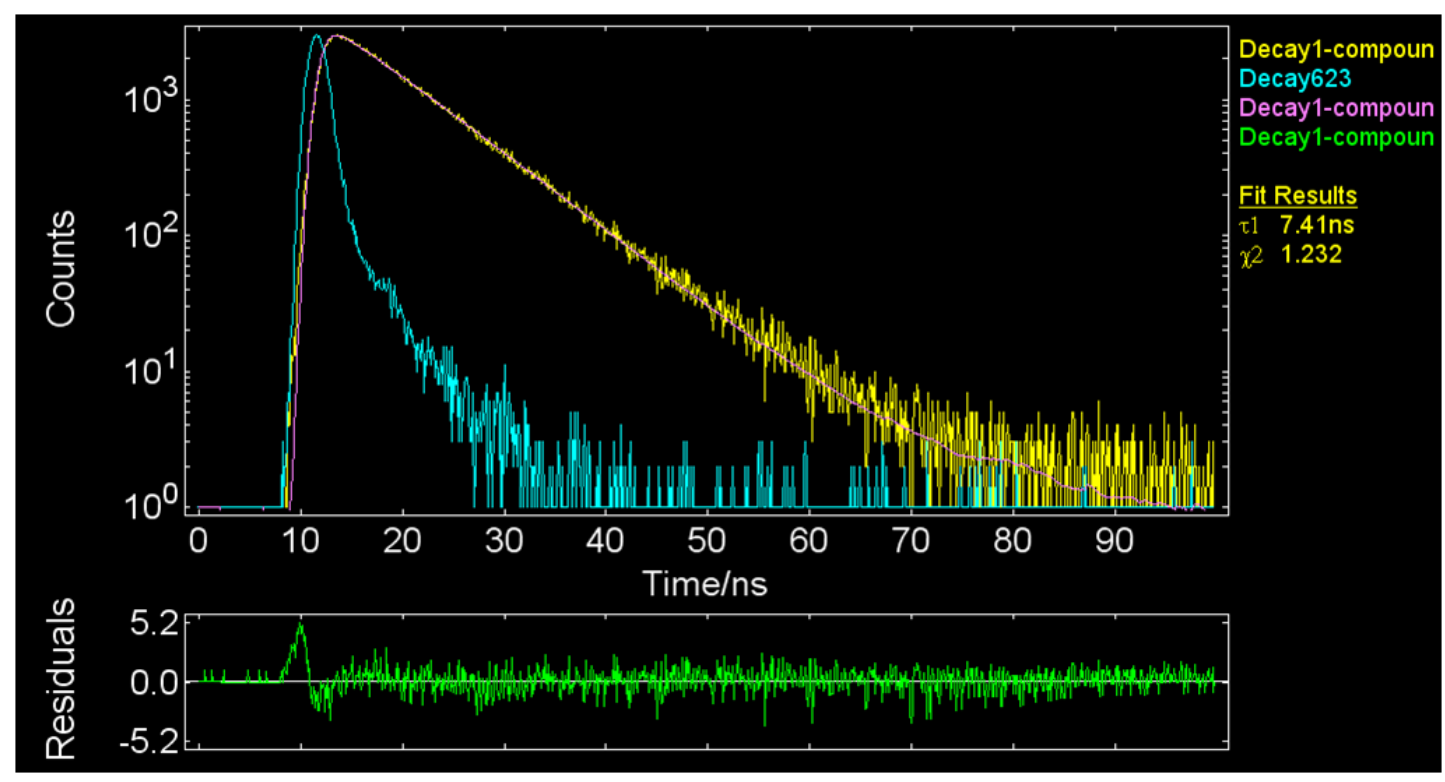

Figure S69. The fluorescence decay of isoindole BODIPY $5 \mathbf{i}$ in distilled $\mathrm{CH}_{2} \mathrm{Cl}_{2}$ measured by single photon counting method with emission was monitored at $629 \mathrm{~nm}$, excited at $575 \mathrm{~nm}$.

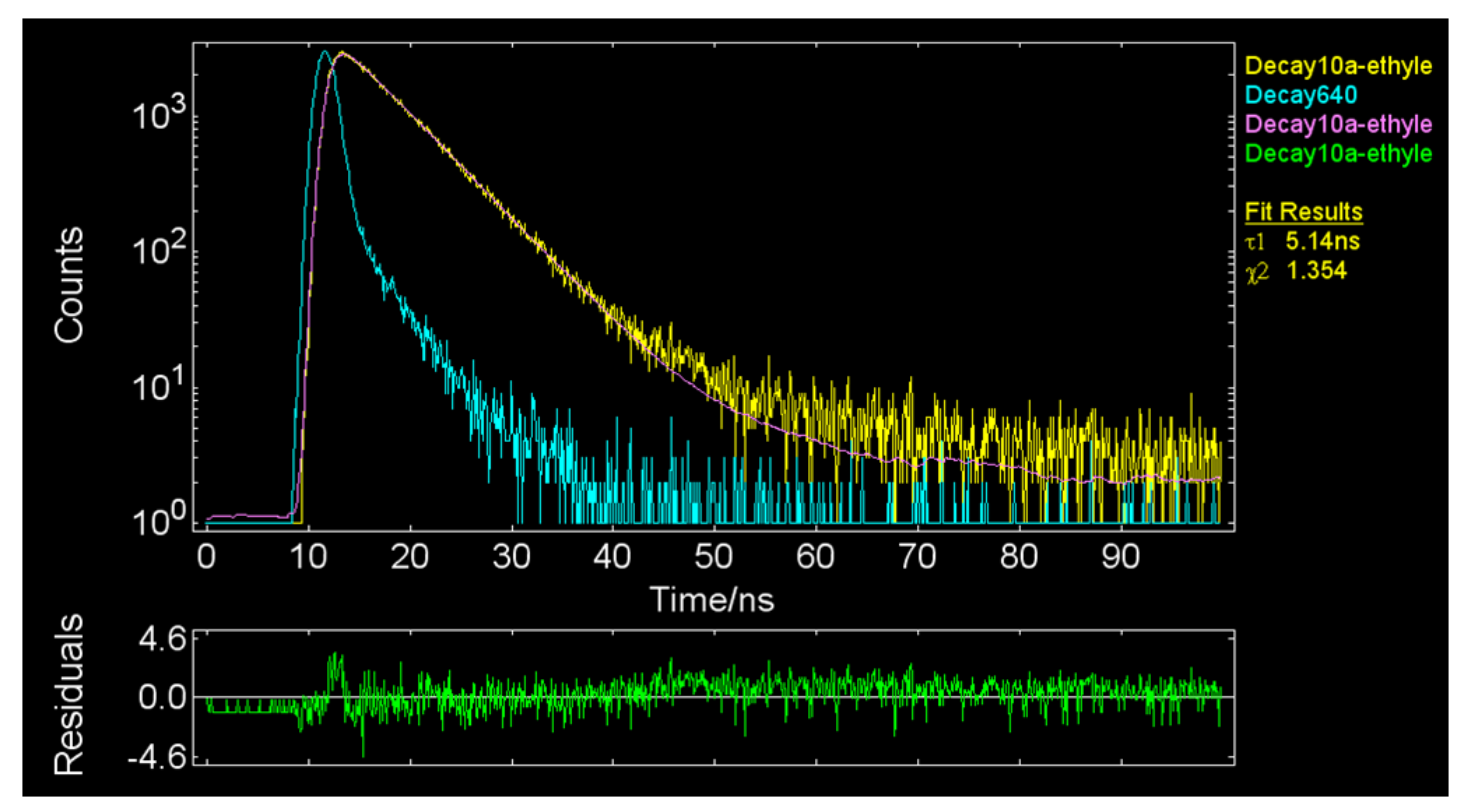

Figure S70. The fluorescence decay of isoindole BODIPY 7a in distilled $\mathrm{CH}_{2} \mathrm{Cl}_{2}$ measured by single photon counting method with emission was monitored at $705 \mathrm{~nm}$, excited at $630 \mathrm{~nm}$. 


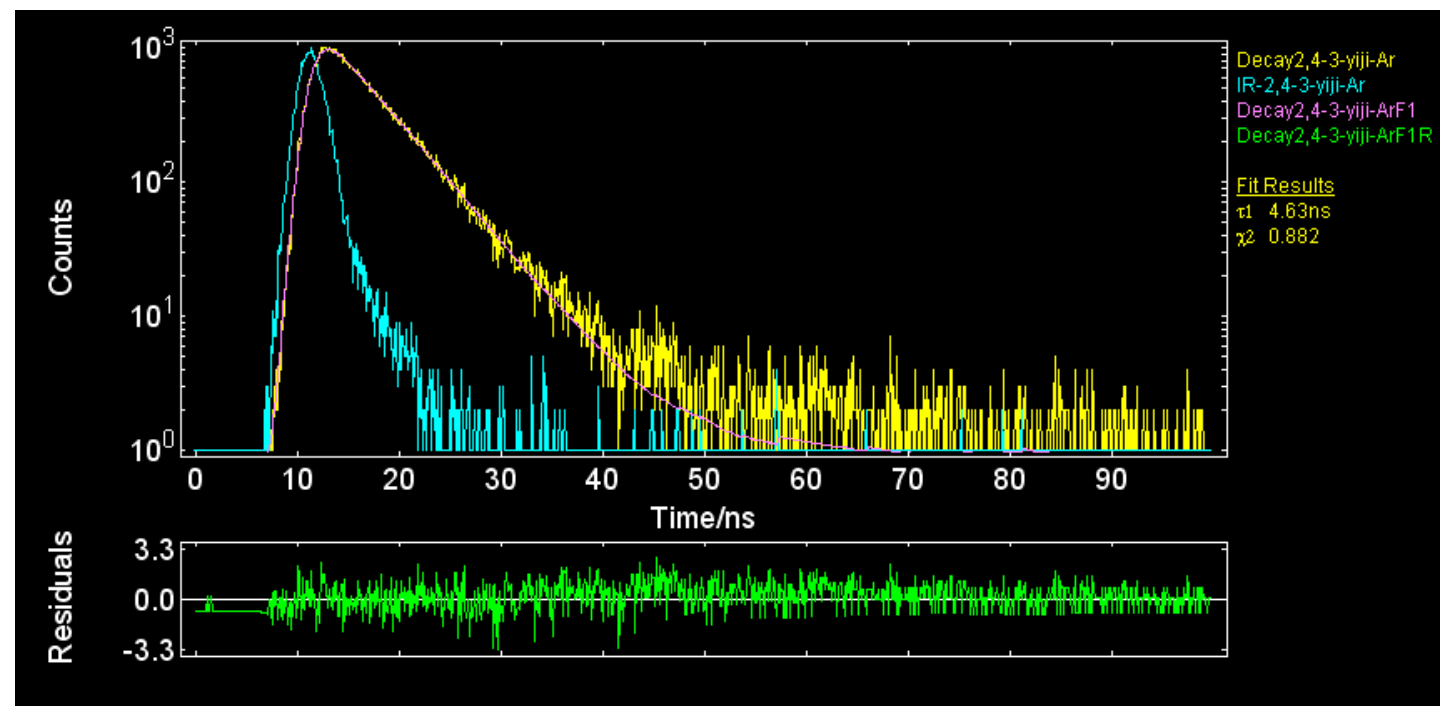

Figure S71. The fluorescence decay of isoindole BODIPY $7 \mathbf{b}$ in distilled $\mathrm{CH}_{2} \mathrm{Cl}_{2}$ measured by single photon counting method with emission was monitored at $714 \mathrm{~nm}$, excited at $630 \mathrm{~nm}$.

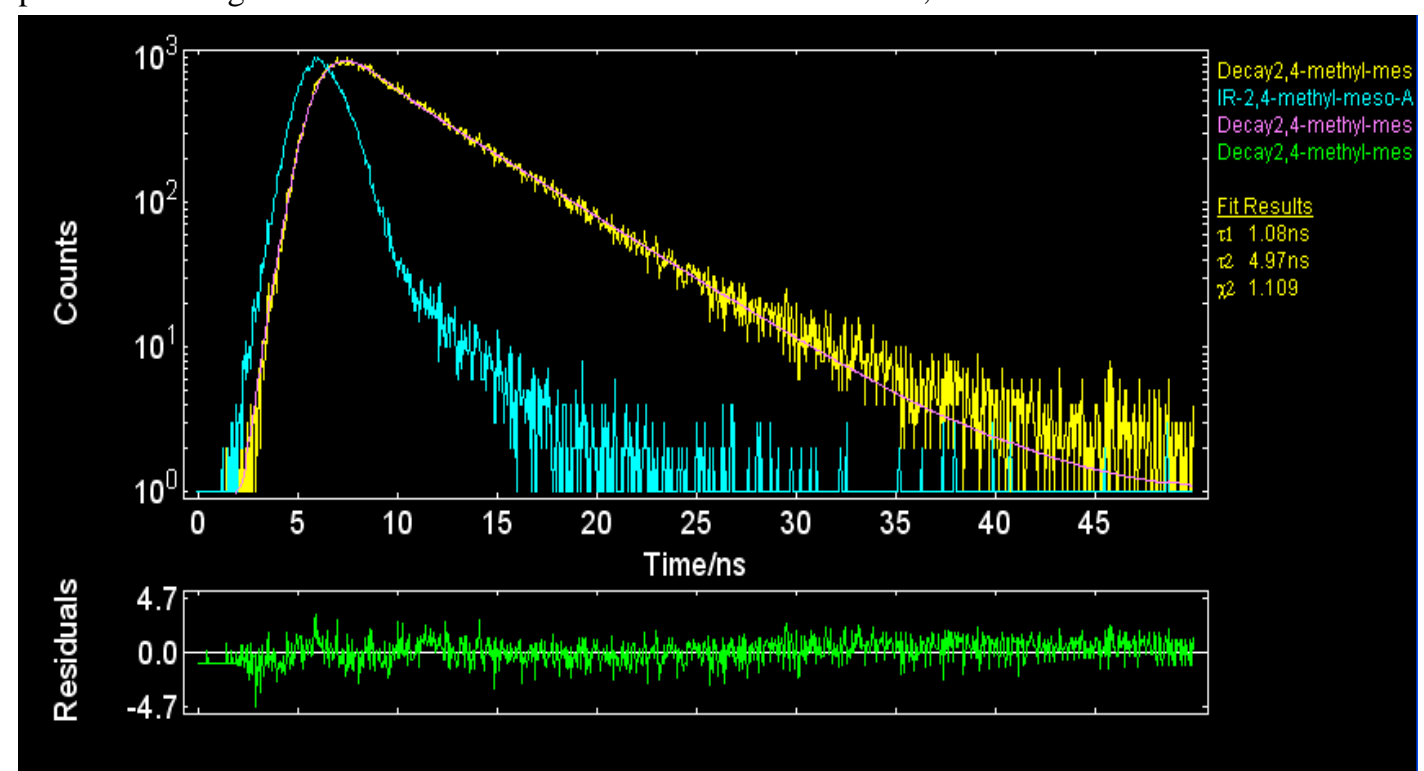

Figure S72. The fluorescence decay of isoindole BODIPY 7c in distilled $\mathrm{CH}_{2} \mathrm{Cl}_{2}$ measured by single photon counting method with emission was monitored at $687 \mathrm{~nm}$, excited at $560 \mathrm{~nm}$.

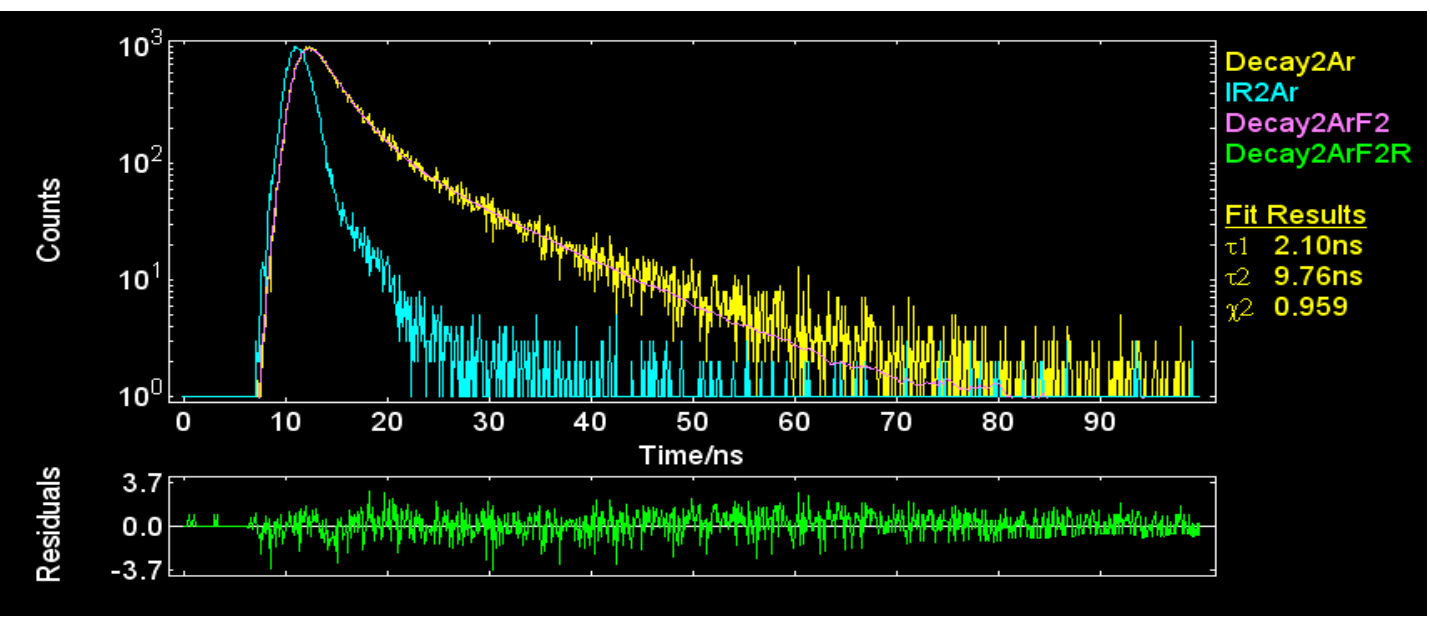


Figure S73. The fluorescence decay of isoindole BODIPY 7d in distilled $\mathrm{CH}_{2} \mathrm{Cl}_{2}$ measured by single photon counting method with emission was monitored at $733 \mathrm{~nm}$, excited at $630 \mathrm{~nm}$.

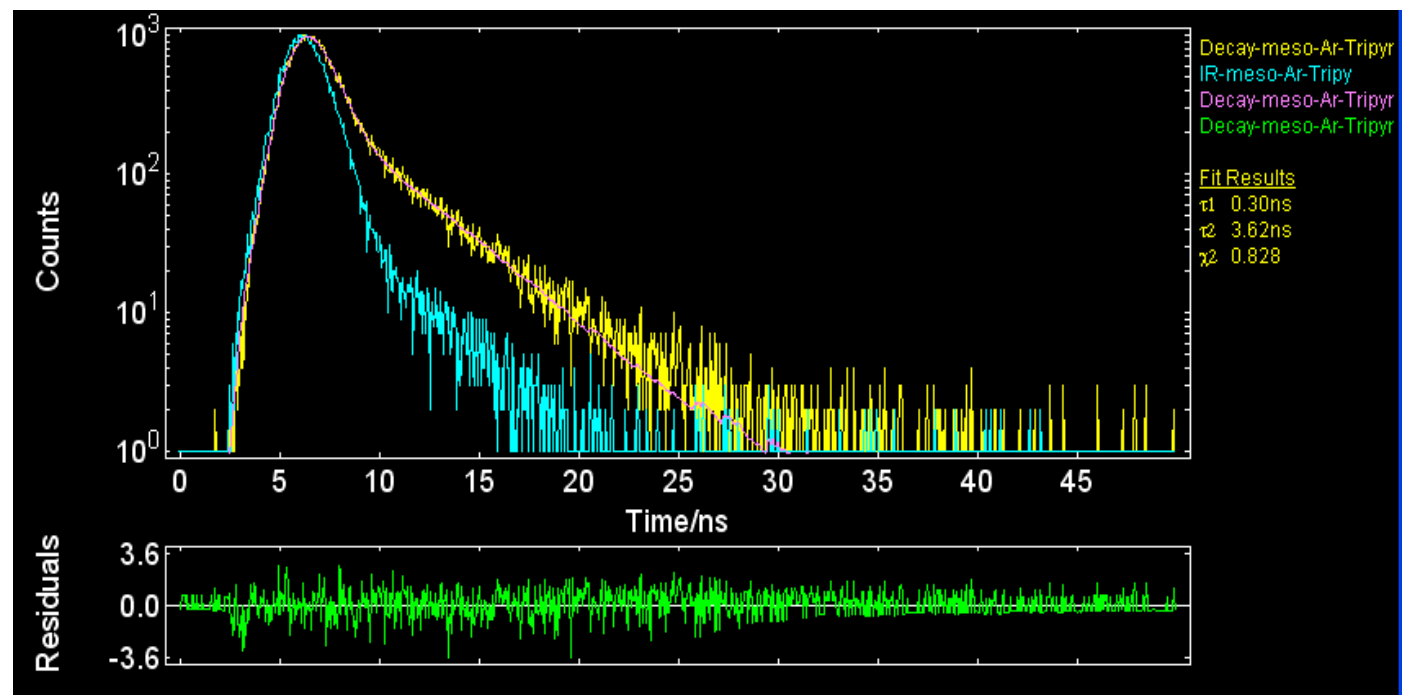

Figure S74. The fluorescence decay of isoindole BODIPY 7e in distilled $\mathrm{CH}_{2} \mathrm{Cl}_{2}$ measured by single photon counting method with emission was monitored at $631 \mathrm{~nm}$, excited at $530 \mathrm{~nm}$.

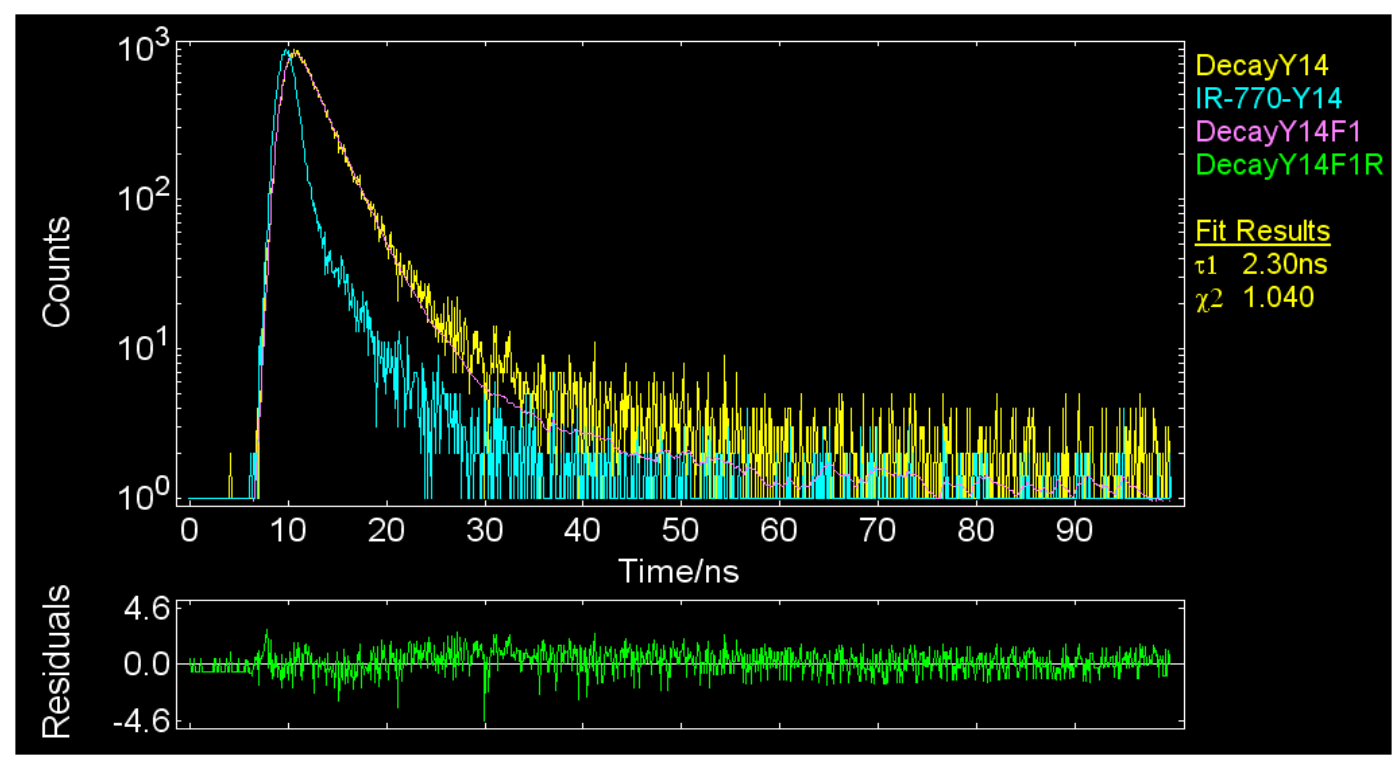

Figure S75. The fluorescence decay of isoindole BODIPY $7 \mathbf{f}$ in distilled $\mathrm{CH}_{2} \mathrm{Cl}_{2}$ measured by single photon counting method with emission was monitored at $770 \mathrm{~nm}$, excited at $670 \mathrm{~nm}$. 


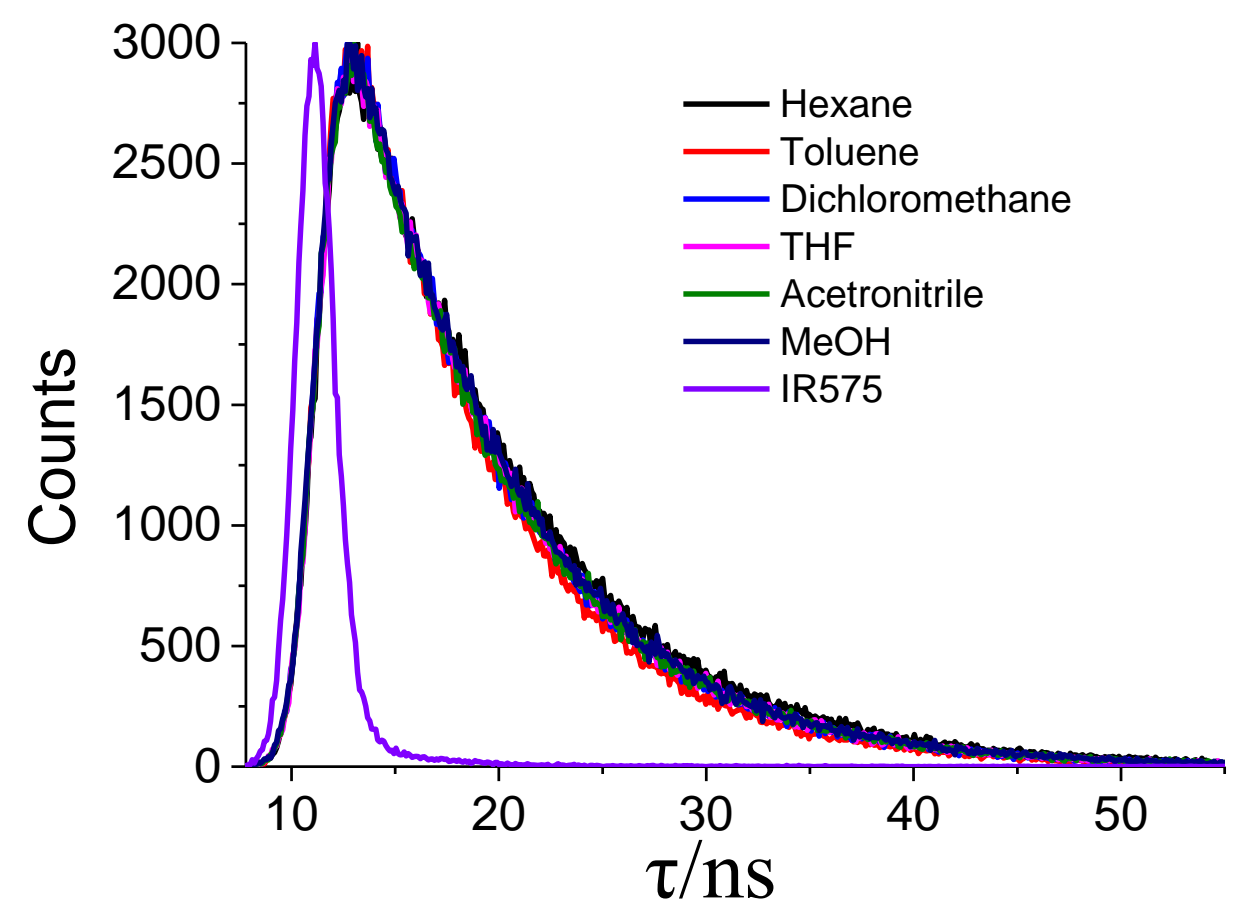

Figure S76. Fluorescence life decay spectra of isoindole BODIPY 5a in different solvents

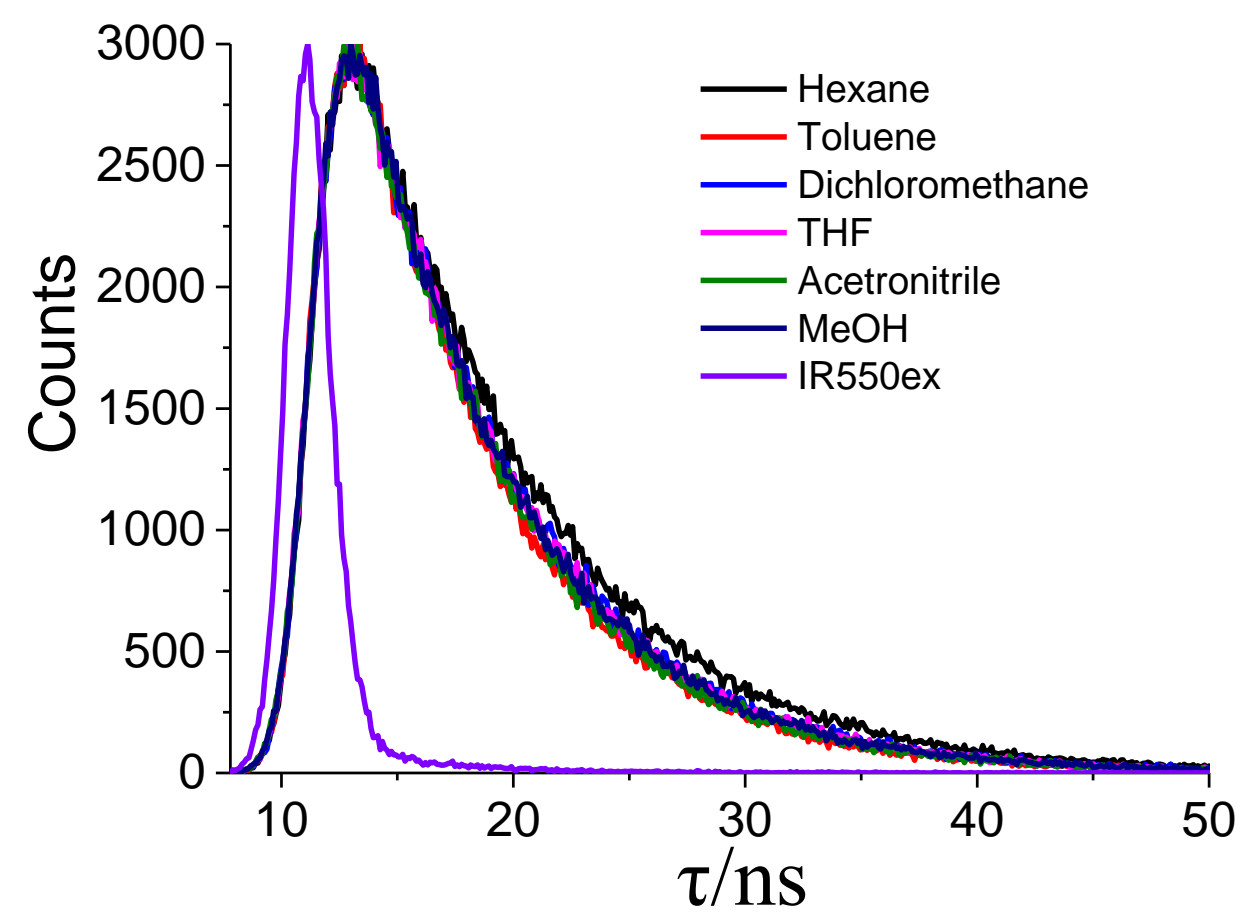

Figure S77. Fluorescence life decay spectra of isoindole BODIPY 5d in different solvents 


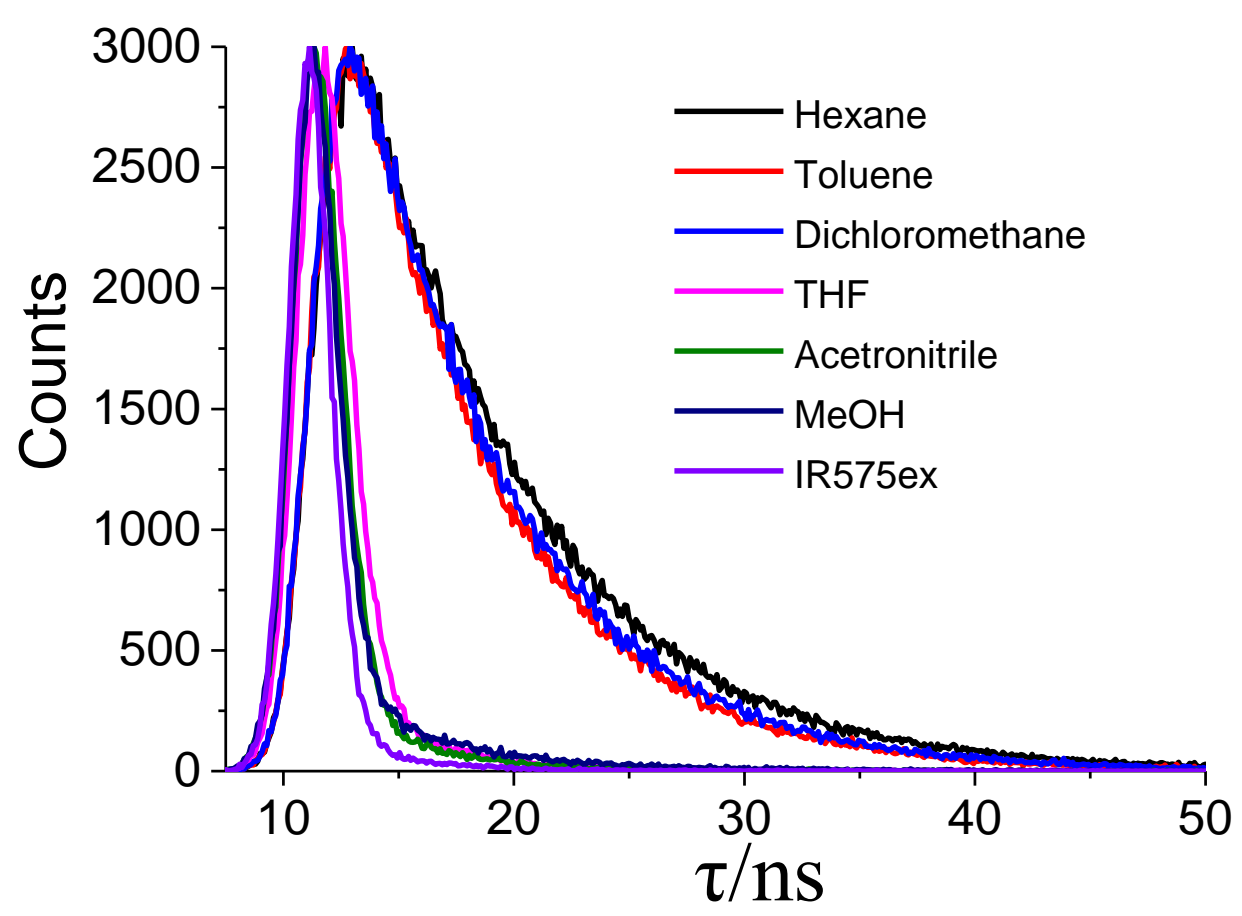

Figure S78. Fluorescence life decay spectra of isoindole BODIPY 1c in different solvents

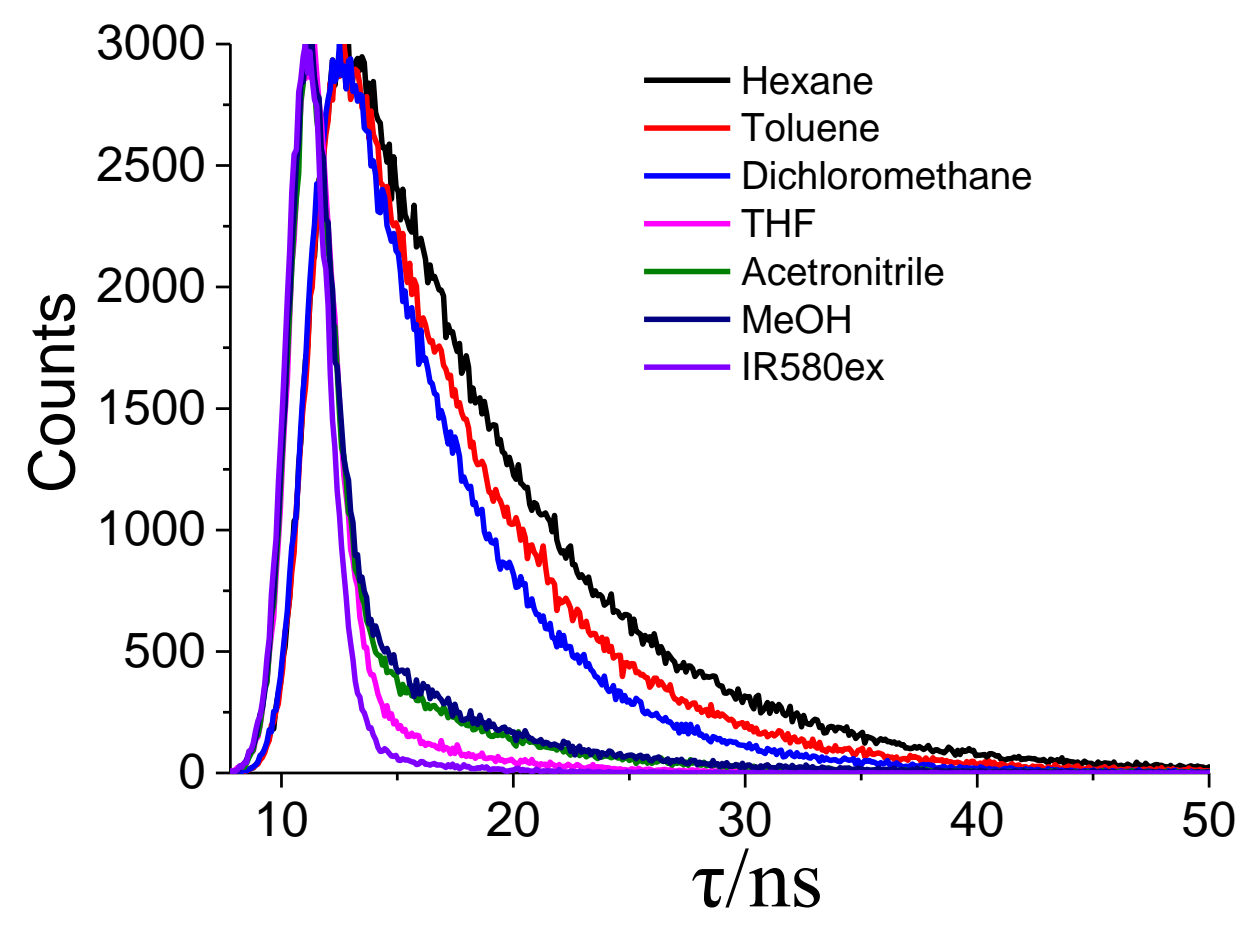

Figure S79. Fluorescence life decay spectra of isoindole BODIPY 5e in different solvents 
8. Normalized titration spectra of $7 \mathrm{f}$ in acetonitrile
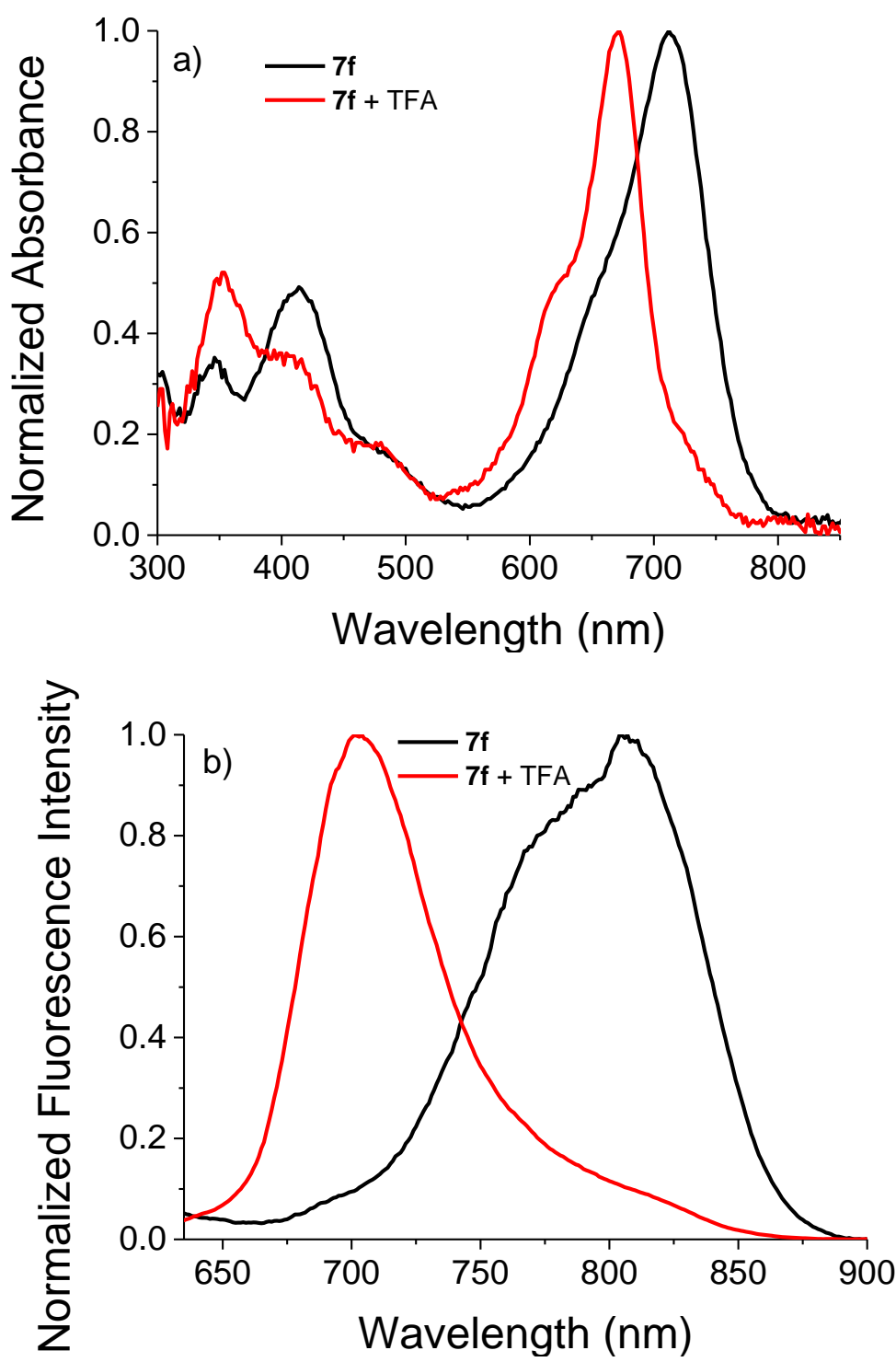

Figure S80. Overlaid and normalized absorption and fluorescence spectra of $\mathbf{7 f}$ in acetonitrile in the absence (black line) and in the presence (red line) of 230 equiv TFA. 


\section{Scanned NMR spectra}

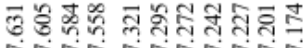

rin

₹ह
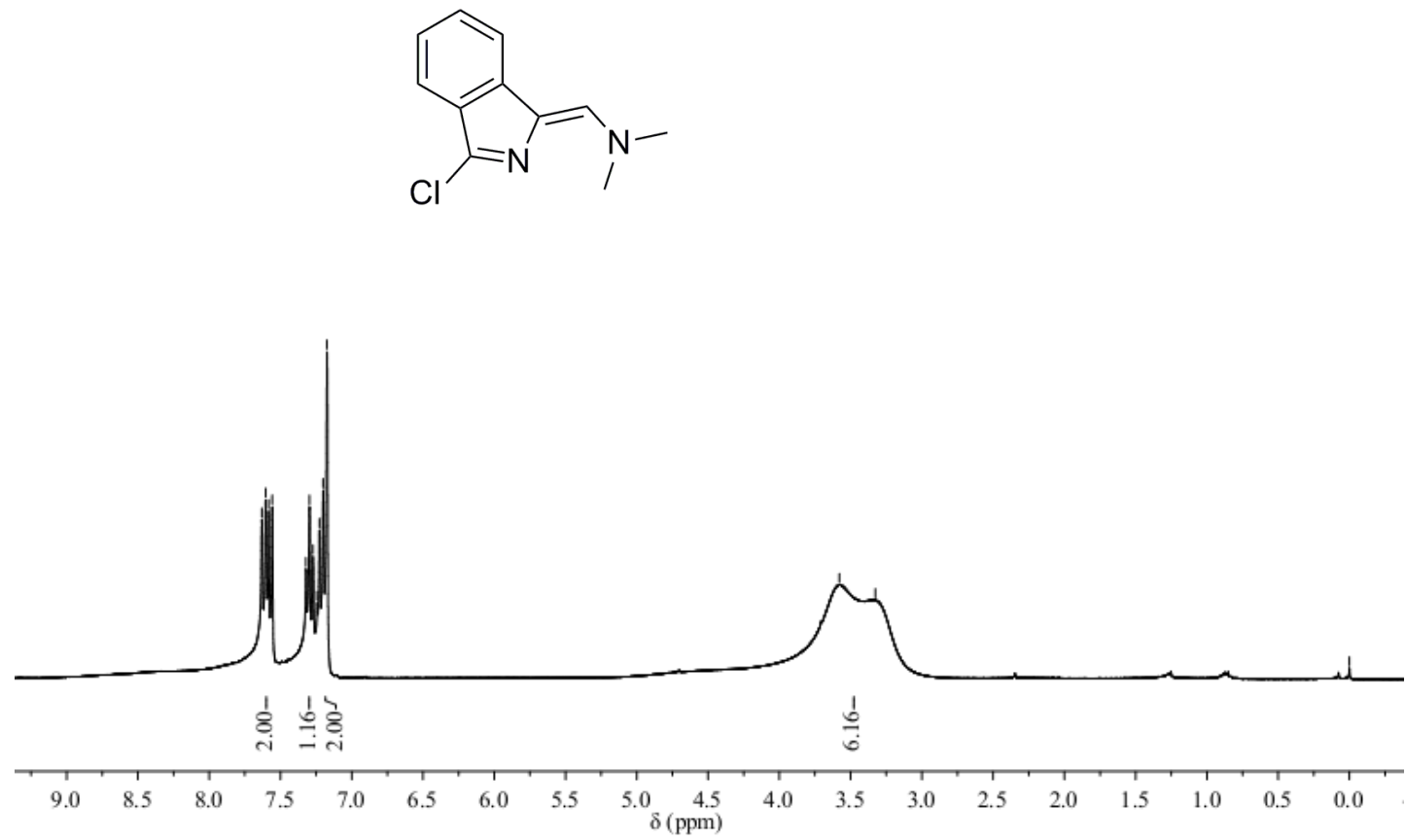

${ }^{1} \mathrm{H}$ NMR of compound $\mathbf{2 a}$ in $\mathrm{CDCl}_{3}$
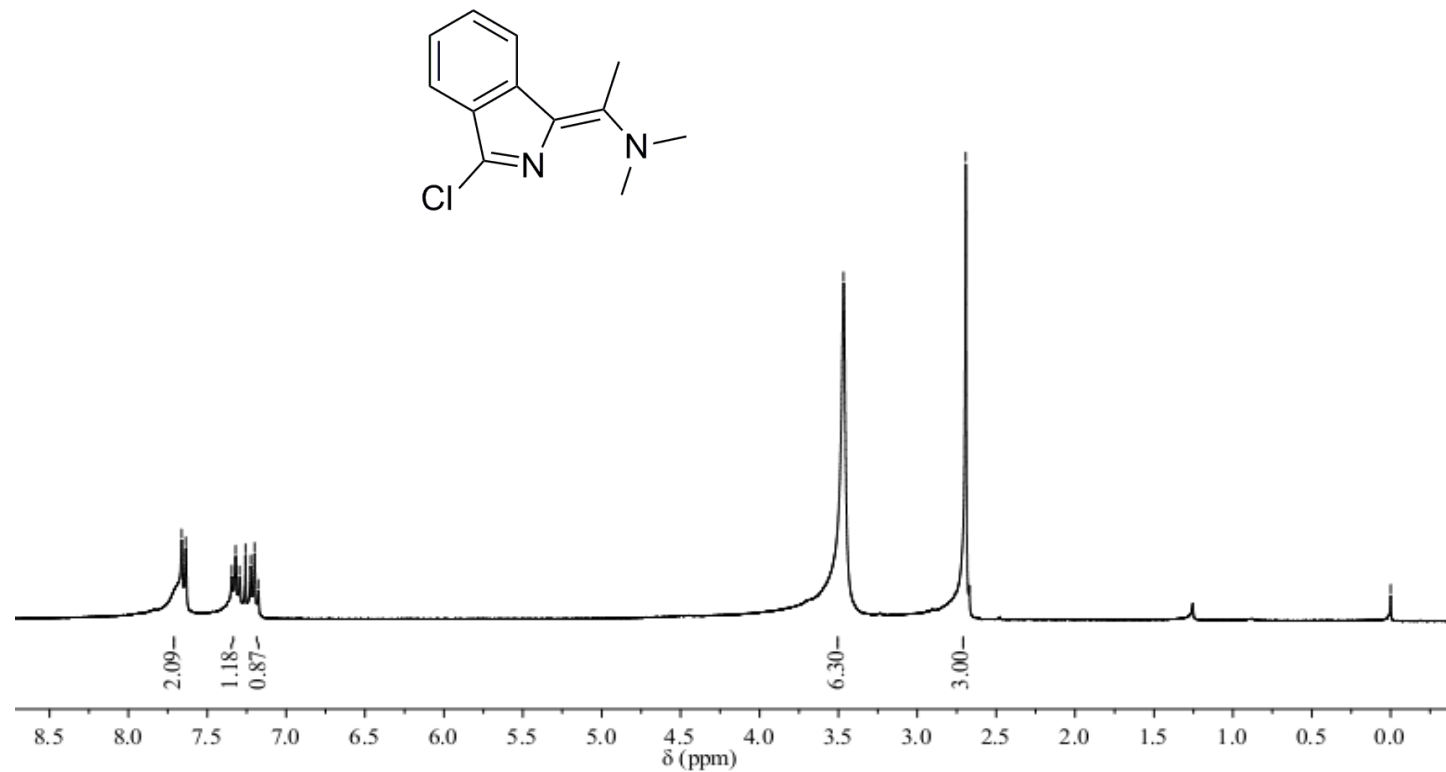

${ }^{1} \mathrm{H}$ NMR of compound $\mathbf{2 b}$ in $\mathrm{CDCl}_{3}$ 

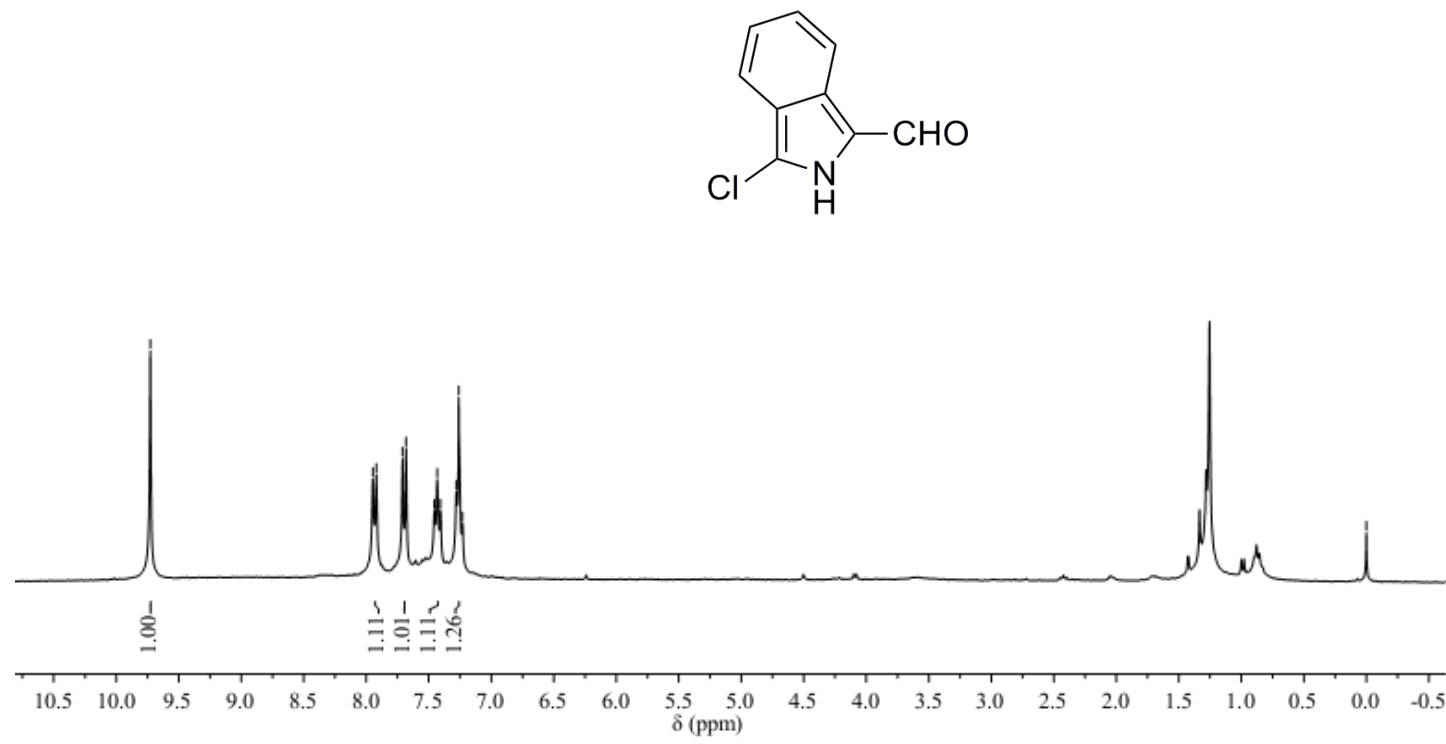

${ }^{1} \mathrm{H}$ NMR of compound $\mathbf{3 a}$ in $\mathrm{CDCl}_{3}$

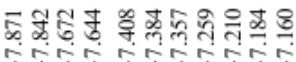

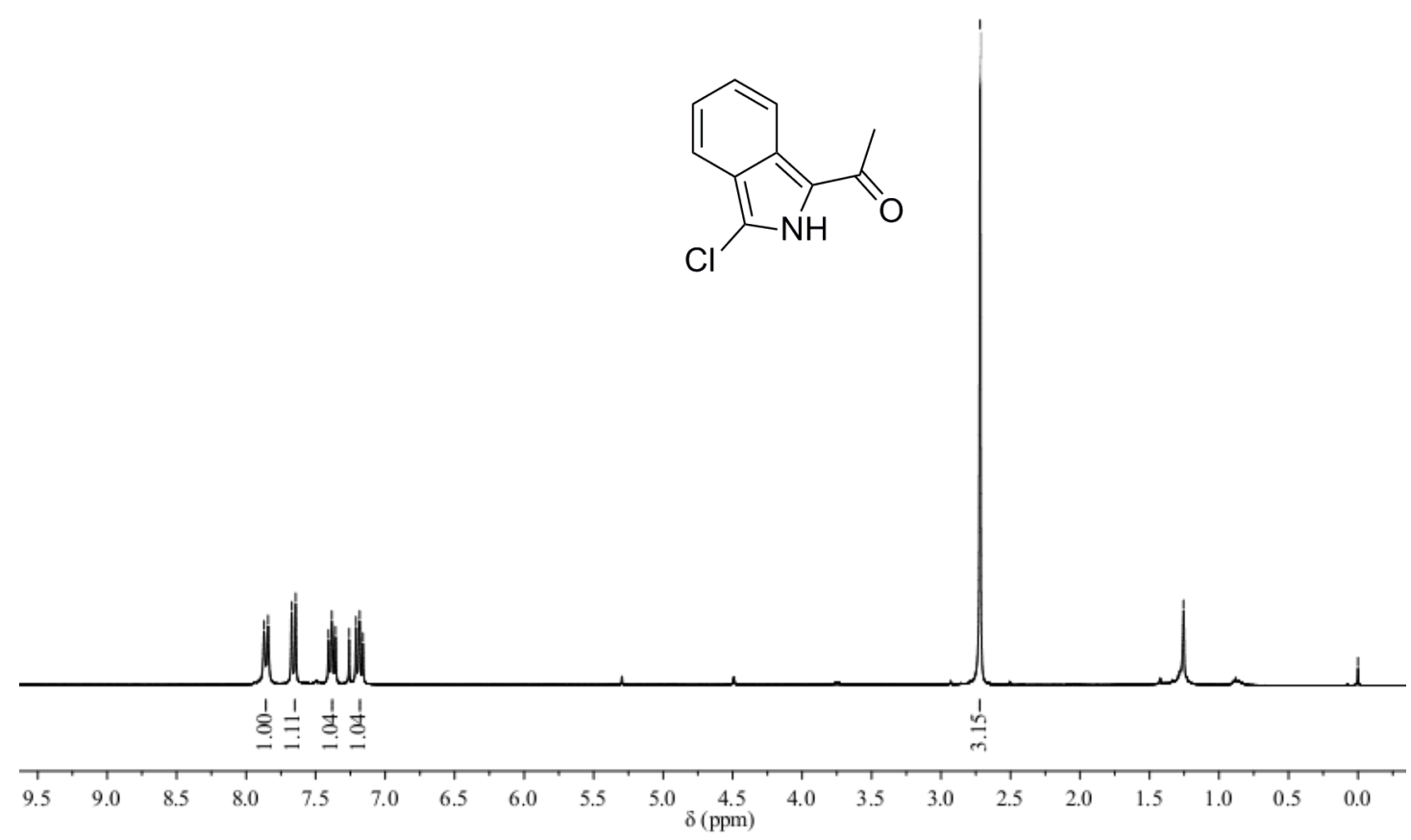

${ }^{1} \mathrm{H}$ NMR of compound $\mathbf{3 b}$ in $\mathrm{CDCl}_{3}$ 

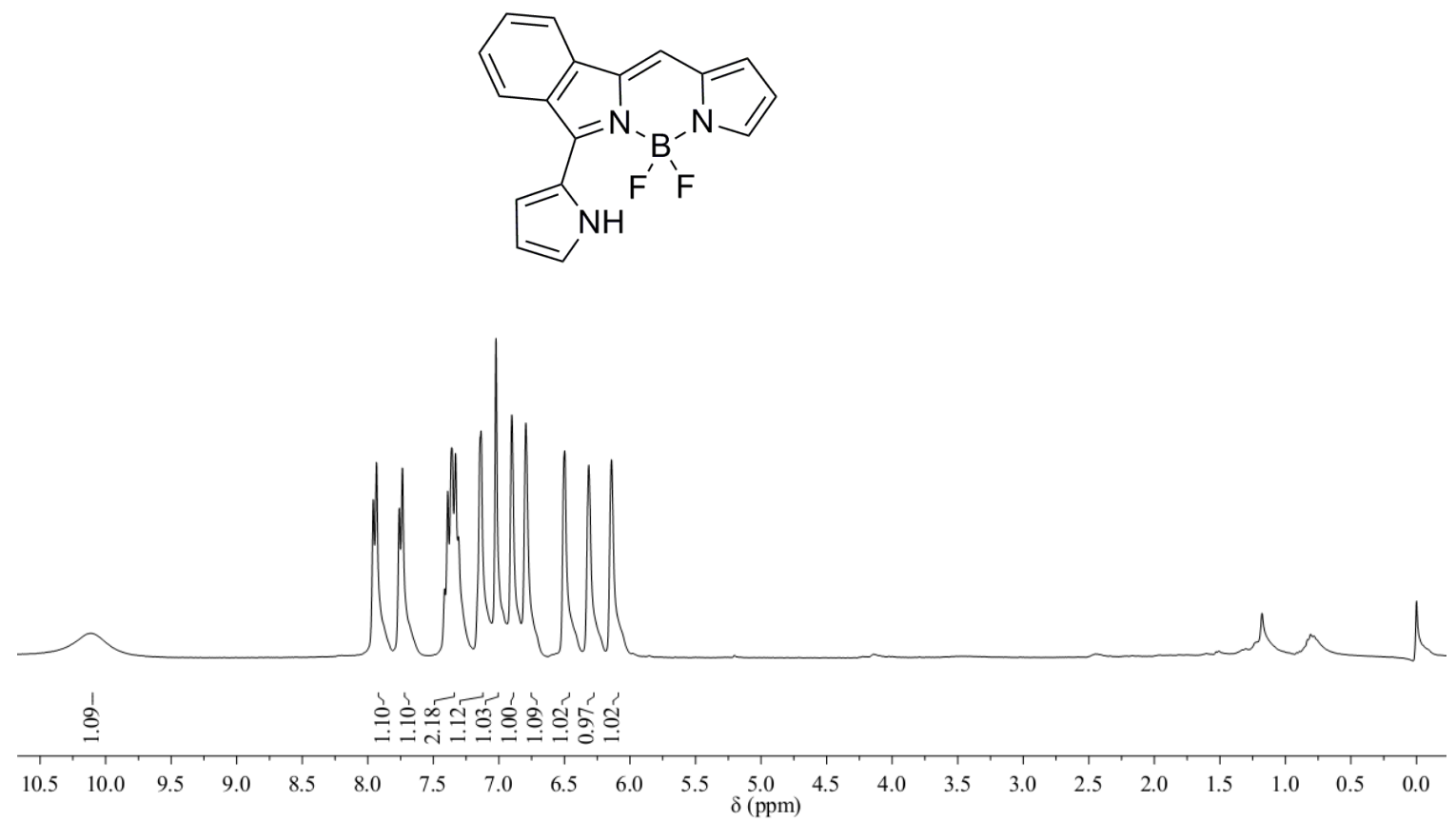

${ }^{1} \mathrm{H}$ NMR of isoindole BODIPY $1 \mathrm{a}$ in $\mathrm{CDCl}_{3}$

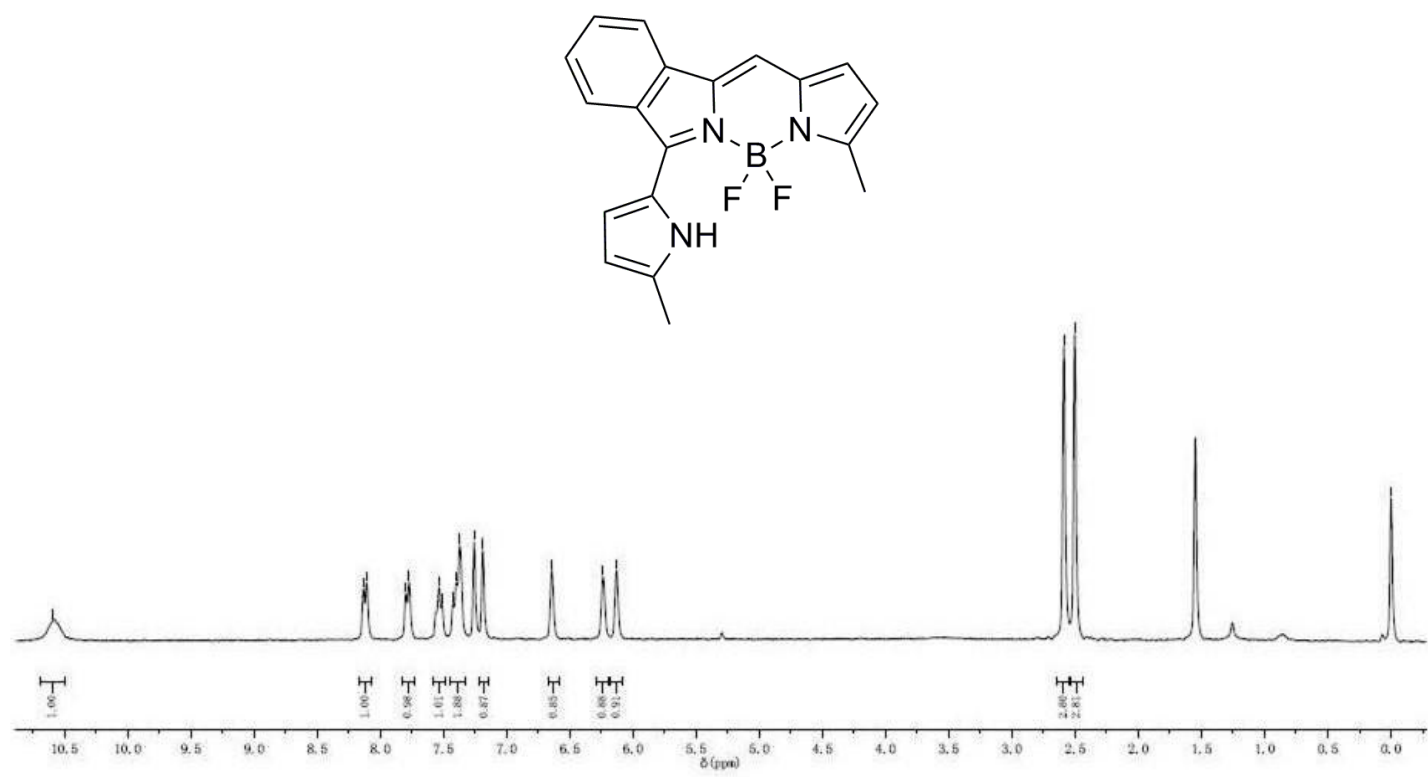

${ }^{1} \mathrm{H}$ NMR of isoindole BODIPY $\mathbf{1 b}$ in $\mathrm{CDCl}_{3}$ 


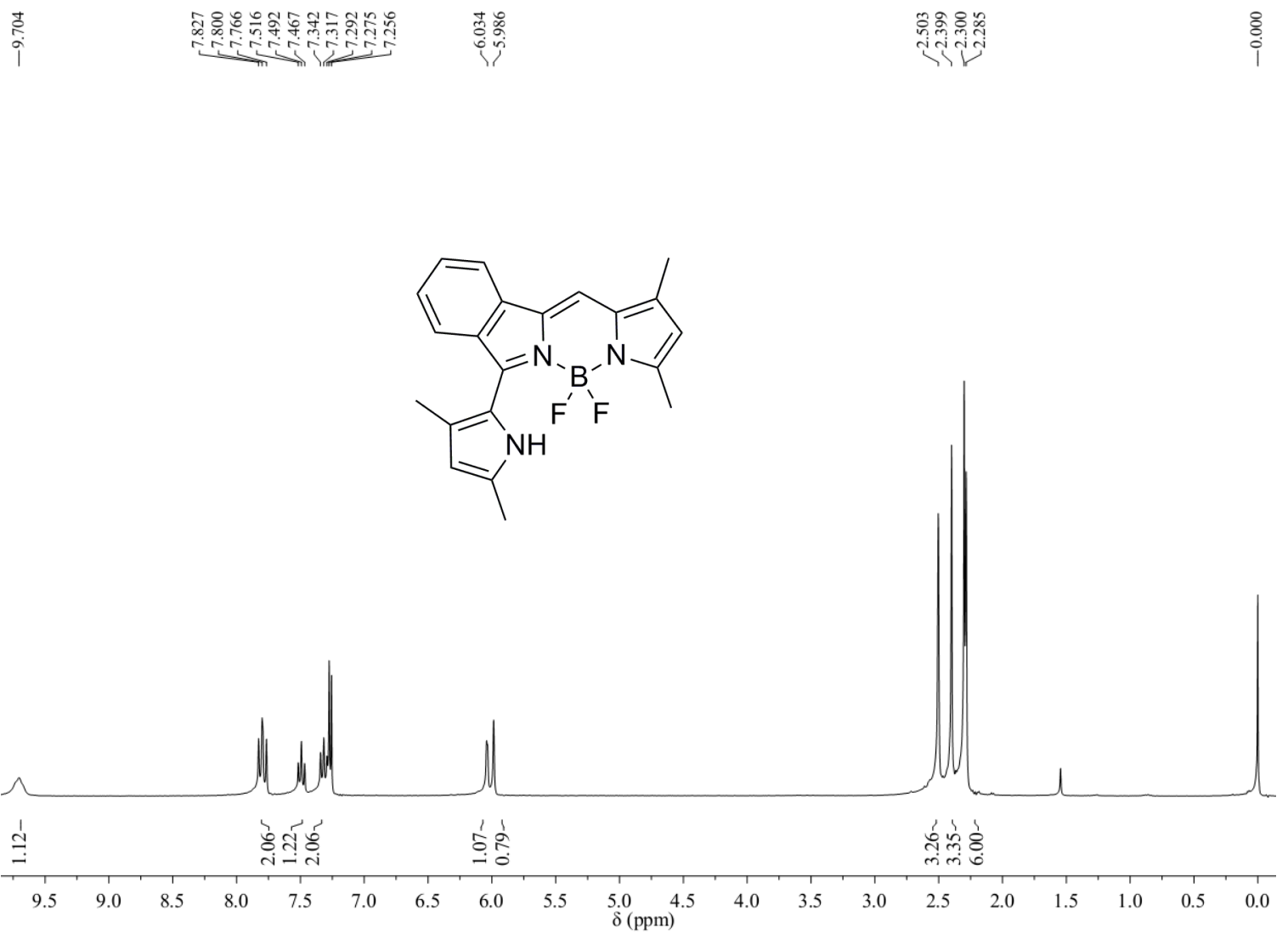

${ }^{1} \mathrm{H}$ NMR of isoindole BODIPY 1c in $\mathrm{CDCl}_{3}$

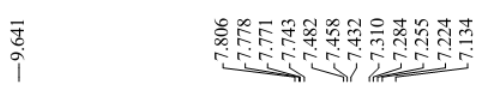

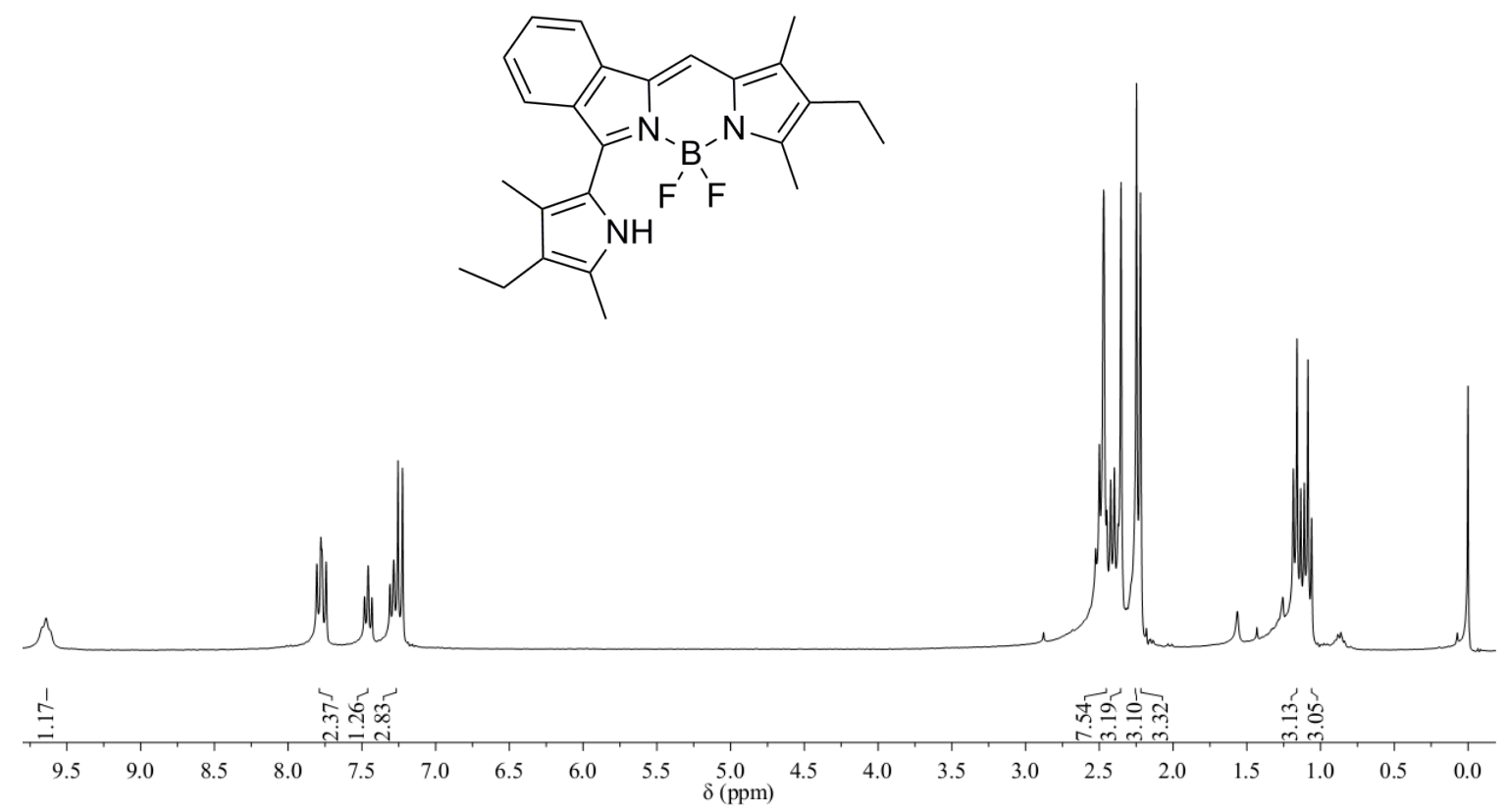

${ }^{1} \mathrm{H}$ NMR of isoindole BODIPY $\mathbf{1 d}$ in $\mathrm{CDCl}_{3}$ 


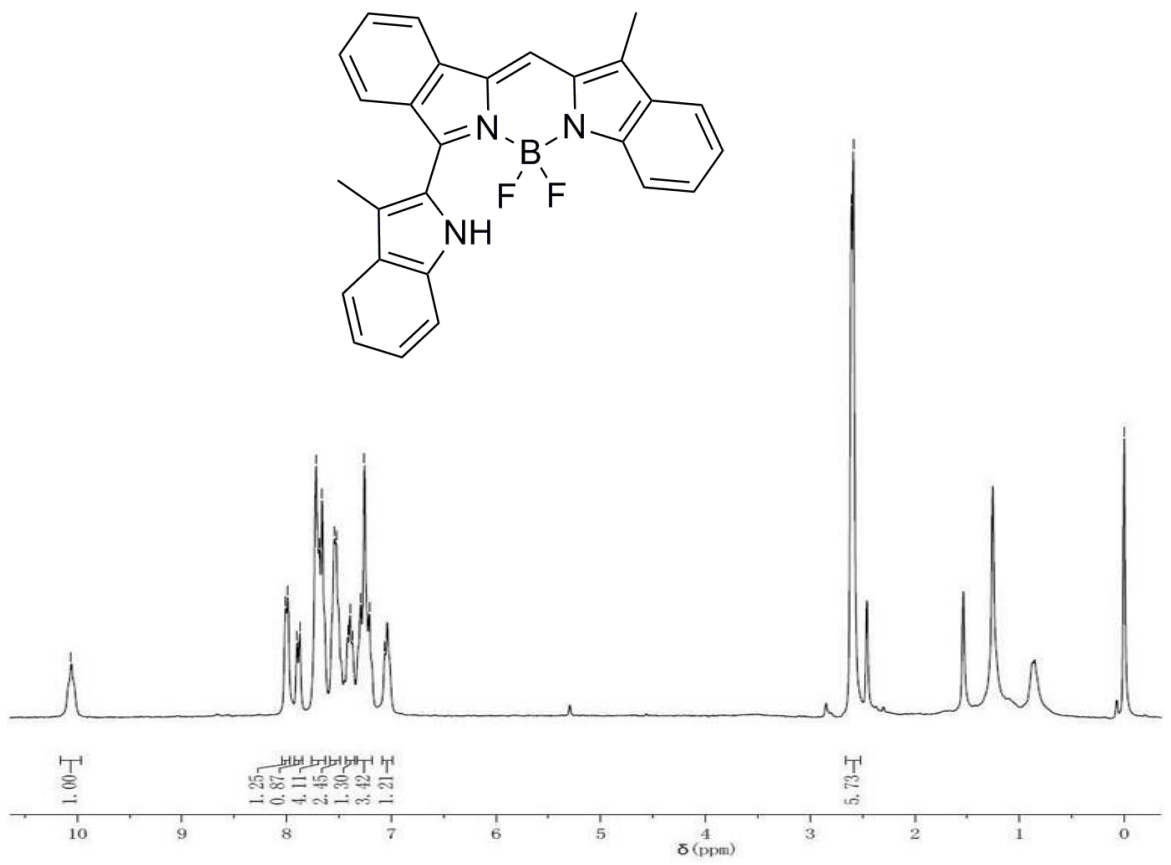

${ }^{1} \mathrm{H}$ NMR of isoindole BODIPY 1e in $\mathrm{CDCl}_{3}$
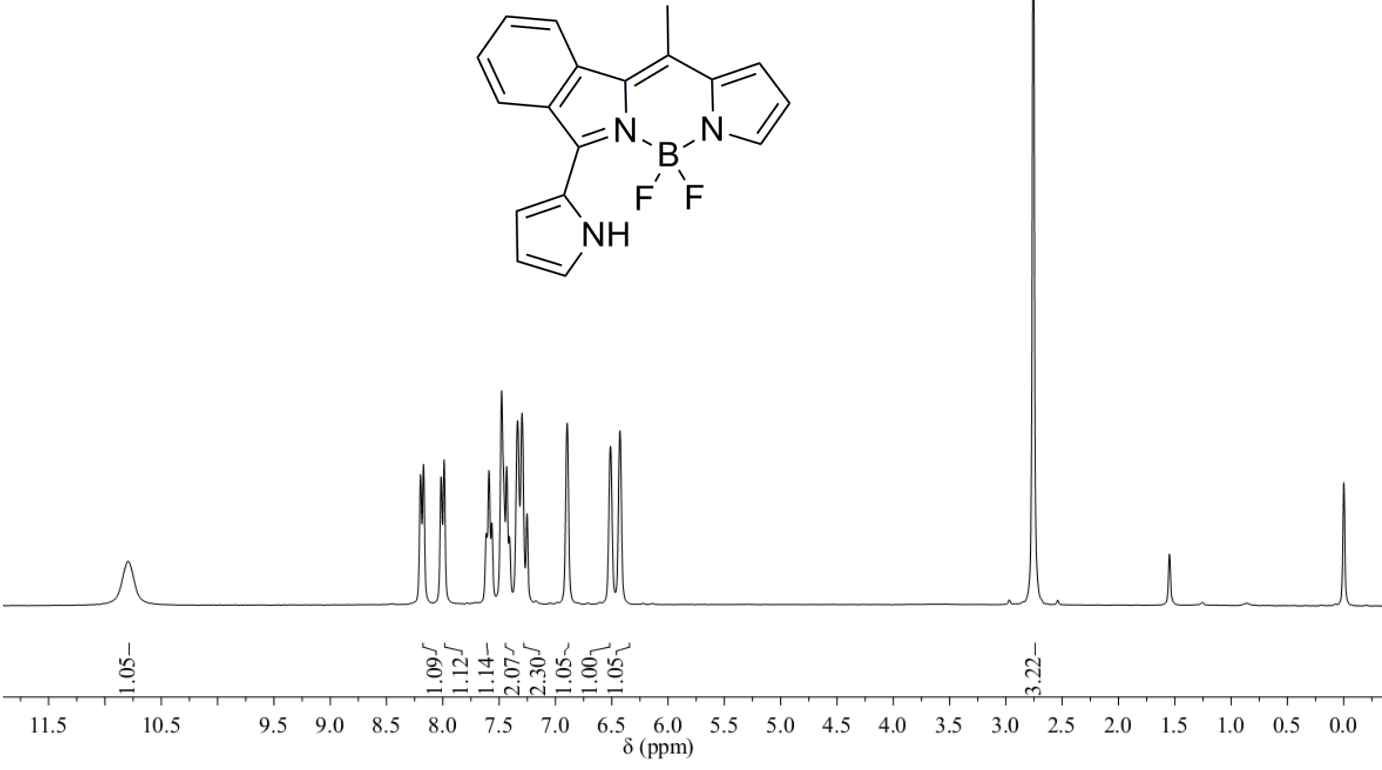

${ }^{1} \mathrm{H}$ NMR of isoindole BODIPY $\mathbf{1 f}$ in $\mathrm{CDCl}_{3}$ 


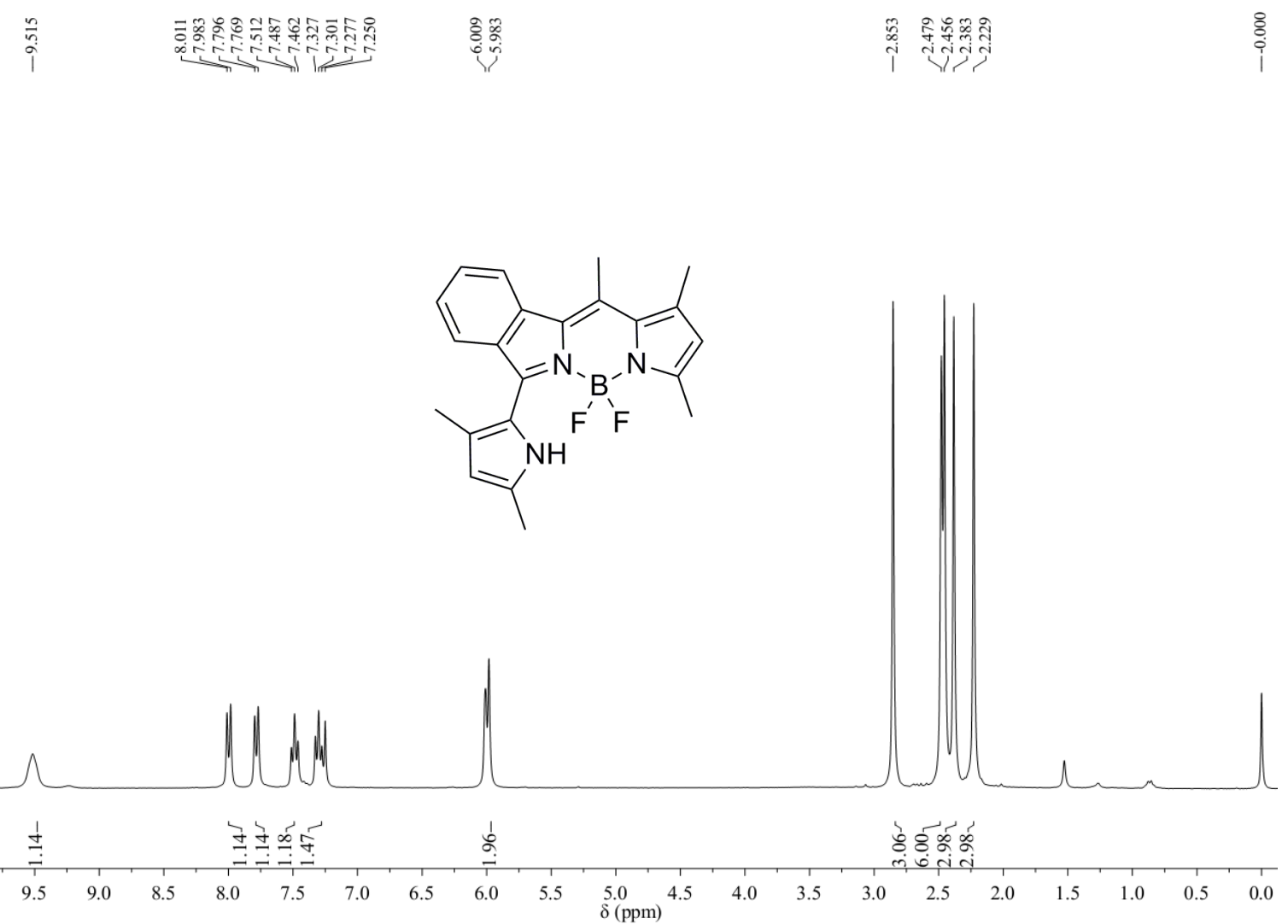

${ }^{1} \mathrm{H}$ NMR of isoindole BODIPY $\mathbf{1 g}$ in $\mathrm{CDCl}_{3}$

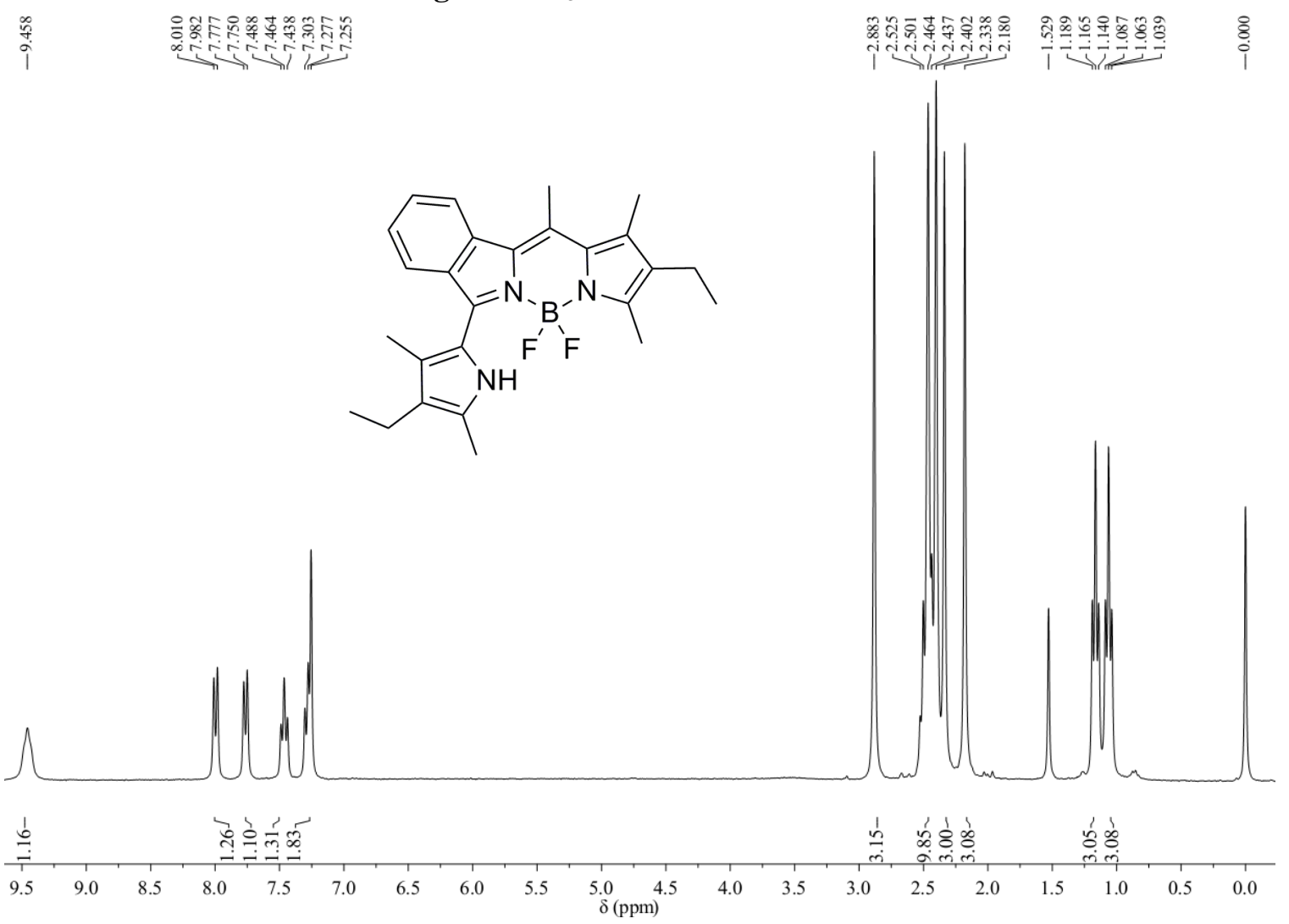

${ }^{1} \mathrm{H}$ NMR of isoindole BODIPY $\mathbf{1 h}$ in $\mathrm{CDCl}_{3}$ 


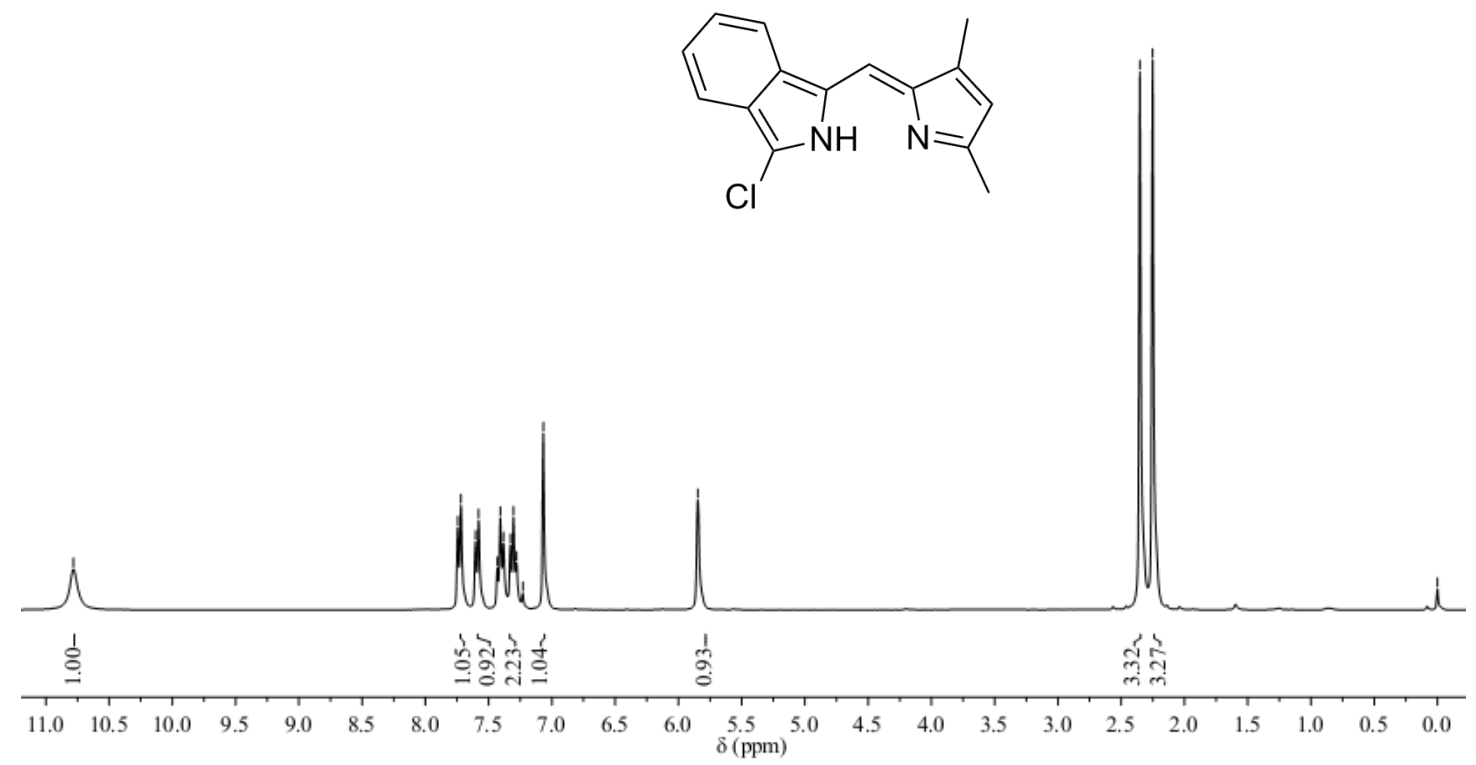

${ }^{1} \mathrm{H} \mathrm{NMR}$ of compound $\mathbf{6 a}$ in $\mathrm{CDCl}_{3}$
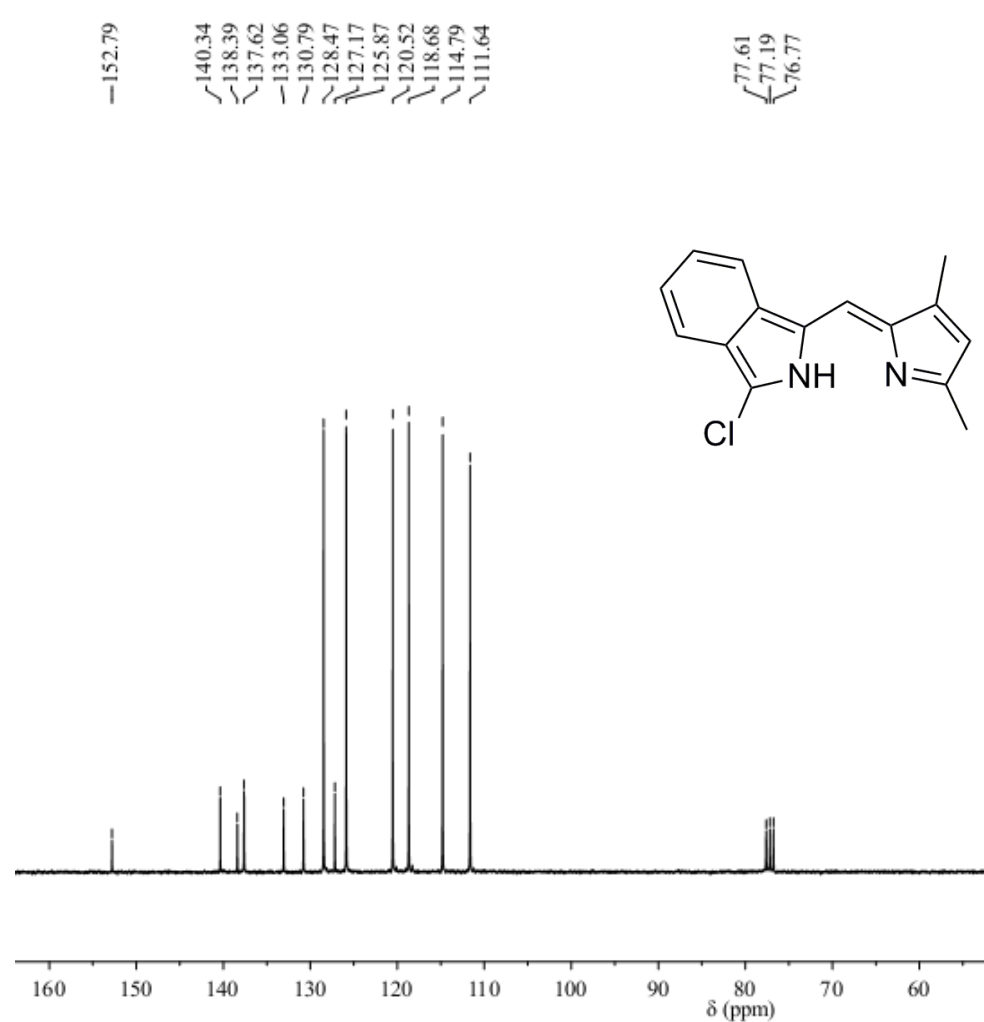

${ }^{13} \mathrm{C}$ NMR of compound $6 \mathbf{a}$ in $\mathrm{CDCl}_{3}$ 


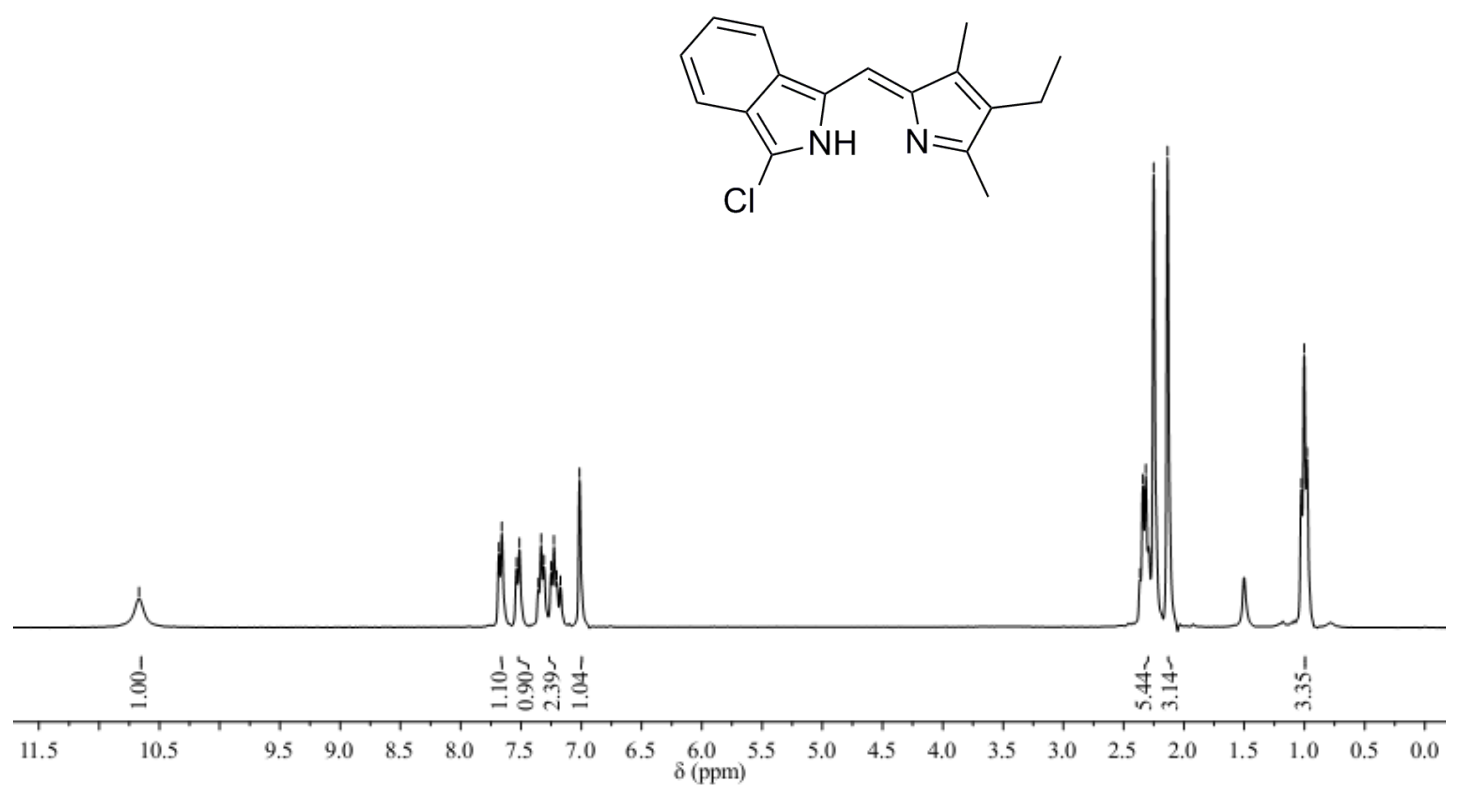

${ }^{1} \mathrm{H}$ NMR of compound $\mathbf{6 b}$ in $\mathrm{CDCl}_{3}$
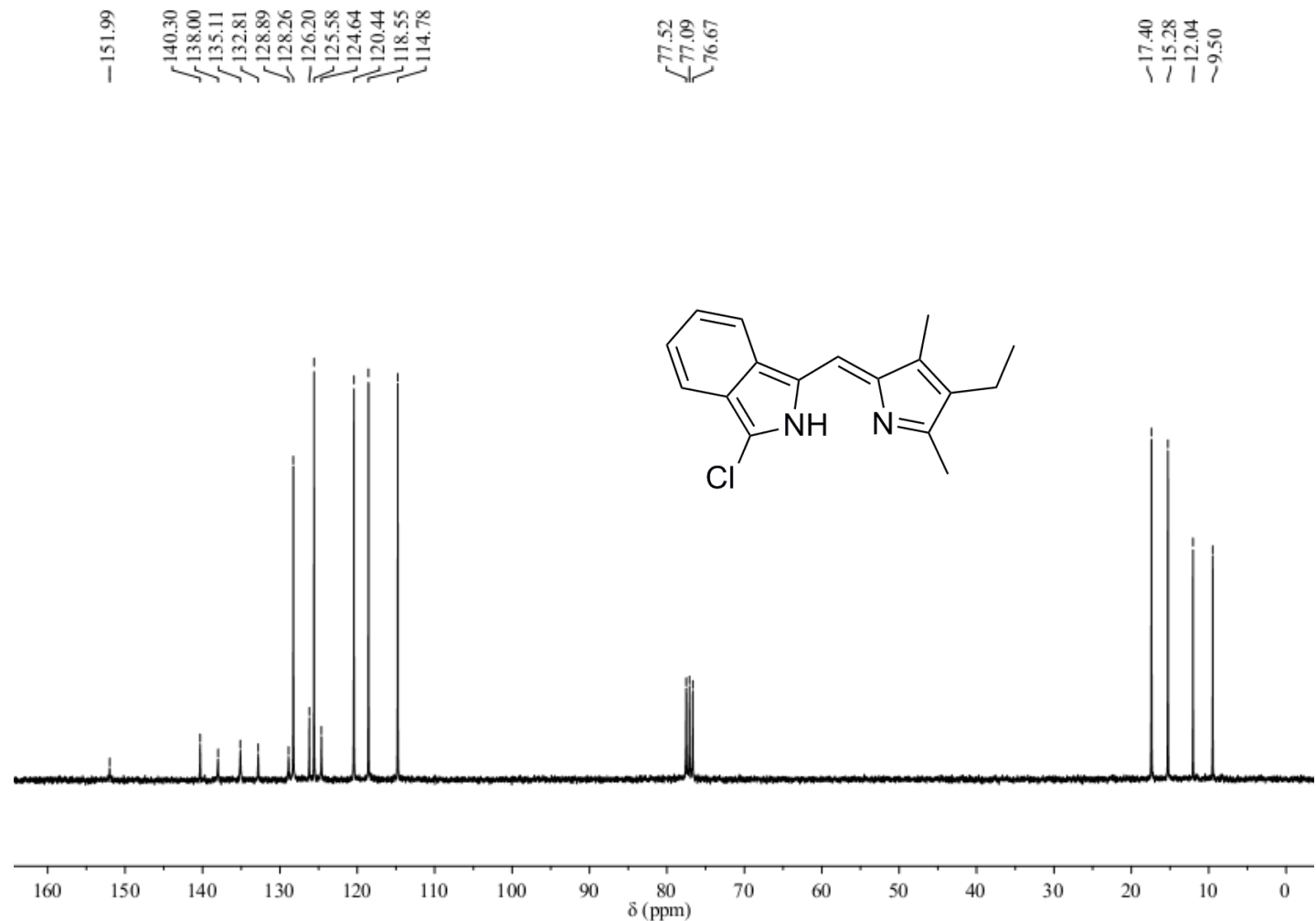

${ }^{13} \mathrm{C}$ NMR of compound $\mathbf{6 b}$ in $\mathrm{CDCl}_{3}$ 

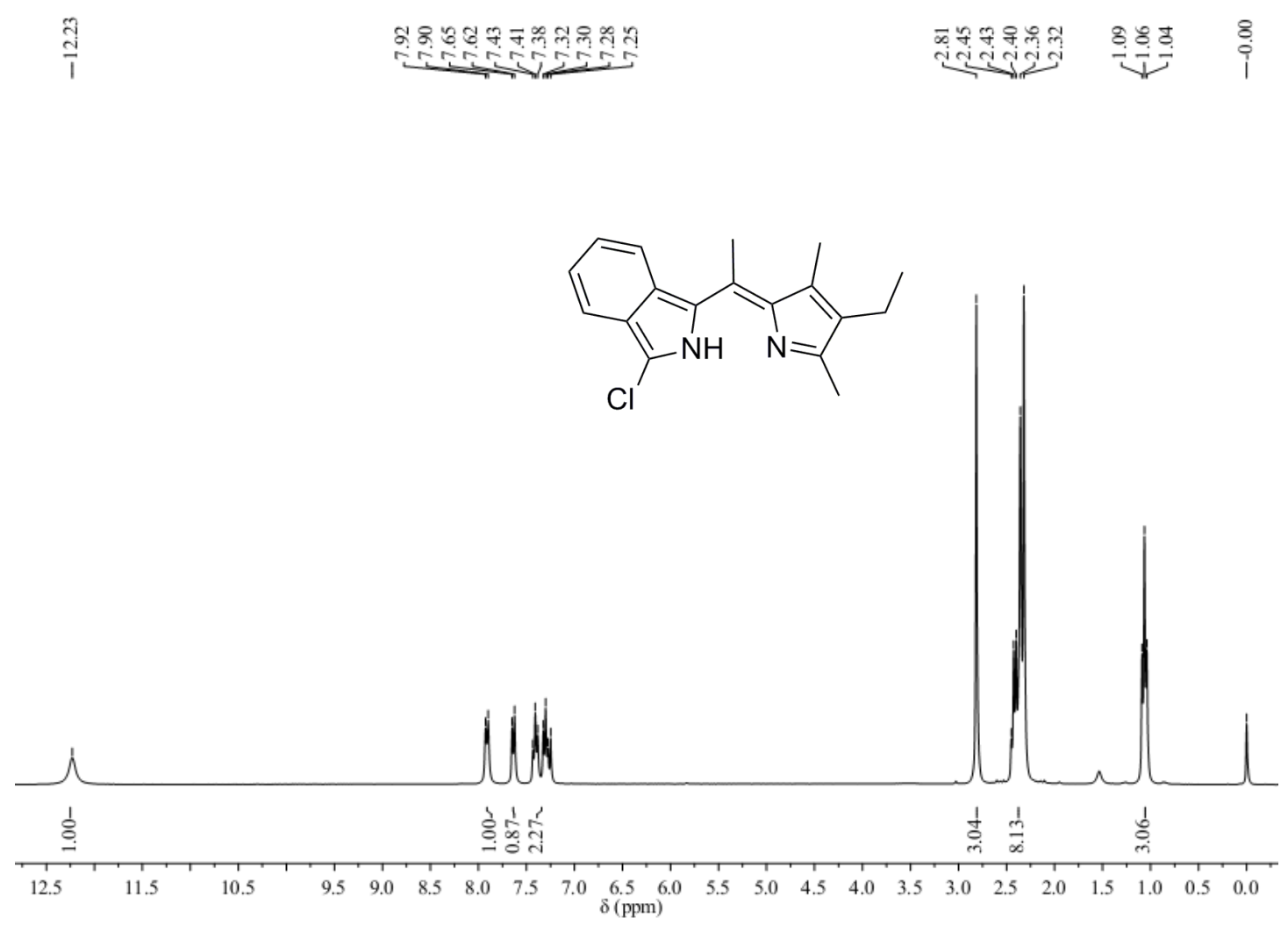

${ }^{1} \mathrm{H}$ NMR of compound $\mathbf{6} \mathbf{c}$ in $\mathrm{CDCl}_{3}$
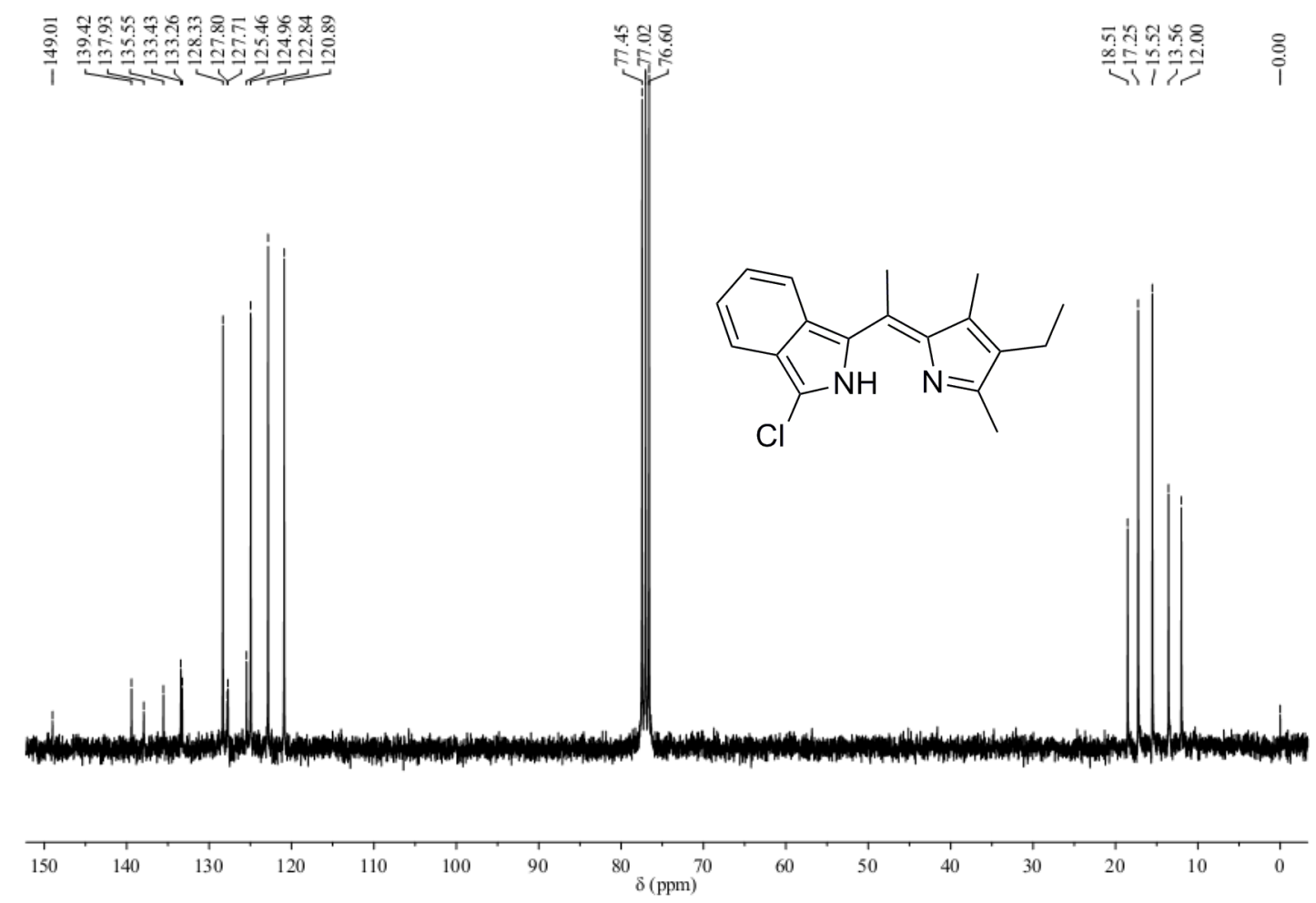

${ }^{13} \mathrm{C}$ NMR of compound $\mathbf{6 c}$ in $\mathrm{CDCl}_{3}$ 


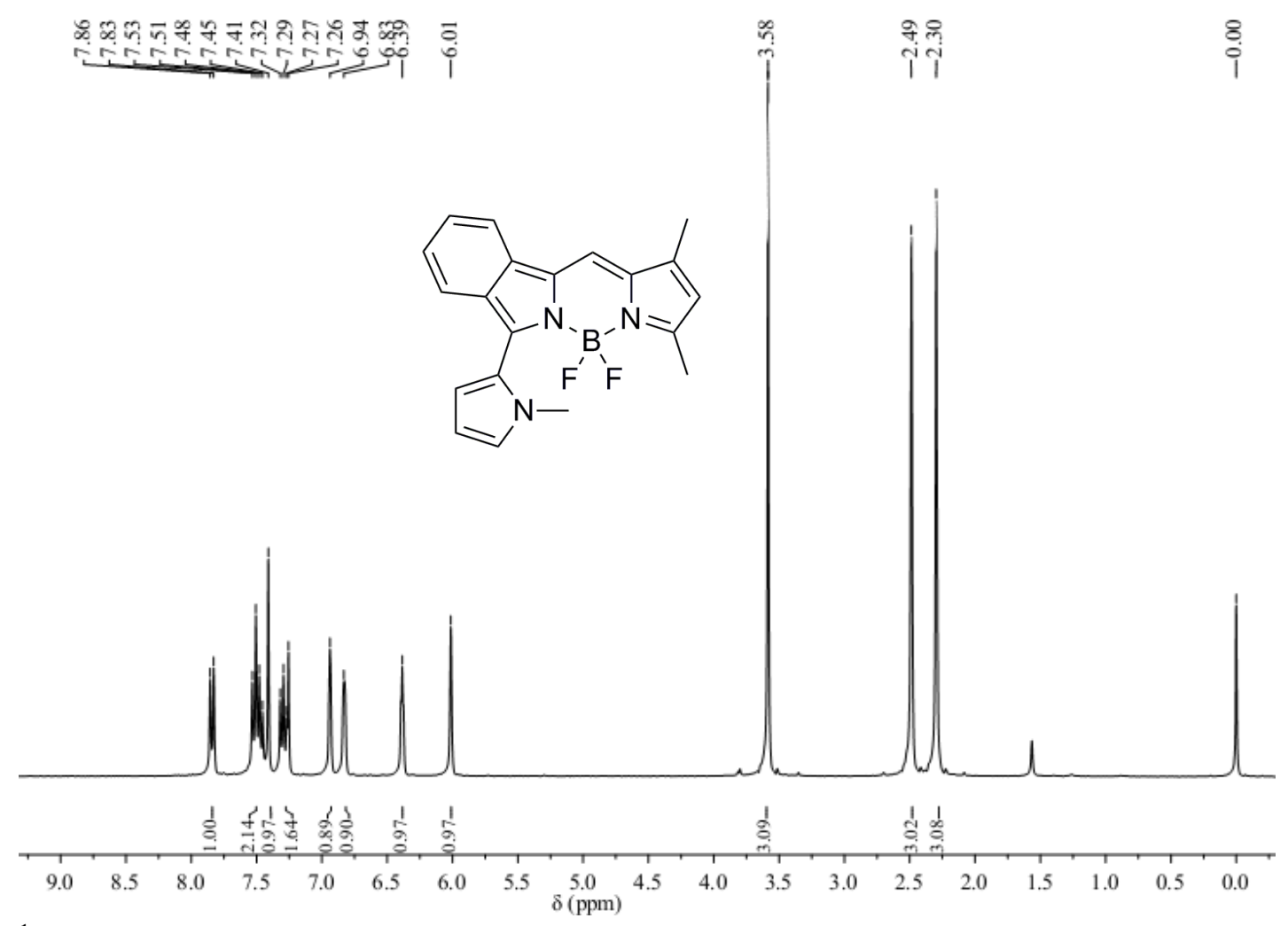

${ }^{1} \mathrm{H}$ NMR of isoindole BODIPY $\mathbf{5 b}$ in $\mathrm{CDCl}_{3}$
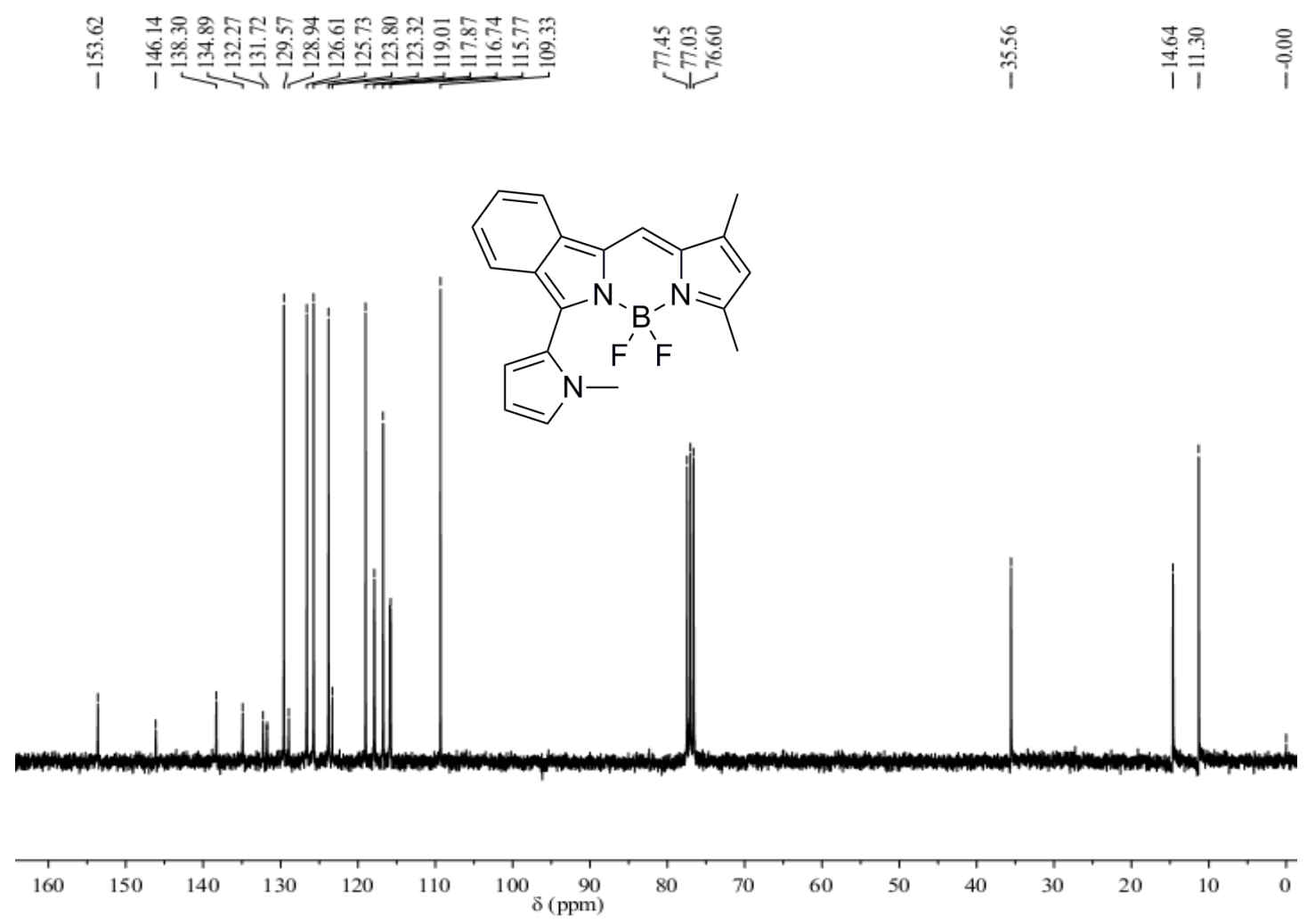

${ }^{13} \mathrm{C}$ NMR of isoindole BODIPY $\mathbf{5 b}$ in $\mathrm{CDCl}_{3}$ 


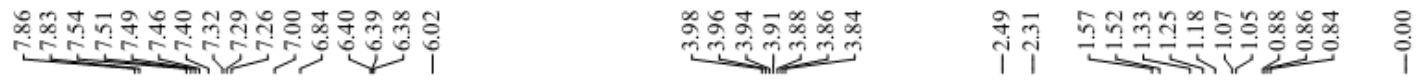

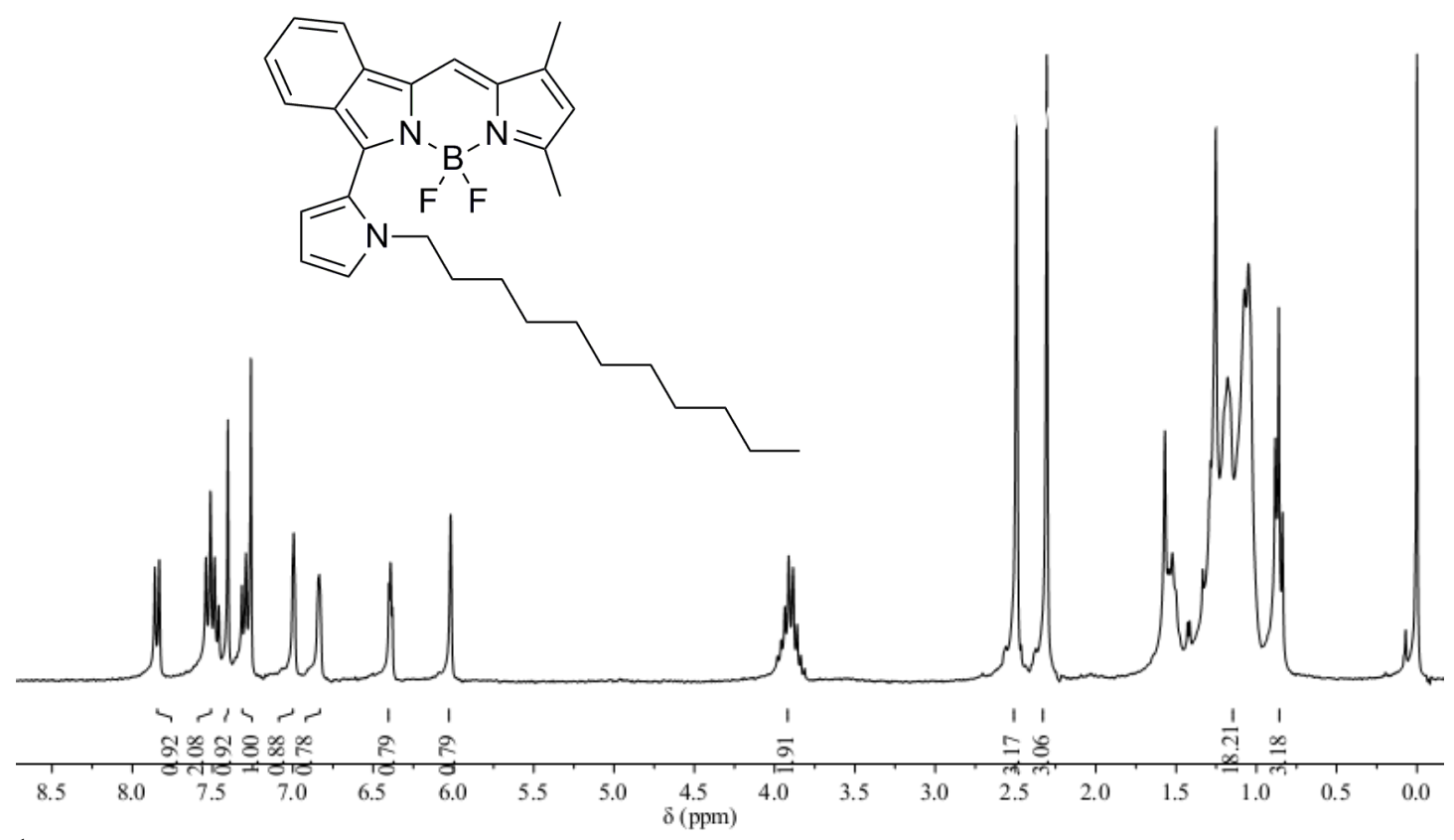

${ }^{1} \mathrm{H}$ NMR of isoindole BODIPY $\mathbf{5 c}$ in $\mathrm{CDCl}_{3}$

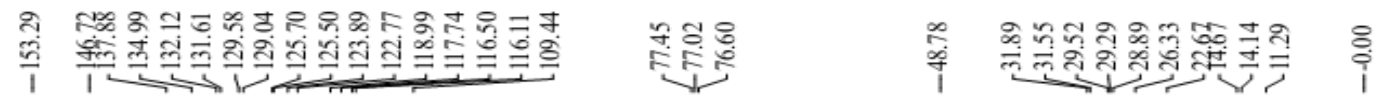
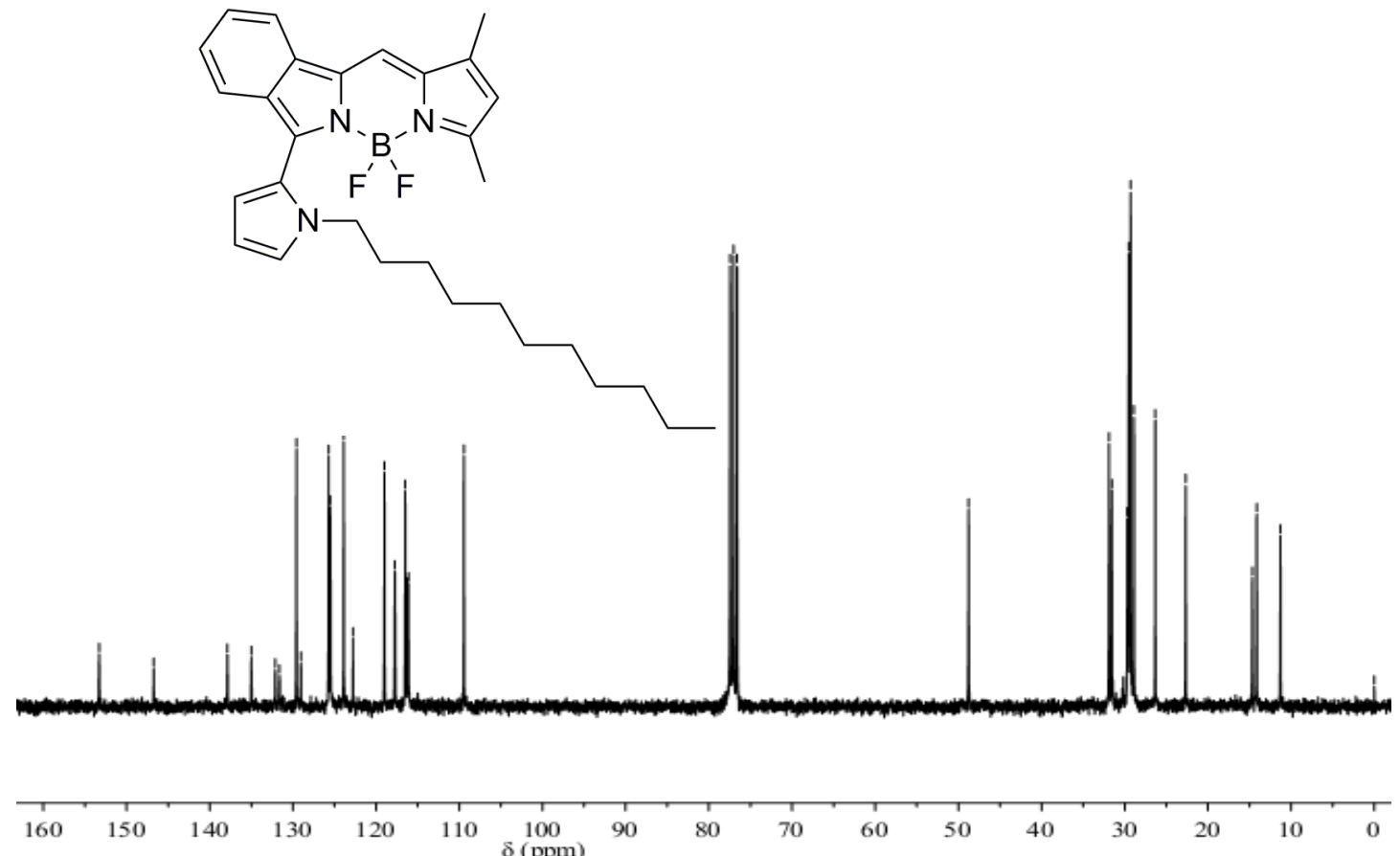

${ }^{13} \mathrm{C}$ NMR of isoindole BODIPY $\mathbf{5 c}$ in $\mathrm{CDCl}_{3}$ 


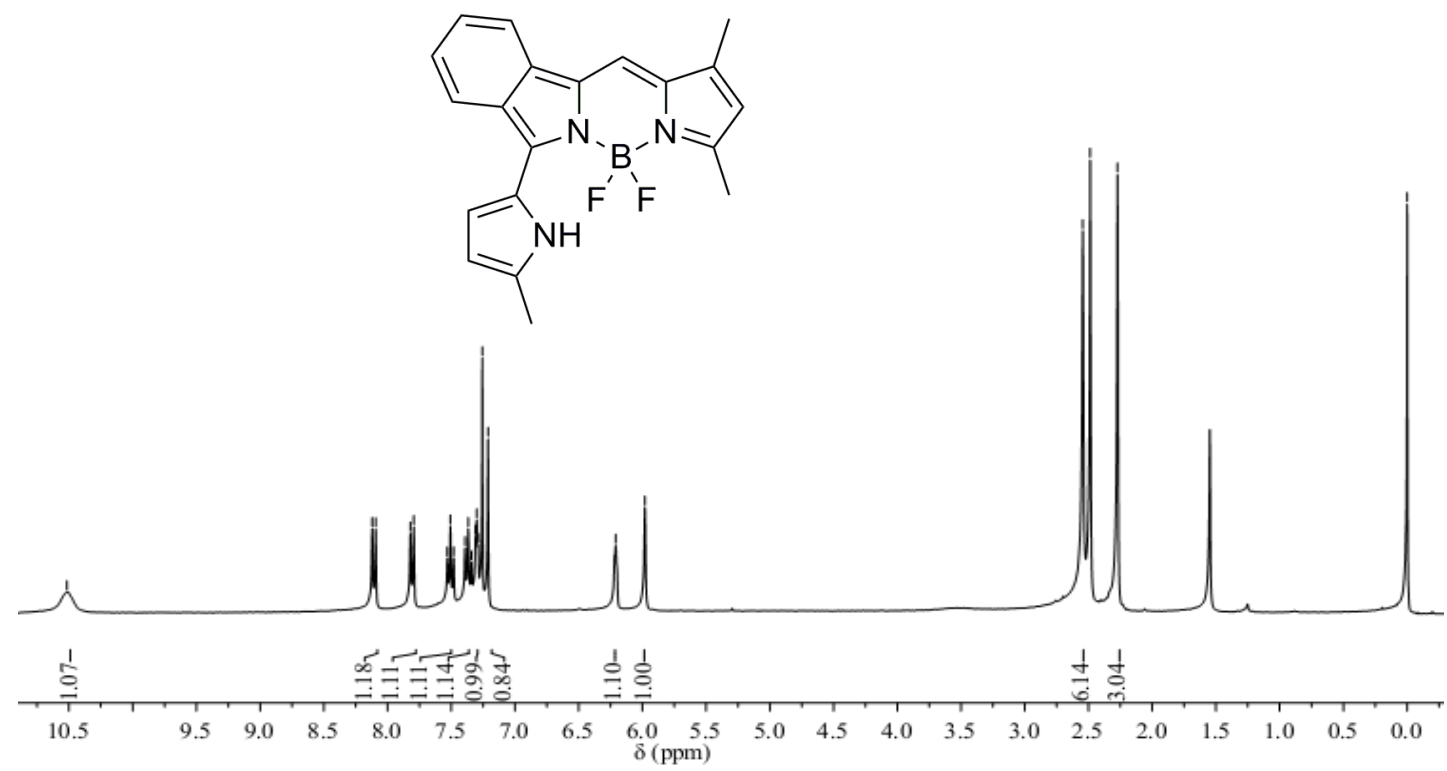

${ }^{1} \mathrm{H}$ NMR of isoindole BODIPY $\mathbf{5 d}$ in $\mathrm{CDCl}_{3}$

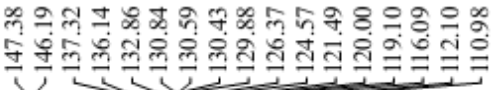
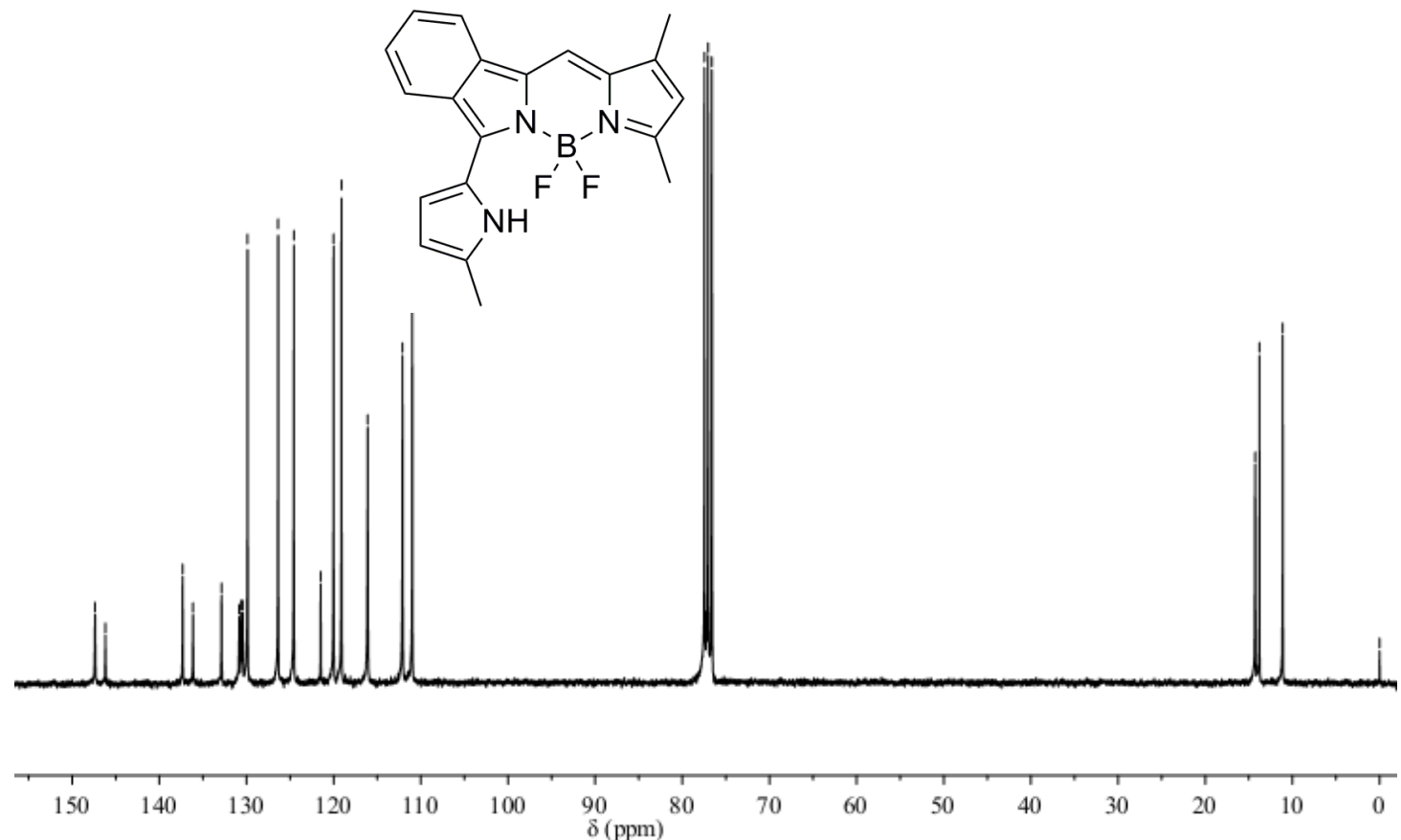

${ }^{13} \mathrm{C}$ NMR of isoindole BODIPY $\mathbf{5 d}$ in $\mathrm{CDCl}_{3}$ 


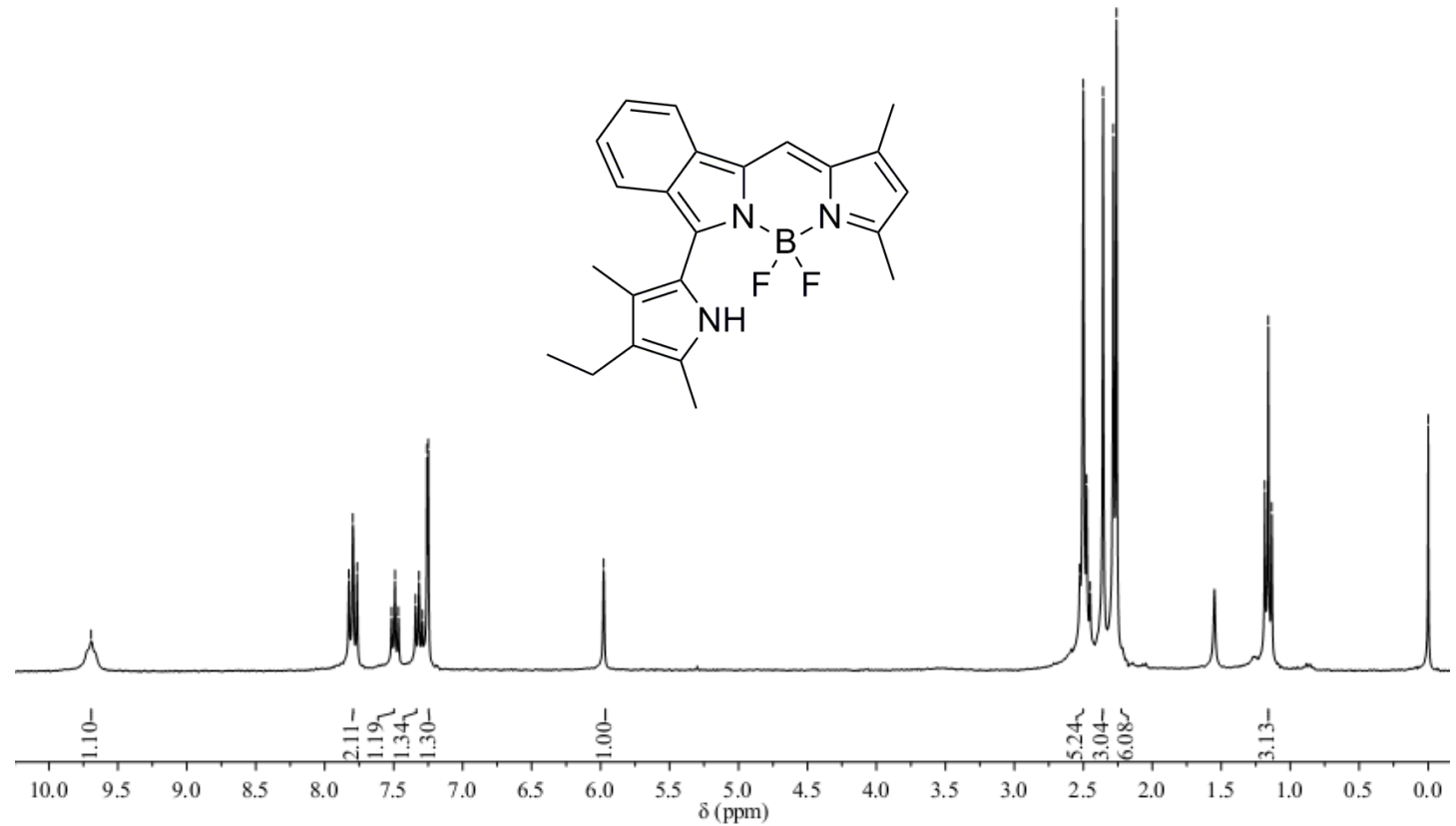

${ }^{1} \mathrm{H}$ NMR of isoindole BODIPY 5e in $\mathrm{CDCl}_{3}$
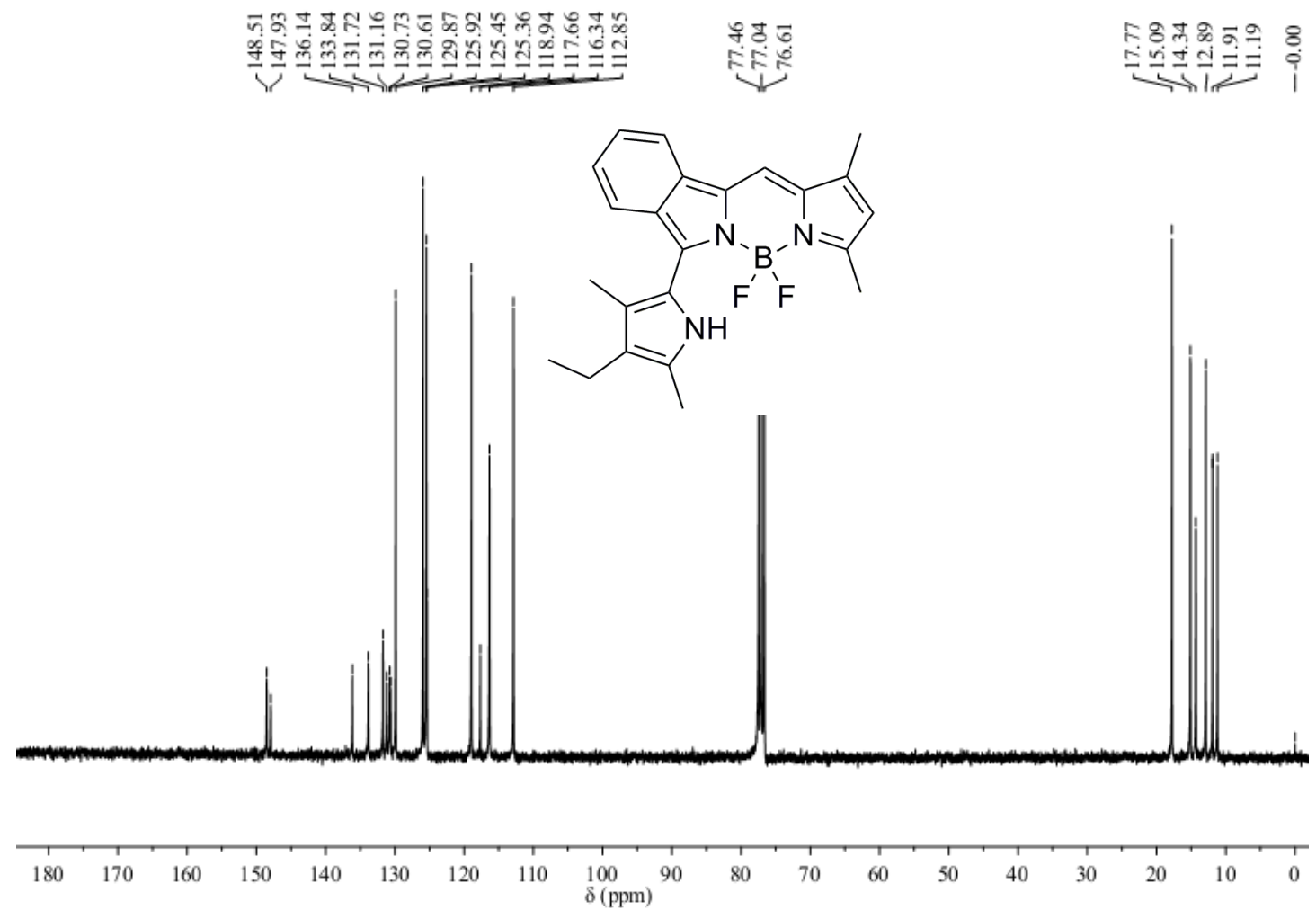

${ }^{13} \mathrm{C}$ NMR of isoindole BODIPY 5e in $\mathrm{CDCl}_{3}$ 

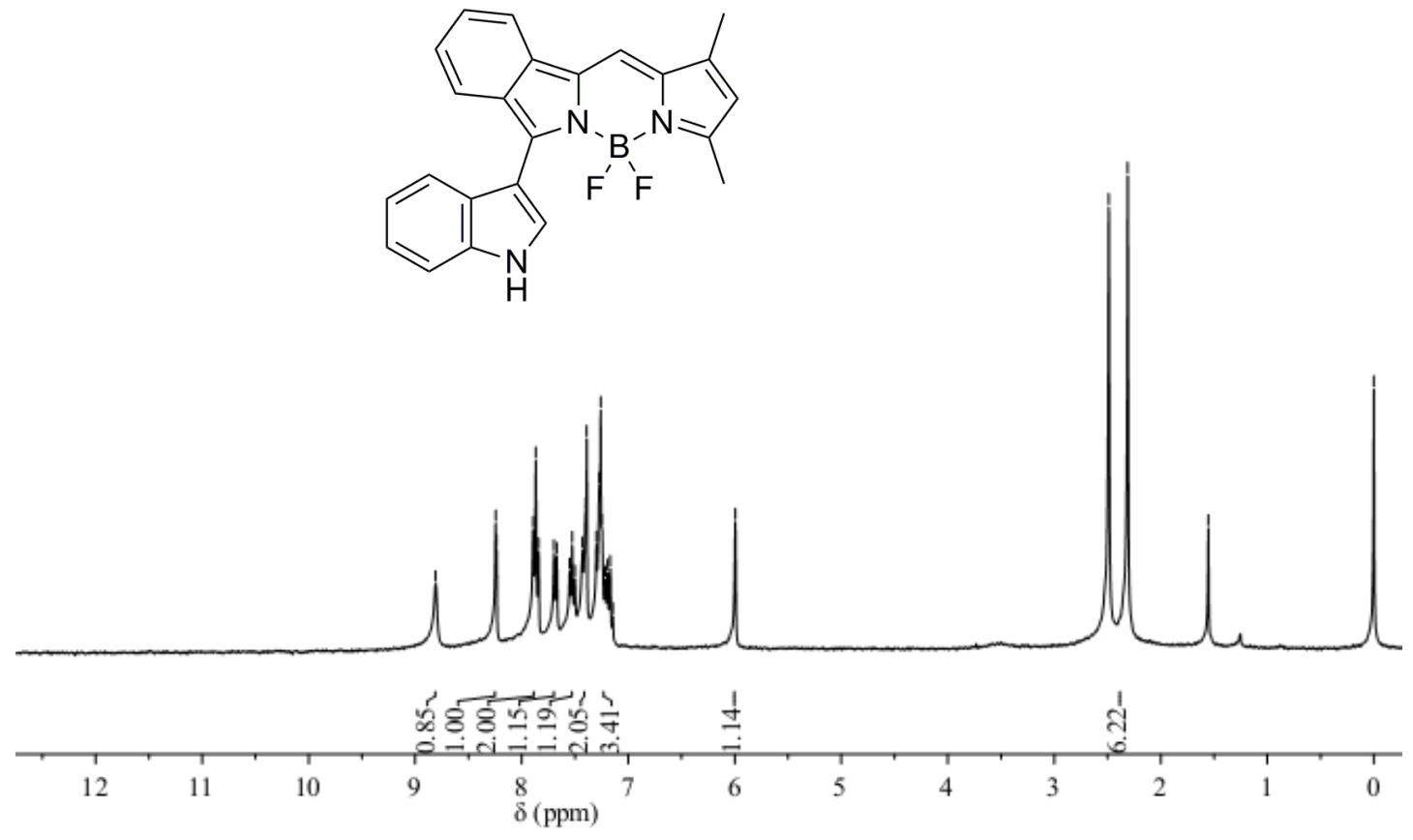

${ }^{1} \mathrm{H}$ NMR of isoindole BODIPY $\mathbf{5 f}$ in $\mathrm{CDCl}_{3}$

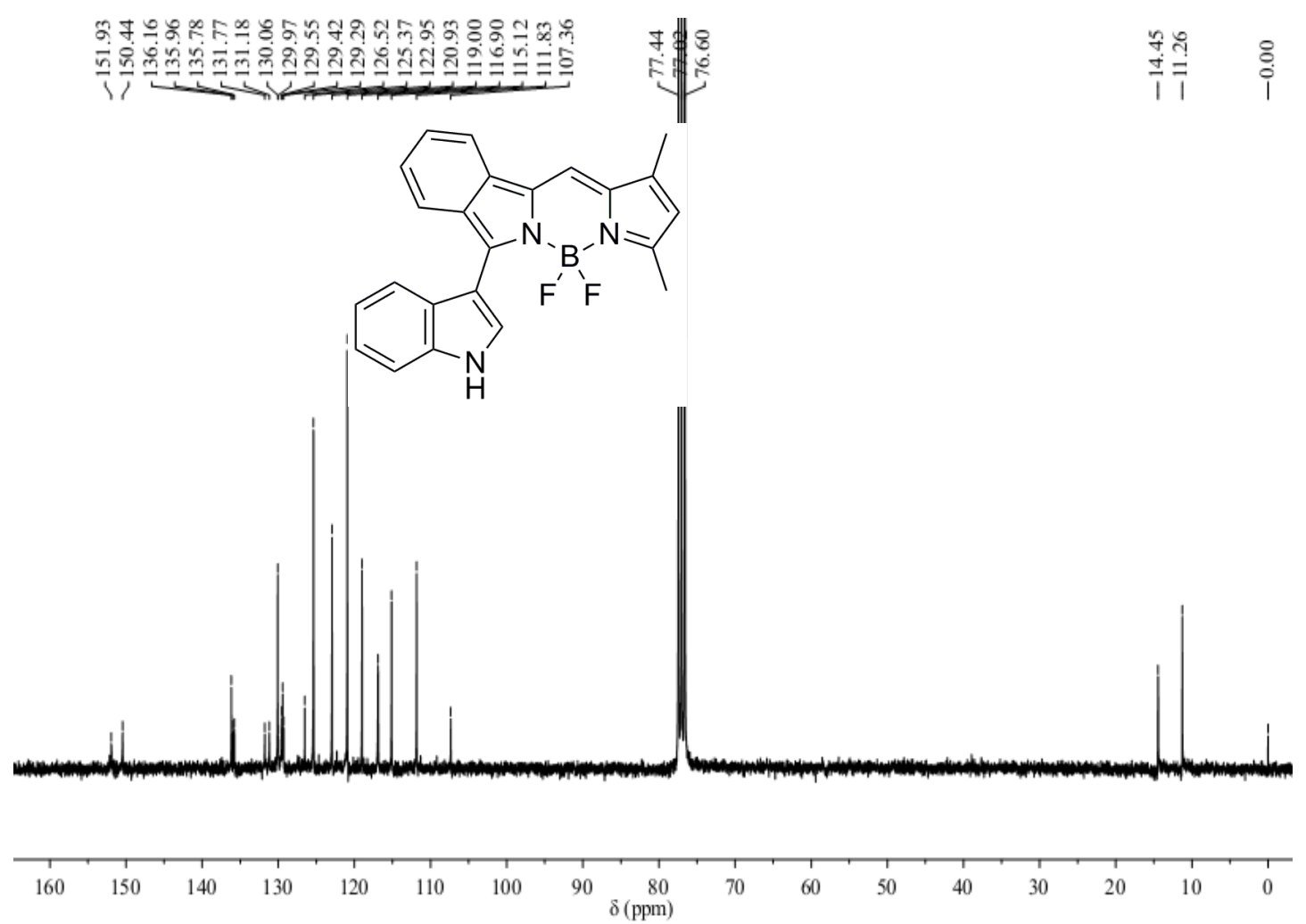

${ }^{13} \mathrm{C}$ NMR of isoindole BODIPY $\mathbf{5 f}$ in $\mathrm{CDCl}_{3}$ 


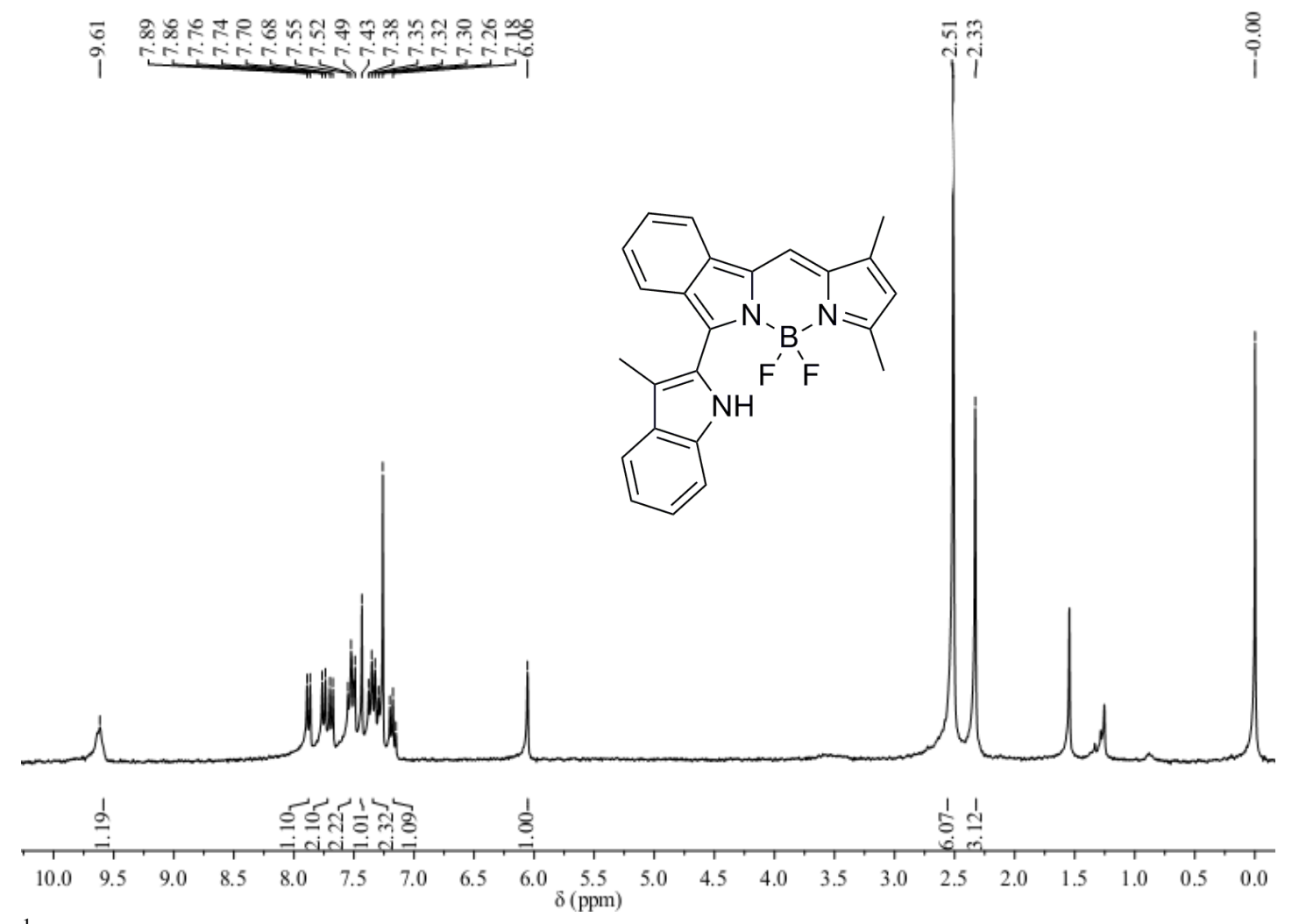

${ }^{1} \mathrm{H}$ NMR of isoindole BODIPY $\mathbf{5 g}$ in $\mathrm{CDCl}_{3}$
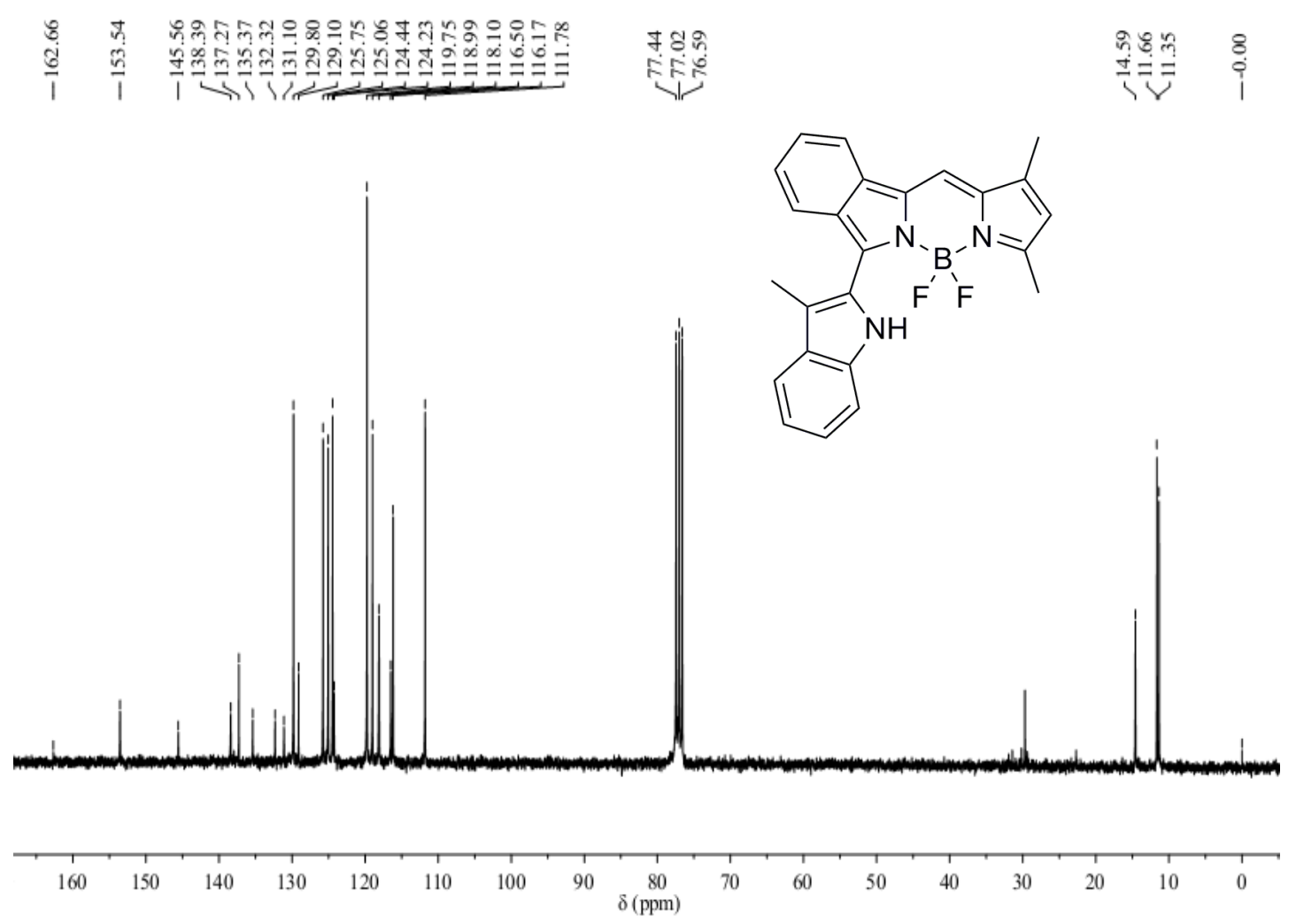

${ }^{13} \mathrm{C}$ NMR of isoindole BODIPY $\mathbf{5 g}$ in $\mathrm{CDCl}_{3}$ 


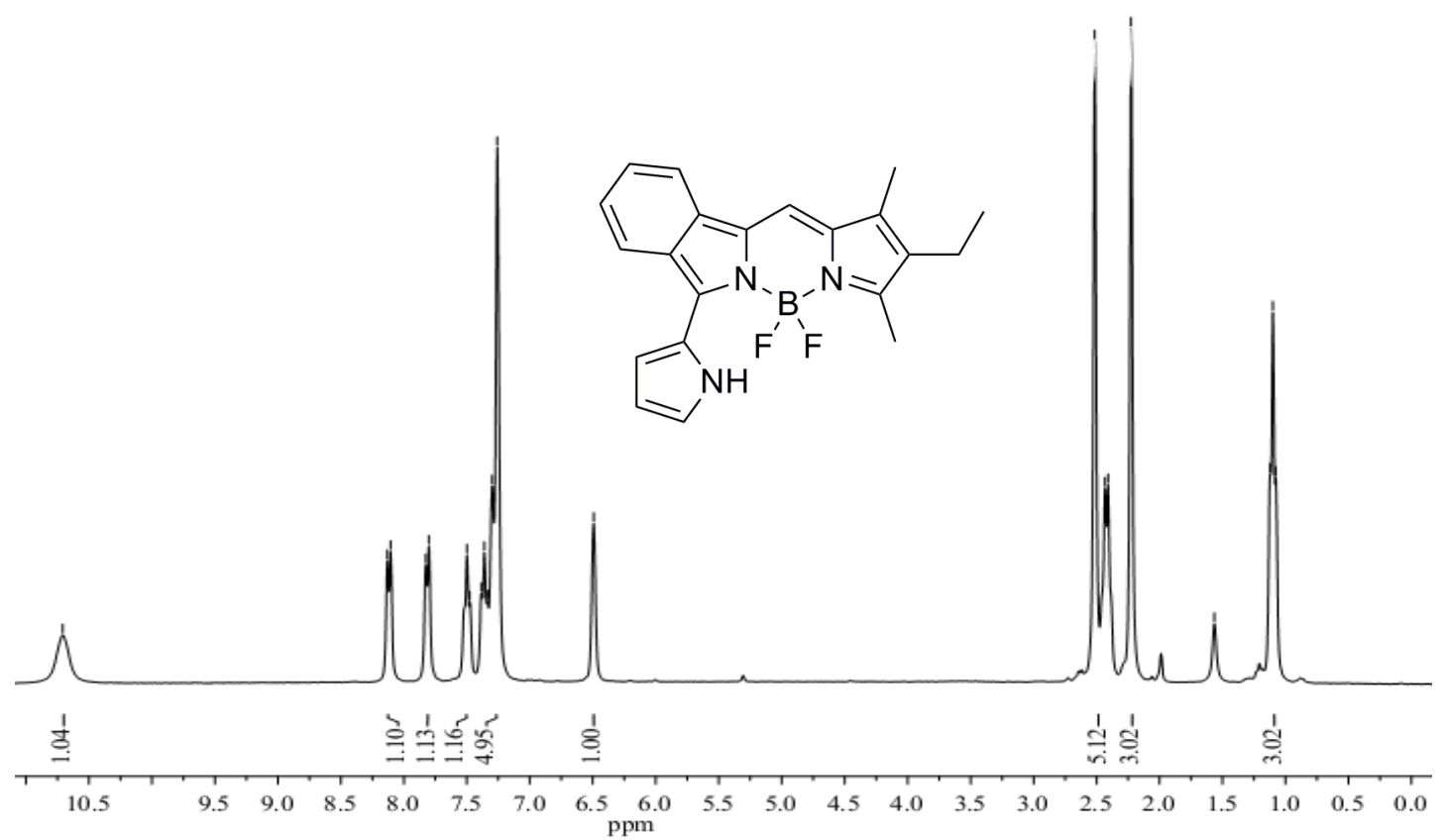

${ }^{1} \mathrm{H}$ NMR of isoindole BODIPY $\mathbf{5 h}$ in $\mathrm{CDCl}_{3}$

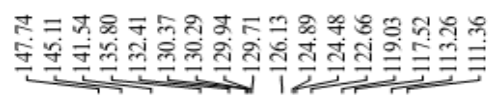

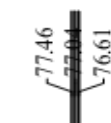

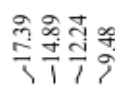
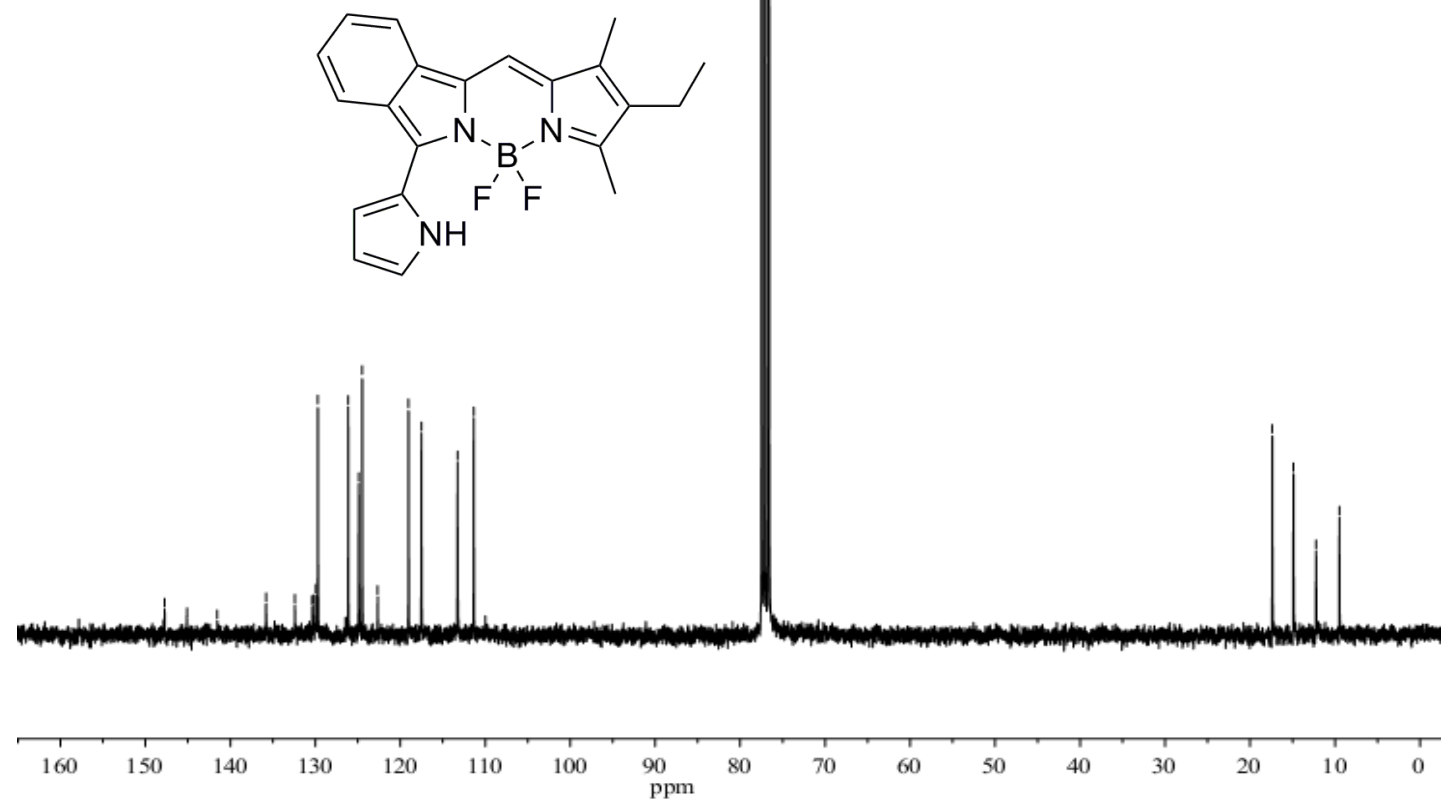

${ }^{13} \mathrm{C}$ NMR of isoindole BODIPY $\mathbf{5 h}$ in $\mathrm{CDCl}_{3}$ 

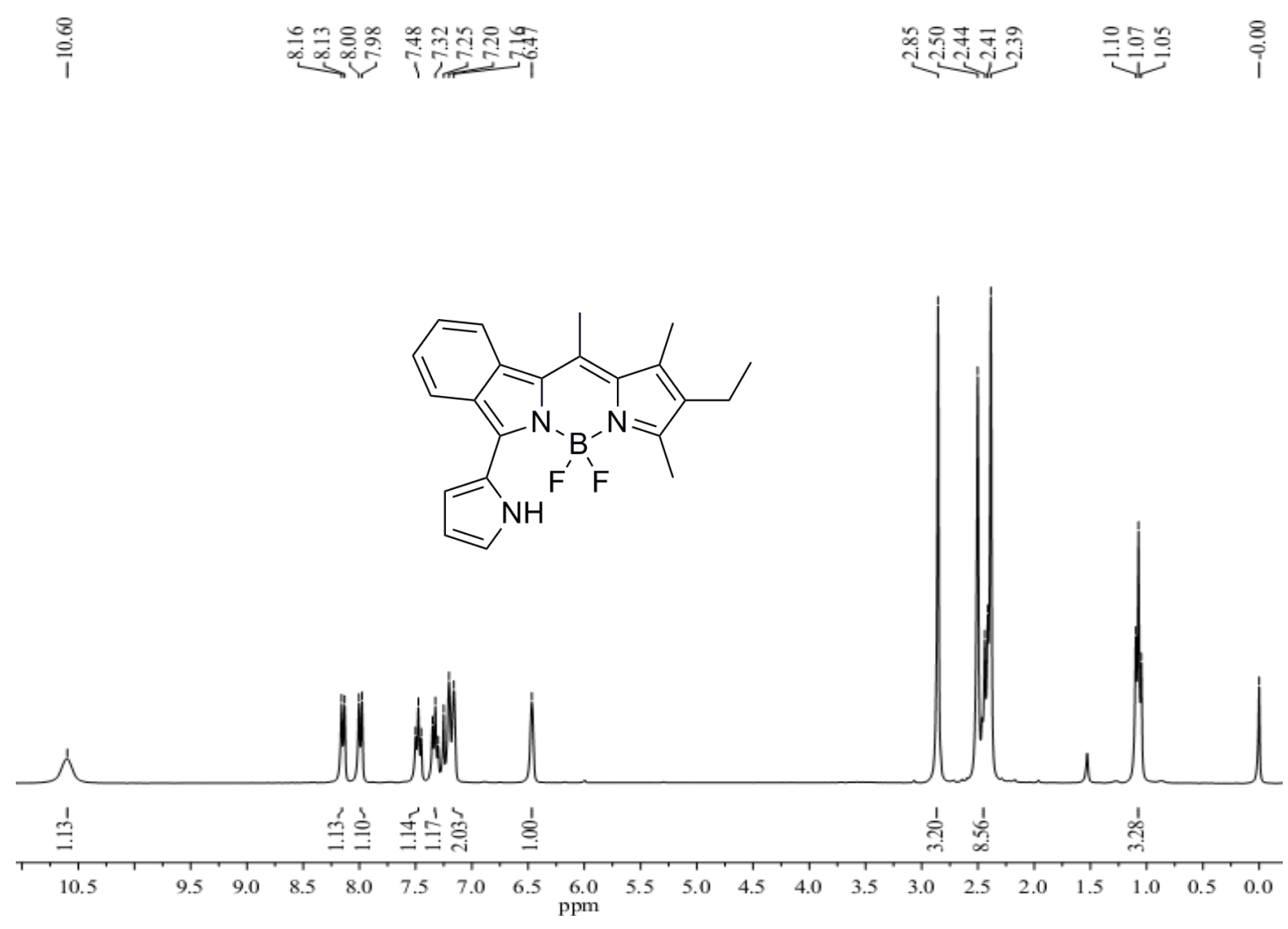

${ }^{1} \mathrm{H}$ NMR of isoindole BODIPY $\mathbf{5 i}$ in $\mathrm{CDCl}_{3}$

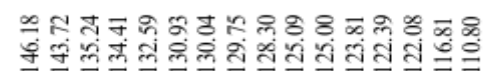
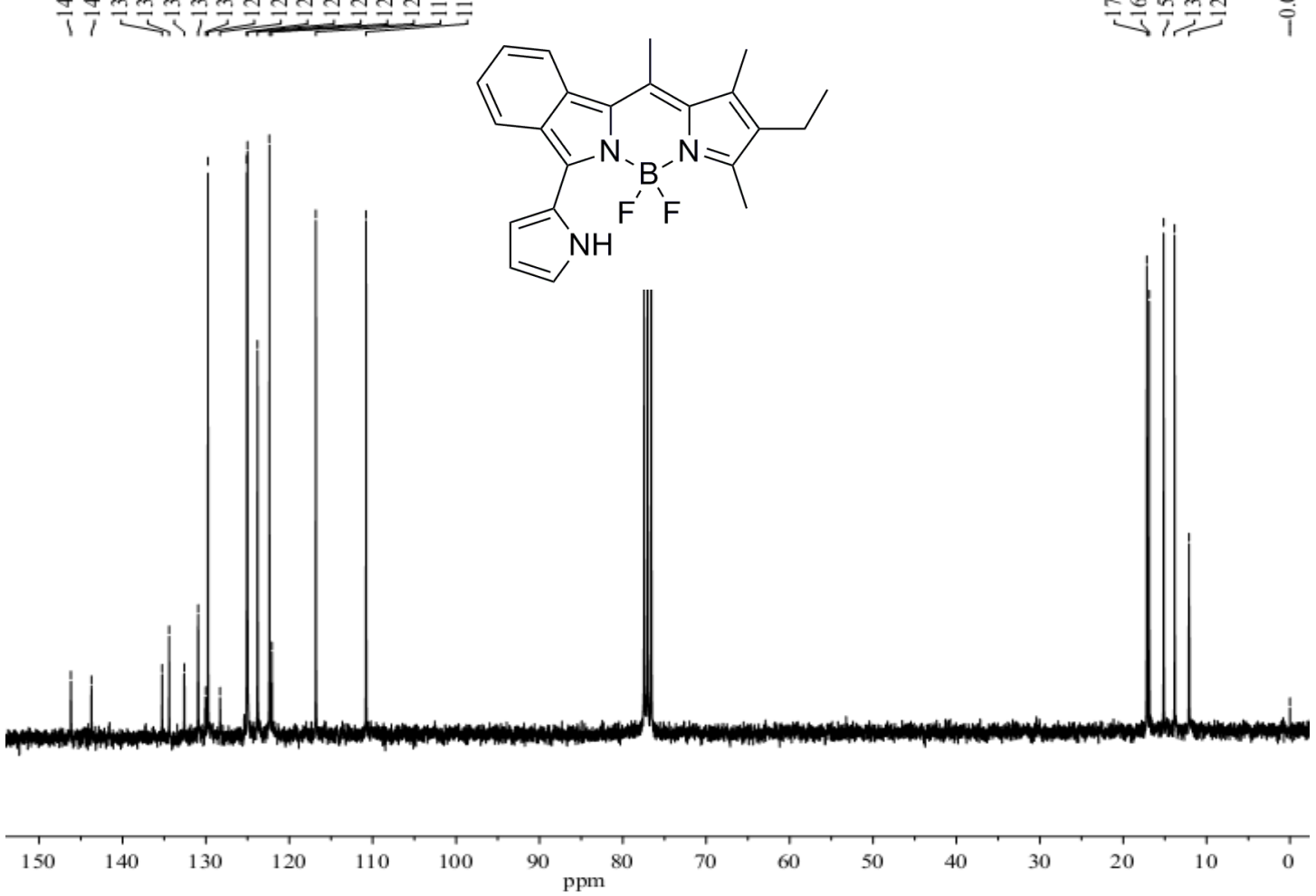

${ }^{13} \mathrm{C}$ NMR of isoindole BODIPY $5 \mathbf{i}$ in $\mathrm{CDCl}_{3}$ 


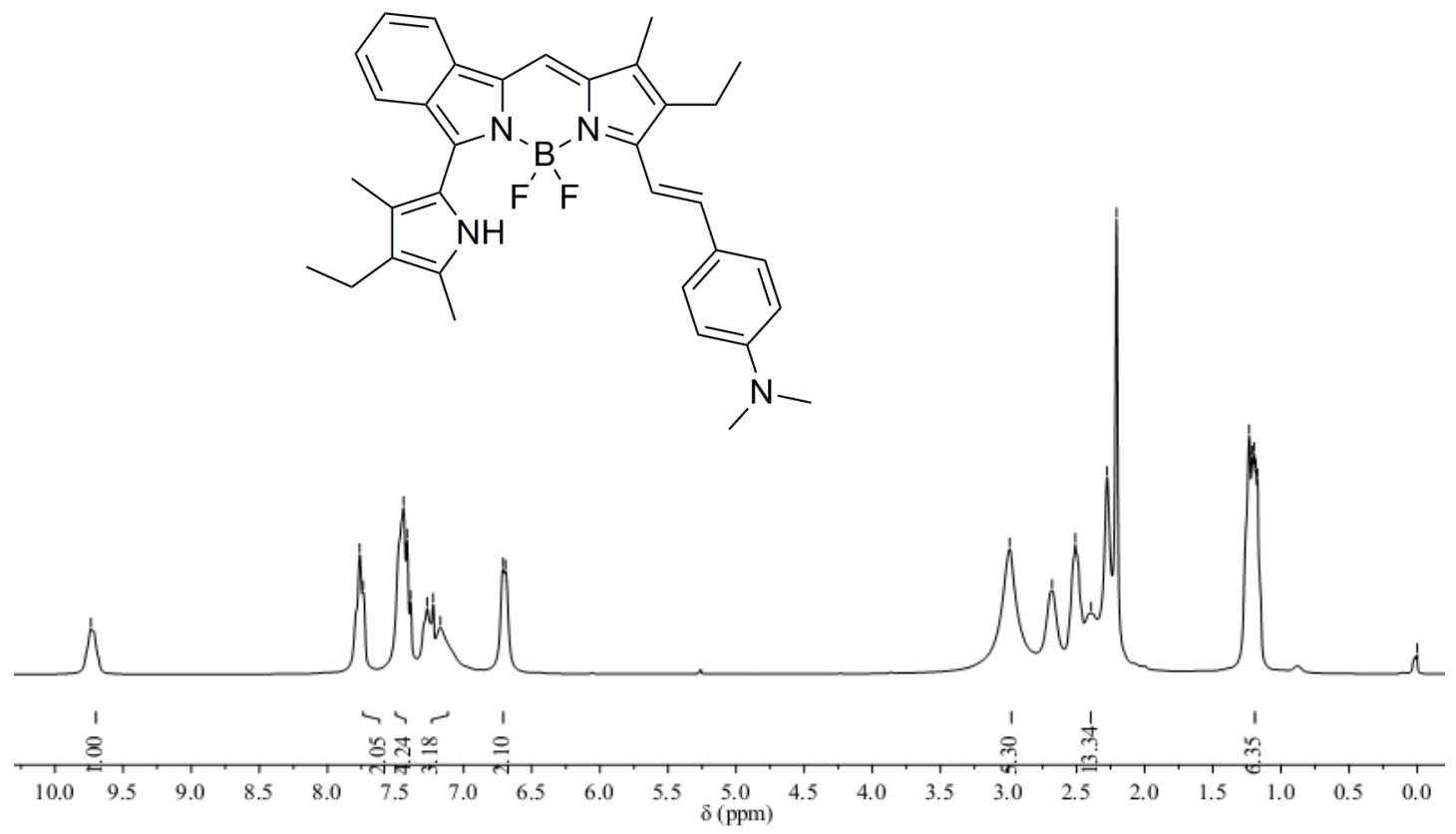

${ }^{1} \mathrm{H}$ NMR of isoindole BODIPY $7 \mathbf{f}$ in $\mathrm{CDCl}_{3}$
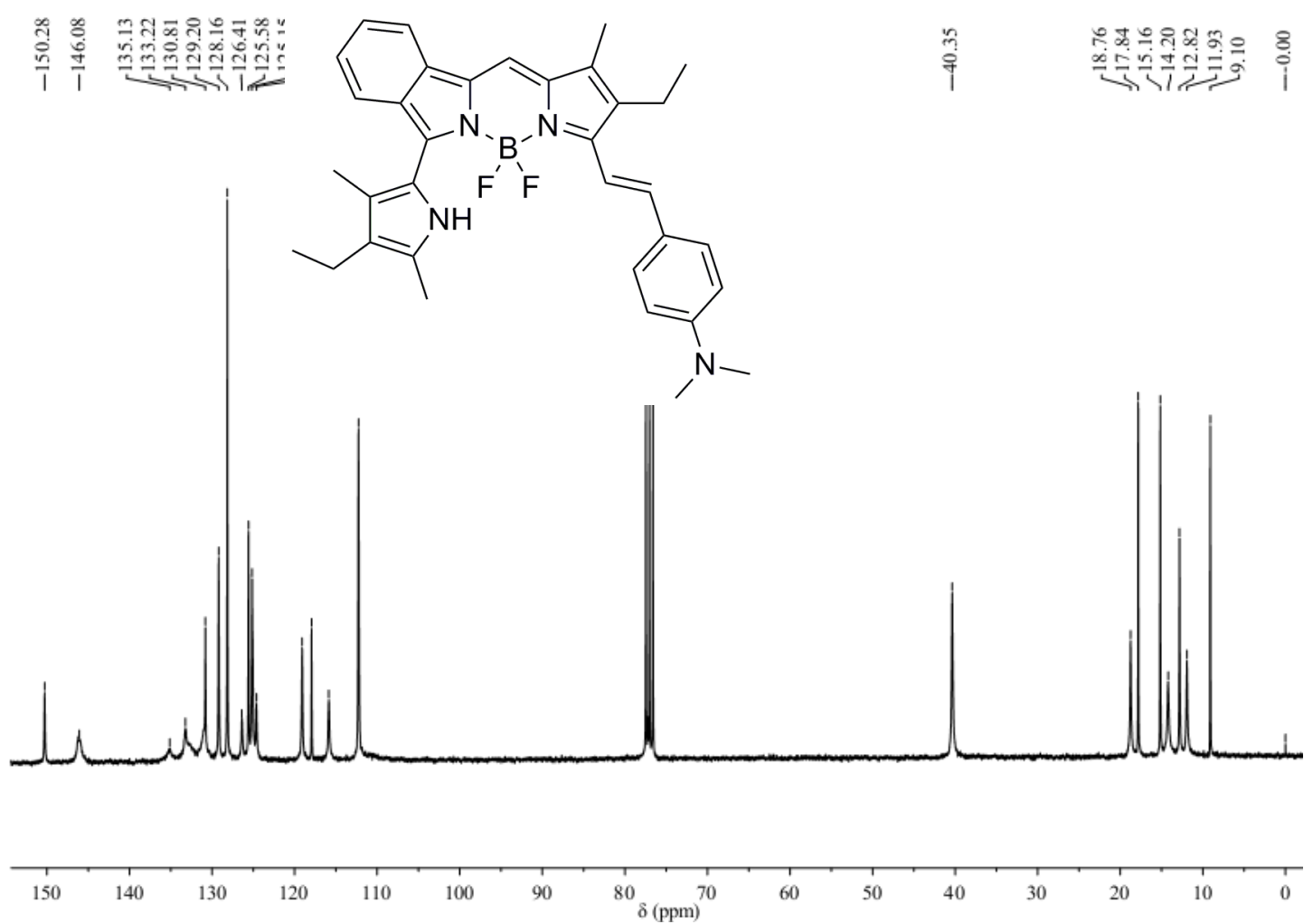

${ }^{13} \mathrm{C}$ NMR of isoindole BODIPY $7 f$ in $\mathrm{CDCl}_{3}$ 


\section{High resolution mass spectra}

\section{MS for compound $\mathbf{6 b}$}

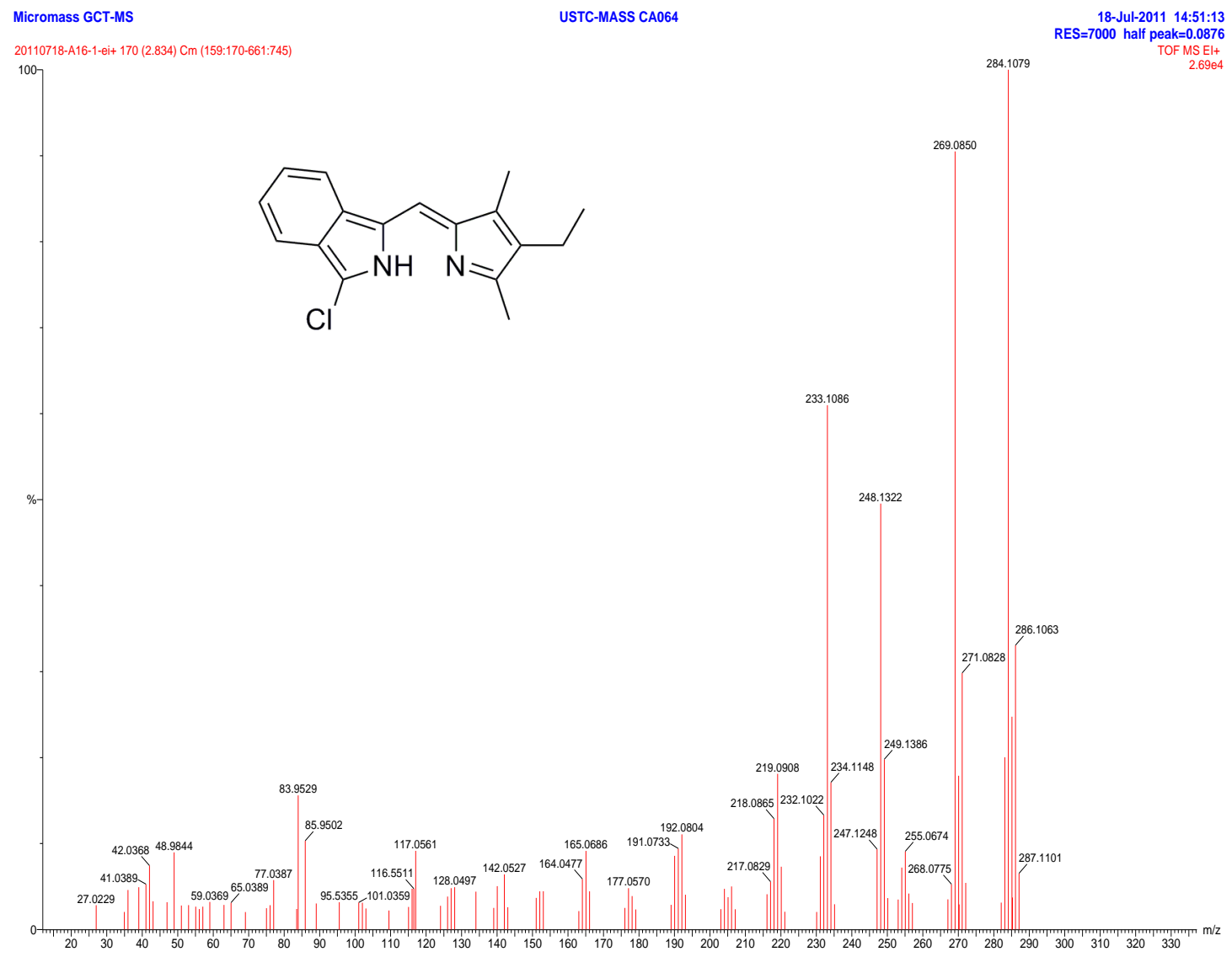

MS for compound $\mathbf{6 c}$

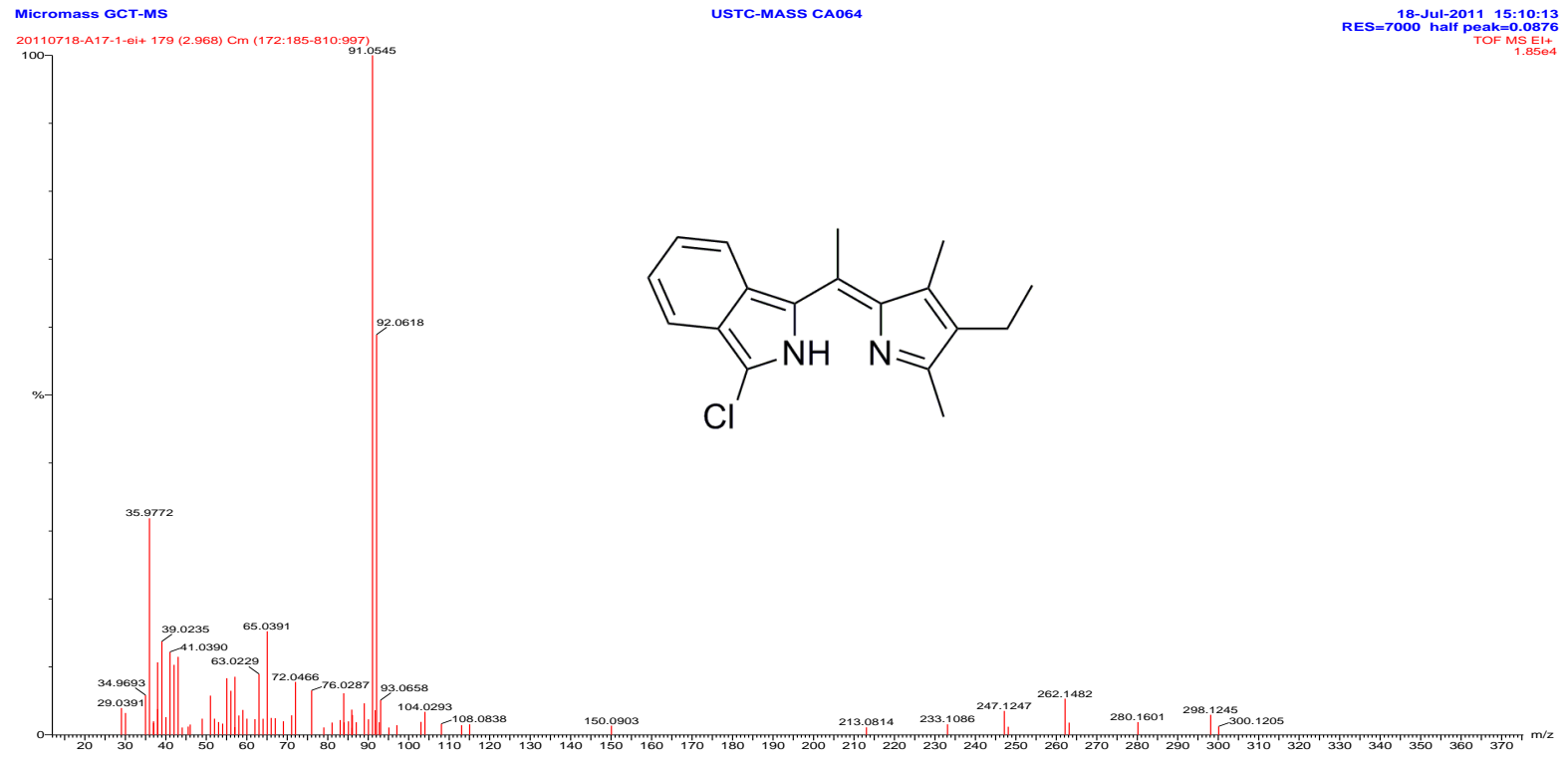




\section{MS for isoindole BODIPY $\mathbf{5 b}$}

20141230_APCI+Y8 \#16 RT: 0.22 AV: 1 NL: 4.24E7

T: FTMS + c APCI corona Full ms [200.00-1000.00]

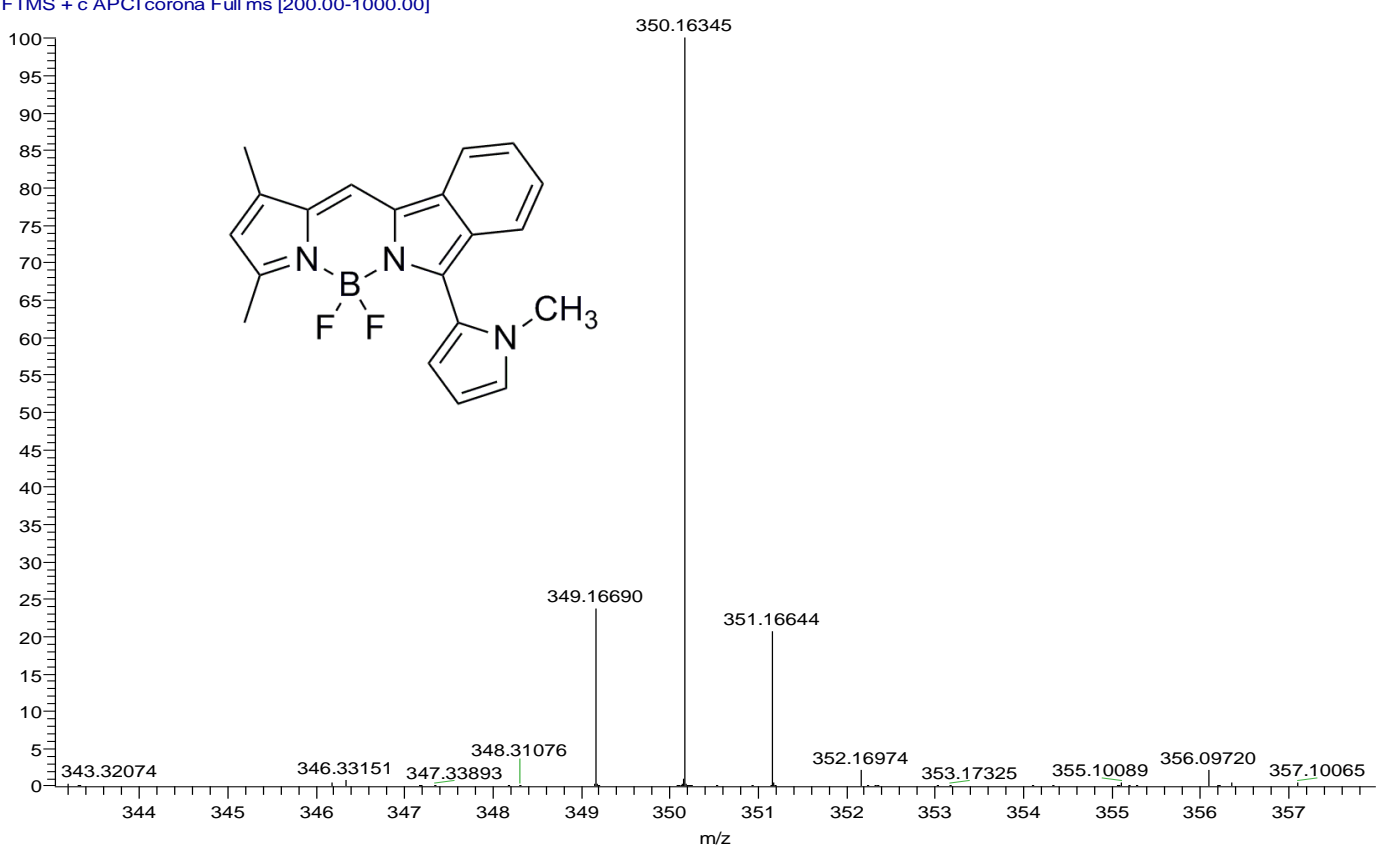

MS for isoindole BODIPY 5c

20140114_APCI+Y4 \#4 RT: 0.06 AV: 1 SB: 3 0.01-0.04 NL: 2.48E4
T:FTMS + + APCl corona Full ms [100.00-800.00]

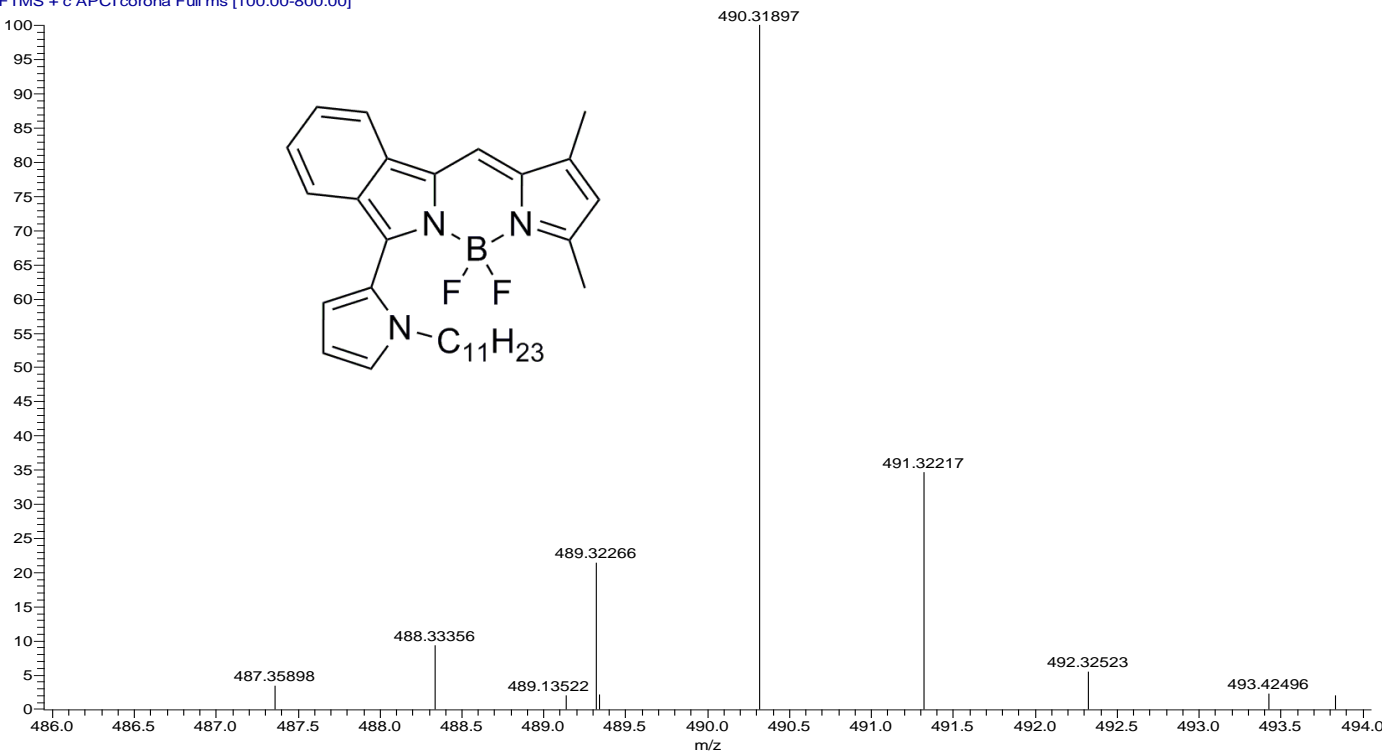




\section{MS for isoindole BODIPY 5d}

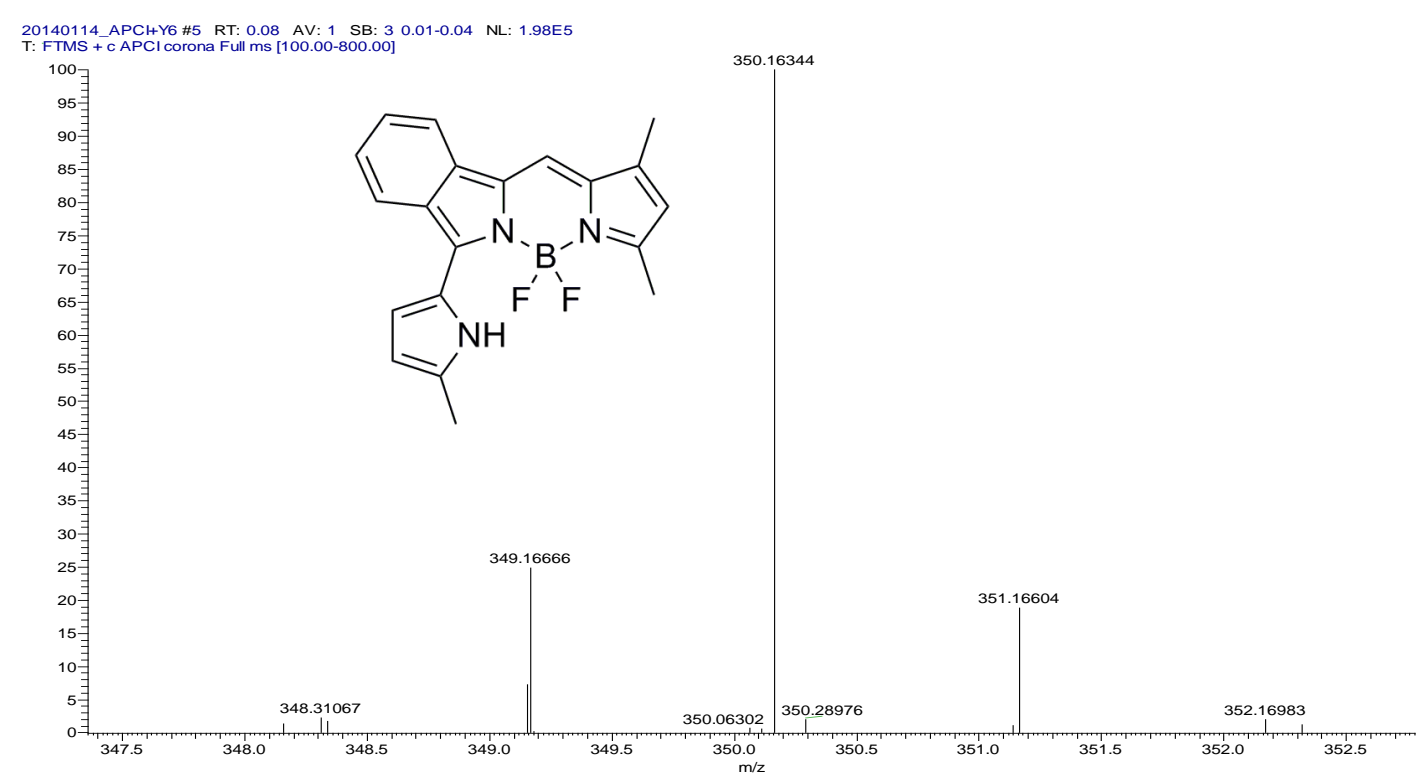

\section{MS for isoindole BODIPY 5e}

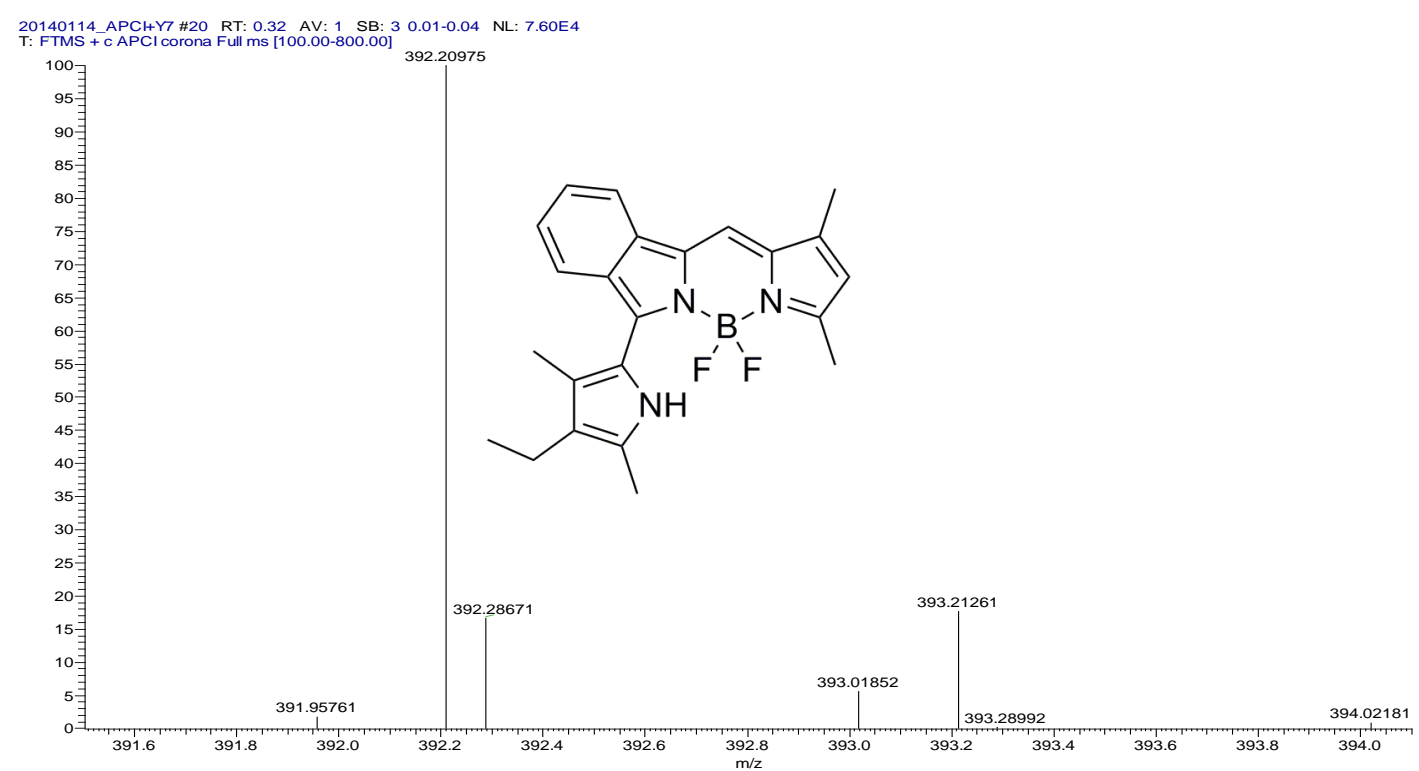




\section{MS for isoindole BODIPY $\mathbf{5 f}$}

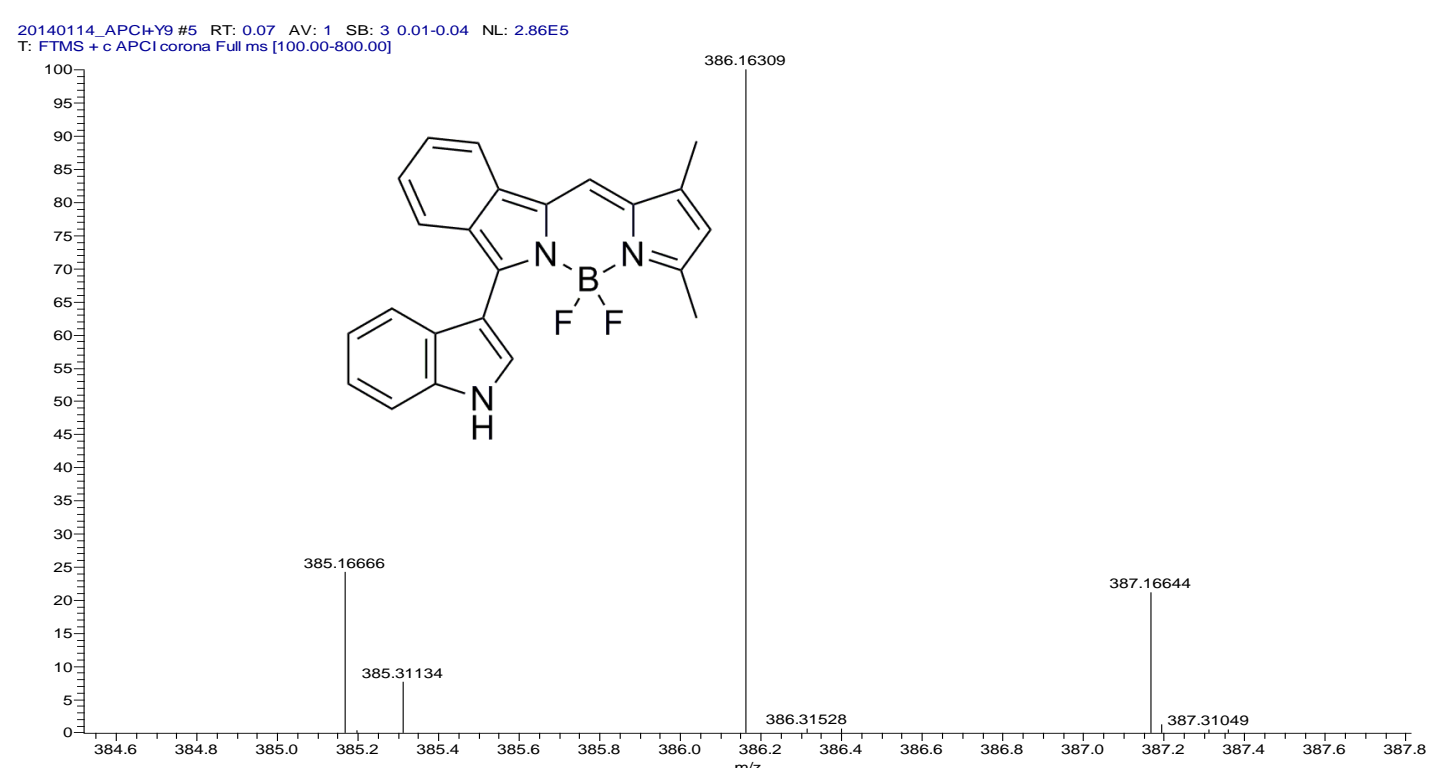

\section{MS for isoindole BODIPY $\mathbf{5 g}$}

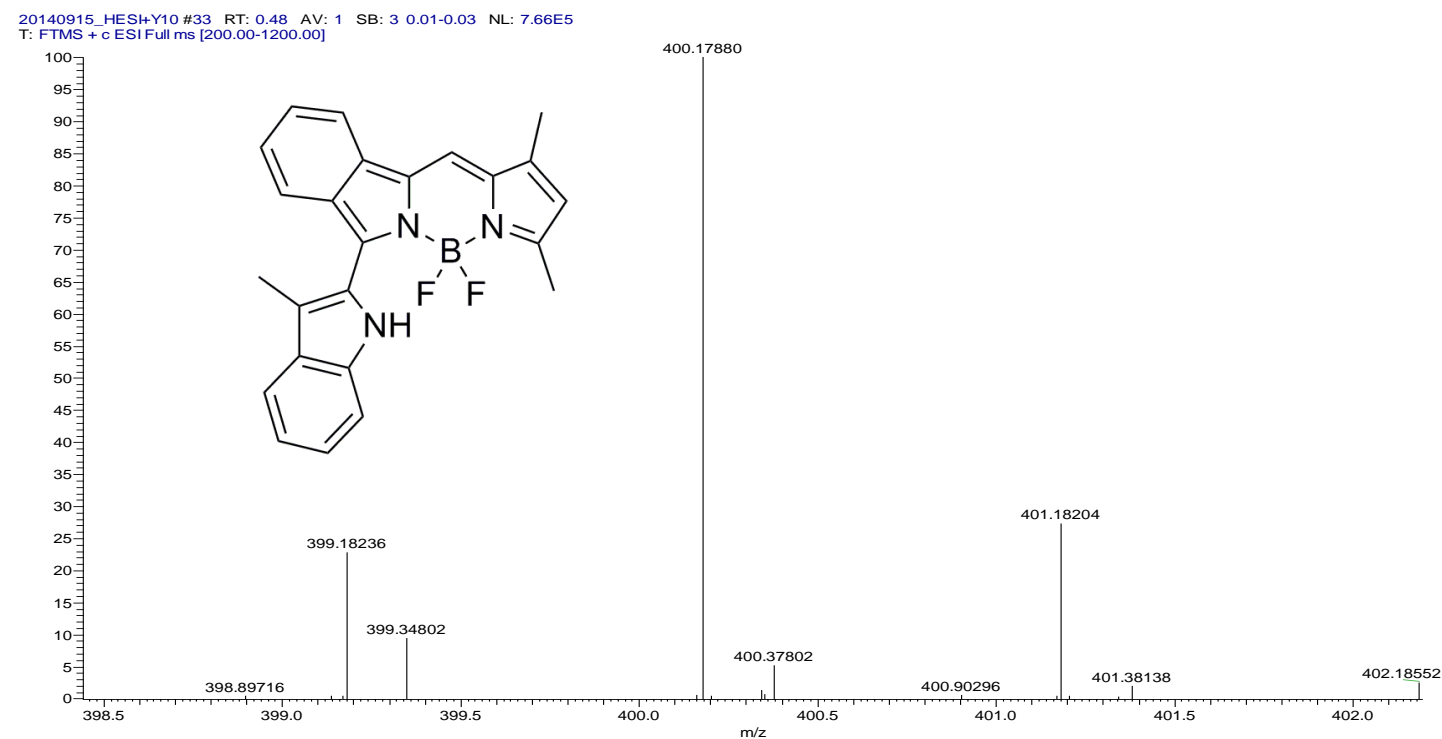




\section{MS for isoindole BODIPY $\mathbf{5 h}$}

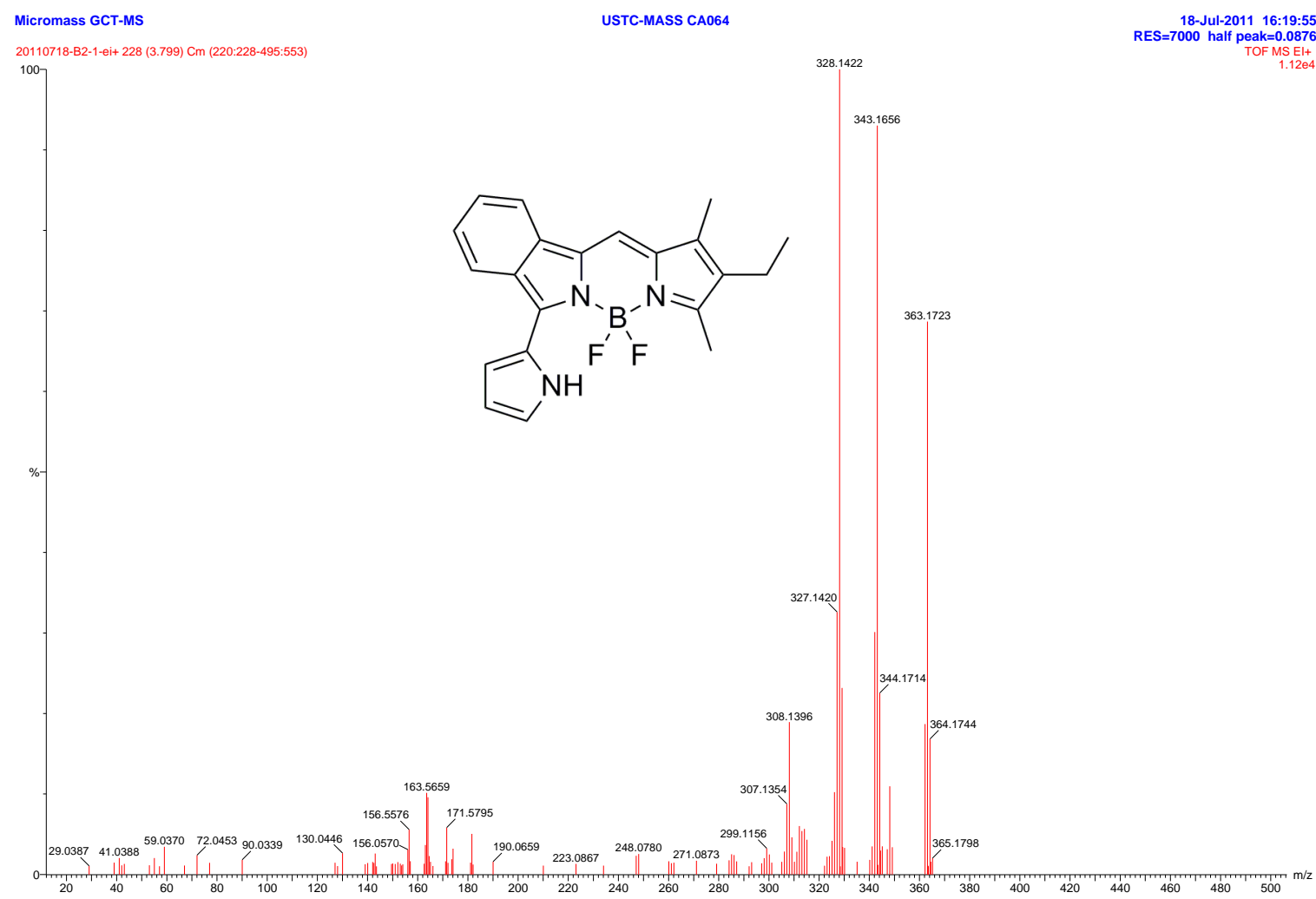

\section{MS for isoindole BODIPY 5i}

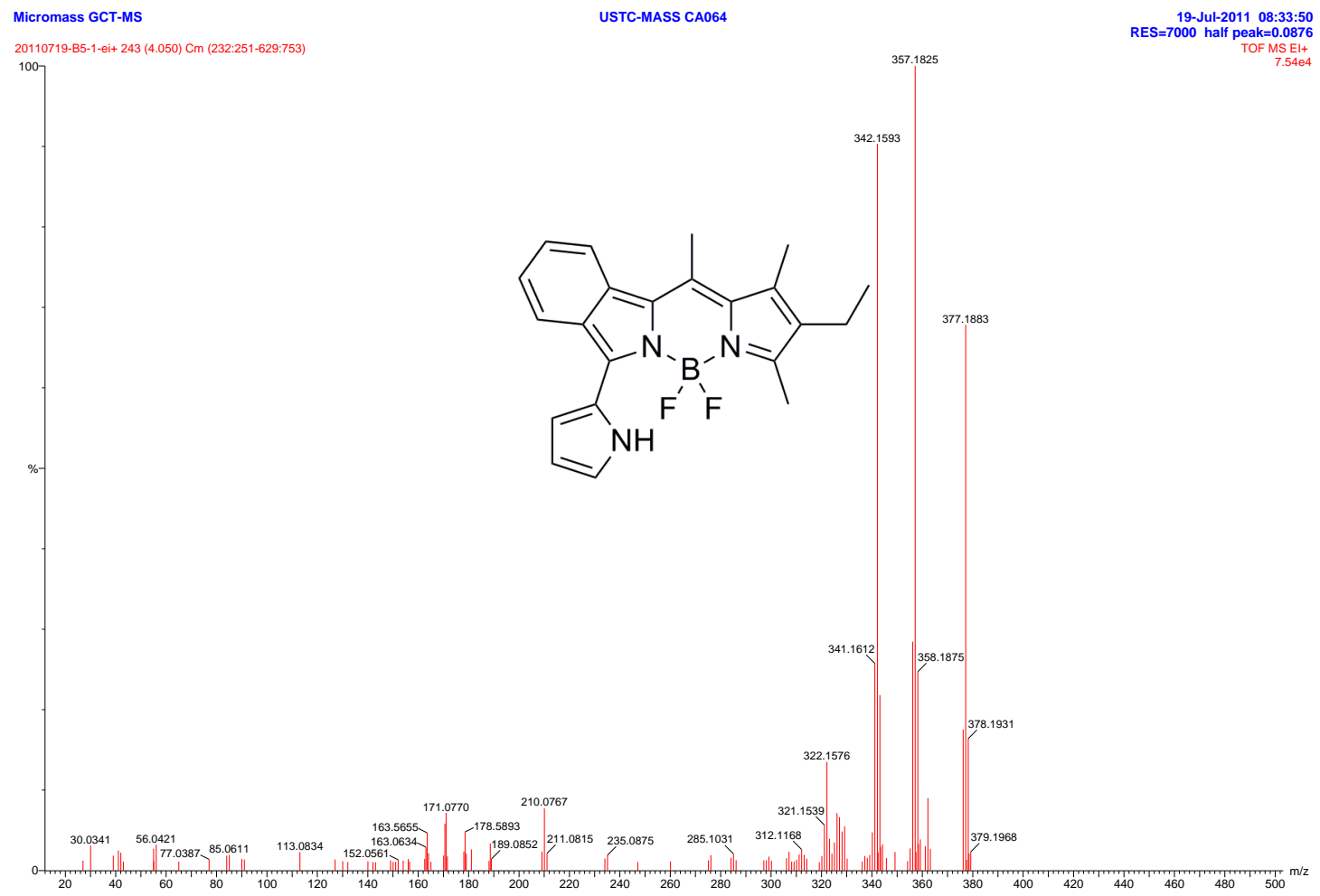


MS for isoindole BODIPY 7f

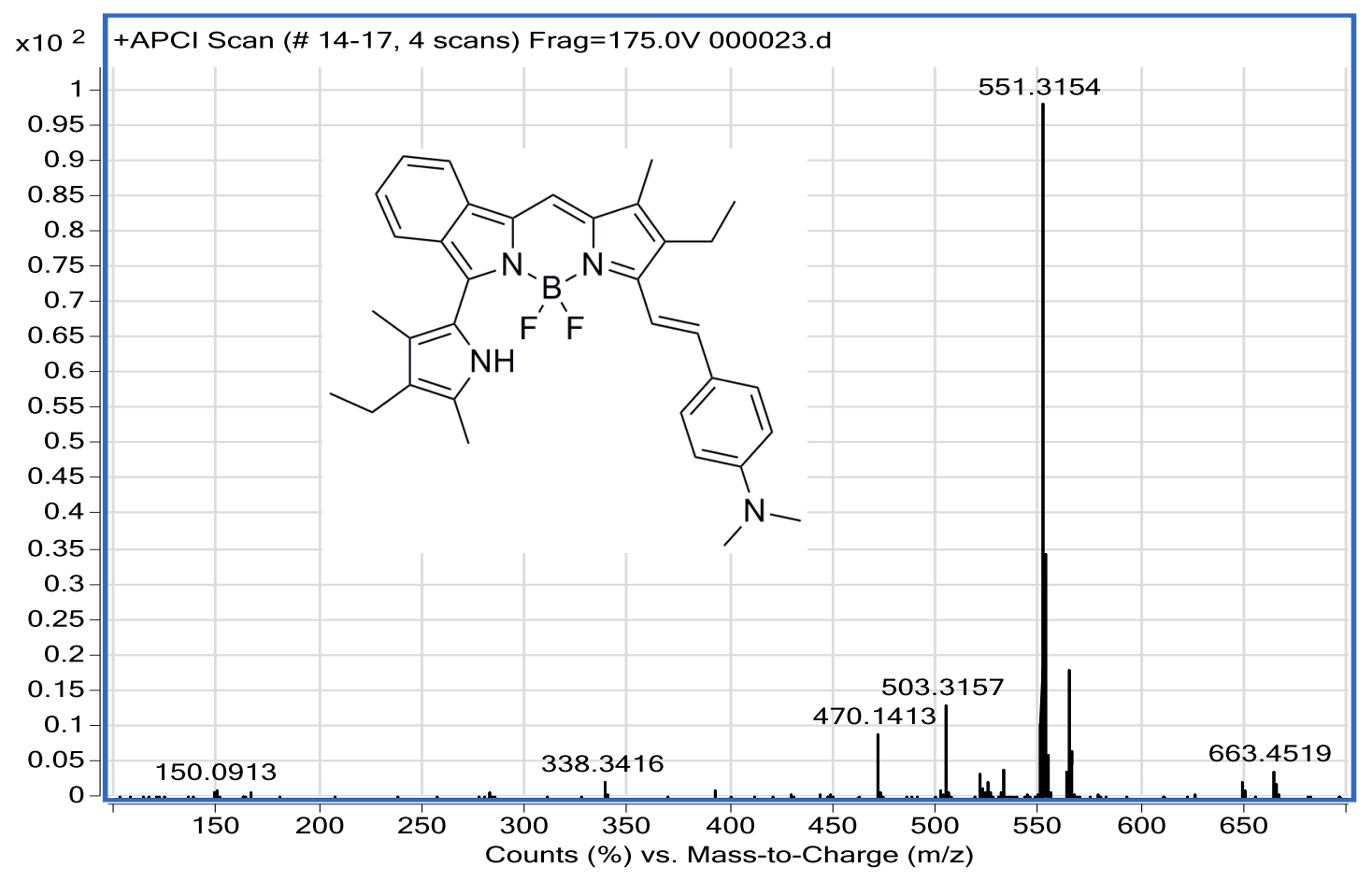




\section{DFT Calculation optimized coordinates}

\section{isoindole BODIPY 1a}

$\begin{array}{lrrr}\mathrm{B} & 1.35288100 & -1.07597100 & 0.04893100 \\ \mathrm{C} & -2.11910800 & -3.66089400 & -0.28685500 \\ \mathrm{~F} & 1.27240300 & -1.90021600 & -1.09956400 \\ \mathrm{~N} & -1.24034100 & -2.64062300 & -0.44446000 \\ \mathrm{C} & -3.28001100 & -3.15962600 & 0.29065400 \\ \mathrm{~F} & 1.20368500 & -1.84326800 & 1.18593000 \\ \mathrm{~N} & 0.20365000 & 0.01538700 & -0.02134100 \\ \mathrm{C} & -3.08589100 & -1.77903200 & 0.47193300 \\ \mathrm{~N} & 2.70423700 & -0.33522200 & 0.03470500 \\ \mathrm{C} & -1.79912800 & -1.46030100 & 0.00833400 \\ \mathrm{C} & -1.13605000 & -0.18765800 & -0.01012100 \\ \mathrm{C} & -1.79996700 & 1.10219100 & -0.01456200 \\ \mathrm{C} & -3.15191900 & 1.47778800 & -0.08580900 \\ \mathrm{C} & -3.46574900 & 2.82964300 & -0.09357500 \\ \mathrm{C} & -2.45292500 & 3.81001600 & -0.04812900 \\ \mathrm{C} & -1.11180900 & 3.45370900 & -0.01381000 \\ \mathrm{C} & -0.78443700 & 2.09069200 & -0.00404100 \\ \mathrm{C} & 0.47396000 & 1.39545900 & -0.00977200 \\ \mathrm{C} & 1.75761100 & 1.88523500 & 0.00973800 \\ \mathrm{C} & 2.88180800 & 1.04060200 & 0.02206100 \\ \mathrm{C} & 4.26324300 & 1.31039300 & 0.02784600 \\ \mathrm{C} & 4.92131800 & 0.07474500 & 0.04336000 \\ \mathrm{C} & 3.93000900 & -0.91231200 & 0.04820400 \\ \mathrm{H} & -1.86516800 & -4.66489100 & -0.59589200 \\ \mathrm{H} & -0.30324400 & -2.69560700 & -0.83718700 \\ \mathrm{H} & -4.15732500 & -3.73310300 & 0.55542900 \\ \mathrm{H} & -3.77061900 & -1.09314200 & 0.94777100 \\ \mathrm{H} & -3.93709400 & 0.73449500 & -0.15957800 \\ \mathrm{H} & -4.50548700 & 3.13914100 & -0.14709200 \\ \mathrm{H} & -2.72884300 & 4.86092600 & -0.05622900 \\ \mathrm{H} & -0.33764400 & 4.21593600 & -0.00211400 \\ \mathrm{H} & 1.90846000 & 2.95999000 & 0.02368000 \\ \mathrm{H} & 5.98845500 & -0.10039600 & 0.05186200 \\ & 4.71006500 & 2.29602100 & 0.01971200 \\ \mathrm{H} & & -1.98885700 & 0.06263200 \\ & & \end{array}$

isoindole BODIPY 1c

$\begin{array}{lrrc}\text { B } & 0.92349600 & -1.10254900 & 0.01500400 \\ \mathrm{C} & -3.08199900 & -4.08061600 & -0.97893000 \\ \mathrm{~F} & 0.52088900 & -1.85603800 & 1.10167900 \\ \mathrm{~N} & -1.98705500 & -1.86555700 & -0.60796200 \\ \mathrm{C} & -3.03703400 & -2.70328800 & -0.39931500\end{array}$




\begin{tabular}{|c|c|c|c|}
\hline $\mathrm{F}$ & 0.67954100 & -1.81925100 & -1.18676100 \\
\hline $\mathrm{N}$ & 0.11449100 & 0.25487900 & -0.03970200 \\
\hline $\mathrm{C}$ & -3.95565100 & -2.02508700 & 0.39213100 \\
\hline $\mathrm{N}$ & 2.42733500 & -0.76050800 & 0.09404300 \\
\hline $\mathrm{C}$ & -3.44881700 & -0.73489600 & 0.66970100 \\
\hline $\mathrm{C}$ & -4.09896900 & 0.25052500 & 1.60040600 \\
\hline $\mathrm{C}$ & -2.20012000 & -0.64960200 & 0.02373200 \\
\hline $\mathrm{C}$ & -1.23481800 & 0.41836800 & -0.02949000 \\
\hline $\mathrm{C}$ & -1.52089400 & 1.83314700 & -0.11885500 \\
\hline $\mathrm{C}$ & -2.72057700 & 2.54962600 & -0.27495700 \\
\hline $\mathrm{C}$ & -2.66060100 & 3.93046100 & -0.38597000 \\
\hline $\mathrm{C}$ & -1.42156800 & 4.60733800 & -0.35979200 \\
\hline $\mathrm{C}$ & -0.22650800 & 3.91150000 & -0.25117800 \\
\hline $\mathrm{C}$ & -0.27503600 & 2.51299400 & -0.14409400 \\
\hline $\mathrm{C}$ & 0.74550400 & 1.50651000 & -0.09200300 \\
\hline $\mathrm{C}$ & 2.11854800 & 1.62971500 & -0.05846000 \\
\hline $\mathrm{C}$ & 2.96741500 & 0.52123700 & 0.03425700 \\
\hline $\mathrm{C}$ & 4.37877200 & 0.42564400 & 0.10039400 \\
\hline $\mathrm{C}$ & 5.35246000 & 1.56594400 & 0.09973600 \\
\hline $\mathrm{C}$ & 4.66601100 & -0.93989600 & 0.19776500 \\
\hline $\mathrm{C}$ & 3.45248900 & -1.64713300 & 0.19168000 \\
\hline $\mathrm{C}$ & 3.23520700 & -3.12358800 & 0.26954800 \\
\hline $\mathrm{H}$ & -2.19669200 & -4.66546600 & -0.69937100 \\
\hline $\mathrm{H}$ & -3.12985000 & -4.06241500 & -2.07577200 \\
\hline $\mathrm{H}$ & -3.96527300 & -4.61291900 & -0.61566900 \\
\hline $\mathrm{H}$ & -1.11862500 & -2.09350400 & -1.08427200 \\
\hline $\mathrm{H}$ & -4.89232700 & -2.43160600 & 0.75210500 \\
\hline $\mathrm{H}$ & -3.40081700 & 1.01746400 & 1.94460000 \\
\hline $\mathrm{H}$ & -4.48476000 & -0.26881800 & 2.48531400 \\
\hline $\mathrm{H}$ & -4.95331500 & 0.76320700 & 1.13821700 \\
\hline $\mathrm{H}$ & -3.67159300 & 2.03327900 & -0.32936400 \\
\hline $\mathrm{H}$ & -3.57710200 & 4.50092400 & -0.50653900 \\
\hline $\mathrm{H}$ & -1.40562400 & 5.69041700 & -0.44683200 \\
\hline $\mathrm{H}$ & 0.72307000 & 4.43982900 & -0.26331200 \\
\hline $\mathrm{H}$ & 2.55176300 & 2.62450400 & -0.08694000 \\
\hline $\mathrm{H}$ & 5.48520600 & 1.98838100 & 1.10517700 \\
\hline $\mathrm{H}$ & 5.02795800 & 2.38263100 & -0.55510600 \\
\hline $\mathrm{H}$ & 6.33778500 & 1.23653300 & -0.24557300 \\
\hline $\mathrm{H}$ & 5.64780900 & -1.39124600 & 0.26752100 \\
\hline $\mathrm{H}$ & 2.63884300 & -3.38660500 & 1.15006800 \\
\hline $\mathrm{H}$ & 4.19355800 & -3.64713700 & 0.32028100 \\
\hline $\mathrm{H}$ & 2.68235900 & -3.48221800 & -0.60630900 \\
\hline
\end{tabular}

isoindole BODIPY 5a 


\begin{tabular}{|c|c|c|c|}
\hline B & 0.87027600 & -1.13324900 & 0.03230900 \\
\hline $\mathrm{C}$ & -2.74667900 & -3.52759800 & -0.30556300 \\
\hline $\mathrm{F}$ & 0.73958400 & -1.94150500 & -1.12762700 \\
\hline $\mathrm{N}$ & -1.81360600 & -2.55510000 & -0.46599700 \\
\hline $\mathrm{C}$ & -3.86771100 & -2.96822200 & 0.29446100 \\
\hline $\mathrm{F}$ & 0.67405100 & -1.90845500 & 1.16134500 \\
\hline $\mathrm{N}$ & -0.21466800 & 0.01613100 & -0.02611300 \\
\hline $\mathrm{C}$ & -3.59236300 & -1.60184000 & 0.48848300 \\
\hline $\mathrm{N}$ & 2.26579400 & -0.47750700 & 0.02821800 \\
\hline $\mathrm{C}$ & -2.29749300 & -1.35131500 & 0.00943400 \\
\hline $\mathrm{C}$ & -1.56531000 & -0.11504600 & -0.01007700 \\
\hline $\mathrm{C}$ & -2.15535700 & 1.20653400 & -0.00916100 \\
\hline $\mathrm{C}$ & -3.48587900 & 1.65665700 & -0.07251000 \\
\hline $\mathrm{C}$ & -3.72544000 & 3.02267300 & -0.07716700 \\
\hline $\mathrm{C}$ & -2.65945100 & 3.94713400 & -0.03536800 \\
\hline $\mathrm{C}$ & -1.34041400 & 3.51899100 & -0.00787700 \\
\hline $\mathrm{C}$ & -1.08581000 & 2.13902900 & -0.00193400 \\
\hline $\mathrm{C}$ & 0.12958200 & 1.37664500 & -0.01436200 \\
\hline $\mathrm{C}$ & 1.44356800 & 1.79281200 & 0.00177100 \\
\hline $\mathrm{C}$ & 2.51460600 & 0.89203700 & 0.01285200 \\
\hline $\mathrm{C}$ & 3.91460100 & 1.10208200 & 0.02473800 \\
\hline $\mathrm{C}$ & 4.61993700 & 2.42441300 & -0.01435700 \\
\hline $\mathrm{C}$ & 4.49310300 & -0.17187100 & 0.04918700 \\
\hline $\mathrm{C}$ & 3.46159400 & -1.12419100 & 0.05189300 \\
\hline $\mathrm{C}$ & 3.57030500 & -2.61438400 & 0.07901200 \\
\hline $\mathrm{H}$ & -2.55377400 & -4.54063300 & -0.62883200 \\
\hline $\mathrm{H}$ & -0.88616900 & -2.65841900 & -0.86991000 \\
\hline $\mathrm{H}$ & -4.77291400 & -3.49360700 & 0.56533600 \\
\hline $\mathrm{H}$ & -4.22971500 & -0.88271700 & 0.98107400 \\
\hline $\mathrm{H}$ & -4.31026000 & 0.95631200 & -0.14182600 \\
\hline $\mathrm{H}$ & -4.74692700 & 3.38888800 & -0.12511700 \\
\hline $\mathrm{H}$ & -2.87814500 & 5.01152400 & -0.04047800 \\
\hline $\mathrm{H}$ & -0.52619600 & 4.23857000 & 0.00174200 \\
\hline $\mathrm{H}$ & 1.65062700 & 2.85813200 & 0.01566800 \\
\hline $\mathrm{H}$ & 5.59555600 & 2.36175900 & 0.47896300 \\
\hline $\mathrm{H}$ & 4.04520600 & 3.21134600 & 0.48673400 \\
\hline $\mathrm{H}$ & 4.79907000 & 2.75866600 & -1.04540600 \\
\hline $\mathrm{H}$ & 5.55094200 & -0.40217200 & 0.06829300 \\
\hline $\mathrm{H}$ & 3.04211100 & -3.02881200 & 0.94482300 \\
\hline $\mathrm{H}$ & 4.61926400 & -2.91879800 & 0.12381800 \\
\hline $\mathrm{H}$ & 3.11226100 & -3.05606500 & -0.81338200 \\
\hline
\end{tabular}

isoindole BODIPY $\mathbf{5 b}$

B

$-0.98634700 \quad-1.18087000 \quad-0.12235800$ 


\begin{tabular}{|c|c|c|c|}
\hline $\mathrm{C}$ & -3.56848400 & -1.30462200 & 0.14832700 \\
\hline $\mathrm{C}$ & -4.65756600 & -0.41226800 & 0.22328500 \\
\hline $\mathrm{C}$ & -4.16022900 & 0.88896400 & 0.16193100 \\
\hline $\mathrm{C}$ & -2.74946300 & 0.76006100 & 0.05094300 \\
\hline $\mathrm{C}$ & -1.74273400 & 1.72255000 & -0.02381200 \\
\hline $\mathrm{C}$ & -0.40271500 & 1.38953300 & -0.10773700 \\
\hline $\mathrm{C}$ & 0.76612700 & 2.22005600 & -0.12090500 \\
\hline $\mathrm{C}$ & 0.95662300 & 3.61130200 & -0.13817700 \\
\hline $\mathrm{C}$ & 2.25321000 & 4.10023300 & -0.19984600 \\
\hline $\mathrm{C}$ & 3.36458200 & 3.22877700 & -0.25847400 \\
\hline $\mathrm{C}$ & 3.19185400 & 1.85358000 & -0.23870600 \\
\hline $\mathrm{C}$ & 1.88390700 & 1.34285600 & -0.14719800 \\
\hline $\mathrm{C}$ & 1.36557500 & -0.00284400 & -0.14465000 \\
\hline $\mathrm{C}$ & 2.13626700 & -1.22968400 & -0.21649800 \\
\hline $\mathrm{C}$ & 2.03756200 & -2.28818900 & -1.11305800 \\
\hline $\mathrm{C}$ & 3.11781200 & -3.16499000 & -0.86626000 \\
\hline $\mathrm{C}$ & 3.84091300 & -2.63487200 & 0.18277900 \\
\hline $\mathrm{C}$ & -3.58734400 & -2.79833900 & 0.16590000 \\
\hline $\mathrm{C}$ & -4.94003600 & 2.16931800 & 0.18393900 \\
\hline $\mathrm{C}$ & 3.54550900 & -0.83501600 & 1.86407600 \\
\hline $\mathrm{F}$ & -0.91198300 & -1.84636700 & -1.34323500 \\
\hline $\mathrm{F}$ & -0.67430300 & -2.01223000 & 0.93827800 \\
\hline $\mathrm{N}$ & -2.42134500 & -0.59345600 & 0.04807700 \\
\hline $\mathrm{N}$ & 0.01672900 & 0.05443000 & -0.13446400 \\
\hline $\mathrm{N}$ & 3.27133600 & -1.44705100 & 0.56857800 \\
\hline $\mathrm{H}$ & -5.69571500 & -0.70557500 & 0.31651600 \\
\hline $\mathrm{H}$ & -2.01590200 & 2.77298000 & 0.00621600 \\
\hline $\mathrm{H}$ & 0.11092700 & 4.29352700 & -0.11453000 \\
\hline $\mathrm{H}$ & 2.42026400 & 5.17384700 & -0.21695600 \\
\hline $\mathrm{H}$ & 4.36489200 & 3.64610700 & -0.33079400 \\
\hline $\mathrm{H}$ & 4.04445900 & 1.18466700 & -0.30968900 \\
\hline $\mathrm{H}$ & 1.27439000 & -2.37703800 & -1.87019300 \\
\hline $\mathrm{H}$ & 3.35005300 & -4.07465600 & -1.40294500 \\
\hline $\mathrm{H}$ & 4.70425900 & -3.01820300 & 0.70932600 \\
\hline $\mathrm{H}$ & -3.14314900 & -3.19952200 & -0.75222700 \\
\hline $\mathrm{H}$ & -4.61211000 & -3.16783600 & 0.25629600 \\
\hline $\mathrm{H}$ & -2.99043500 & -3.18525400 & 0.99864900 \\
\hline $\mathrm{H}$ & -5.02933400 & 2.60852300 & -0.81877700 \\
\hline $\mathrm{H}$ & -4.47209900 & 2.92405700 & 0.82721500 \\
\hline $\mathrm{H}$ & -5.95482400 & 1.99939200 & 0.55687400 \\
\hline $\mathrm{H}$ & 4.59767100 & -0.99767300 & 2.11212300 \\
\hline $\mathrm{H}$ & 2.92132000 & -1.27965100 & 2.64781500 \\
\hline $\mathrm{H}$ & 3.35837800 & 0.23813300 & 1.83100700 \\
\hline
\end{tabular}




\begin{tabular}{|c|c|c|c|}
\hline B & 0.73377100 & -1.11270200 & 0.08257600 \\
\hline $\mathrm{C}$ & -3.35220500 & -2.59465200 & -0.14117400 \\
\hline $\mathrm{C}$ & -4.29699300 & -1.75161400 & 0.44152900 \\
\hline $\mathrm{C}$ & -3.70799600 & -0.48322200 & 0.58360400 \\
\hline $\mathrm{C}$ & -2.39607500 & -0.56408300 & 0.09329400 \\
\hline $\mathrm{C}$ & -1.39058700 & 0.45674300 & 0.03211200 \\
\hline $\mathrm{C}$ & -1.64604500 & 1.88223500 & 0.00066700 \\
\hline $\mathrm{C}$ & -2.83000200 & 2.63738600 & -0.06510800 \\
\hline $\mathrm{C}$ & -2.73496200 & 4.02059900 & -0.10704800 \\
\hline $\mathrm{C}$ & -1.47799100 & 4.66239100 & -0.10066100 \\
\hline $\mathrm{C}$ & -0.30024400 & 3.92996800 & -0.07210500 \\
\hline $\mathrm{C}$ & -0.38452200 & 2.53013100 & -0.02835000 \\
\hline $\mathrm{C}$ & 0.61304200 & 1.49842000 & -0.03032000 \\
\hline $\mathrm{C}$ & 1.98750800 & 1.58992000 & -0.03744400 \\
\hline $\mathrm{C}$ & 2.81353100 & 0.45937700 & -0.00962600 \\
\hline $\mathrm{C}$ & 4.22250000 & 0.32931300 & -0.01475600 \\
\hline $\mathrm{C}$ & 4.48086100 & -1.04555000 & 0.04182600 \\
\hline $\mathrm{C}$ & 3.25272400 & -1.72310100 & 0.08003000 \\
\hline $\mathrm{C}$ & -3.44637300 & -4.03467300 & -0.53120100 \\
\hline $\mathrm{C}$ & 5.22226900 & 1.44356500 & -0.09682300 \\
\hline $\mathrm{C}$ & 3.00287100 & -3.19479100 & 0.15200400 \\
\hline $\mathrm{F}$ & 0.39571900 & -1.89967200 & -1.05057200 \\
\hline $\mathrm{F}$ & 0.37661000 & -1.78919200 & 1.23633300 \\
\hline $\mathrm{N}$ & -2.21898000 & -1.86725000 & -0.33667900 \\
\hline $\mathrm{N}$ & -0.04700700 & 0.25983100 & -0.00090400 \\
\hline $\mathrm{N}$ & 2.24508700 & -0.80985900 & 0.04686000 \\
\hline $\mathrm{H}$ & -5.29746300 & -2.04042600 & 0.73424200 \\
\hline $\mathrm{H}$ & -4.15185100 & 0.38246900 & 1.05215400 \\
\hline $\mathrm{H}$ & -3.79945700 & 2.15458700 & -0.10863000 \\
\hline $\mathrm{H}$ & -3.63944700 & 4.62000600 & -0.15740500 \\
\hline $\mathrm{H}$ & -1.43453500 & 5.74764100 & -0.13472800 \\
\hline $\mathrm{H}$ & 0.66312900 & 4.43239400 & -0.09060200 \\
\hline $\mathrm{H}$ & 2.44248100 & 2.57511500 & -0.05514800 \\
\hline $\mathrm{H}$ & 5.45346100 & -1.52122600 & 0.05948700 \\
\hline $\mathrm{H}$ & -3.31853800 & -4.17432400 & -1.61257800 \\
\hline $\mathrm{H}$ & -4.42578700 & -4.43524500 & -0.25639600 \\
\hline $\mathrm{H}$ & -2.68107300 & -4.64053200 & -0.02983900 \\
\hline $\mathrm{H}$ & 6.15685900 & 1.16821900 & 0.40319700 \\
\hline $\mathrm{H}$ & 4.85308800 & 2.36164600 & 0.37377900 \\
\hline $\mathrm{H}$ & 5.47224900 & 1.68943100 & -1.13799600 \\
\hline $\mathrm{H}$ & 2.41652500 & -3.44861000 & 1.04217800 \\
\hline $\mathrm{H}$ & 3.94971700 & -3.74030000 & 0.18383200 \\
\hline $\mathrm{H}$ & 2.42695000 & -3.53665400 & -0.71551100 \\
\hline
\end{tabular}


isoindole BODIPY $5 \mathbf{e}$

B

C

F

$\mathrm{N}$

C

F

$\mathrm{N}$

C

$\mathrm{N}$

C

C

C

C

C

C

$\mathrm{C}$

C

C

$\mathrm{C}$

C

C

C

C

$\mathrm{C}$

C

C

C

C

C

$\mathrm{H}$

$\mathrm{H}$

$\mathrm{H}$

$\mathrm{H}$

$\mathrm{H}$

$\mathrm{H}$

$\mathrm{H}$

$\mathrm{H}$

$\mathrm{H}$

$\mathrm{H}$

$\mathrm{H}$

$\mathrm{H}$
$-1.18238800$

3.00602300

$-0.61909900$

1.80815400

3.80277700

$-0.82225300$

$-0.65915700$

3.04121300

$-2.72230600$

1.78879100

0.63120200

0.62964500

1.66119900

1.32664800

$-0.02176900$

$-1.05325800$

$-0.72648500$

$-1.52653300$

$-2.89591600$

$-3.50687200$

$-4.86992100$

$-4.87928200$

$-3.55016400$

3.29302600

5.21027000

6.28922300

3.47761300

$-6.05021200$

$-3.04313500$

0.99392400

2.69560800

2.11011800

$-0.25371100$

$-2.08899100$

$-3.51819000$

$-5.75071500$

2.42166200

4.12547700

3.56362400

5.38115700

5.34107100
$-1.17498300$

$-0.00171900$

$-1.94999800 \quad-0.50949300$

$-1.83991600 \quad 1.07166900$

$-1.33333800 \quad-0.68556300$

$-1.12220800 \quad 0.28460200$

$-1.82223000-1.21356500$

$0.31634700 \quad-0.05519600$

$0.03912800 \quad 0.58813300$

$-1.13816200$

0.10307000

$-0.11177900$

$-0.03621300$

$0.74429700 \quad-0.05823000$

$2.18883400-0.13540800$

$3.13103200 \quad-0.29458300$

$4.47331400 \quad-0.39077500$

$4.88995700 \quad-0.34659300$

$3.96937400 \quad-0.23376600$

$2.60766800-0.14174500$

$1.41817600 \quad-0.08864500$

$1.26663100 \quad-0.03738700$

$0.01089600 \quad 0.05791600$

$-0.36299200 \quad 0.14061500$

$-1.75921800 \quad 0.23291200$

$\begin{array}{ll}-2.21123800 & 0.20714000\end{array}$

$-3.27619900-1.13870900$

$-1.40504900 \quad 0.73506100$

$-0.75022300 \quad-0.14792200$

$1.11650500 \quad 1.54081200$

$0.56153000 \quad 0.15984300$

$\begin{array}{ll}-3.61576800 & 0.26670600\end{array}$

$-1.72278300-1.15261700$

$2.81484400-0.36100500$

$5.21572300-0.51324700$

$5.94889800-0.42244200$

$4.29839400 \quad-0.23099300$

$2.15577700 \quad-0.05284400$

$-2.39717400 \quad 0.31156100$

$-3.93915200-1.08107000$

$-3.77361600 \quad-0.63298200$

$-3.18019400 \quad-2.19914600$

$-2.48879800 \quad 0.76028800$

$-1.05955700 \quad 1.76934700$ 


$\begin{array}{crrr}\mathrm{H} & 6.22333600 & -1.11152800 & -1.18041200 \\ \mathrm{H} & 7.29490900 & -0.97403600 & 0.22760500 \\ \mathrm{H} & 6.17239100 & 0.33910900 & -0.17211800 \\ \mathrm{H} & 4.23540300 & 1.78398400 & 1.10858500 \\ \mathrm{H} & 3.92884500 & 0.67143800 & 2.43621700 \\ \mathrm{H} & 2.64068400 & 1.73668600 & 1.86993900 \\ \mathrm{H} & -6.93777200 & 0.07067300 & -0.25304600 \\ \mathrm{H} & -5.87038600 & 1.46884300 & -0.42751900 \\ \mathrm{H} & -6.30134100 & 0.87891200 & 1.18123200 \\ \mathrm{H} & -2.47857000 & -3.86471200 & -0.63958000 \\ \mathrm{H} & -3.87567800 & -4.31732800 & 0.36588100 \\ \mathrm{H} & -2.36007300 & -3.75012000 & 1.11223200\end{array}$

isoindole BODIPY $\mathbf{5 h}$

$\begin{array}{lrrr}\text { B } & 0.37863600 & -1.06769400 & -0.07463500 \\ \mathrm{C} & -3.13499800 & -3.62689200 & -0.25200700 \\ \mathrm{~F} & 0.22702300 & -1.86871500 & -1.23773800 \\ \mathrm{~N} & -2.25845600 & -2.60983100 & -0.45226400 \\ \mathrm{C} & -4.24737200 & -3.12548300 & 0.41155400 \\ \mathrm{~F} & 0.27334900 & -1.86380600 & 1.05238800 \\ \mathrm{~N} & -0.75927100 & 0.02947900 & -0.06682400 \\ \mathrm{C} & -4.02644700 & -1.74875000 & 0.60407400 \\ \mathrm{~N} & 1.74091700 & -0.34801900 & -0.13414600 \\ \mathrm{C} & -2.77225200 & -1.43393200 & 0.05994600 \\ \mathrm{C} & -2.10014300 & -0.16424300 & 0.01331100 \\ \mathrm{C} & -2.74926400 & 1.12821200 & 0.04786000 \\ \mathrm{C} & -4.10073300 & 1.51642000 & 0.05184000 \\ \mathrm{C} & -4.40283400 & 2.86982100 & 0.06275300 \\ \mathrm{C} & -3.37961700 & 3.84261200 & 0.05479700 \\ \mathrm{C} & -2.04254200 & 3.47601600 & 0.01639600 \\ \mathrm{C} & -1.72437900 & 2.10918600 & 0.00521900 \\ \mathrm{C} & -0.47757400 & 1.40366000 & -0.06860100 \\ \mathrm{C} & 0.81595500 & 1.87968500 & -0.11465400 \\ \mathrm{C} & 1.92666200 & 1.02947800 & -0.15247300 \\ \mathrm{C} & 3.31420000 & 1.29935200 & -0.19923200 \\ \mathrm{C} & 3.96693900 & 0.05410300 & -0.20935400 \\ \mathrm{C} & 2.96495900 & -0.93935400 & -0.16574500 \\ \mathrm{H} & -2.91218400 & -4.62728200 & -0.59485000 \\ \mathrm{H} & -1.35003500 & -2.66608000 & -0.90546800 \\ \mathrm{H} & -5.11128900 & -3.69505500 & 0.72472800 \\ \mathrm{H} & -4.66970900 & -1.06388500 & 1.13629100 \\ \mathrm{H} & -4.89418700 & 0.77852500 & 0.02176100 \\ \mathrm{H} & -5.44119900 & 3.18872200 & 0.06625300 \\ \mathrm{H} & -3.64732600 & 4.89574600 & 0.06369200 \\ & & & \\ & & \end{array}$




$\begin{array}{lrrc}\mathrm{H} & -1.26292800 & 4.23248700 & -0.01122400 \\ \mathrm{H} & 0.97179000 & 2.95362200 & -0.10849900 \\ \mathrm{C} & 3.95212800 & 2.65557900 & -0.22540700 \\ \mathrm{H} & 3.22520600 & 3.44440200 & -0.44332100 \\ \mathrm{H} & 4.42541800 & 2.90283200 & 0.73430500 \\ \mathrm{H} & 4.73615500 & 2.71292200 & -0.99039000 \\ \mathrm{C} & 3.11973100 & -2.42661100 & -0.15615000 \\ \mathrm{H} & 2.67882600 & -2.85660200 & 0.75018700 \\ \mathrm{H} & 2.59572500 & -2.87728700 & -1.00641200 \\ \mathrm{H} & 4.17367200 & -2.71107100 & -0.20187700 \\ \mathrm{C} & 5.45352700 & -0.18113900 & -0.22973700 \\ \mathrm{H} & 5.67817100 & -1.10565600 & -0.77649400 \\ \mathrm{H} & 5.94039800 & 0.62432300 & -0.79501500 \\ \mathrm{C} & 6.08760800 & -0.26077500 & 1.17193100 \\ \mathrm{H} & 5.65436500 & -1.08237500 & 1.75317700 \\ \mathrm{H} & 7.16968700 & -0.42474200 & 1.10487700 \\ \mathrm{H} & 5.91927000 & 0.66455500 & 1.73429400\end{array}$

